Prepared for the U.S. Department of Energy

under Contract DE-AC05-76RL01830

\title{
PNNL Hoisting and Rigging Manual
}

PNNL Worker Safety \& Health Division

December 2008

Pacific Northwest

NATIONAL LABORATORY 


\title{
DISCLAIMER
}

This report was prepared as an account of work sponsored by an agency of the United States Government. Neither the United States Government nor any agency thereof, nor Battelle Memorial Institute, nor any of their employees, makes any warranty, express or implied, or assumes any legal liability or responsibility for the accuracy, completeness, or usefulness of any information, apparatus, product, or process disclosed, or represents that its use would not infringe privately owned rights. Reference herein to any specific commercial product, process, or service by trade name, trademark, manufacturer, or otherwise does not necessarily constitute or imply its endorsement, recommendation, or favoring by the United States Government or any agency thereof, or Battelle Memorial Institute. The views and opinions of authors expressed herein do not necessarily state or reflect those of the United States Government or any agency thereof.

\author{
PACIFIC NORTHWEST NATIONAL LABORATORY \\ operated by \\ BATTELLE \\ for the
} UNITED STATES DEPARTMENT OF ENERGY under Contract DE-AC05-76RL01830 


\title{
PNNL Hoisting and Rigging Manual
}

\author{
PNNL Worker Safety \& Health Division
}

December 2008

Prepared for

the U.S. Department of Energy

under Contract DE-AC05-76RL01830

Pacific Northwest National Laboratory

Richland, Washington 99352 



\section{Acknowledgments}

The content of the PNNL Hoisting and Rigging Manual was derived from the Hanford Site Hoisting and Rigging Manual (DOE-RL-92-36). Permission was given to the Hanford Site Hoisting and Rigging Committee to use and reproduce portions of standards and information from the following sources:

- American Society of Mechanical Engineers

- Committee of Wire Rope Producers of the American Iron and Steel Institute

- Construction Safety Association of Ontario

- $\quad$ The Crosby Group, Inc. 


\section{Acronyms and Abbreviations}

$\begin{array}{ll}\text { ANSI } & \text { American National Standards Institute. } \\ \text { AWS } & \text { American Welding Society } \\ \text { ASME } & \text { American Society of Mechanical Engineers } \\ \text { ASTM } & \text { American Society of Testing and Materials } \\ \text { DL } & \text { Designated Leader } \\ \text { FM } & \text { Factory Mutual } \\ \text { OSHA } & \text { Occupational Safety and Health Act of 1970 } \\ \text { NEMA } & \text { National Electrical Manufacturers Association } \\ \text { NFPA } & \text { National Fire Protection Association } \\ \text { NDE } & \text { Nondestructive Examination } \\ \text { NDT } & \text { Nondestructive Test } \\ \text { SME } & \text { Subject Matter Expert } \\ \text { SWL } & \text { Safe Working Load } \\ \text { UL } & \text { Underwriters Laboratories }\end{array}$




\section{Contents}

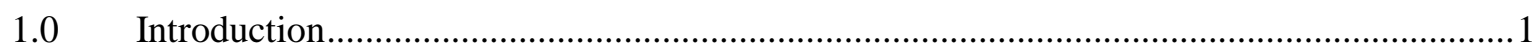

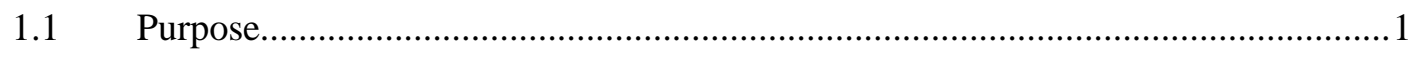

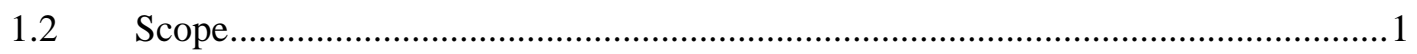

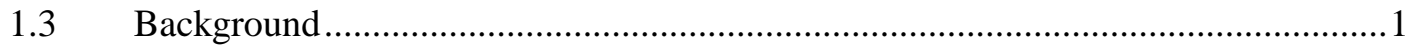

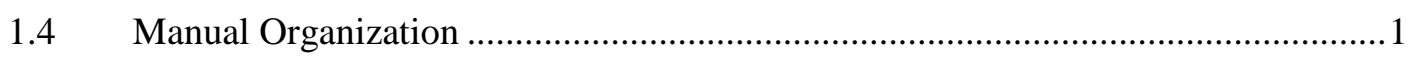

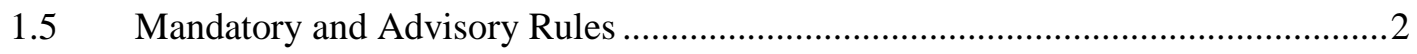

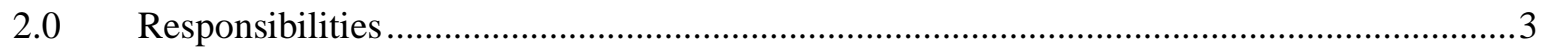

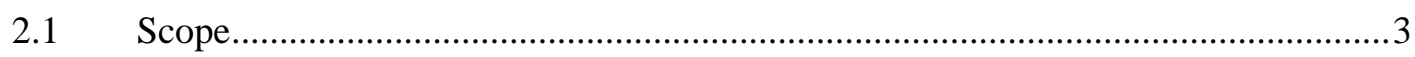

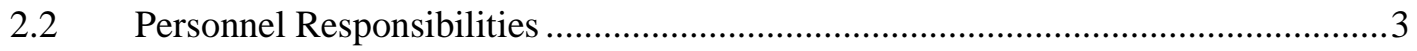

2.2.1 Responsibilities...........................................................................

2.2.2 Supervisor or Manager, Hoisting and Rigging Operations .......................3

2.2.3 Supervisor or Manager, Inspection, Maintenance, and Repair.................4

2.2.4 Designated Leader for Critical Lifts ......................................................

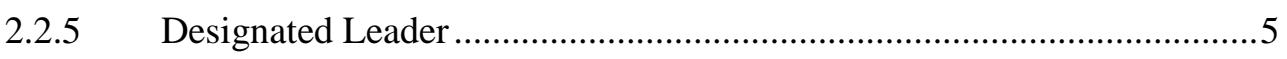

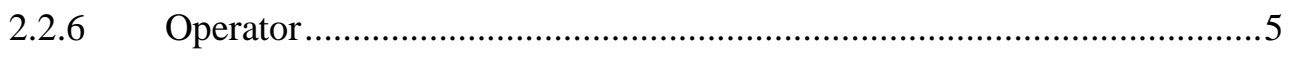

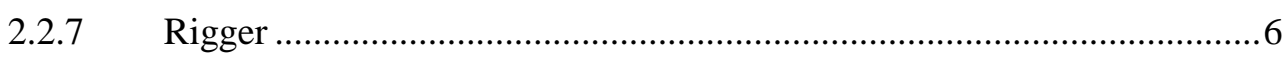

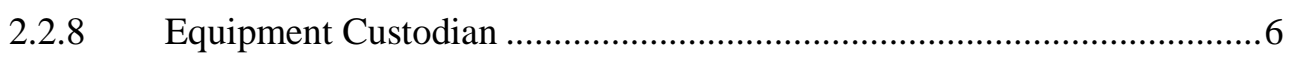

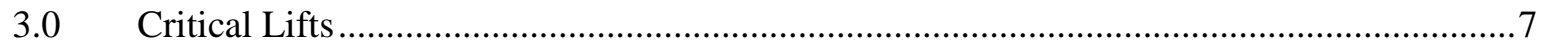

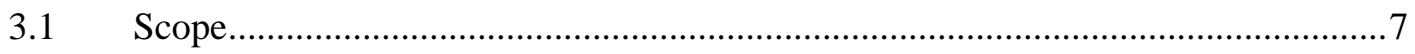

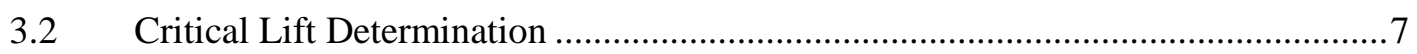

3.3 Guidelines and Rules for Critical Lifts ........................................................... 7

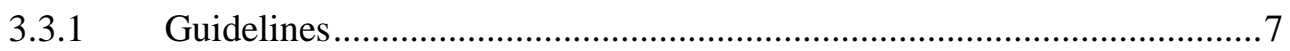

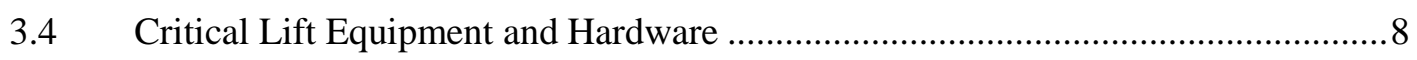

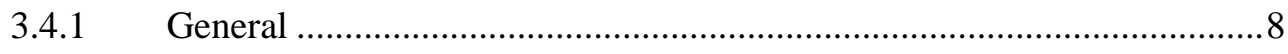

3.4.2 Rigging Hardware for Critical Lifts ................................................. 8

3.4.3 Rigging Hardware Rated-Capacity Testing for Critical Lifts................... 9

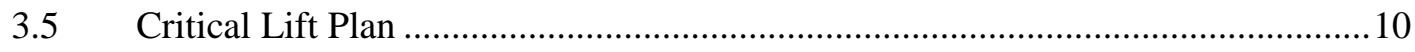

3.5.1 Critical Lift Plan Approval ...............................................................11

3.5.2 Critical Lift Plan Field Revisions ........................................................... 11

3.6 Prelift and Field Revision Review Meetings ........................................................ 12

3.7 Special Lifts - Non-Critical Lifts That Require Special Precautions ......................12

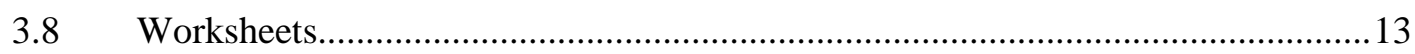

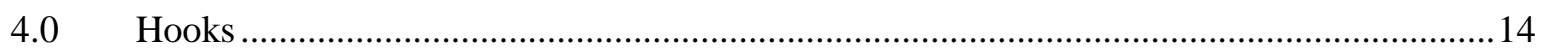

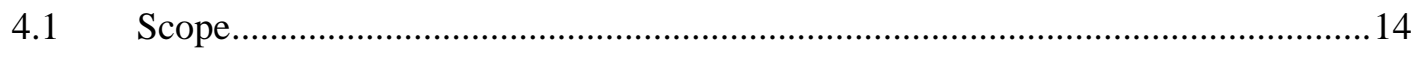

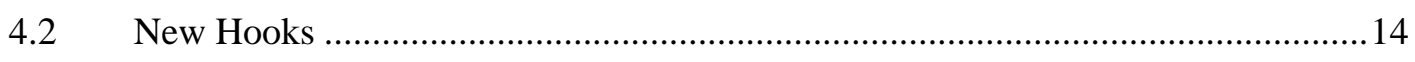

4.2.1 Performance Tests ................................................................... 14 


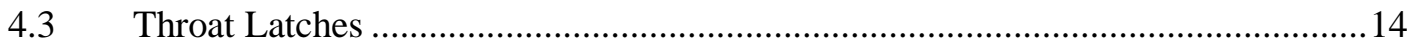

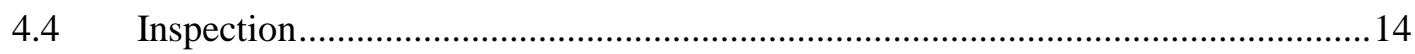

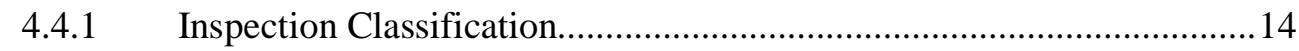

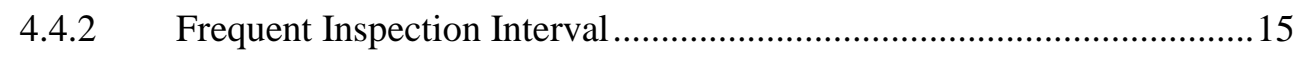

4.4.3 Periodic Inspection Interval............................................................... 15

4.4.4 Frequent Inspection .......................................................................

4.4.5 Monthly and Periodic Inspections (Records Required)..........................16

4.4.6 Inspection Records .......................................................................... 16

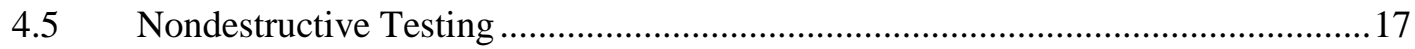

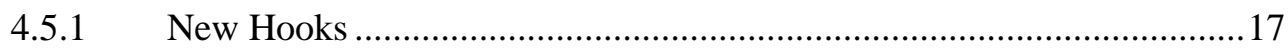

4.5.2 Existing Hooks ........................................................................... 17

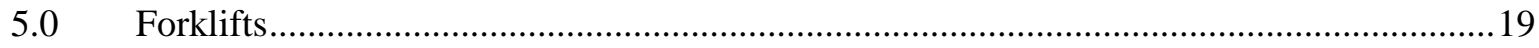

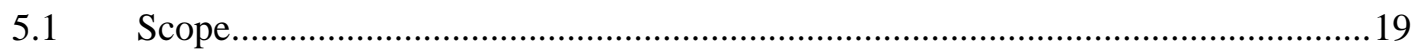

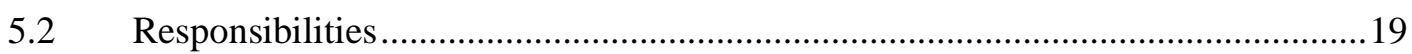

5.2.1 Forklift Requirements...................................................................... 19

5.2.2 Common Errors during Forklift Operation............................................20

5.2.3 Management at the Using Organization ...............................................2

5.2.4 Forklift Truck Custodian ..................................................................22

5.2.5 Forklift Truck Operator .................................................................22

5.2.6 Industrial Safety Representative ........................................................22

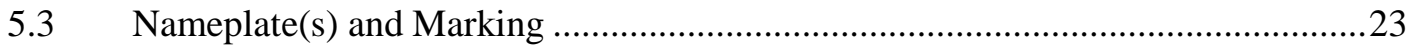

5.3.1 Truck Marking by the Manufacturer ….................................................22

5.3.2 Fork Arm Stamping by the Manufacturer .............................................23

5.3.3 Attachment Marking..........................................................................2 24

5.3.4 User's Obligation for Truck Marking..................................................2 24

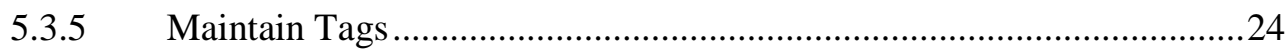

$5.4 \quad$ Attachments, Modifications, and Free Rigging from Tines...................................24

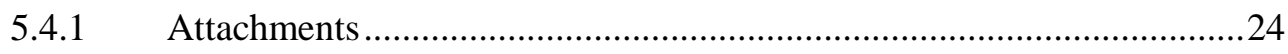

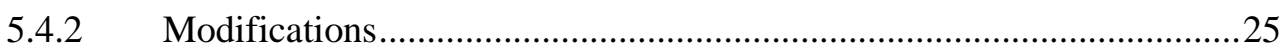

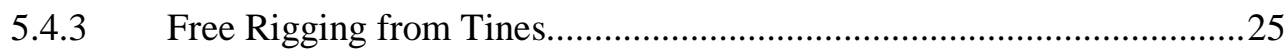

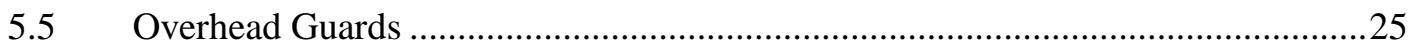

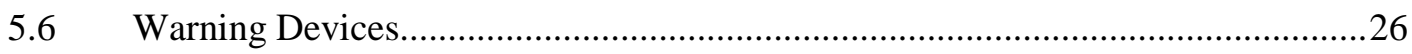

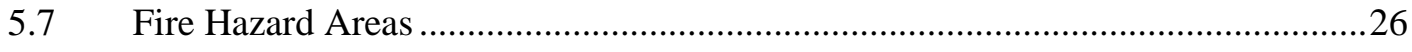

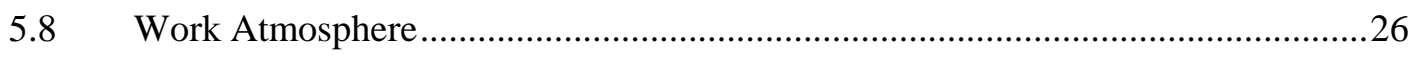

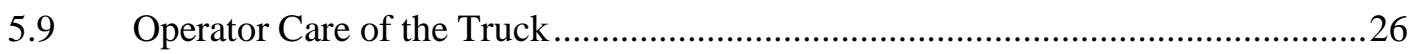

5.9.1 Frequent (Pre-use) Inspection..............................................................26

5.9.2 Key Steps in a Pre-use Inspection ....................................................27

5.9.3 Truck Unsafe or Needs Repair ...........................................................2

5.9.4 No Repair by Operator .....................................................................2 


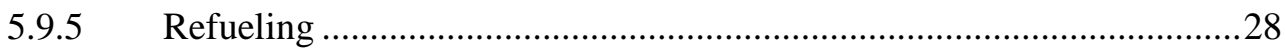

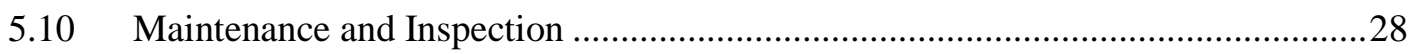

5.10.1 Inspection of New and Rented Equipment ............................................28

5.10.2 Modified or Extensively Repaired Equipment ......................................28

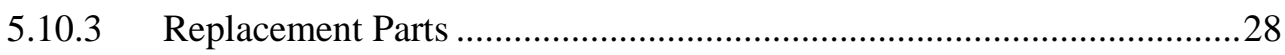

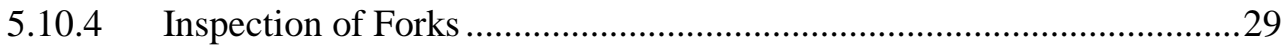

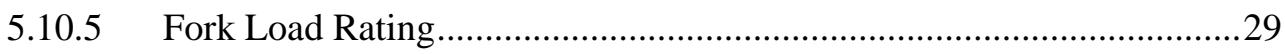

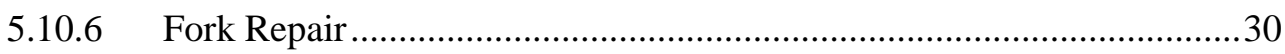

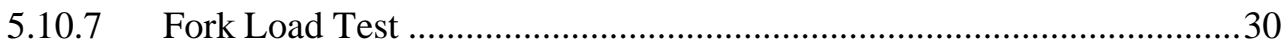

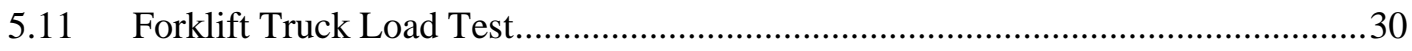

5.11.1 Verify Maintenance/Inspection is Current............................................30

$5.11 .2 \quad$ Test Weight Accuracy ….........................................................................30

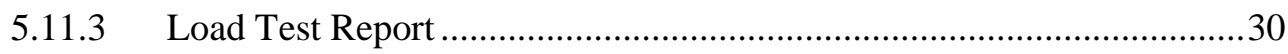

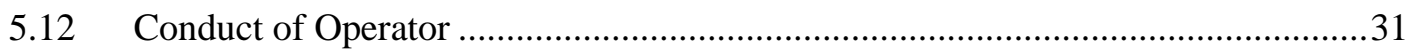

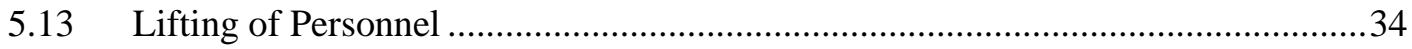

5.13.1 Special Provisions Prior to Lifting Personnel..........................................34

5.13.2 Qualification of Trucks Used for Lifting Personnel ...............................34

5.13.3 Standard Precautions_-Lifting Personnel with Forklift Truck................34

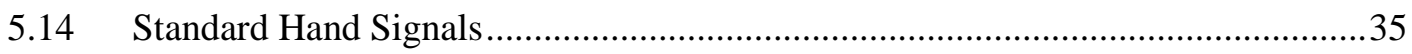

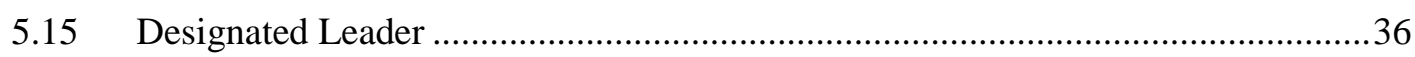

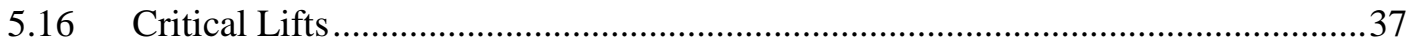

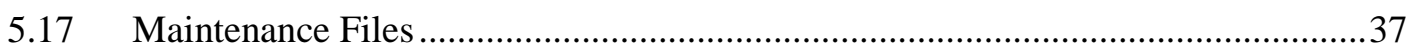

5.17.1 Contents of Maintenance Files ............................................................3

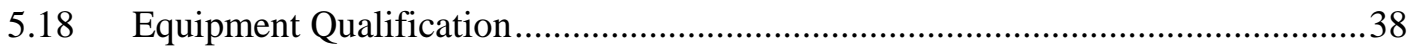

5.19 Forklift Trucks in Hazardous (Explosive) Atmospheres .......................................38

5.19.1 Hazardous Area Equipment..................................................................38

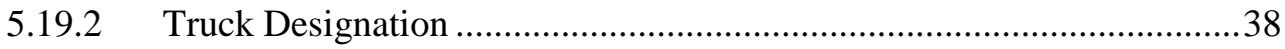

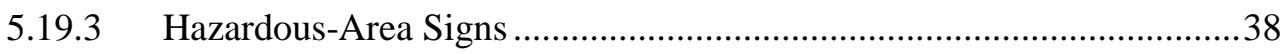

5.19.4 Hazardous Area Classification .............................................................40

5.19.5 Non-Hazardous Areas............................................................... 41

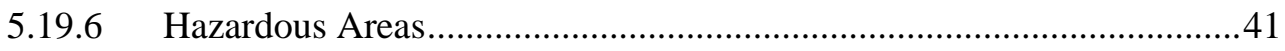

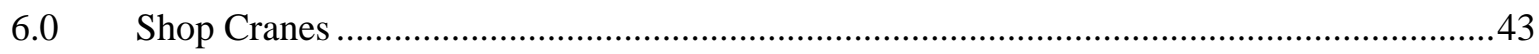

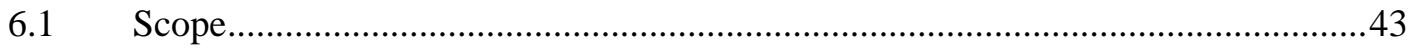

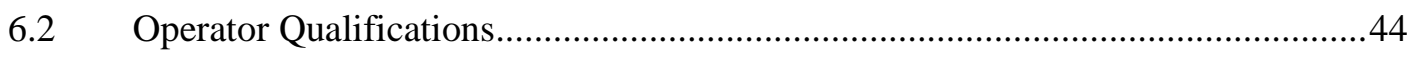

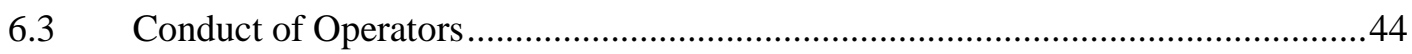

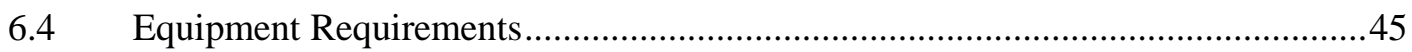

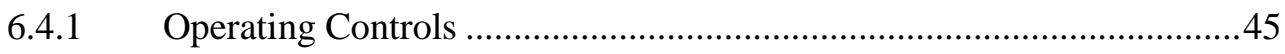

6.4.2 Hook-Throat Latches......................................................................... 45

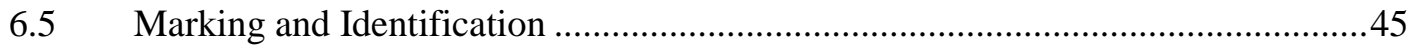




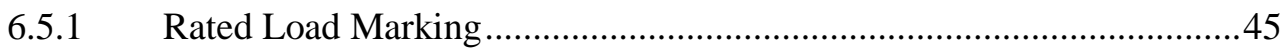

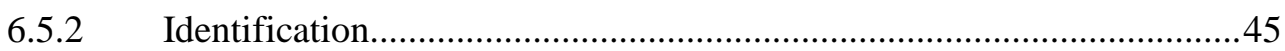

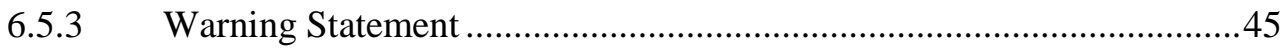

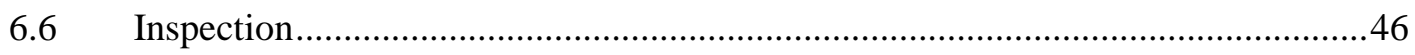

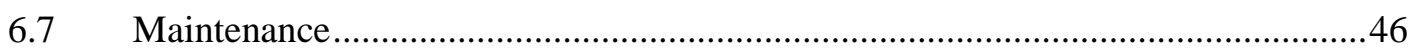

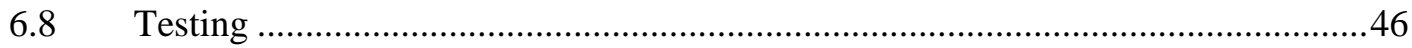

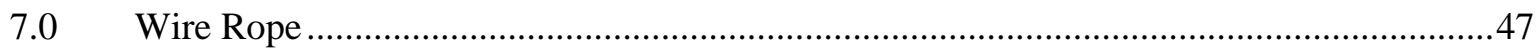

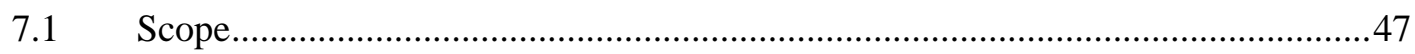

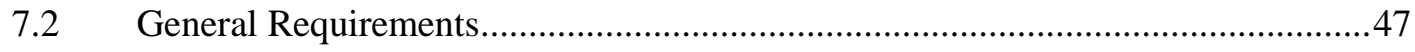

7.2.1 Design Factors for Wire Ropes ….................................................47

7.2.2 Rotation-Resistant Rope................................................................4

7.2.3 Requirement for Independent Wire Rope Core ....................................47

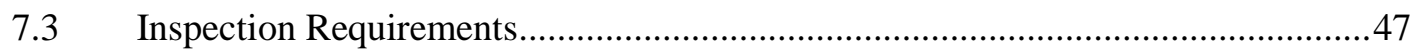

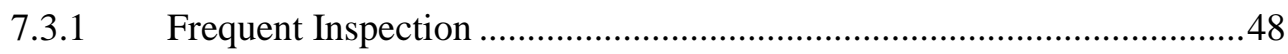

7.3.2 Monthly Inspection...........................................................................49

7.3.3 Periodic Wire Rope Inspection (Active Cranes and Hoists)...................49

7.3.4 Inspection of Ropes Not in Regular Use ...............................................50

7.3.5 Inspection of Ropes before Returning to Lift Service .............................50

7.4 Wire Rope Inspection, Acceptance Criteria..........................................................51

7.4.1 Wire Rope Replacement Criteria-Overhead and Gantry Cranes, Monorail Cranes and Hoists, Overhead Hoists........................................51

$7.5 \quad$ Wire Rope Receiving, Storage, and Maintenance ................................................51

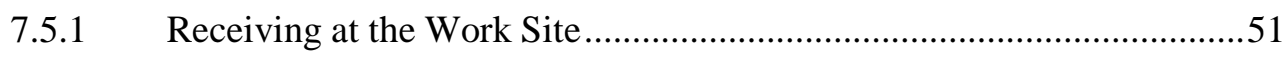

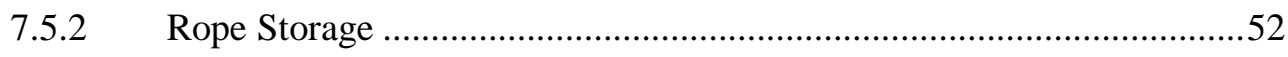

7.5.3 Unreeling, Cutting, and Seizing ……................................................52

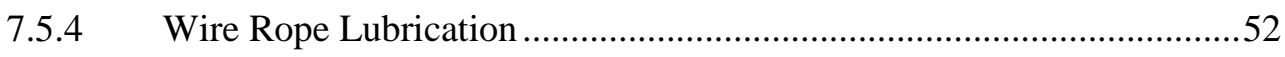

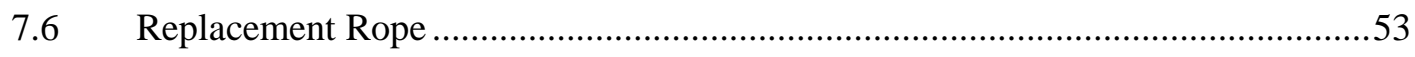

7.6.1 Rope Replacement Frequency (Recommended) …...............................53

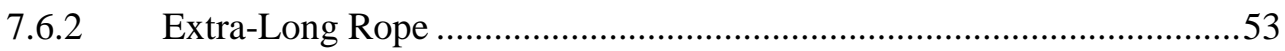

7.6.3 Replacement Rope as Recommended by Equipment Manufacturer .......53

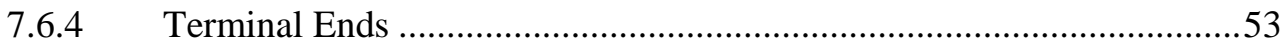

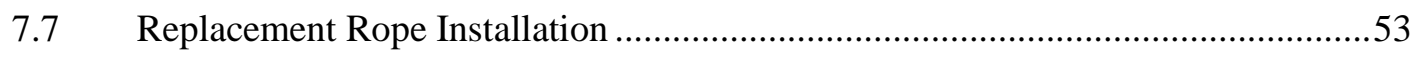

7.7.1 Before Initial Load Cycle ................................................................53

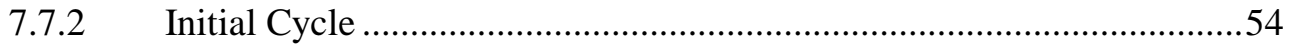

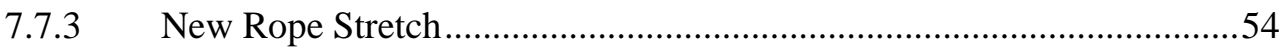

7.7.4 Verification of Fasteners ................................................................54

7.7.5 Documentation of Rope Replacement ....................................................54

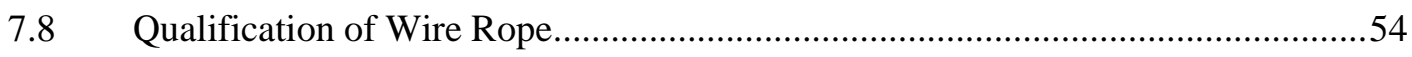

7.8.1 Qualification of Original Rope Supplied with New Equipment..............54 
7.8.2 Qualification of Replacement Rope .................................................54

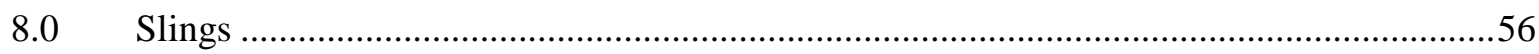

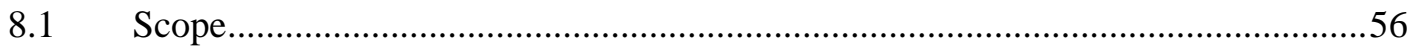

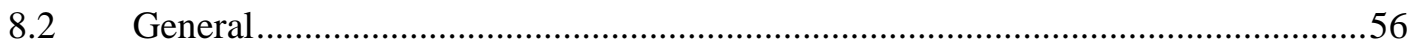

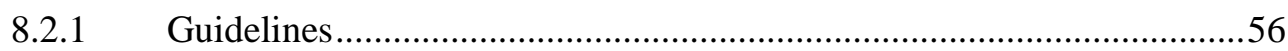

8.2.2 Alloy Steel Chain Slings.................................................................... 58

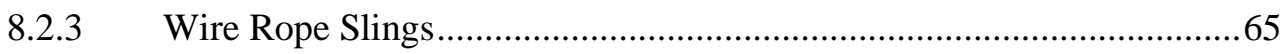

8.2.4 Synthetic Web Slings...................................................................... 76

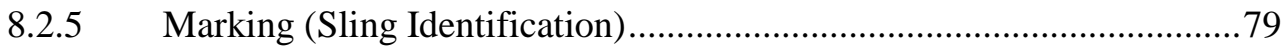

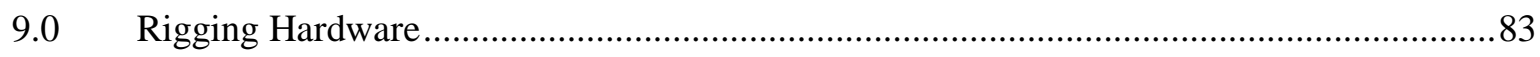

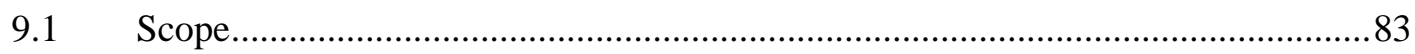

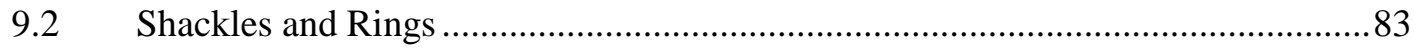

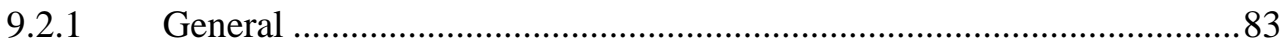

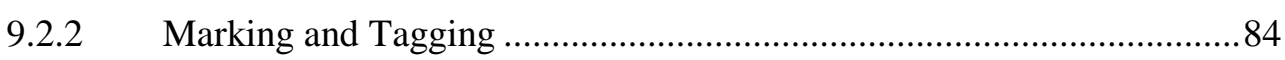

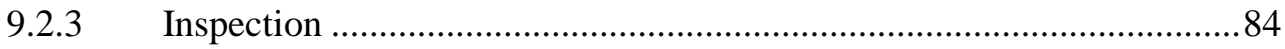

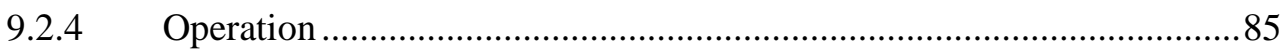

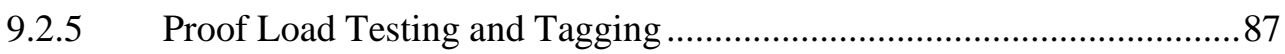

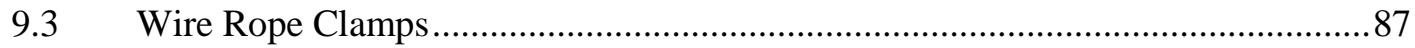

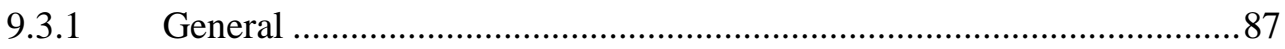

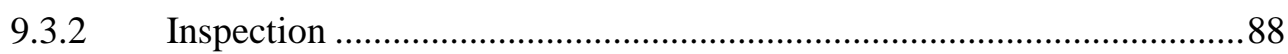

9.4 Eyebolts, Manufacturer-Installed Lift Points, and Swivel Hoist Rings ...................89

9.4.1 Manufacturer-Installed Eyebolts vs. Eyebolts Used as Rigging

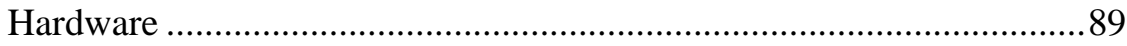

9.4.2 Manufacturer-Installed Lift Points ......................................................89

9.4.3 Eyebolt Rigging Hardware ..................................................................89

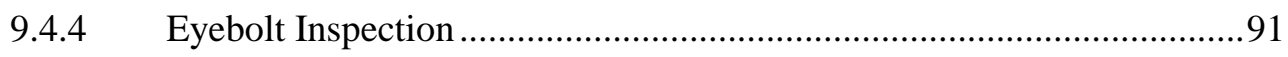

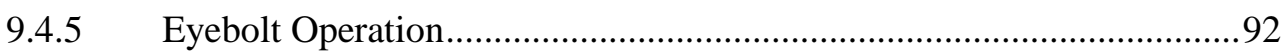

9.4.6 Swivel Hoist Ring Inspection ........................................................94

9.4.7 Qualification of Eyebolts and Swivel Hoist Rings ................................95

9.4.8 Swivel Hoist Ring Operation...............................................................96

9.4.9 Hoisting and Rigging Bulletin - Eyebolt and Swivel Hoist Ring Temperature Limitations ....................................................................96

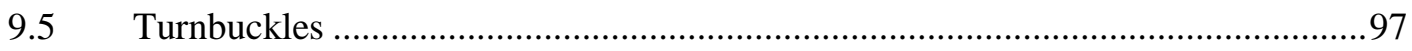

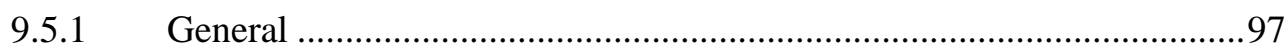

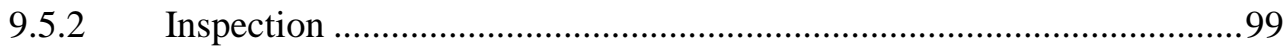

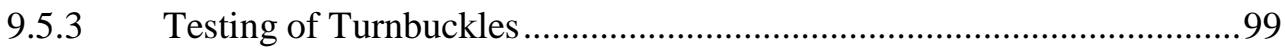

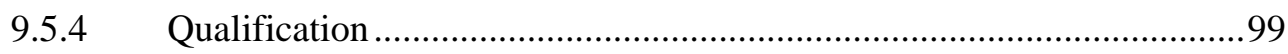

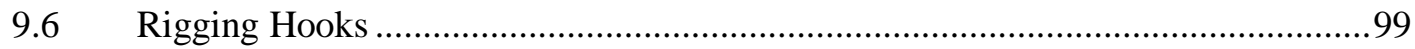

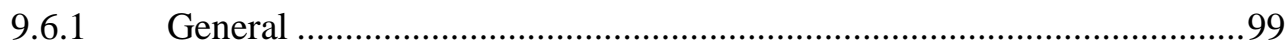




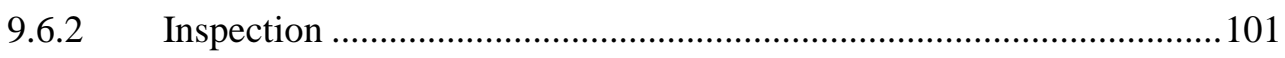

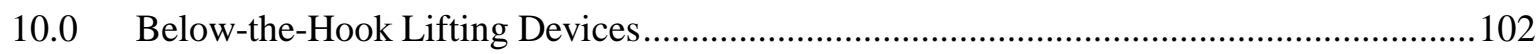

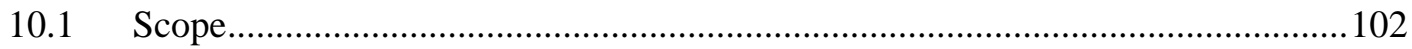

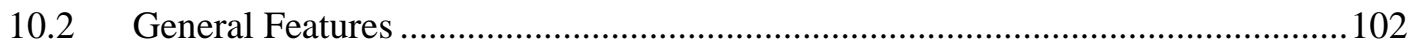

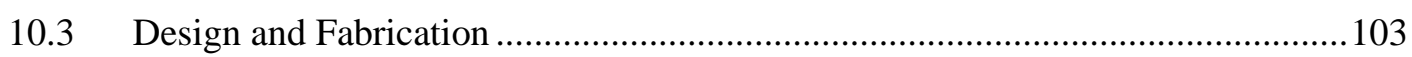

10.3.1 Design Factor................................................................................. 103

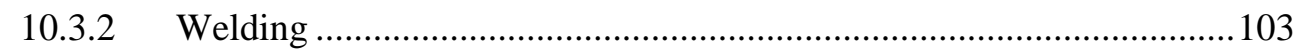

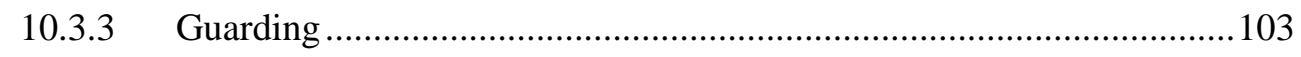

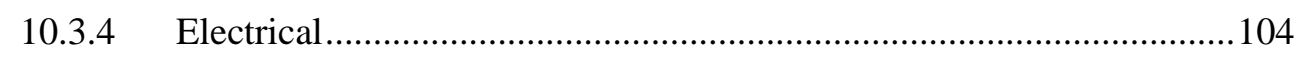

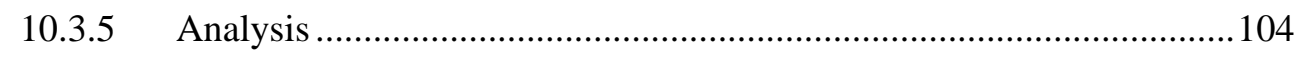

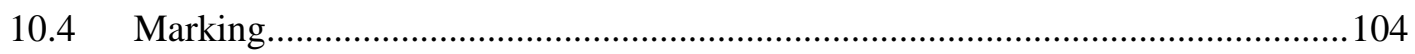

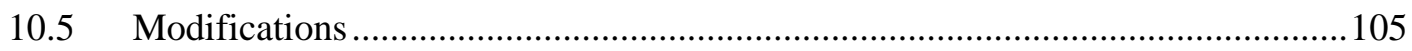

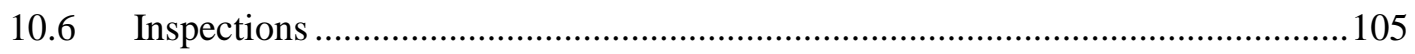

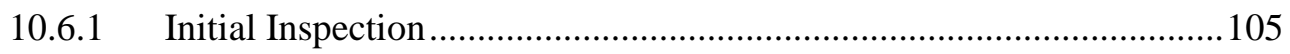

10.6.2 Frequent Inspections...................................................................... 105

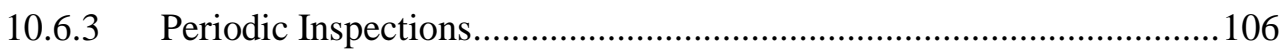

10.6.4 Inspection Records ....................................................................... 106

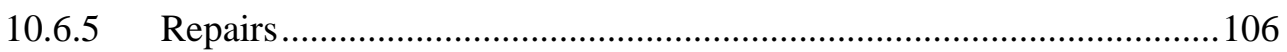

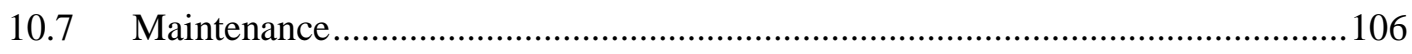

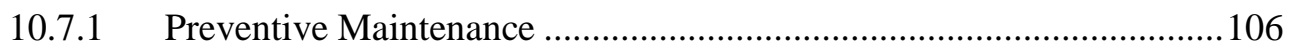

10.7.2 Replacement Parts ............................................................................ 107

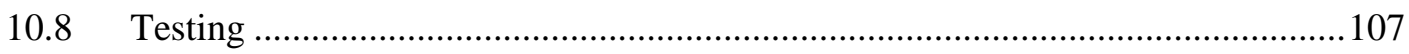

10.8.1 Structural and Mechanical Below-the-Hook Lifting Devices ..............107

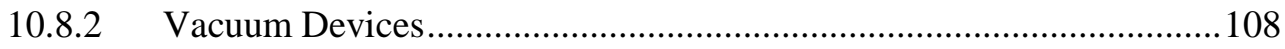

10.8.3 Close Proximity Operated Magnets.....................................................109

10.8.4 Remotely Operated Lifting Magnets ................................................109

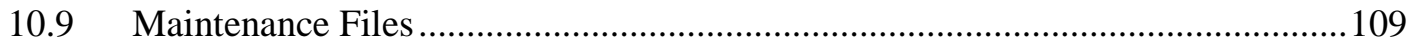

10.9.1 Intent of Maintenance Files …........................................................109

10.9.2 Maintenance File Contents .............................................................. 109

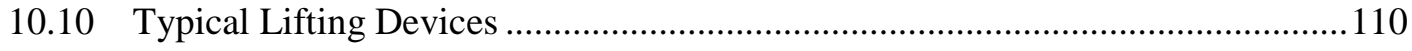

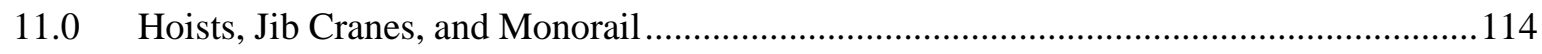

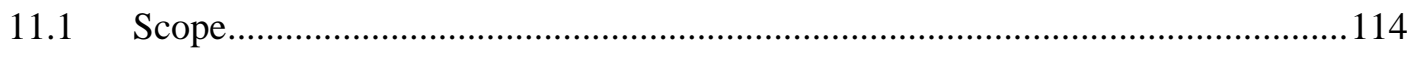

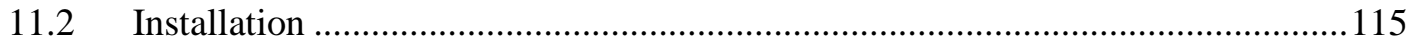

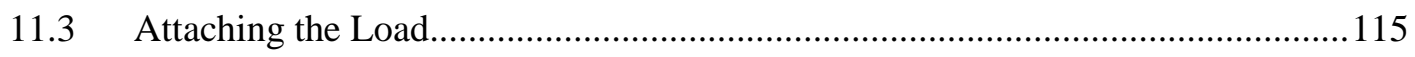

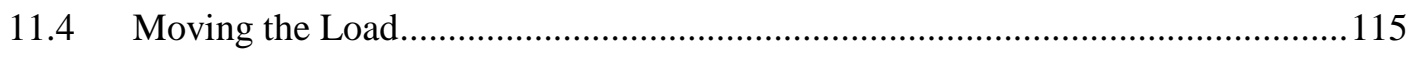

11.5 General Construction and Installation ….........................................................117

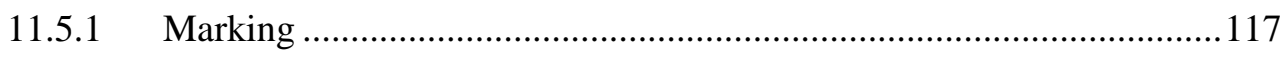

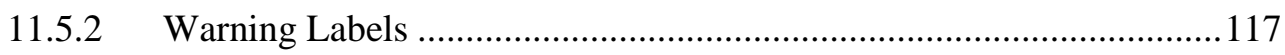

11.5.3 Hand Signal Posting ...................................................................... 119 
11.5.4 Design Factors ..................................................................................120

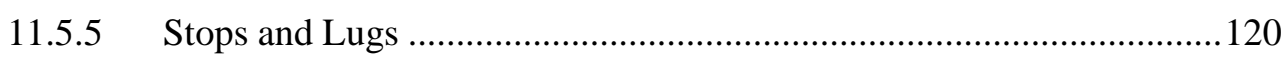

11.5.6 Sheave Guards .............................................................................120

11.5.7 Over-Travel Protection.......................................................................121

11.5.8 Load Chain Bucket .............................................................................121

11.5.9 Throat Latches ...............................................................................121

11.5.10 Monorail System, Clearance at Curves ................................................121

$11.6 \quad$ Brakes - Load-Controlling Mechanism ................................................................122

11.6.1 Manually Lever Operated Hoists - Chain Type.......................................122

11.6.2 Hand Chain-Operated Hoists................................................................122

11.6.3 Electric-Powered Hoists ...................................................................122

11.6.4 Air-Powered Hoists ..........................................................................122

11.6.5 Cab-Operated Monorail .......................................................................123

11.6.6 Monorail Carriers (No Cab) ……………………………………….....123

11.6.7 Jib Crane Carriers .............................................................................123

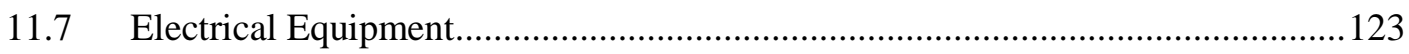

11.7.1 National Electrical Code Compliance ..................................................123

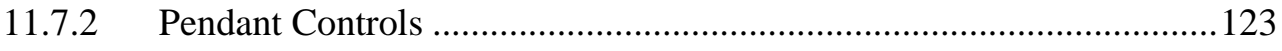

11.7.3 Electrical Supply, Hoist, and Monorail Systems ...................................124

11.7.4 Monorail Conductors.........................................................................124

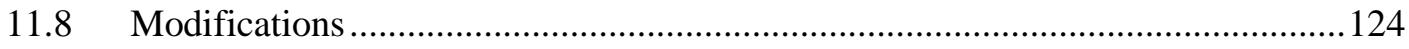

11.8.1 Monorail Systems ............................................................................124

11.8.2 Manual- or Power-Operated Hoists......................................................124

11.8.3 Documentation for Modifications ………………………………........124

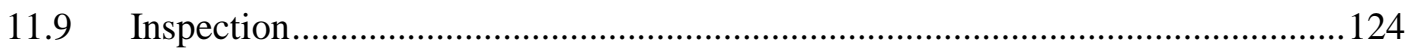

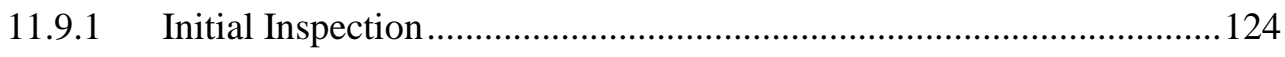

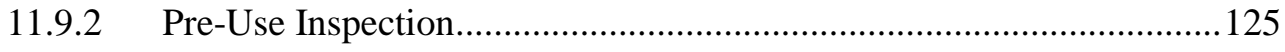

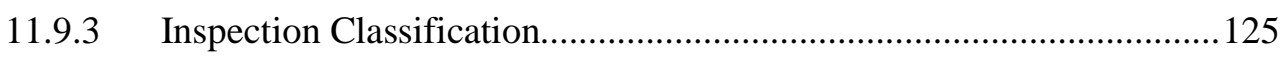

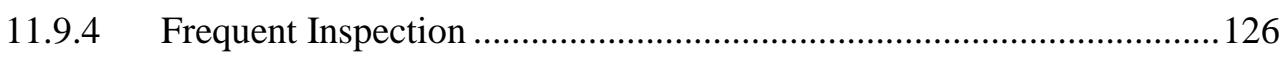

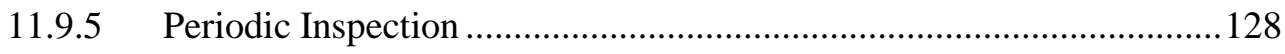

11.9.6 Inspection of Equipment Not in Regular Use......................................135

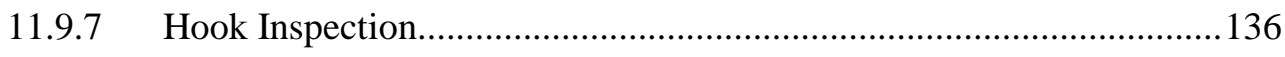

11.9.8 Third-Party Inspection ....................................................................136

11.9.9 Inspection Records .......................................................................136

11.10 Wire Rope Inspection, Replacement, and Maintenance .......................................136

11.11 Welded-Link Chain Inspection, Replacement, and Maintenance...........................136

11.11.1 Welded-Link Chain Inspection.........................................................136

11.11.2 Welded Link Chain Replacement.......................................................137

11.11.3 Welded-Link Chain Maintenance...........................................................138 
11.12 Roller Chain Inspection, Replacement, and Maintenance .................................138

11.12.1 Roller Chain Inspection ..............................................................138

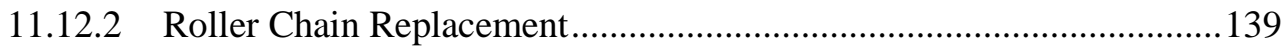

11.12.3 Roller Chain Maintenance …..........................................................139

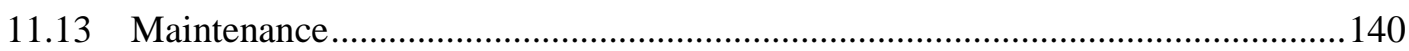

11.13.1 Preventive Maintenance ....................................................................140

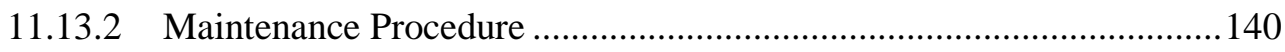

11.13.3 Adjustments and Repairs............................................................141

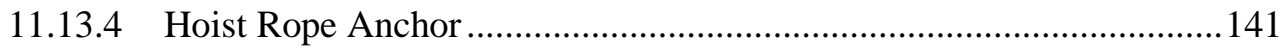

11.13.5 Preoperational Check after Maintenance or Repair.............................142

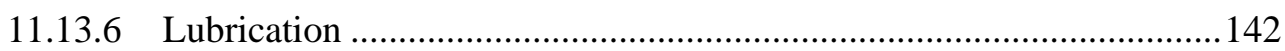

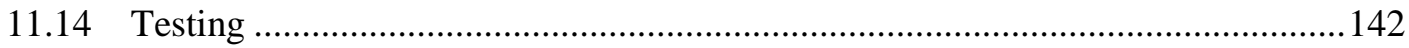

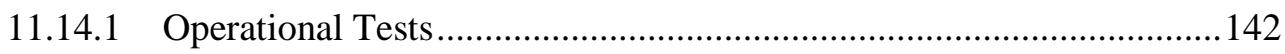

11.14.2 Load Test ....................................................................................... 143

11.14.3 Periodic Load Test............................................................................ 144

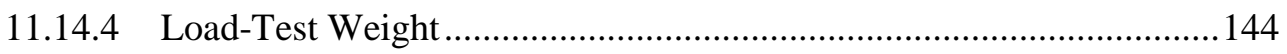

11.14.5 Load-Test Procedures ............................................................................144

11.14.6 Hook Nondestructive Testing ...........................................................145

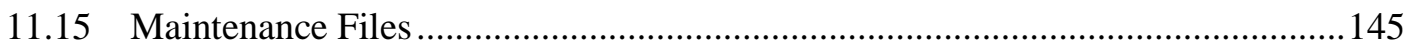

11.15.1 Intent of Maintenance Files ............................................................145

11.15.2 Maintenance File Contents ...............................................................146

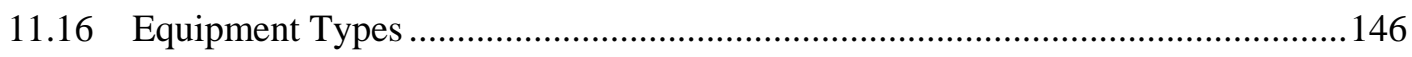

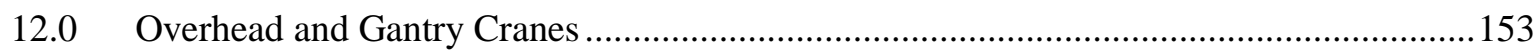

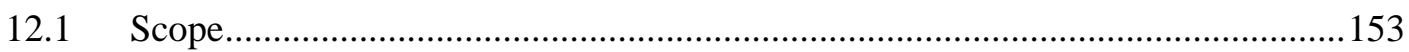

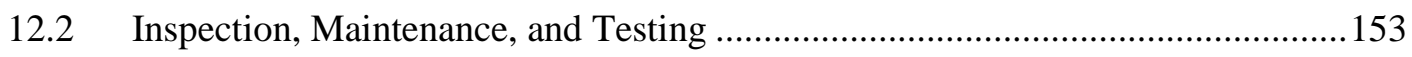

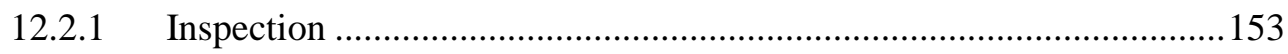

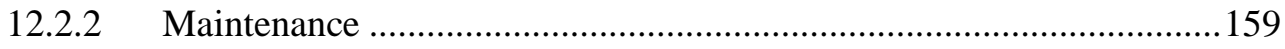

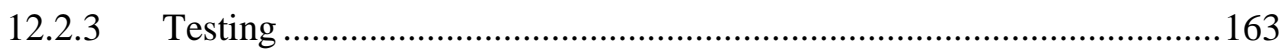

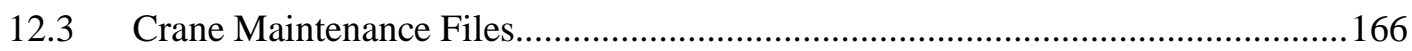

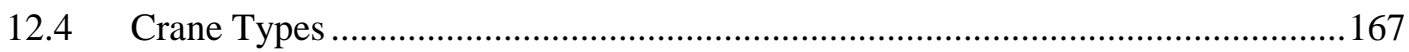

13.0 Hoisting and Rigging in Hostile Environments ......................................................... 172

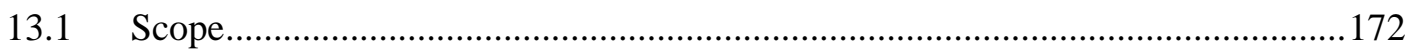

13.1.1 Normal Operations ..................................................................... 172

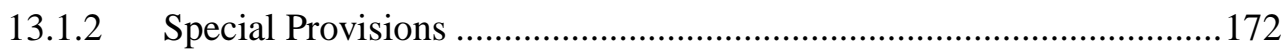

13.2 Equipment and Operations Review …............................................................. 172

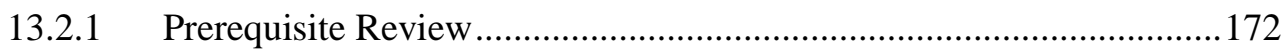

13.2.2 As Low As Reasonably Achievable ..................................................172

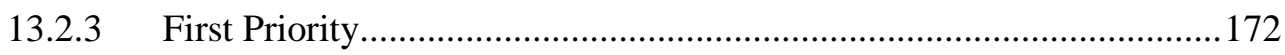

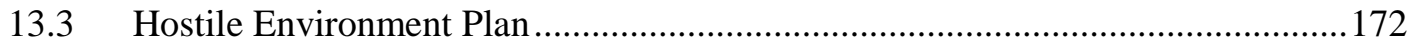




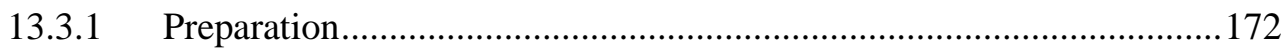

13.3.2 Review/Approval Requirements.................................................173

13.3.3 Hostile Environment Plan Contents ................................................173

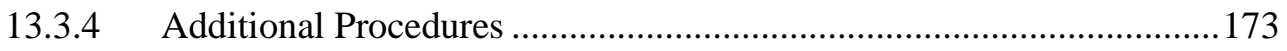

13.3.5 Hostile Environment Plan Distribution ............................................. 173

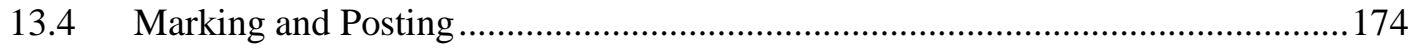

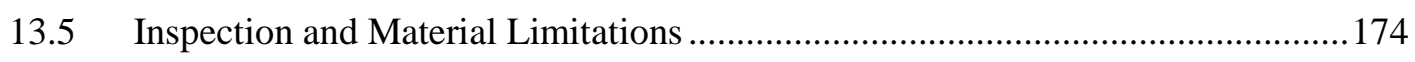

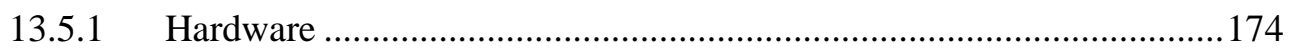

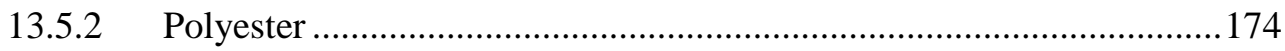

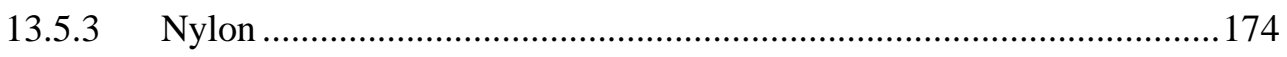

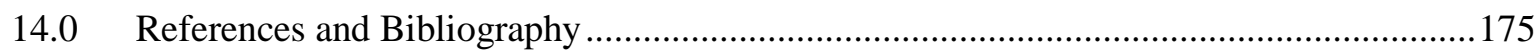

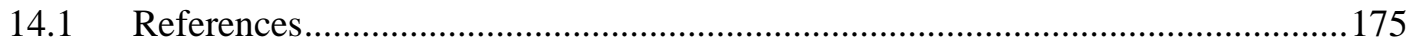

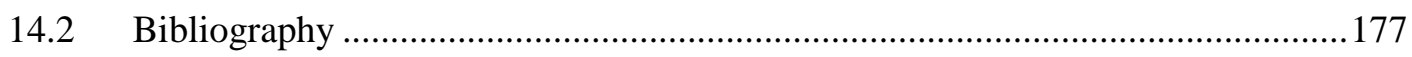

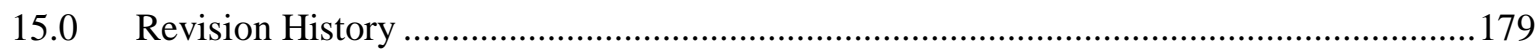

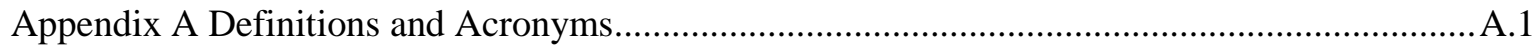

Appendix B Worksheets and Checklists ................................................................................. B.

B.1 Lift Determination Worksheet .................................................................. B. 1

B.2 Special Lift Determination Worksheet ……..................................................... B.2

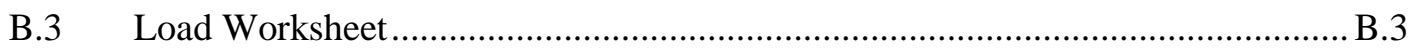

B.4 Rigging Hardware Worksheet.................................................................... B.

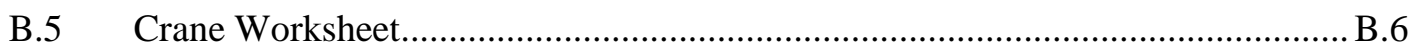

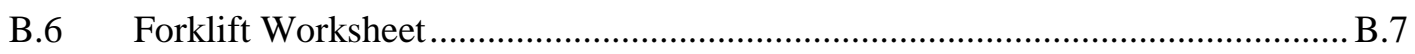

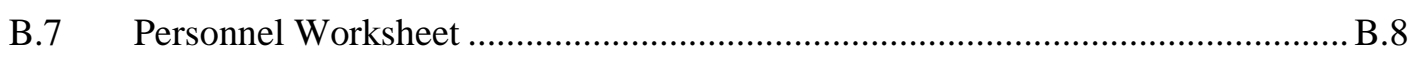

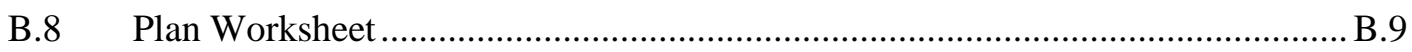

B.9 Forklift Workplace Hazard Evaluation Checklist........................................... B.10

B.10 Wire Rope Replacement Checklist .............................................................. B. 11

B.11 Typical Hostile Environment Plan................................................................ B.13 


\section{Figures}

Figure 5.1. Standard Hand Signals for Controlling Forklift Operations .........................................36

Figure 5.2. Markers to Identify Type of Industrial Truck...........................................................39

Figure 5.3. Building Signs for Posting at Entrance to Hazardous Areas ........................................40

Figure 6.1. Typical Shop Cranes............................................................................................43

Figure 8.1. Sling Stresses at Various Sling Angles.................................................................57

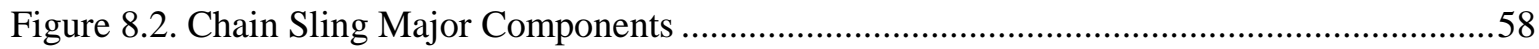

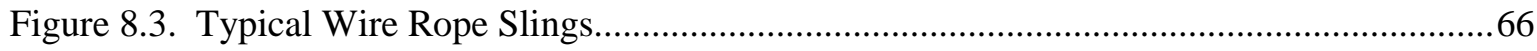

Figure 8.4. Nominal End Attachment Efficiency......................................................................68

Figure 8.5. Wire Rope Efficiencies for Various D/d Ratios .........................................................68

Figure 8.6. Rigging Tackle and Equipment Identification Tag Example ......................................70

Figure 8.7. Correct and Incorrect Ways to Use Wire Rope Clips (Clamps) ..................................75

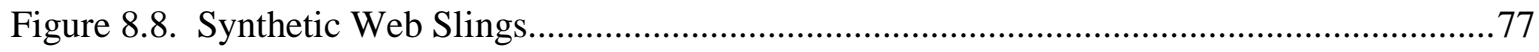

Figure 8.9. Web Sling with Loop Eyes or End Fittings ..............................................................78

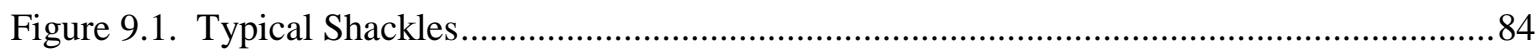

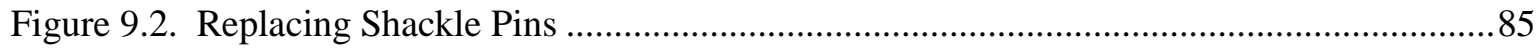

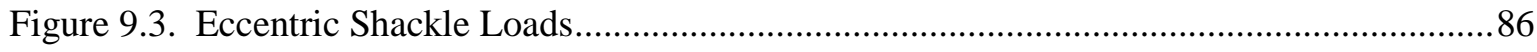

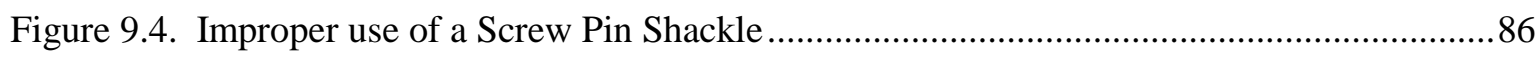

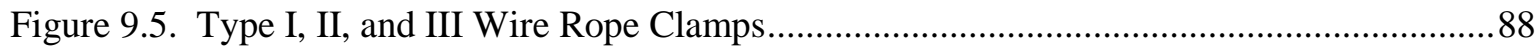

Figure 9.6. Angle of Load for use with Table 9.1......................................................................

Figure 9.7. Use of Shoulder-Type Eyebolts..........................................................................93

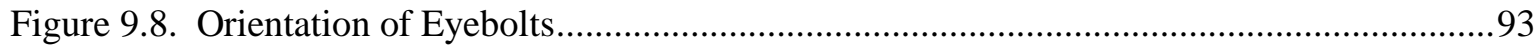

Figure 9.9. Swivel Hoist Ring Inspection Points ......................................................................95

Figure 9.10. Using Swivel Hoist Rings...............................................................................96

Figure 9.11. Swivel Hoist Ring Rigging Techniques ...............................................................96

Figure 9.12. Turnbuckle Types, Inspection Areas, and Safe Working Load.................................98

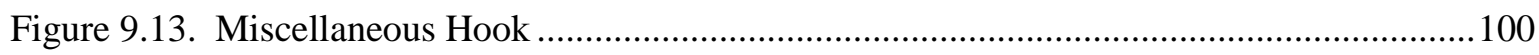

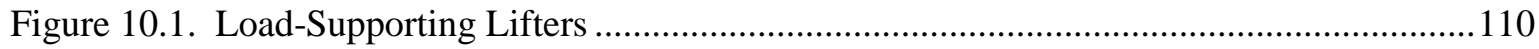

Figure 10.2. Indentation-Type Pressure Gripping Lifters.........................................................111

Figure 10.3. Friction-Type Pressure Gripping Lifters ..........................................................112

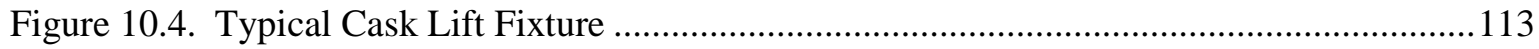

Figure 10.5. Below-the-Hook Lifting Device........................................................................113

Figure 11.1. Wire Rope Ratchet and Pawl Lever-Operated Hoist ..............................................114

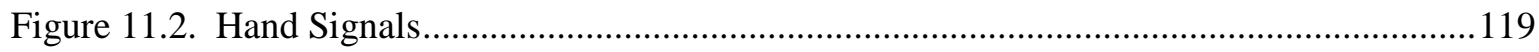

Figure 11.3. Monorail Cab-Operated Carrier............................................................................146

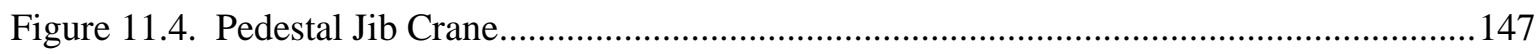

Figure 11.5. Wall-Supported Jib Crane ...................................................................................147 


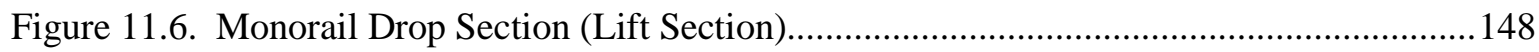

Figure 11.7. Lever-Operated Hoist - Chain Type ................................................................... 148

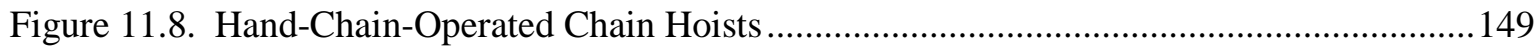

Figure 11.9. Electric-Powered Chain Hoists.......................................................................... 149

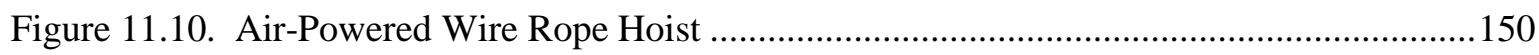

Figure 11.11. Electric-Powered Wire Rope Hoist ...................................................................150

Figure 11.12. Air-Powered Wire Rope Hoist .......................................................................151

Figure 12.1. Top-Running Single-Girder Bridge with Underhung Trolley Hoist ........................167

Figure 12.2. Overhead Floor Operated Crane and Gantry Crane ..............................................168

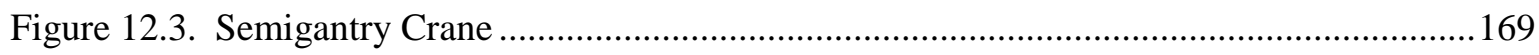

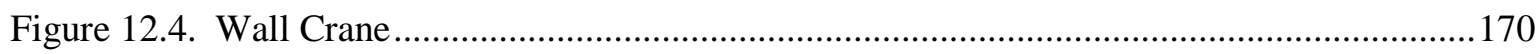

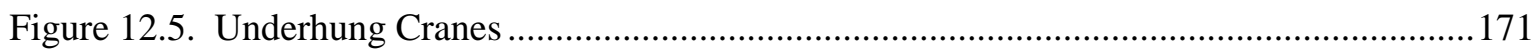

\section{Tables}

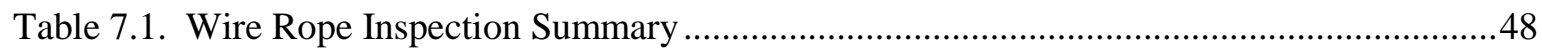

Table 8.1. Rated Load for Alloy Steel Chain Slings ASTM A391 ..............................................59

Table 8.2. Typical Reduction of Chain Sling Working Load According to Temperature(a)...........60

Table 8.3. Frequent and Periodic Inspection of Chain Slings.......................................................62

Table 8.4. Maximum Allowable Wear at any Point of Link......................................................63

Table 8.5. Wire Rope Slings in Choker Hitch .......................................................................67

Table 8.6. Allowable Broken Wires in Braided and Cable-Laid Slings ........................................72

Table 9.1. Safe Working Load for Carbon Steel Shouldered Eyebolts (ANSI/ASME B18.15)......91

Table 11.1. Inspection for Hand Chain-Operated Hoists ...........................................................129

Table 11.2. Inspection for Electric- or Air-Powered Hoists ......................................................131

Table 11.3. Minimum Inspection for Lever-Operated Hoists - Chain Type.................................134 



\subsection{Introduction}

\subsection{Purpose}

This manual describes the safe and cost effective operation, inspection, maintenance, and repair requirements for cranes, hoists, fork trucks, slings, rigging hardware and hoisting equipment. From time to time, lifting is performed with equipment other than cranes, hoists, and fork trucks. When using any equipment for material handling, follow the equipment manufacturer's instructions.

EXAMPLE: excavation equipment, such as a backhoe, may have a hook installed on the bucket. It is acceptable to use such equipment for hoisting and rigging if the manufacturer provides instructions for use. The manufacturer’s instructions should include load capacity information.

See footnote 1 for examples of other equipment not within the scope of this manual. ${ }^{1}$

\subsection{Scope}

This manual is intended to be a user's guide to requirements, codes, laws, regulations, standards, and practices that apply to Pacific Northwest National Laboratory and its Sub-Contractors.

This Manual is generally invoked via contract. Whether or not this Manual is invoked, hoisting and rigging work is required by law to be in compliance with the Occupational Safety and Health Act of 1970 (OSHA) (29 CFR 1910 or 29 CFR 1926) and work involving critical lifts should follow this manual. As a minimum, acceptability of equipment, rigging and critical lift procedures should be verified by the Hoisting and Rigging Subject Matter Expert (SME).

\subsection{Background}

Information for this manual is based on the Hanford Site Hoisting and Rigging Manual (DOE-RL-92-36). Any lack of clarity, errors, omissions, interpretations or discrepancies should be addressed to Hoisting and Rigging SME.

\subsection{Manual Organization}

This is a user's manual. It designates areas of responsibility regarding hoisting and rigging activities and stipulates operation, maintenance, and repair requirements for H\&R equipment and components. Topics have been grouped to make the manual user friendly and to minimize jumping around within the manual. While selected design considerations are included in this manual, primarily as information to operators and inspectors, this manual is a user's manual, not a design manual.

Editor's Note: All section numbers within this document are linked to the section.

\footnotetext{
${ }^{1}$ For example, the following types of equipment are not within the scope of this manual: elevators, dumbwaiters, escalators, moving walks, conveyor systems, drill and pump setting rigs, manipulators, specially insulated hoists for handling high-voltage lines, door- and hatch-opening equipment, vehicle-mounted elevating and rotating aerial devices, elevating work platforms, aerial lifts, and earth-moving and excavation equipment.
} 


\section{$1.5 \quad$ Mandatory and Advisory Rules}

Mandatory rules are characterized by use of the word shall. If a provision is of an advisory nature, it is indicated by use of the word should and is to be considered; its advisability depends on the facts in each situation. 


\subsection{Responsibilities}

\section{$2.1 \quad$ Scope}

This section provides guidance in delineating the responsibilities of personnel and organizations directly involved in hoisting and rigging activities at PNNL.

Job classification terms used in this manual (e.g., rigger, operator, and inspector) refer to the function performed and in no way relate to a classification in any union or bargaining unit.

\subsection{Personnel Responsibilities}

\subsubsection{Responsibilities}

PNNL's hoisting and rigging program is based on equipment manufacturers' specifications and limitations for operation, maintenance, and inspection of equipment addressed by this manual. Where manufacturers' specifications are not available, operation limitations and maintenance and inspection requirements assigned to the equipment shall be based on determinations of a qualified person competent in this field and such determinations will be appropriately documented and disseminated to equipment operators, and maintenance and test personnel.

\subsubsection{Supervisor or Manager, Hoisting and Rigging Operations}

A supervisor or manager either in charge of the work (e.g., Cognizant Space Manager) or those conducting the work (e.g., Facilities \& Operations Work Team Lead) shall be responsible for each hoisting and rigging operation and shall ensure that the following activities are completed:

- The equipment is operated by qualified personnel.

- The equipment is operated safely.

- Preplanned and approved hoisting and rigging instructions are used when necessary and always for critical lifts.

- The equipment found to be unsafe or requiring restrictive use is properly tagged.

- The equipment custodian is notified of equipment problems.

- A designated leader shall be assigned to all lifts (including forklift operations) that require more than one person. 


\subsubsection{Supervisor or Manager, Inspection, Maintenance, and Repair}

A supervisor or manager shall be responsible for inspection, maintenance, and repair on hoisting and rigging equipment and components and shall ensure the following:

- $\quad$ Equipment is inspected, maintained, and repaired by qualified personnel.

- Inspectors, maintenance, and repair personnel have the tools to safely accomplish their work.

- Responsible inspectors, maintenance, and test personnel have access to adequate information, as applicable:

- operating instructions

- maintenance, repair, and parts information furnished by the manufacturer or the responsible maintenance/engineering organization

- the manufacturer's recommendations as to points and frequency of lubrication, maintenance of lubrication levels, and types of lubricant to be used

- maintenance or repair procedures from the manufacturer or responsible maintenance/engineering organization

- wiring diagrams

- inspection, maintenance, and repair activities are documented in accordance with the requirements of this manual

- for equipment furnished with a manual, personnel responsible for inspection or maintenance are familiar with the applicable contents of the manual.

\subsubsection{Designated Leader for Critical Lifts}

Management shall assign a DL for critical lifts. The DL may be a crew member or any qualified person. The DL for critical lifts shall ensure that the following activities are completed:

- A critical lift procedure is prepared.

- The critical lift procedure is properly approved (refer to Section 3.0, “Critical Lifts”).

- A documented prelift meeting is held.

- Involved personnel (e.g., operators, riggers, flagman, designated leader) are qualified and understand how the job will be done.

- $\quad$ Proper equipment and hardware are identified in the critical lift procedure.

- The lifting operation is directed by a DL to ensure that the job is done safely and efficiently.

- Involved personnel are familiar with, and follow, the critical lift procedure. 
- After the critical lift is completed, critical lift documentation is transmitted to the manager for whom the lift was done. The DL should advise responsible personnel that this documentation is subject to audit for 1 year. (See Section 3.0.)

\subsubsection{Designated Leader}

A designated leader shall be appointed to all lifting activities that involve more than one person (including forklift operations), including both critical and ordinary lifts. The DL may be the operator, a crew member, or any qualified person. The DL shall perform the following activities:

- Ensure that a flagger or signaler, if required, is assigned and identified to the hoist/crane/forklift operator.

- Ensure that the personnel involved are qualified and understand how the job is to be done.

- Ensure that the weight of the load is determined, that the proper equipment and hardware are selected and inspected, and that the capacity of the lifting device is not exceeded.

- Ensure that the equipment is properly set up and positioned.

- Examine the work area for hazardous or unsafe conditions.

- Direct the lifting operation to ensure that the job is done safely and efficiently.

- Ensure that the job is stopped when any potentially unsafe condition is recognized.

- If an injury or accident occurs, ensure that the emergency is promptly reported. (Call 375-2400, or local emergency services for off-site locations.)

\subsubsection{Operator}

The operator shall perform the following activities:

- Safely operate equipment.

- Follow the equipment operating guidelines and, for mobile cranes, the load charts.

- $\quad$ Perform the pre-use and frequent equipment inspection.

- Ensure that the load will not exceed the rated capacity of the equipment.

- Abide by any restrictions placed on the use of the equipment.

- Ensure inspections are current via inspection sticker, other documentation or verbal confirmation from the equipment custodian. 


\subsubsection{Rigger}

The rigger shall perform the following activities:

- Ensure that the rigging equipment and materials have the required capacity for the job and that all items are in good condition, are currently qualified (inspection is up to date), and are properly used.

- Confirm that the load path is clear of personnel and obstacles.

\subsubsection{Equipment Custodian}

Equipment owner shall designate an individual who shall have custodial responsibility for each crane, hoist, lift truck, or other hoisting and rigging equipment that requires scheduled maintenance, inspection, and record keeping. The custodian shall perform the following activities:

- Verify that operating equipment is properly maintained and maintenance, inspection, and testing of the equipment remain current.

- Ensure that records of the maintenance, repair, inspection, and testing are available for audit in a maintenance file.

- Verify that equipment is properly tagged and, if necessary, removed from service when discrepancies are found during inspection or operation.

\section{Note:}

1. It is important that equipment users know how to contact the equipment custodian (e.g., labeled on the equipment, identified in the supporting procedures, etc).

2. See Section 5.2.4 for specific duties of a forklift truck custodian.

3. It is important to recognize that more specific, and possibly additional, responsibilities are stated in individual chapters. 


\subsection{Critical Lifts}

\subsection{Scope}

This section includes guidelines, rules, and requirements applicable to critical lifts and describes the planning and documentation required to perform a critical lift. This section also summarizes ordinary (noncritical) lifts for which special precautions are required. Non-mandatory worksheets are provided as an aid in determining whether something is a critical lift and planning critical and special lifts.

\subsection{Critical Lift Determination}

The manager who has responsibility for the item to be lifted has the authority to require that it be handled as a critical lift. In addition, the Building Manager and/or Cognizant Space Manager where the lift will be performed also have the authority to require that it be handled as a critical lift. The manager who designates a lift as a critical lift shall ensure that a DL be assigned. (See Appendix 15.0B.1, "Lift Determination Worksheet.”)

\subsection{Guidelines and Rules for Critical Lifts}

It is important to ensure that rigging, below-the-hook lifting devices, and cranes, hoists, and forklifts have current inspections and are never loaded beyond their rated capacity except for testing.

\subsubsection{Guidelines}

A lift shall be designated as a critical lift under any of the following circumstances.

1. If the item being lifted were to be damaged or upset, it could result in a release of radioactive or hazardous material into the environment which could exceed the established Permissible Environmental Limits. (Contact the Environmental organization for a determination of these levels.)

2. The item being lifted is unique and, if damaged, would be irreplaceable or not repairable and is vital to a system, facility, or project operation.

3. The cost to replace or repair the item being lifted, or the delay in operations of having the item damaged would have a severe negative impact on facility, organizational, or budget to the extent that it would affect program commitments.

4. The item, although non critical, is to be lifted above or in close proximity to a critical item or component.

5. The load being lifted is $95 \%$ or more of a mobile crane's chart rating for the maximum radius that will be experienced.

6. Two mobile cranes are lifting the load and the load share equals more than $70 \%$ of one or both crane's chart rating for the maximum radius that will be experienced.

Note: A critical lift designation provides the following: 
- documented step-by-step instructions

- $\quad$ pre-identified load path

- $\quad$ sign-off approvals for technical, management, and safety or engineering.

- documentation of lift and pre-job meeting.

- independent pre-identification of load weight, load center of gravity, lift attachment points, and lifting hardware minimum capacities (slings, below-the-hook lifting devices, shackles, etc.) that will be used for the lift or series of lifts.

- load testing of the lifting hardware (slings, below-the-hook lifting devices, shackles, etc.) that will be used for the lift.

- evaluation of hazards associated with the lift that may include environmental, ground support, and physical obstructions

- pre-identified special limiting or stop-work conditions.

\subsection{Critical Lift Equipment and Hardware}

\subsubsection{General}

Before making a critical lift, the DL shall ensure that equipment (cranes, hoists, forklift trucks, etc.) inspections are current and that load tests have been done for slings, rigging, rigging hardware, and below-the-hook devices. (Exceptions apply to manufacturer-installed rigging hardware.)

\subsubsection{Manufacturer-Installed Rigging Hardware on Engineered Equipment}

Engineered equipment with manufacturer-installed rigging hardware (eyebolts, swivel hoist rings, etc.) should be purchased with load-test documentation supplied. Rigging hardware on engineered equipment, installed by the equipment manufacturer, without test documentation, may be used if approved by a rigging specialist or qualified engineer and inspected by a qualified inspector before use.

\subsubsection{Rigging Hardware for Critical Lifts}

The rigging hardware components (slings, shackles, chain, etc.) to be used in critical lifts shall be ratedcapacity/load tested. Rigging components that have been load tested shall be marked or tagged by the user, a third party, or the manufacturer to verify the rated-capacity/load test. Documentation shall be traceable to the hardware. Traceability may be accomplished placing a tag or other permanent marking on the hardware. The manufacturer, the user, or a third party may perform load tests. Tags or other permanent marking fulfill documentation requirements without paperwork, except for below-the-hook lifting devices, which require additional documentation (see Section 10.0, "Below-the-Hook Lifting Devices”). 


\subsubsection{Rigging Hardware Rated-Capacity Testing for Critical Lifts}

Rigging hardware for critical lifts can include the following and shall meet the requirements found in the referenced Section.

- Wire Rope Slings, including the following:

- swaged socket and poured socket assemblies

- hand tucked

- mechanical-splice, single-leg, and endless wire rope slings

- multiple-leg bridal

- master link to which multiple-leg slings are connected.

See Section 8.0, "Slings," for wire rope sling rated load test requirements.

- Alloy Chain Slings, including the following:

- a. Single- or multiple-leg slings, each leg.

- b. Master links and coupling links (forged or welded) for multiple-leg chain slings

See Section 8.0, “Slings,” for alloy chain slings rated load test requirements.

- Metal Mesh Slings. See Section 8.0, “Slings," for metal mesh slings rated load test requirements.

- Synthetic Web Slings. See Section 8.0, “Slings,” for synthetic web slings rated load test requirements.

- Synthetic Rope Slings. See Section 8.0, “Slings,” for synthetic rope slings rated load test requirements.

- Shackles. See Section 9.0, “Rigging Hardware,” for shackles rated load test requirements.

- Eyebolts. See Section 9.0, “Rigging Hardware,” for eyebolts rated load test requirements.

- Rings (Forged and Welded). See Section 9.0, "Rigging Hardware,” for rings rated load test requirements.

- Swivel Hoist Rings. See Section 9.0, “Rigging Hardware,” for swivel hoist rings rated load test requirements.

- Turnbuckles. See Section 9.0, "Rigging Hardware,” for turnbuckles rated load test requirements.

- Below-the-Hook Lifting Devices (in accordance with American Society of Mechanical Engineers (ASME) B30.20). See Section 10.0, “Below-the-Hook Lifting Devices,” for rated load 
test requirements and for requirements imposed by American National Standards Institute (ANSI) N14.6.

- Dynamometers and Precision Load-Position Devices (hydro-set). Load test at maximum capacity.

Note: The tolerance for load tests/proof tests is $+0 \%,-5 \%$. If the hardware manufacturer recommends loads greater than those listed in the referenced Section, the manufacturer's recommendations should be followed.

\subsection{Critical Lift Plan}

A step-by-step plan or work instructions shall be prepared or approved by a technically qualified person. (See Appendix 15.0B.8, "Plan Worksheet.”) Critical lift plans shall contain the following:

Note: The items in the following list are required as designated by the key:

* Generally required, depending on situation and equipment used

** Required.

1. ** Identity of the items to be lifted.

2. * Special precautions, if any (such as mats for mobile cranes).

3. ** Weight of the item and total weight of the load. (For mobile cranes, see the manufacturer's instructions regarding components and attachments that must be considered as part of the load.)

4. * Location of the center of gravity.

5. ** A list that specifies each piece of equipment (e.g., crane, hoist, fork truck), accessory, and rigging component (e.g., slings, shackles, spreader bars, yokes) to be used for the lift. (This list shall identify each piece of equipment by type and rated capacity.)

6. * Designated checkpoints or hold points and estimated instrument readings, as relevant, so that job progress can be checked against the plan.

Note: Sign-offs in the plan generally are appropriate. For example, initial and time/date the plan as key steps are completed. Hold points or sign-off points should be provided for personnel assigned to witness the work.

7. * Rigging sketches, which include the following:

- lift point identification

- $\operatorname{method(s)~of~attachment~}$

- load angle factors (e.g., vertical and horizontal vectors of sling loads)

- sling angles

- $\quad$ accessories used 
- other factors affecting the equipment capacity

- rated capacity of equipment in the configurations in which it will be used. (For mobile cranes, many factors affect rated capacity, including boom length, boom angle, and work area.)

8. * A load-path sketch that shows the load path and height at key points in the job. (For lifts with mobile cranes, include the crane positions relative to the load and relative to surrounding obstructions. Where appropriate, include floor- or soil-loading diagrams.)

9. * A sketch indicating lifting and travel speed limitations. (This may be noted on the load- path sketch or on a separate sketch.)

10. ** A sign-off sheet to verify that equipment and hardware inspections and tests are current.

11. * Practice lifts are recommended. (If used, requirements for the practice lift should be documented in the plan.)

Note: Although individual plans are prepared for one-time critical lifts, more general (multi-use) plans may be employed to accomplish recurrent critical lifts. For example, a general plan may be used to lift an item or series of similar items that are handled repeatedly in the same manner.

\subsubsection{Critical Lift Plan Approval}

The critical lift plan or work instructions should be approved as required by the responsible organization and, as a minimum, shall be signed and dated by the following:

- manager responsible for the item to be lifted

- qualified engineer or assigned occupational safety representative.

\subsubsection{Critical Lift Plan Field Revisions}

Critical lift plan or work instruction field revisions shall be accomplished by drawing a single line through the original (deleted) text and inserting the field revision close to the deleted text. The field revision shall be initialed and dated by the persons making the revision. Text shall not be obliterated by the use of correction fluid, correction tape, scribbling, erasure, or any other method. Field revisions should be approved as required by the responsible contractor's plans. As a minimum, critical lift field revisions shall be signed and dated in the margin of each revised page by all of the following:

- the manager of the lifting operation or facility manager

- the designated leader

- the qualified engineer, or assigned occupational safety representative.

Note: Critical lift field revisions may be confirmed by telephone and must be signed and dated within two working days of the field revision. 


\subsection{Prelift and Field Revision Review Meetings}

Before performing a critical lift and immediately following a field revision, participating personnel shall meet to accomplish the following.

Note: The DL or facility-assigned person shall ensure that all members of the work team completely understand the work instructions or field revision.

- Review the critical lift plan or field revision.

- Discuss any hazards, controls, hold points, coordination with other work groups, unique conditions, and emergency contingencies.

- $\quad$ Resolve questions before beginning work.

This section also provides for use of pre-engineered lifting that may include independent preidentification of load weight, load center of gravity, lift attachment points, and minimum lifting hardware (slings, below-the-hook lifting devices, shackles, etc.) capacities that will be used for the lift or series of lifts of non critical items.

\subsection{Special Lifts - Non-Critical Lifts That Require Special Precautions}

As addressed in other parts of this manual, certain lifting operations require special precautions. (See Appendix 15.0B.2, "Special Lift Determination Worksheet.”) Special precautions are suggested under the following conditions:

- Personnel are being lifted with cranes or forklifts. For forklift trucks, follow the requirements found in Section 5.0.

- Two or more cranes will be used to make a lift. (For hoists, jib cranes, and monorail systems, follow the requirements found in Section 11.0. For overhead and gantry cranes, follow the requirements found in Section 12.0.)

Pre-Engineered Lifts. Independent pre-identification of load weight, load center of gravity, lift attachment points, and minimum lifting hardware capacities (slings, below-the-hook lifting devices, etc.) that will be used for the lift or series of lifts for non critical items, such as the following:

- Large or unusually configured loads outside a fork truck's load center will be handled. Follow the requirements found in Section 5.0.

- Loads in close proximity to an existing building or operating equipment.

- Non routine rigging configurations are being used or items require special care because of size, weight, close-tolerance installation, or high susceptibility to damage. 
Note: The special lift section provides elements of chapters in the manual that contain additional requirements when performing specific hoisting and rigging activities and allows the adoption of elements of the critical lift requirements, at management's discretion, to provide additional administrative and physical controls. The special lift category provides for the use of pre-engineered lifting that may include independent pre-identification of load weight, load center of gravity, lift attachment points and minimum lifting hardware (slings, below-the-hook lifting devices, shackles, spacers, softeners, etc.) capacities that will be used for the lift or series of lifts of non critical items.

\subsection{Worksheets}

Worksheets are provided as an aid and are not required documents. A qualified engineer, occupational safety representative, DL, or rigging specialist may determine that additional elements need to be considered. The following sample worksheets are provided in 15.0Appendix B.

- $\quad$ Lift Determination Worksheet

- Special Lift Determination Worksheet

- Load Worksheet

- $\quad$ Rigging Hardware Worksheet

- Crane Worksheet

- $\quad$ Forklift Worksheet

- Personnel Worksheet

- Plan Worksheet. 


\subsection{Hooks}

\subsection{Scope}

This section applies to hooks installed on cranes or hoists and implements the requirements of ASME B30.10. For rigging hooks, see Section 9.0.

\subsection{New Hooks}

When new hooks are purchased, pertinent requirements of ASME B30.10 shall be specified in the procurement document.

\subsubsection{Performance Tests}

Performance testing of hooks shall not be required except where necessary to conform to the requirements for the equipment of which they are a part.

When tests are specified, documentation shall be uniquely identified to the hook, by serial number, or other identifier.

\subsection{Throat Latches}

A latch, or mousing, bridges the throat opening of the hook for the purpose of retaining slings, chains, or similar parts under slack conditions and is not intended to support the load. Mousing shall not be used to secure the hook throat in manlift operations.

Latch equipped hooks shall be used for all hoisting and rigging operations unless the application makes use of the latch impractical, or unsafe. The absence of a hook throat latch is not indiscriminately allowed. Unless a specific impractical or unsafe situation can be substantiated, the hook latch is mandatory.

Questions concerning requirements for throat latches shall be resolved by the Hoisting and Rigging SME.

\subsection{Inspection}

\subsubsection{Inspection Classification}

- Initial Inspection. Before initial use, all new and repaired hooks shall be inspected to ensure compliance with the applicable provisions of ASME B30.10, HOOKS.

- Daily Inspection. Hook visual inspection shall be conducted daily (before use) by the operator or other designated person to identify the following:

- cracks, nicks, gouges 
- deformation

- damage from chemicals

- damage or malfunction of the throat latch, if provided.

- Classifications. There shall be two general inspection classifications based on intervals at which examination shall be performed. The classifications are designated frequent and periodic, with intervals between examinations as defined below.

\subsubsection{Frequent Inspection Interval}

Visual examinations by the operator or other designated person with records not required:

- $\quad$ normal service - monthly

- $\quad$ heavy service - weekly to monthly

- $\quad$ severe service - daily to weekly.

\section{Hook Service Classifications}

Normal Service. Service that involves operating at less than $85 \%$ of rated load except for isolated instances.

Heavy Service. Service that involves operating at $85 \%$ to $100 \%$ of rated load as a regular specified procedure.

Severe Service. Heavy service coupled with abnormal operating condition.

\subsubsection{Periodic Inspection Interval}

Visual inspections shall be performed by a qualified inspector who shall record apparent external conditions to provide the basis for continuing evaluation:

- Normal service - yearly, with equipment in place.

- Heavy service - semiannually, with equipment in place unless external conditions indicate that disassembly should be done to permit detailed inspection.

- Severe service - quarterly, as in heavy service, except that detailed inspection may show the need for nondestructive type testing.

\subsubsection{Frequent Inspection}

- Frequent inspection shall include observations during operation. 
- A designated person shall determine whether conditions found during the inspection constitute a hazard and whether a more detailed inspection is required.

- Hooks shall be inspected for the following items and conditions:

- distortion, such as bending, twisting, or increased throat opening

- wear

- cracks, nicks, or gouges

- latch engagement, damaged or malfunctioning latch (if provided)

- hook attachment and securing means.

\subsubsection{Monthly and Periodic Inspections (Records Required)}

- Monthly and periodic inspections shall include the requirements of Section 4.4.4, be done by a qualified person, and be documented.

- A monthly documented hook inspection is required on overhead and gantry cranes. Monthly hook inspection is a visual inspection for deformation, throat opening, and wear. Measurements are only required if the inspector finds evidence of distortion or damage. Monthly hook inspections on such cranes should be done in conjunction with the monthly wire rope or chain inspection. On manually operated lever hoists, overhead (underhung) hoists, jibs, and monorail systems, periodic hook inspection is required, but monthly hook inspection is not required.

- When monthly and periodic inspection fall in the same month, only the periodic documented hook inspection is required that month.

- Hooks having any of the following conditions shall be discarded.

- Deformation. Any bending or twisting visible to the inspector.

- Throat Opening. Any distortion causing an increase in throat opening exceeding $5 \%$ or as otherwise directed by the hook manufacturer.

- Wear. Any wear exceeding $10 \%$ of the original section dimension of the hook or its load pin or as otherwise directed by the hook manufacturer.

- Cracks. Any visible crack.

\subsubsection{Inspection Records}

For documented inspections, inspection records shall include the date of inspection, the signature of the person who performed the inspection, and the serial number, or other identifier, of the hook inspected. The most recent inspection records shall be retained in the equipment maintenance file. Following is a summary of inspection record requirements.

- Initial Inspection. A record of the initial inspection shall be made.

- Pre-use and Frequent Inspection. No records are required. 
- Monthly and Periodic Inspection. A record of monthly and/or periodic inspections shall be made.

\subsection{Nondestructive Testing}

\subsubsection{New Hooks}

New crane/hoist hooks that will be assigned to critical lift service should receive a nondestructive test (NDT) by the hook manufacturer. New crane/hoist hooks that will be assigned to heavy or severe service should receive an NDT by the hook manufacturer. The NDT method, acceptance criteria, and documentation requirements should be determined before the hook is purchased and specified on the purchase requisition.

CAUTION: Hooks purchased without an acceptable NDT may not pass applicable in-service NDT requirements.

\subsubsection{Existing Hooks}

Existing crane/hoist hooks with a rated load greater than or equal to 10 tons and assigned to heavy or severe service shall receive an NDT by a qualified inspector at the following intervals:

- $\quad$ heavy service - annually

- $\quad$ severe service - semi-annually (every 6 months).

Note: Hooks in normal service do not routinely require NDT.

\section{Hook Service Classifications}

Normal Service. Service that involves operating at less than $85 \%$ of rated load except for isolated instances

Heavy Service. Service that involves operating at $85 \%$ to $100 \%$ of rated load as a regular specified procedure

Severe Service. Heavy service coupled with abnormal operating condition

\subsubsection{Hooks in Normal Service}

Hooks in normal service shall receive NDT for site-specific reasons if deemed appropriate by facility management, the equipment custodian, a qualified inspector, or another designated person. 


\subsubsection{Hooks with Potential Defects}

If visual examination reveals a surface intersecting discontinuity, twist, increased throat opening, or any other potential defect, NDT shall be employed to further evaluate the hook, regardless of the hook's service classification or rated load.

\subsubsection{Hook NDT Records}

Dated and signed NDT records, traceable to the hook by serial number or other identifier, shall be kept on file as long as the hook remains in service or is accessible for service. NDT records shall be readily available to appointed personnel.

\subsubsection{Hook NDT Methods}

Magnetic particle testing or liquid penetrant testing methods shall be utilized to inspect for surface intersecting discontinuities (i.e., stress or fatigue cracks).

- $\quad$ NDT shall be done in accordance with the following American Society of Testing and Materials (ASTM) standards:

- ASTM E-709, Standard Practice for Magnetic Particle Examination

- $\quad$ ASTM E-165, Standard Practice for Liquid Penetrant Inspection Method

- For magnetic particle testing, a coil, yoke, or wet technique should be used to eliminate the possibility of prod burns or arc strikes.

- $\quad$ NDT should be done with the hook in place unless conditions indicate that disassembly for thread or shank inspection is necessary.

\subsubsection{NDT Acceptance Criteria}

The following relevant indications shall be documented and resolved by a designated person:

- $\quad$ arc strikes (welding/electrical).

- $\quad$ surface intersecting discontinuities 0.25 inch long or longer. 


\subsection{Forklifts}

\subsection{Scope}

Management and forklift operators review the following requirements, the accompanying list of commonly made errors during forklift operation, and Appendix 15.0B.9, "Forklift Workplace Hazard Evaluation Checklist.”

\subsection{Responsibilities}

This section specifies inspection, testing, and maintenance requirements for forklift trucks (also referred to in this section as "truck" and "forklift") powered by internal combustion engines or electric motors. This includes manually propelled high-lift trucks controlled by a walking operator.

This section excludes vehicles used for moving earth.

Guidelines may be taken from this section regarding pallet trucks and other small miscellaneous nonpowered lift trucks. Inspection, maintenance, and testing requirements for non-powered equipment are based on the manufacturer's instructions and recommendations.

\subsubsection{Forklift Requirements}

Forklift Operators and management are responsible for complying with the following requirements:

- Personnel shall be trained and evaluated on the specific class of forklift they will operate to be qualified.

- Personnel who do not operate a class or forklift for which they were qualified for more than 12 months shall be re-evaluated prior to operating.

- Forklifts shall be maintained in a safe operating condition, and be inspected by qualified personnel.

- Forklifts operators shall have knowledge and operate the lifts per the manufacturer's instructions and Section 5.12, "Conduct of Operators."

- The manufacturers' operators manual shall be retained on the lift.

- Operators shall complete a forklift inspection each shift, which includes verification that all lifts planned for the shift DO NOT exceed the rated capacity of the forklift.

- Forklift front-end attachments have compatible operation plates, tags, or decals identifying approved use and capacity.

- Personnel shall know the weight of the loads they lift and stay within the capacities of the forklift. 
- Personnel who handle loads in other than U.S. measurements shall be capable of converting weights and dimensions to and from U.S. and metric measurements to achieve accurate load determinations.

- Personnel operating forklifts shall be aware of the environment in which the forklift is to be used (e.g., physical constraints, energized sources, uneven surfaces).

- Management shall ensure on-the-job training and evaluation are provided for the specific class of forklifts personnel will operate.

\subsubsection{Common Errors during Forklift Operation}

Forklift operators and management must be aware of the following commonly made errors during forklift operation:

- driving while load obstructs view

- taking turns with excessive speed, resulting in tip-over

- leaving forklift unattended and in unsafe condition (e.g., engine running, load raised, parking brake not set)

- attempting to jump clear of the forklift during a tip-over accident

- failing to wear seatbelt when provided

- $\quad$ standing on load while it is lifted

- allowing others to ride on the forklift

- failing to check for adequate clearance

- $\quad$ not securing the load

- failing to keep loads low and balanced

- failing to wear seatbelt when provided

- failing to secure the load for transport

- failing to accurately determine the weight of load

- $\quad$ failing to maintain a safe distance from dock and ramp edges

- $\quad$ attempting to jump clear of the forklift during a tip-over accident

- failing to keep the load “uphill” when traveling on ramps or grades 
- taking turns with excessive speed (could result in a tip-over accident)

- failing to check for adequate clearance around the forklift and load path

- failing to maintain the forklift center of gravity within the vehicle stability triangle

- failing to maintain a safe distance from dock and ramp edges

- failing to keep the load “uphill” when traveling on ramps or grades

- failing to consider the effect of shape and size characteristics as a part of safe loading configuration

- leaving the forklift unattended and in unsafe condition (e.g., engine running, load raised, parking brake not set).

- inadequate planning of travel routes/paths (e.g., obstacles, bumps, changes in elevation, colocated workers, nearby structures).

Equipment custodians may consider using the Forklift Workplace Hazard Evaluation Checklist to evaluate their workplace prior to the operation of forklifts.

\subsubsection{Management at the Using Organization}

Management shall be responsible to:

- Classify hazardous locations and post appropriate building signs before a forklift truck is assigned to work in the area.

- $\quad$ Ensure that the proper forklift truck is assigned to hazardous areas.

- Coordinate with and acquire concurrence from the responsible industrial safety representative before using forklift trucks in a hazardous area.

- $\quad$ Ensure that forklift truck operators are trained and qualified.

- If battery-powered forklift trucks are used, designate an area for charging batteries.

- If LP-gas-powered forklift trucks are used, ensure that personnel are assigned and trained to exchange LP-gas containers.

- Ensure that each forklift truck has been assigned a custodian.

- $\quad$ Be sure the selected forklift truck has adequate capacity for the planned work. (This requires special attention if the load's center of gravity will be beyond the truck's load center.)

- Do not allow forklift trucks designed for indoor use to be used in wet outdoor locations without the manufacturer's approval. 
- Before purchasing, leasing, or renting any forklift truck, consult with the responsible occupational safety and health organization to ensure that the equipment selected is appropriate for its intended work environment and will not introduce any unacceptable safety risk.

- Assign a designated leader when more than one person is involved with forklift lifting operations.

\subsubsection{Forklift Truck Custodian}

The forklift truck custodian has the following responsibilities:

- Acts as "owner" of the assigned forklift truck.

- Ensures that frequent (pre-use) inspection instructions are readily available to operators.

- Ensures that proper approval is obtained before using an attachment (see Section 5.4.1).

- Ensures that nameplates and caution and instruction markings are in place and legible. This includes markings required on trucks using attachments.

- Ensures that a planned maintenance and inspection program is implemented for each forklift truck and for any attachments used with it.

- Ensures that, if the truck is obtained on a rental agreement, it is inspected and found suitable for its intended function before putting it in service.

- Ensures that initial inspections are performed and maintenance files are maintained.

\subsubsection{Forklift Truck Operator}

The forklift truck operator has the following responsibilities:

- $\quad$ Operate the truck in a safe responsible manner.

- Is familiar with information provided on the forklift truck data plate.

- Is knowledgeable with the forklift truck pre-use inspection criteria and performs inspections accordingly.

- Notifies the responsible supervisor when a problem is detected during either inspection or operation of the truck.

- Ensures that the truck is taken out of service if a problem is detected that would compromise safe operation of the truck.

\subsubsection{Industrial Safety Representative}

The industrial safety representative has the following responsibilities: 
- Ensures that the entrances to hazardous areas are properly posted to identify which trucks are permitted in the area. (See Figure 5.3, "Building Signs for Posting at Entrance to Hazardous Areas,” and Section 5.19, "Forklift Trucks in Hazardous (Explosive) Atmospheres.”)

- Approves the use of forklift trucks assigned to operate in hazardous areas

- Assists management at user facilities with safety issues regarding forklift truck selection and issues regarding areas for LP-gas refueling and battery charging.

- Where internal combustion-powered forklift trucks are proposed for use indoors, assist management at user facilities in establishing precautions to preclude the buildup of carbon monoxide in the work atmosphere.

- Provide safety- and health-related information to managers and supervisors to assist them in selecting or procuring the proper class and type of vehicle for the planned work activity.

\subsection{Nameplate(s) and Marking}

\subsubsection{Truck Marking by the Manufacturer}

Every truck shall have a durable, corrosion-resistant nameplate, legibly inscribed with the following information:

- truck model and serial number

- truck weight

- designation of compliance with the mandatory requirements of ASME B56.1, "Safety Standard for Low and High Lift Trucks," applicable to the manufacturer

- type designation to show conformance with the requirements, such as those prescribed by Underwriters Laboratories, Inc., and Factory Mutual Research Corporation

- rated capacity.

In addition to these requirements, additional information is required (and allowed) on nameplates on high-lift trucks, electric trucks, and trucks intended for use in hazardous locations (see ASME B56.1, "Safety Standard for Low and High Lift Trucks").

\subsubsection{Fork Arm Stamping by the Manufacturer}

For forklift trucks purchased after December 1984, each fork arm shall be clearly stamped with its rated capacity in an area readily visible and not subject to wear. For example, the designation " $1500 \mathrm{x}$ 24 ” means 1,500-lb (680-kg) capacity at 24-in. (600 mm) load center. 


\subsubsection{Attachment Marking}

On every removable attachment (excluding fork extensions), a nameplate with the following information is required:

- model number

- serial number on hydraulically actuated attachments

- maximum hydraulic pressure (on hydraulically actuated attachments)

- weight

- capacity

The following instructions (or equivalent): "Capacity of truck and attachment combination may be less than capacity shown on attachment. Consult truck nameplate.”

Note: This information should be provided by the attachment manufacturer.

\subsubsection{User's Obligation for Truck Marking}

The using organization shall ensure that trucks using attachments (including fork extensions) are marked to identify the attachments, show the approximate weight of the truck and attachment combination, and show the capacity of the truck with attachments at maximum elevation with the load laterally centered. The using organization shall see that nameplates and caution and instruction markings are in place and legible.

\subsubsection{Maintain Tags}

The forklift truck manufacturer's capacity, operating, and maintenance instruction plates, tags, or decals shall be maintained in legible condition.

\subsection{Attachments, Modifications, and Free Rigging from Tines}

\subsubsection{Attachments}

Attachments almost always affect rated capacity of the truck. Employers must seek written approval from powered industrial truck manufacturers when modifications and additions affect the capacity and safe operation of powered industrial trucks. When approval has been granted, the capacity, operation, and maintenance instruction plates, tags, or decals shall be changed accordingly. However, if no response or a negative response is received from the manufacturer, OSHA will accept a written approval of the modification/addition from a qualified Registered Professional Engineer. A qualified Registered Professional Engineer must perform a safety analysis and address any safety or structural issues contained in the manufacturer's negative response prior to granting approval. When approval has been granted, machine data plates must be changed accordingly. See OSHA’s Letter of Interpretation. 
The rated capacity of an attachment-truck combination shall not be exceeded.

Attachments shall be maintained and lubricated based upon the recommendations of the manufacturer or a qualified person.

Attachments shall be inspected no less than annually. The inspection should be documented and should include the following:

- Hooks included as part of attachments shall be inspected as specified for hooks on cranes and hoists (see Section 4.0, “Hooks”).

- Load-bearing components shall be examined for deformation and load-bearing welds shall be visually examined for cracks.

Load capacity of an attachment shall be verified by the manufacturer or by a load test at $100 \%$ capacity. The load test shall be performed on site. Load tests are not routinely required because a catalog cut, user's manual, decals on attachment, or other manufacturer's data serves as capacity verification.

\subsubsection{Modifications}

Modifications or additions which affect capacity or safe operation shall not be performed by the customer or user without the manufacturers’ prior written approval. Employers must seek written approval from powered industrial truck manufacturers when modifications and additions affect the capacity and safe operation of powered industrial trucks. When approval has been granted, the capacity, operation, and maintenance instruction plates, tags, or decals shall be changed accordingly. However, if no response or a negative response is received from the manufacturer, OSHA will accept a written approval of the modification/addition from a qualified Registered Professional Engineer. A qualified Registered Professional Engineer must perform a safety analysis and address any safety or structural issues contained in the manufacturer's negative response prior to granting approval. When approval has been granted, machine data plates must be changed accordingly. See OSHA’s Letter of Interpretation.

\subsubsection{Free Rigging from Tines}

Free rigging is the direct attachment to or placement of rigging equipment (slings, shackles, rings, etc.) onto the tines of a powered industrial truck for a below-the-tines lift. This type of lift does not use an approved lifting attachment, and could affect the capacity and safe operation of a powered industrial truck. 29 CFR 1910.178 (o)(1) requires that "Only stable or safely arranged loads shall be handled. Caution shall be exercised when handling off-center loads which cannot be centered.” Free rigging from the tines shall be treated as a modification and would only be allowed if approved. See OSHA's Letter of Interpretation.

\subsection{Overhead Guards}

High-lift rider trucks, order-picker trucks and rough-terrain forklift trucks shall be equipped with an overhead guard that is manufactured in accordance with ASME B56.1, "Safety Standard for Low and High Lift Trucks,” unless an exception is approved in writing by the responsible industrial safety 
organization. Rough-terrain forklift trucks shall be fitted with an overhead guard manufactured in accordance with ASME B56.6, “Safety Standard for Rough Terrain Forklift Trucks.”

\subsection{Warning Devices}

Every power-propelled truck shall be equipped with an operator-controlled horn, whistle, gong, or other sound-producing device. For manually propelled trucks, the using organization shall determine if operating conditions require the truck to be equipped with sound-producing or visual warning devices and be responsible for providing and maintaining them.

The using organization shall determine if operating conditions require the truck to be equipped with additional sound-producing or visual devices (such as lights or blinkers), and shall be responsible for providing and maintaining such devices. Backup or motion alarms that sound continuously may be warranted in special cases but generally are less effective than operator-controlled devices.

\subsection{Fire Hazard Areas}

Powered forklift trucks for operation in fire hazard areas shall be of the type that is recommended in National Fire Protection Association 505, Powered Industrial Trucks, Type Designation and Areas of Use. (See Section 5.19, "Forklift Trucks in Hazardous (Explosive) Atmospheres.”)

\subsection{Work Atmosphere}

The operation of forklift trucks affects the concentrations of carbon monoxide and oxygen at indoor work locations. The atmosphere in the work locations must meet the requirements of 29 CFR 1910, “Occupational Safety and Health Standards for General Industry.” Contact your industrial safety representative if guidance is needed or if questions arise. (See Section 5.19, "Forklift Trucks in Hazardous (Explosive) Atmospheres.”)

\section{$5.9 \quad$ Operator Care of the Truck}

\subsubsection{Frequent (Pre-use) Inspection}

\subsubsection{Frequent Inspection Instructions}

Frequent inspection instructions that list inspection steps shall be readily available to the operator. It is recommended that the instructions be attached to the equipment. Standard instructions will be suitable for most forklift trucks; however, operating conditions may require additional instructions.

\subsubsection{Results of Frequent Inspection}

The operator shall report any deficiencies or unusual conditions to the responsible supervisor. Conditions adversely affecting safety shall be corrected before the forklift truck is placed into service. 


\subsubsection{Key Steps in a Pre-use Inspection}

Prior to each use, before operating the truck, check its condition, giving special attention to the following:

- periodic maintenance and inspections have been performed and are current

- condition of tires (proper inflation pressure, if pneumatic tires)

- warning and safety devices

- lights

- $\quad$ battery

- controls

- lift and tilt systems - ensure interlocks \& safety devices are in-place for lifts that are capable of tilting forward for transportation

- forks or other load-engaging means

- chains and cables

- limit switches

- brakes hold in forward and reverse directions

- $\quad$ steering mechanism

- fuel systems

- additional items as specified by the manufacturer or that are unique to the facility at which the truck is operated.

- ensure forklift and forklift attachment inspections are current via inspection stickers, other documentation or verbal confirmation from the equipment custodian.

\subsubsection{Truck Unsafe or Needs Repair}

If during pre-use inspection or during operation the truck is found to need repair or is in any way unsafe, the operator shall immediately report the matter to the equipment custodian. The truck shall not be operated until it has been restored to safe operating condition.

\subsubsection{No Repair by Operator}

Do not make repairs or adjustments unless specifically authorized to do so. 


\subsubsection{Refueling}

When refueling the truck, move to the refueling area, if one is designated at your facility, and always stop the engine before refueling. Always follow company- and facility-specific refueling and spill prevention and response procedures.

\subsection{Maintenance and Inspection}

Maintenance and inspection of powered forklift trucks shall be performed in conformance with the following practices:

- A scheduled planned maintenance, lubrication, and inspection program shall be followed; consult the manufacturer's recommendations.

- Only trained and authorized personnel shall be permitted to maintain, repair, adjust, and inspect forklift trucks; these services shall be provided in accordance with manufacturer's specifications.

- No repairs shall be made while the truck is in a hazardous (explosive/classified) area.

\subsubsection{Inspection of New and Rented Equipment}

For newly purchased equipment or newly arrived rental equipment, an initial inspection shall verify that requirements of the purchase order or rental agreement have been met and that the equipment is suitable for its intended use. This inspection should be documented and retained in the forklift truck's maintenance file. (Note: The custodian shall retain the initial inspection report while the unit is on Site.)

CAUTION: For forklift trucks on rental, ensure that a suitable maintenance and inspection program is established for the duration of the rental period.

\subsubsection{Modified or Extensively Repaired Equipment}

For modified or repaired equipment, an inspection shall ensure that the equipment is in good condition and suitable for its intended use.

\subsubsection{Replacement Parts}

All parts that require replacement shall be replaced only with parts that meet the safety standards of those used in the original design. 


\subsubsection{Inspection of Forks}

\subsubsection{Fork Inspection Frequency}

Forks in use (single shift operation) shall be inspected at intervals of not more than 12 months or whenever any defect or permanent deformation is detected. Severe applications require more frequent inspection at an interval set by facility management.

\subsubsection{Fork Load Rating}

Forks used in pairs (the normal arrangement) have a rated capacity for each fork that is at least half the manufacturer's truck rated capacity at the center distance shown on the forklift truck nameplate.

\subsubsection{Fork Inspection Procedures}

Fork inspection shall be carried out carefully by trained personnel with the aim of detecting any damage, failure, deformation, or other condition that might impair safe use. A fork that shows any of the following defects shall be withdrawn from service, and shall not be returned to service until it is satisfactorily repaired by the fork manufacturer or an expert of equal competence:

- Surface Cracks. The forks shall be thoroughly examined visually for cracks and, if their condition warrants, they are subject to nondestructive crack detection, paying special attention to the heel and to the welds that attach the mounting components to the fork blank. Inspection for cracks shall include any mounting mechanisms of the fork blank to the fork carrier. Forks shall not be returned to service if surface cracks are detected.

- Straightness of Blade and Shank. Straightness of the upper face of the blade and the front face of the shank shall be checked. If deviation from straightness exceeds $0.5 \%$ of the length of the blade and/or the height of the shank, respectively, the fork shall not be returned to service until it has been repaired in accordance with Section 5.10.6, "Fork Repair."

- Fork Angle (Upper Face of Blade to Load Face of the Shank). Any fork with a deviation greater than 3\% from the original specification shall not be returned to service. The rejected fork shall be reset and tested in accordance with Section 5.10.6, "Fork Repair."

- Difference in Height of Fork Tips. If the difference in height between forks in a set when mounted on the fork carrier exceeds $3 \%$ of the length of the blade, the set of forks shall not be returned to service until repaired in accordance with Section 5.10.6, "Fork Repair."

- Positioning Lock (When Provided). It shall be confirmed that the positioning lock is in good repair and in correct working order. If any fault is found, the fork shall be withdrawn from service until satisfactory repairs are made.

- Fork Blade and Shank Wear. The fork blade and shank shall be thoroughly checked for wear, with special attention to the vicinity of the heel. If thickness is reduced to $90 \%$ of the original thickness, the fork shall not be returned to service. 
- Fork Hooks Wear. When fork hooks are provided, the support face of the top hook and the retaining faces of both hooks shall be checked for wear, crushing, and other local deformations. If clearance between the fork and the fork carrier becomes excessive, the fork shall not be returned to service until repaired in accordance with Section 5.10.6, "Fork Repair."

- Legibility of Fork Marking. When fork marking is not clearly legible, it shall be renewed. Marking shall be renewed per instructions from the original fork supplier.

\subsubsection{Fork Repair}

Only the manufacturer of the fork or an expert of equal competence shall decide if a fork may be repaired for continued use, and the repairs shall be carried out only by such authorities. Surface cracks or wear should not be repaired by welding. When resetting repairs are required, the fork shall be subject to heat treatment.

\subsubsection{Fork Load Test}

A fork that has undergone repair, other than repair or replacement of positioning locks or marking, shall be subject to a load test as described in ASME B56.1, "Safety Standard for Low and High Lift Trucks," which lists loading and method of test for forks; except for the test load, which shall correspond to 2.5 times the rated capacity marked on the fork.

\subsection{Forklift Truck Load Test}

Forklift truck load tests are not routinely required. Load tests shall be performed after major repair or modification to components that affect the load-carrying ability of the truck. The manufacturer should be consulted if questions arise as to whether a load test is appropriate. Forklift trucks shall be load tested by or under the direction of a qualified person and in accordance with the manufacturer's recommendations.

\subsubsection{Verify Maintenance/Inspection is Current}

Load tests shall be conducted only after confirmation that inspection and maintenance is up to date.

\subsubsection{Test Weight Accuracy}

Test weights shall be accurate within $-5 \%$ to $+0 \%$ of stipulated values.

\subsubsection{Load Test Report}

After a load test is performed, a written report shall be furnished by the qualified person that shows test procedures and confirms the adequacy of repairs or alterations. Test reports shall be retained in the truck's maintenance file. 


\subsection{Conduct of Operator}

The operator has the following responsibilities while operating a forklift truck:

- Be certain the truck has been subjected to pre-use inspection, and a workplace hazard evaluation has been performed.

- If the truck is equipped with a seat belt, $u$ se it.

- Never exceed rated capacity. In determining total weight of the load to be handled, account for added weight that may be present as a result of field modifications, rigging hardware, shipping containers, and vessel or container contents.

Note: Rated capacity is the weight established by the manufacturer at a required load center at an established height. For large or unusually configured loads, the position of the load's center of gravity relative to the truck's load center must be considered when determining the truck's ability to carry the load.

- When handling large or unusually configured loads outside the truck's load center, the forklift manufacturer's instructions must be consulted. If applicable manufacturer's instructions are not available, for a counterbalance-type truck, field calculations may be used to estimate the reduced lifting capacity.

Example: A 5,000-lb (2268 kg)-capacity forklift truck having a 24 in. $(61 \mathrm{~cm})$ load center must handle a load with the load's center of gravity (c. g.) 28 in. $(71 \mathrm{~cm}$ ) from the front face of the forks. In this configuration, with the load's c. g. 4 in. $(10 \mathrm{~cm})$ beyond the fork load center, estimate the truck's safe load capacity.

$24 \mathrm{in} / 28$ in X 5,000 lb = 4,285 lb (approximate safe load capacity)

$61 \mathrm{~cm} / 71 \mathrm{~cm}$ X $2268 \mathrm{~kg}=1949 \mathrm{~kg}$ (approximate safe load capacity)

This calculation method will not produce exact load reduction figures. Use this method only as a rule of thumb. The forklift truck manufacturer is the source of more precise information.

- "Free rigging" from tines is considered a modification and requires approval in accordance with Section 5.4.2, "Modifications."

- $\quad$ Prohibit riders on forklift trucks, unless the truck is built with passenger seating.

- To avoid personal injury, keep head, arms, and legs inside the operator's area of the machine.

- Under all travel conditions, operate the truck at a speed that will permit it to be brought to a stop in a safe manner. Unless facility-specific procedures state otherwise, the guideline is: inside plant buildings, drive no more than $5 \mathrm{mi}(8 \mathrm{~km})$ per hour; on in-plant roads drive no more than 15 $\mathrm{mi}(24 \mathrm{~km})$ per hour. Go slowly around curves.

- Stop and sound the horn at blind intersections and doorways. Watch out for blind corners, stop and/or sound horn if appropriate. 
- Use low gear or slowest speed control when descending ramps.

- Always spread the forks to suit the load width.

- $\quad$ Prohibit any person from standing or passing under the elevated forks, whether forks are loaded or empty.

- Lift, lower, and carry loads with the mast vertical or tilted back; never forward. n. Avoid reaching through the mast for any purpose.

- Lower and raise the load slowly, and only while the vehicle is stopped. Make smooth gradual stops.

- Use special care when high-tiering. Return the mast to a vertical position before lowering load.

- $\quad$ Avoid sudden stops and starts.

- Watch overhead clearance. If in doubt, measure.

- Never travel with forks raised to unnecessary heights. Approximately 4 to 6 in.(10 cm to $15 \mathrm{~cm})$ above floor level is adequate.

- Drive slowly over railroad tracks and rough surfaces. Cross tracks at an angle whenever possible.

CAUTION: Parking closer than $8 \mathrm{ft}(2.4 \mathrm{~m})$ from the center of railroad tracks is prohibited.

- Consider both the truck and load weight when operating in railcars and semitrailers.

- When loading trucks or trailers, ensure that the wheels are chocked and the brakes are set. Operate in front end of the semitrailer only if the tractor is attached, or if adequate trailer jacks are in place.

CAUTION: Semitrailers not coupled to a tractor may require supports (e.g., fixed jacks) to prevent upending or corner dipping.

- Inspect floors on trucks, boxcars, unfamiliar ramps, or platforms before beginning operation.

- Ensure that dockboards and bridge plates into trucks or freight cars are sufficiently wide, strong, and secure. Check them frequently. Portable or powered dockboards and bridge plates must be marked to show their carrying capacity. The carrying capacity indicated shall not be exceeded.

- While turning, be cautious of rear-end swing and keep clear of the edge of loading docks. 
- If the load being carried obstructs the forward view, travel with the load trailing, except when ascending a ramp or incline.

- When ascending or descending grades in excess of 5\%, drive a loaded rider truck with the load upgrade.

- Operate unloaded forklift trucks on grades with the forks downgrade.

- Avoid turning, if possible, and use extreme caution on grades, ramps, or inclines; normally travel straight up and down.

- Unless a towing hitch is supplied by the manufacturer, do not use forklift trucks as tow trucks. When a towing hitch is provided, use tow bars rather than wire rope for towing.

- Never butt loads with forks or rear end of truck.

- Do not drive forklift trucks onto any elevator unless specifically authorized and instructed to do so by a written, approved procedure.

- Safeguard pedestrians at all times. Do not drive a truck up to anyone standing in front of a fixed object. All trucks must yield the right of way to pedestrians and emergency vehicles. Manually powered trucks must yield the right of way to power propelled trucks.

- Before leaving a forklift truck unattended, fully lower the forks, neutralize the controls, shut off the power, and set the brakes. If parked on an incline, block the wheels. (A forklift truck is unattended when the operator is $25 \mathrm{ft}$ (7.6 m) or more away from the truck, or whenever the truck cannot be viewed directly by the operator.)

- If the operator is dismounted, less than $25 \mathrm{ft}$ (7.6 m) away, and within view of the truck, before dismounting, fully lower the forks, neutralize the controls, and set the brakes.

- At the end of the operator's shift, return the forklift truck to its assigned parking place, set the brakes, lower forks flat on the floor, place controls in neutral position, turn ignition off, and secure the key.

- Report all accidents and "near misses” promptly to the operator’s supervisor.

- Do not attach or operate any attachment that has not been approved for use on that forklift truck.

- Never lift with only one fork without an engineering analysis and approval.

- Use guides and signalers as necessary; if in doubt, check the conditions personally before proceeding. Standard hand signals are shown in Section 5.14, "Standard Hand Signals."

- Exercise extra caution when handling loads that cause the truck to approach its maximum design characteristics. For example, when handling a maximum load, the load should be carried at the lowest position possible, the truck should be accelerated slowly and evenly, and the forks should 
be tilted forward cautiously. However, no precise rules can be formulated to cover all eventualities. The final responsibility for the handling of a truck remains with the operator.

\subsection{Lifting of Personnel}

\subsubsection{Special Provisions Prior to Lifting Personnel}

Only operator-up high-lift trucks have been designed to lift personnel. If a personnel lifting platform is used on trucks designed and intended for handling materials, the manager who is specifically responsible for the work to be performed shall determine that there is no practical alternative way to perform the needed work. For each platform lifting operation, the manager who is responsible for the task shall issue a written statement describing the procedure and its time frame. The statement shall be signed by the authorizing manager and, when approved, the statement also shall be signed by the responsible industrial safety representative. The statement shall be readily available at the job site when personnel lifting is in progress.

\subsubsection{Qualification of Trucks Used for Lifting Personnel}

Hydraulic or pneumatic hoisting systems shall include means to prevent unintended descent in excess of $120 \mathrm{ft} / \mathrm{min}(0.6 \mathrm{~m} / \mathrm{s})$ in the event of a hose failure. Be certain that the lifting mechanism is operating smoothly throughout its entire lift height, both empty and loaded, and that lift-limiting devices and latches, if provided, are functional.

\subsubsection{Standard Precautions-Lifting Personnel with Forklift Truck}

The following precautions will be used when lifting personnel with a forklift truck:

- Be certain the truck is set on a firm and level surface.

- Use only work platforms that are manufactured for the purpose of lifting personnel. Platforms shall be in conformance with ASME B56.1, "Safety Standard for Low and High Lift Trucks"

- Be certain that the platform is securely attached to the lifting carriage or forks. When being supported by a forklift, the personnel platform shall be attached in such a manner that it cannot slide or bounce off the forks.

- Be certain the platform is horizontal and is never tilted forward or rearward when elevated.

- $\quad$ The operator shall remain in the control position of the forklift truck.

- $\quad$ Overhead protection, as necessary by operating conditions, shall be provided.

- Means shall be provided to protect personnel from moving parts of the forklift truck that present a hazard when the personnel platform is in the normal working position. 
- Do not transport personnel from one location to another while they are on the personnel lifting platform.

- Whenever a truck (except for high-lift order-picker trucks) is equipped with vertical hoisting controls that can be elevated with the lifting carriage or forks, take the following additional precautions to protect personnel:

- Provide means for personnel on the platform to shut off power to the truck.

- Provide means to render inoperative all operating controls, other than those on the elevating platform, when the controls on the elevating platform have been selected for use. Only one location of controls shall be capable of being operated at one time.

- Ensure that emergency-lowering means are available at ground level and are protected against misuse.

\subsection{Standard Hand Signals}

Standard hand signals are shown in Figure 5.1 below.

- The operator should respond to signals only from the designated signaler, but obey a STOP signal no matter who gives it.

- For operations not covered by standard hand signals, special signals shall be agreed on in advance by both the operator and the signal person, and should not conflict with the standard signals. 


\begin{tabular}{|c|c|c|}
\hline $\begin{array}{l}\text { RAISE THE TINES. With } \\
\text { forearm vertical, forefinger } \\
\text { pointing up, move hand in small } \\
\text { horizontal circle. }\end{array}$ & $\begin{array}{l}\text { LOWER THE TINES. With } \\
\text { arm extended, palm down, lower } \\
\text { arm vertically. }\end{array}$ & $\begin{array}{l}\text { TILT MAST BACK. With } \\
\text { forearm vertical, thumb } \\
\text { extended, jerk thumb over } \\
\text { shoulder. }\end{array}$ \\
\hline $\begin{array}{l}\text { TILT MAST FORWARD. With } \\
\text { arm extended, thumb down, } \\
\text { lower arm vertically. }\end{array}$ & $\begin{array}{l}\text { MOVE TINES IN DIRECTION } \\
\text { FINGER POINTS. With arm } \\
\text { extended, palm down, point } \\
\text { forefinger in direction of } \\
\text { movement. }\end{array}$ & $\begin{array}{l}\text { DOG EVERYTHING. Clasp } \\
\text { hands in front of body. }\end{array}$ \\
\hline$\because$ & tend both arms, palms d & 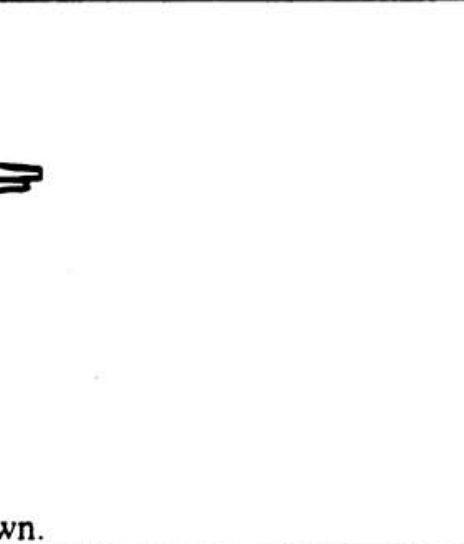 \\
\hline
\end{tabular}

Figure 5.1. Standard Hand Signals for Controlling Forklift Operations 


\subsection{Designated Leader}

Forklift lifting operations that involve more than one person require a DL. See Section 2.0, "Responsibilities."

\subsection{Critical Lifts}

Critical lifts require approved procedures. See Section 3.0, "Critical Lifts.”

\subsection{Maintenance Files}

The forklift truck maintenance file is a compilation of various documents and records relating to operation, maintenance, inspection, testing, evaluating, and repair of the equipment. The file may be centrally located or proportioned into satellite holding areas. The methods selected for establishing adequate information retention and retrieval shall be determined by the equipment custodian, who is the responsible person for ensuring that a safe and reliable maintenance program is in place.

\subsubsection{Contents of Maintenance Files}

The maintenance file shall contain, as a minimum, the required current, dated periodic inspection records and other documentation to provide the user with evidence of a safe and reliable maintenance program. Inspection records should be retained in an easily accessible format and location. Maintenance file information should provide a source for comparing present and past equipment conditions. This comparison will help determine whether existing conditions show a trending pattern of wear, deterioration, or other conditions that may compromise continued safe use of the equipment. Length of record retention shall be determined by the equipment custodian's established maintenance program.

A typical maintenance file should contain the following types of documentation, as applicable:

- waivers applicable to the forklift truck

- documentation for replacement forks or other altered, replaced, or repaired load- sustaining parts

- records of documented inspection, repair, modification, and overhaul

- the most recent periodic inspection records

- $\quad$ load test reports

- initial inspection records for procured or newly arrived rental equipment

- written approval for any modifications or additions in accordance with Section 5.4. 


\subsection{Equipment Qualification}

To qualify for operation, a forklift truck should have the following:

- a record of successful inspection and maintenance

- a frequent (pre-use) inspection instruction available to the operator

- a qualified operator

- the proper type designation for working in a classified hazardous area, if applicable.

\subsection{Forklift Trucks in Hazardous (Explosive) Atmospheres}

\subsubsection{Hazardous Area Equipment}

It is essential to use proper equipment in hazardous (explosive) areas. Trucks approved for use in hazardous areas shall have the manufacturer's label or some other identifying mark indicating approval for the intended use by a recognized national testing laboratory [e.g., Underwriters Laboratories (UL) or Factory Mutual (FM)].

\subsubsection{Truck Designation}

Durable markers indicating the designation of the type of truck for use in hazardous areas shall be applied to each side of the vehicle in a visible but protected area. These markers shall be distinctive in shape, as indicated in Figure 5.2.

\subsubsection{Hazardous-Area Signs}

The entrance to hazardous areas shall be posted with a sign to identify the type of forklift truck permitted (see Figure 5.3). 

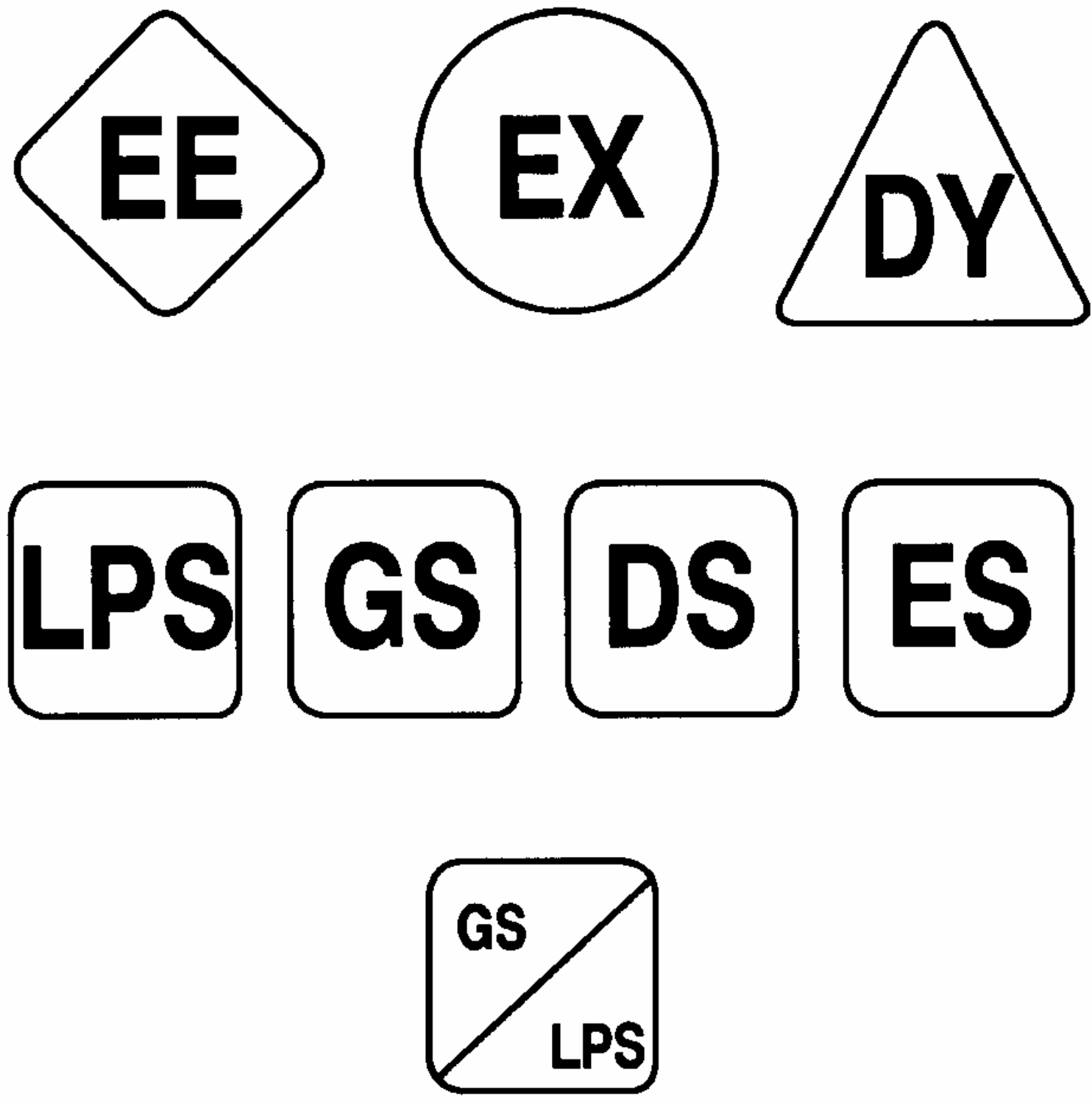

Note: The markers for EE, EX, and DY are 5 in. $(12.7 \mathrm{~cm})$ high. The rest are 4 in. $(10 \mathrm{~cm})$ square. The signs shall have black borders and lettering on a yellow background. For Marker definitions see Sections 5.19.5 and 5.19.6 below.

Figure 5.2. Markers to Identify Type of Industrial Truck 


\section{CAUTION}

ONLY TRUCKS

MARKED

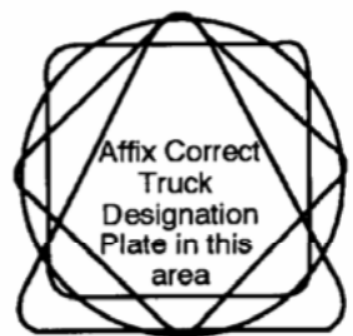

PERMITTED IN

THIS AREA

Note: The minimum width of the sign is 11 in. (28 $\mathrm{cm})$; the minimum height is $16 \mathrm{in} .(40 \mathrm{~cm})$. The sign shall have the word CAUTION in yellow letters on a black background.

The body of the sign shall have black letters on a yellow background. A marker, identical to the one used on the side of the truck as shown in Attachment 5-2, shall be installed on the sign.

Figure 5.3. Building Signs for Posting at Entrance to Hazardous Areas

\subsubsection{Hazardous Area Classification}

The responsible industrial safety organization shall classify hazardous locations where a powered forklift truck is to be used. Location classifications are described as follows:

- Class I. Locations in which flammable gases or vapors are present or may be present in the air in quantities sufficient to produce explosive or ignitable mixtures

- Class II. Locations that are hazardous because of the presence of combustible dust 
- Class III. Locations where easily ignitable fibers or filings are present but are not likely to be suspended in quantities sufficient to produce ignitable mixtures

- Unclassified. Locations not possessing atmospheres defined as Class I, II, or III locations.

\subsubsection{Non-Hazardous Areas}

The following units are not suitable for use in hazardous areas because they include only minimum safeguards against inherent fire hazards:

- Type D Forklifts. Diesel powered units having minimum acceptable safeguards against inherent fire hazards

- Type E Forklifts. Electrically powered units having minimum acceptable safeguards against inherent fire and electrical shock hazards

- Type G Forklifts. Gasoline powered units having minimum acceptable safeguards against inherent fire hazards

- $\quad$ Type LP Forklifts. Liquefied petroleum gas (LPG) powered units having minimum acceptable safeguards against inherent fire hazards

- $\quad$ Type G/LP Forklifts. Gasoline or LPG powered units having minimum acceptable safeguards against inherent fire hazards.

\subsubsection{Hazardous Areas}

The following units are suitable for use in hazardous areas because they are equipped with additional safeguards (i.e., special exhaust, fuel, or electrical systems) or other modifications against inherent fire hazards:

- Type DS Forklifts. Diesel powered units that are provided with all the requirements for the type $\mathrm{D}$ units and that have additional safeguards to the exhaust, fuel, and electrical systems

- Type DY Forklifts. Diesel powered units that have all the safeguards of the type DS units except that they do not have any electrical equipment, including ignition; they are equipped with temperature-limitation features

- Type ES Forklifts. Electrically powered units that are provided with all the requirements for the type E units and that have additional safeguards to the electrical system to prevent emission of hazardous sparks and to limit surface temperatures

- Type EE Forklifts. Electrically powered units that are provided with all the requirements for the type E and ES units, and that also have electric motors and all other electrical equipment completely enclosed 
- Type EX Forklifts. Electrically powered units that differ from type E, ES, or EE units in that the electrical fittings and equipment are designed, constructed, and assembled so that the units may be used in atmospheres containing specifically named flammable vapors, dusts, and, under certain conditions, fibers; type EX units are specifically tested and classified for use in Class I, Group D, or for Class II, Group G locations as defined in NFPA 70, National Electrical Code

- Type GS Forklifts. Gasoline powered units that, in addition to all the requirements for the type $\mathrm{G}$ units, are provided with additional safeguards to the exhaust, fuel, and electrical systems

- Type GS/LPS Forklifts. Gasoline or LPG powered units that, in addition to all the requirements for the type G/LP units, are provided with additional safeguards to the exhaust, fuel, and electrical systems

- Type LPS Forklifts. LPG powered units that, in addition to the requirements for the type LP units, are provided with additional safeguards to the exhaust, fuel, and electrical systems. 


\subsection{Shop Cranes}

\subsection{Scope}

This section applies to self-contained hydraulic and pneumatic-hydraulic shop cranes characterized by a pair of laterally spaced legs, an upright mast, a pivoting boom with a boom extension and hook, and a hydraulic unit. This hydraulic unit moves the boom up and down at a pivot point for the purpose of raising, removing, transporting in the lowered position, and replacing automotive engines, transmissions and other components (see Figure 6-1). Shop cranes have a capacity of 4 tons (8,000 pounds) or less.

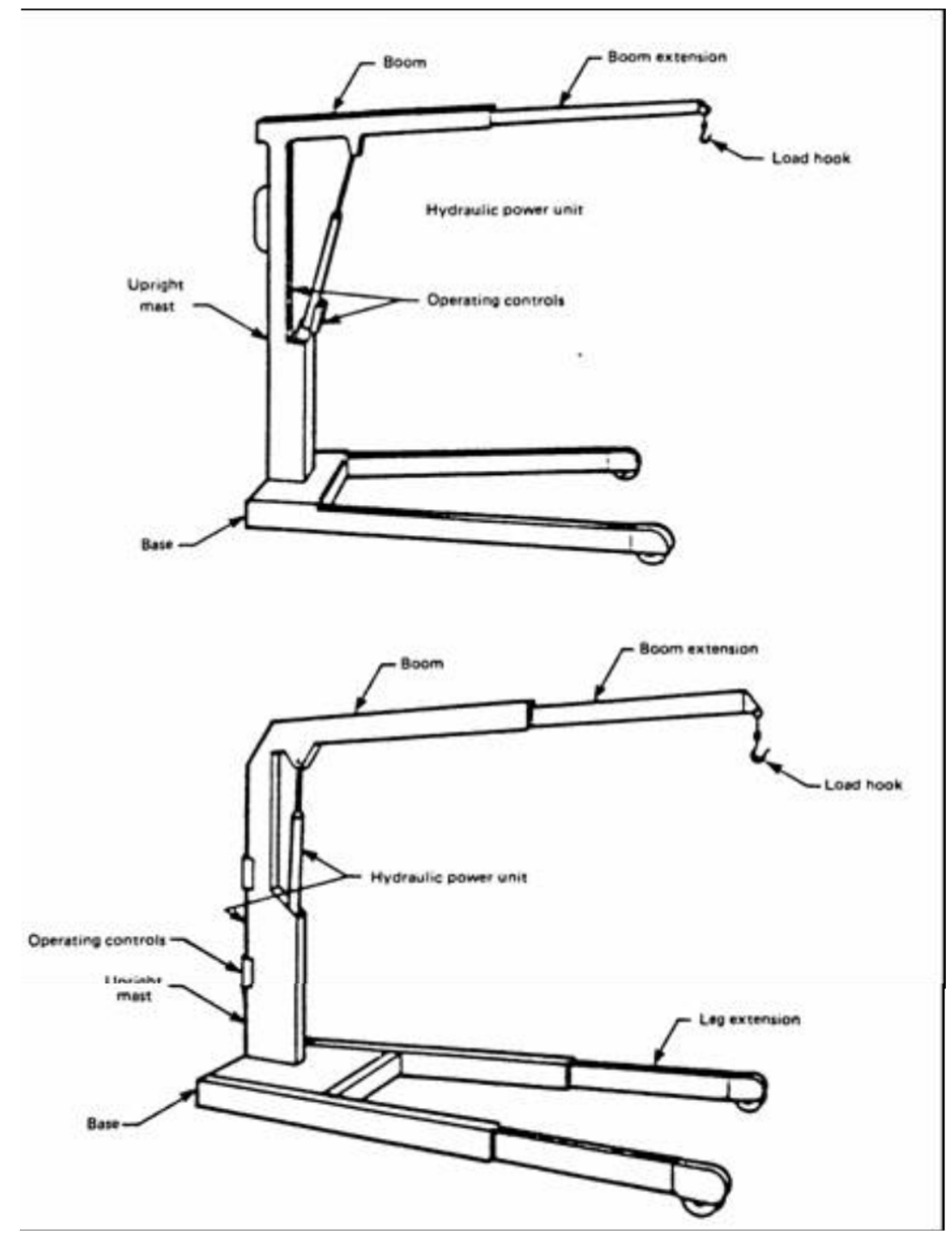

Figure 6.1. Typical Shop Cranes 


\subsection{Operator Qualifications}

No formal training is required to operate shop cranes. Operators shall study, understand, and follow operating instructions provided by the shop crane manufacturer.

Responsible managers shall ensure that operating instructions are readily available.

\subsection{Conduct of Operators}

There is no substitute for good sense and a "safety first" attitude. Failure to heed warnings posted on the shop crane may result in loss of load, damage to the shop crane, personal injury, or property damage.

Rules for operators follow:

1. The operator shall not engage in any practice that will divert attention while actually engaged in operating the shop crane.

2. The operator shall not operate equipment when physically or mentally unfit.

3. The operator shall not load the shop crane beyond its rated capacity (except for proof tests) for each specified boom and leg position.

4. Before moving the load, the operator shall lower the boom and the load to the lowest possible point.

5. The operator shall use the shop cranes only on hard, level surfaces capable of sustaining the load.

CAUTION: Use on other than hard, level surfaces can result in shop crane instability and possible loss of load.

6. The operator shall ensure that the load does not drop suddenly or swing during transportation.

7. Whenever there is doubt as to safety, the operator shall consult with the responsible management before operating the shop crane.

8. If necessary to leave a suspended load unattended, the immediate area (about 30 inches) around the shop crane should be posted or barricaded to restrict entry of unauthorized personnel.

9. If there is a tag, sign, or lock on the shop crane, the operator shall not operate the crane until the tag, sign, or lock is removed by the person who placed it there or by an authorized person.

Facility-specific lock and tag procedures shall be strictly followed.

10. If adjustments or repairs are necessary, or any defects are known, the operator shall report the potential problem promptly to responsible management. 


\subsection{Equipment Requirements}

\subsubsection{Operating Controls}

Operating controls shall be readily visible and accessible to the operator and shall not subject the operator to pinch points, sharp edges, or snagging hazards. The release system shall require intentional positive action by the operator for release to prevent accidental lowering.

\subsubsection{Hook-Throat Latches}

Latch-equipped hooks shall be used for all operations unless the application makes using the latch impractical, unnecessary, or unsafe. The absence of a hook-throat latch is not indiscriminately allowed.

\subsection{Marking and Identification}

\subsubsection{Rated Load Marking}

Shop cranes shall have the rated capacity for each specified boom and leg position marked in a prominent location.

\subsubsection{Identification}

Each shop crane shall include identification or identifying marks of the original manufacturer. The manufacturer shall be able to identify the date of manufacture of each shop crane

\subsubsection{Warning Statement}

A warning statement shall be affixed to the shop crane by the manufacturer in a location readily visible to the operator. The warning shall contain the following:

- The word "WARNING" as a heading.

- A statement of the hazard related to the warning.

- A statement of what to do to avoid or reduce the hazard.

- $\quad$ Statements to warn the operator to study, understand, and follow the instructions.

Below is an example of a warning statement.

WARNING: DO NOT LOAD THIS SHOP CRANE BEYOND ITS RATED CAPACITY FOR EACH SPECIFIED BOOM AND LEG POSITION. OVERLOADING CAN CAUSE DAMAGE TO OR FAILURE OF THE PRODUCT. BEFORE MOVING THE LOAD, LOWER THE BOOM AND LOAD TO THE LOWEST POSSIBLE POINT. DO NOT ALLOW LOAD TO SWING OR DROP 
VIOLENTLY WHILE LOWERING OR MOVING. MAKE SURE THE BOOM IS LOWERED COMPLETELY BEFORE ADDING OIL TO UNIT RESERVOIR. THIS SHOP CRANE IS DESIGNED FOR USE ONLY ON HARD, LEVEL SURFACES CAPABLE OF SUSTAINING THE LOAD. FAILURE TO HEED THESE WARNINGS MAY RESULT IN LOSS OF LOAD, DAMAGE TO THE SHOP CRANE, AND/OR FAILURE RESULTING IN PERSONNEL INJURY AND/OR PROPERTY DAMAGE. STUDY, UNDERSTAND, AND FOLLOW ALL INSTRUCTIONS.

\subsection{Inspection}

Before operating the crane on each shift, the operator shall perform the following operations:

- Visually inspect for leaks and damaged, loose, or missing parts.

- Ensure that hooks and hook-throat latches show no noticeable damage, wear, or deformation.

- Perform other inspections in accordance with the manufacturer's operating instructions.

- In addition to pre-use inspections, a shop crane shall be inspected immediately if it is believed to have been subjected to abnormal load or shock.

Note: Pre-use inspection documentation is not required unless the equipment custodian requires it. No periodic or other scheduled inspection program is required.

\subsection{Maintenance}

The shop crane shall be maintained in accordance with the manufacturer's instructions. Modifications to shop cranes shall be approved by the manufacturer or a qualified engineer.

\section{$6.8 \quad$ Testing}

Shop cranes built to design specifications are proof tested by the manufacturer in accordance with ASME PALD-1997, Part 12, "Shop Cranes.” Routine or scheduled tests by the contractor are not required. After major repair or modification, the responsible maintenance or engineering organization shall determine if testing is required. 


\subsection{Wire Rope}

\subsection{Scope}

This section specifies inspection and replacement requirements and acceptance criteria for wire rope on, overhead cranes, monorail cranes, jib cranes, and hoists that are used in lifting service.

Wire rope slings are not included in this section. For wire rope slings, see Section 8.0. Wire rope that has been removed from a crane or hoist shall not be used to fabricate slings. ${ }^{1}$

\subsection{General Requirements}

\subsubsection{Design Factors for Wire Ropes}

The design factor (safety factor) is the nominal strength of the rope divided by the rated load.

\subsubsection{Hoists and Overhead Crane Wire Ropes}

On hoists and overhead cranes, the wire rope design factor is 5:1.

\subsubsection{Rotation-Resistant Rope}

Use of rotation-resistant rope shall be approved by the manufacturer of the equipment on which it is used. Application of rotation-resistant rope requires special installation procedures, higher design factors, and special inspection and maintenance procedures.

\subsubsection{Requirement for Independent Wire Rope Core}

Overhead cranes and hoists exposed to ambient temperatures at the rope in excess of $180^{\circ} \mathrm{F}$ shall use rope with an independent wire rope core.

\subsection{Inspection Requirements}

Only inspection can determine whether or not rope must be replaced (see Table 7-1). Based on experience, and in accordance with wire rope inspection criteria in this section, a qualified rope inspector must determine the following:

- If the rope's existing condition presents a likelihood of failure.

- If the rate of deterioration of the rope is such that it will remain in safe condition until the next scheduled inspection by a qualified wire rope inspector.

\footnotetext{
${ }^{1}$ The term "nonrotating” wire rope, originally referred to 19 x 7 or 18 x 7 rope. "Nonrotating” has been replaced by the term "rotation-resistant" wire rope. Many other rotation-resistant ropes, besides 19 x 7 and 18 x 7, are currently available.
} 
CAUTION: Proper maintenance of the drums and sheaves over which ropes operate is important to rope life (e.g., worn grooves or poorly aligned sheaves can cause short service life for wire rope). If, during wire rope inspection, equipment maintenance problems are found, the inspector shall promptly notify the equipment custodian.

Table 7.1. Wire Rope Inspection Summary

\begin{tabular}{|c|c|c|c|c|}
\hline Inspection type & $\begin{array}{c}\text { Equipment } \\
\text { type }\end{array}$ & Frequency & Performed by & Records \\
\hline Frequent & All & Each day of use & Operator & Not required \\
\hline Monthy & $\begin{array}{l}\text { Overhead and } \\
\text { gantry, crawler } \\
\text { locomotive and } \\
\text { truck crane }\end{array}$ & Monthly & $\begin{array}{l}\text { Wire rope } \\
\text { inspector }\end{array}$ & $\begin{array}{l}\text { Checklist or } \\
\text { inspection } \\
\text { report. Signed } \\
\text { and dated. }\end{array}$ \\
\hline Periodic & All & $\begin{array}{l}\text { To meet } \\
\text { conditions, but } \\
\text { no less than } \\
\text { annually. When } \\
\text { returning to lift } \\
\text { service }\end{array}$ & $\begin{array}{l}\text { Wire rope } \\
\text { inspector }\end{array}$ & $\begin{array}{l}\text { Inspection } \\
\text { report. Signed } \\
\text { and Dated }\end{array}$ \\
\hline $\begin{array}{l}\text { When } \\
\text { equipment has } \\
\text { been idle for } \\
1 \text { month or more }\end{array}$ & All & Before service & $\begin{array}{l}\text { Wire rope } \\
\text { inspector }\end{array}$ & $\begin{array}{l}\text { Inspection } \\
\text { report. Signed } \\
\text { and dated. }\end{array}$ \\
\hline
\end{tabular}

\subsubsection{Frequent Inspection}

Running ropes should be visually inspected once each working day by the equipment operator. This visual inspection shall consist of observing any rope that can reasonably be expected to be in use during the day's operations. These visual observations should be concerned with discovering gross damage that may be an immediate hazard, such as the following:

- rope distortion such as kinking, crushing, unstranding, birdcaging, main strand displacement, or core protrusion

- corrosion

- broken or cut strands. 


\subsubsection{Monthly Inspection ${ }^{2}$}

For overhead and gantry cranes, ${ }^{3}$ a monthly inspection of running ropes shall be performed and documented by a qualified wire rope inspector. Documentation shall include the date of inspection, the signature of the person who performed the inspection and the identity of the ropes that were inspected. This documentation shall be kept readily available. A checklist near the operator's station is recommended. This inspection does not necessitate a breakdown of the crane. For overhead and gantry cranes, lower the hook blocks to the floor or lowest attainable position. Inspect the ropes from the floor and bridge walkway or trolley floor where there is a means of access.

Visually inspect running ropes for any condition that could result in an appreciable loss of strength and thus constitute a safety hazard. Some conditions that could result in an appreciable loss of strength are the following:

- reduction of rope diameter below nominal diameter as a result of loss of core support, internal or external corrosion, or wear of outside wires

- a number of broken outside wires and the degree of distribution or concentration of such broken wires

- $\quad$ worn outside wires

- corroded or broken wires at end connections

- $\quad$ corroded, cracked, bent, worn, or improperly applied end connections

- severe kinking, crushing, cutting, or unstranding.

Note: A monthly inspection of running rope is not required if a periodic inspection of running and standing rope is accomplished during that month.

\subsubsection{Periodic Wire Rope Inspection (Active Cranes and Hoists)}

\subsubsection{Periodic Inspection Intervals}

A thorough inspection of running rope and standing rope shall be made at least annually or more frequently as determined by a qualified person. The inspection frequency shall be based on such factors as expected rope life, determined by experience on the particular equipment or similar equipment, severity of environment, percentage of capacity lifts, frequency of operation, and exposure to shock loads. Inspections need not be at equal calendar intervals and should be more frequent as the rope approaches the end of its useful life.

\footnotetext{
${ }^{2}$ Basis: Overhead and gantry cranes-29 CFR 1910.179(m), Crawler, locomotive, and truck cranes29 CFR 1910.180(g).

${ }^{3}$ The overhead and gantry crane equipment classification includes semigantry, cantilever gantry, wall cranes, storage bridge cranes, and others having the same fundamental characteristics. These cranes have trolleys and similar travel characteristics. This classification does not include hoists, monorail hoists, or jib cranes.
} 


\subsubsection{Inspector}

Periodic wire rope inspections shall be performed by a qualified wire rope inspector

\subsubsection{Inspection Area}

The inspection shall cover the entire length of each rope. Only the surface wires of the rope must be inspected. No attempt should be made to open the rope. Any deterioration resulting in loss of original strength shall be documented and a determination made as to whether further use of the rope would constitute a hazard. As a minimum, ropes shall be inspected for the following:

- $\quad$ items listed for frequent wire rope inspection

- reduction of rope diameter below nominal diameter resulting from loss of core support, internal or external corrosion, or wear of outside wires

- severely corroded or broken wires at end connections

- $\quad$ severely corroded, cracked, bent, worn, or improperly applied end connections

- improper and insufficient rope lubrication

- evidence of heat damage from any source.

\subsubsection{Sections of Rapid Deterioration}

Additional care shall be taken when inspecting sections of rapid deterioration, such as:

- Sections in contact with saddles, equalizer sheaves, or other sheaves where rope travel is limited.

- Sections of the rope at or near terminal ends where corroded or broken wires may protrude.

\subsubsection{Inspection of Ropes Not in Regular Use}

Rope that has been idle for a period of one month or more due to shutdown or storage of the hoist or crane on which it is installed shall be given a thorough inspection by a qualified wire rope inspector, which shall include running and standing ropes, and be equal to a periodic inspection, as described previously. (The condition of wire rope lubricant is a key concern.) This inspection shall be completed before the equipment is returned to service.

\subsubsection{Inspection of Ropes before Returning to Lift Service}

Cranes that have been used for excavation or demolition work shall have a periodic wire rope inspection before being returned to lifting service. 


\subsection{Wire Rope Inspection, Acceptance Criteria}

\subsubsection{Wire Rope Replacement Criteria-Overhead and Gantry Cranes, Monorail Cranes and Hoists, Overhead Hoists}

The following criteria determine when a wire rope is no longer acceptable for service:

- in running ropes, 12 randomly distributed broken wires in one lay or four broken wires in one strand in one lay

- one outer wire broken at the contact point with the core of the rope, which has worked its way out of the rope structure and protrudes or loops out from the rope structure

- wear of one-third the original diameter of outside individual wires

- kinking, crushing, birdcaging, or any other damage resulting in distortion of the rope structure

- evidence of heat damage from any cause

- reduction from nominal diameter greater than those listed below:

\begin{tabular}{||c|c|}
\hline Rope Diameter (inch) & $\begin{array}{c}\text { Maximum allowable reduction from } \\
\text { Nominal Diameter (inch) }\end{array}$ \\
\hline Less than or equal to $5 / 16$ & $1 / 64$ \\
\hline More than $5 / 16$ to $1 / 2$ & $1 / 32$ \\
\hline More than $1 / 2$ to $3 / 4$ & $3 / 64$ \\
\hline More than $3 / 4$ to $11 / 8$ & $1 / 16$ \\
\hline More than $11 / 8$ to $11 / 2$ & $3 / 32$ \\
\hline
\end{tabular}

- attention shall be given to end connections. Upon development of two broken wires adjacent to socket end connections, the rope shall be resocketed or replaced. Resocketing shall not be attempted if the resulting rope length will be insufficient for proper operation.

\subsection{Wire Rope Receiving, Storage, and Maintenance}

\subsubsection{Receiving at the Work Site}

Before the wire rope is installed on the machine, it must be carefully checked for size, construction and core, to ensure that it matches the description on the tags, requisition, packing slips, purchase order, or invoice. 


\subsubsection{Rope Storage}

If the rope is to be held for a considerable length of time (longer than 3 months) it must be protected from the elements. A dry, well-ventilated building is the proper storage place. Avoid closed, unheated, tightly sealed places. Wire rope shall not be stored in areas subject to elevated temperatures or subject to dust, grit, or a chemically laden atmosphere. If the delivery site precludes inside storage and the rope must be kept outside, the rope shall be covered with a waterproof tarp. The reel should be on a platform so as to keep it from direct contact with the ground.

\subsubsection{Unreeling, Cutting, and Seizing}

\subsubsection{Unreeling}

Unreeling or uncoiling of rope shall be done in a manner to avoid kinking or inducing a twist. (A qualified engineer should be consulted, if necessary.)

\subsubsection{Cutting}

Before cutting a rope, seizing should be placed on each side of the place where the rope is to be cut to prevent unlaying of the strands. (For preformed rope, one seizing each side of the cut. For nonpreformed rope, 7/8-inch diameter or smaller, two seizings on each side of cut; for larger diameter, three seizings each side of cut.)

\subsubsection{Wire Rope Lubrication}

\subsubsection{Lubrication by the Rope Manufacturer}

The lubrication ropes receive during manufacture is adequate only for initial storage and the early stages of the rope's service life.

\subsubsection{Rope Lubrication on Active Cranes and Hoists}

Rope on active hoists and cranes shall be maintained in a well-lubricated condition. It is important that lubricant be applied as part of the maintenance program. The lubricant must be compatible with the original lubricant, so the rope manufacturer should be consulted. The lubricant applied shall be of the type that does not hinder visual inspection. Rope sections that are located over sheaves, or otherwise hidden during inspection and maintenance procedures, require special attention when lubricating rope.

\subsubsection{Lubrication Frequency}

This manual does not specify the time interval between lubrications. A thorough periodic inspection will indicate when lubrication is required and whether lubrication frequencies, as part of the maintenance program, must be adjusted. 


\subsection{Replacement Rope}

\subsubsection{Rope Replacement Frequency (Recommended)}

Where equipment is consistently in use, it is recommended that wire rope be given a certain length of service (e.g., several hundred operating hours or a certain number of months) and then the rope replaced regardless of its condition. This method will eliminate the risk of fatigue causing rope failure.

\subsubsection{Extra-Long Rope}

If a longer rope than necessary can be installed, well-defined, localized abrasion and fatigue may be dealt with without discarding the whole rope. In such a case, one end shall be cut to expose a different section of rope to the place where the deterioration occurs. (This method is most applicable to running ropes on mobile cranes.)

\subsubsection{Replacement Rope as Recommended by Equipment Manufacturer}

Replacement ropes shall be of a construction recommended by the rope manufacturer or the crane or hoist manufacturer. Replacement rope shall be the same size, grade and construction, and have a strength rating equal to the original rope furnished or recommended by the crane or hoist manufacturer.

\subsubsection{Terminal Ends}

Terminal ends shall be prepared and socketed in the manner specified by the manufacturer of the wire rope or fitting.

\subsection{Replacement Rope Installation}

\subsubsection{Before Initial Load Cycle}

After wire rope replacement, and before the initial load cycle, a qualified inspector shall verify the following conditions:

- The rope attachment points to the hoist drum and dead end (if applicable) are properly installed.

- Fasteners are properly torqued.

- Overhead cranes and hoists will have no less than two full wraps of rope on the drum when the hoist is at the lower limit. Mobile cranes will have an adequate rope length so that neither the load nor the boom lowering will result in less than two full wraps of rope on respective drums.

- Reeving is in accordance with the manufacturer's recommendations. 


\subsubsection{Initial Cycle}

After rope replacement and before returning the equipment to service, it is recommended that the hoist unit be cycled from maximum down position to maximum up position eight to ten times with $10 \%$ to $20 \%$ of rated load.

\subsubsection{New Rope Stretch}

On equipment having multiple part lines (other than rotation-resistant wire rope) a new rope will stretch and unlay slightly, causing turns to appear in the load block. The anchorage, if not fitted to a swivel, may be disconnected, the turns removed and reconnected.

\subsubsection{Verification of Fasteners}

After the initial load cycle has been completed, a qualified inspector shall verify that the fasteners on drum and/or dead end have been re-torqued.

\subsubsection{Documentation of Rope Replacement}

A wire rope replacement checklist (see Appendix 15.0B.10, “Wire Rope Replacement Checklist”), signed and dated by a qualified inspector, shall document proper installation of replacement rope.

\subsection{Qualification of Wire Rope}

\subsubsection{Qualification of Original Rope Supplied with New Equipment}

Original rope, supplied with new equipment, is qualified for service by the inspection performed on the new equipment.

\subsubsection{Qualification of Replacement Rope}

A completed wire rope replacement checklist, documenting the most recently installed replacement rope (see Appendix A, “Wire Rope Replacement Checklist”), signed and dated by a qualified inspector, shall be in the equipment maintenance file. In addition to inspection records in the equipment maintenance file, replacement rope shall have certification from the rope manufacturer. The manufacturer's certification shall contain adequate information to identify the rope and should contain the following information:

- rope diameter (e.g., 1/2 inch)

- $\quad$ rope classification (number of strands x wires per strand) (e.g., 6 x 37)

- $\quad$ lay (e.g., right regular lay, or left lang lay)

- grade of wire (e.g., improved plow steel, or extra improved plow steel) 
- $\quad$ type of core (e.g., independent wire rope core, or fiber core)

- $\quad$ nominal strength (e.g., 10.7 tons)

- rope’s purchase order number, if known. 


\subsection{Slings}

\subsection{Scope}

This section addresses the requirements for lifting slings manufactured from the following materials:

- alloy steel chain

- $\quad$ wire rope

- metal mesh

- $\quad$ sewn synthetic web.

\subsection{General}

\subsubsection{Guidelines}

Slings, other than those described in this section, such as polyester round slings and Kevlar $^{1}$ fiber (yarn) slings shall be used in accordance with recommendations of the sling manufacturer. Slings manufactured from conventional three-strand natural or synthetic fiber rope are not recommended for use in lifting service. Natural or synthetic fiber rope slings shall be used only if other sling types are not suitable for the unique application. For natural or synthetic rope slings, the requirements of ASME B30.9, and OSHA 1910.184(h) shall be followed. All types of slings shall have, as a minimum, the rated capacity clearly and permanently marked on each sling. Each sling shall receive a documented inspection at least annually, more frequently if recommended by the manufacturer or made necessary by service conditions.

\subsubsection{Defective Slings}

Slings to be repaired and recertified shall be stored in a secure manner that renders them inaccessible for use while repair is pending. Unless defective slings are to be repaired and recertified, they shall be destroyed to prevent future use.

\subsubsection{Multiple Leg Slings}

When lifting rigid objects with multiple-leg slings (three or four legs), two of the legs should be capable of supporting the total load. Multiple-leg slings shall be selected to suit the most heavily loaded leg rather than the total weight.

\subsubsection{Sling Angles}

A key factor in determining sling stress is sling angles (see Figure 8-1).

\footnotetext{
${ }^{1}$ Kevlar is a registered trademark of DuPont de Nemours and Company.
} 


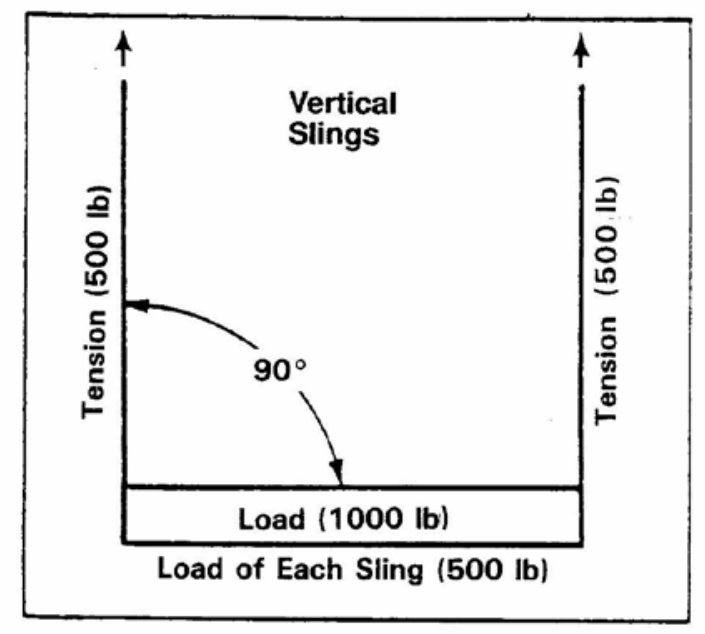

$\begin{aligned} & \text { Tension in } \\ & \text { Each Leg }\end{aligned}=\frac{\text { Load }}{2} \times$ Load Angle Factor

Horizontal

Sling Load Angle

Angle Factor

$90^{\circ}$

1.000

$85^{\circ} \quad 1.004$

$80^{\circ} \quad 1.015$

$75^{\circ} \quad 1.035$

$70^{\circ} \quad 1.064$

$65^{\circ} \quad 1.104$

$60^{\circ} \quad 1.155$

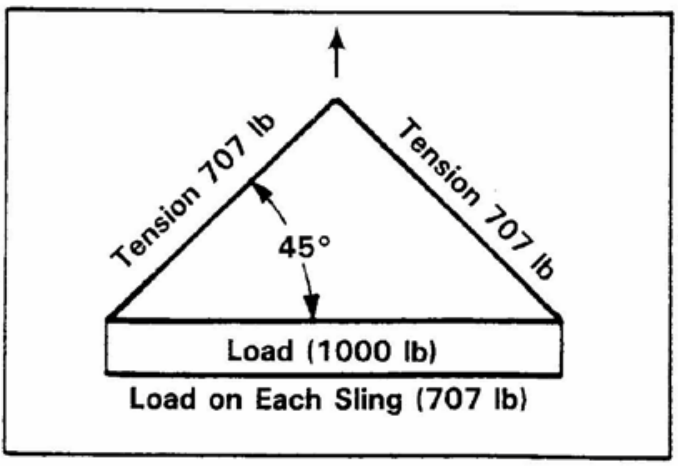

$55^{\circ}$

1.221

$50^{\circ} \quad 1.305$

$45^{\circ} \quad 1.414$

$40^{\circ} \quad 1.555$

$35^{\circ} \quad 1.742$

\begin{tabular}{ccc}
$30^{\circ}$ & 2.000 & \\
\hline $25^{\circ}$ & 2.364 & Not
\end{tabular}

$20^{\circ} \quad 2.924$

$15^{\circ}$

3.861

$10^{\circ}$

5.747

$5^{\circ}$

11.490

Recommended

38805-185.5

Figure 8.1. Sling Stresses at Various Sling Angles (Sling Angles Less than $30^{\circ}$ Not Recommended)

\subsubsection{Periodic Load Tests}

Periodic load testing of slings is not recommended. 


\subsubsection{Alloy Steel Chain Slings}

\subsubsection{Design Factors and Chain Properties}

Chain for alloy steel chain slings shall conform to the requirements of ASTM A391/A 391M, Standard Specification for Grade 80 Alloy Steel Chain. Rated loads for alloy steel chain slings shall be based on a minimum design factor of 4 .

The general configuration of a chain sling is shown in Figure 8-2.

Quadruple Leg Slings

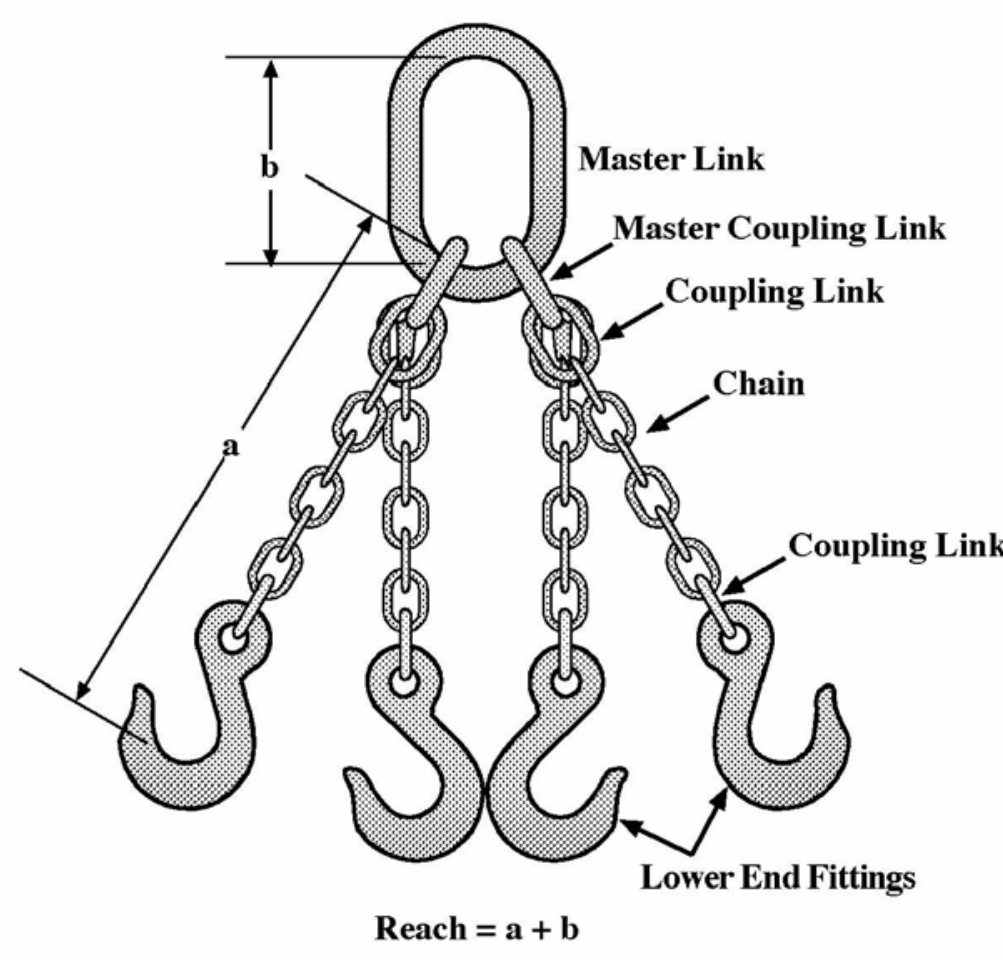

Single Leg Slings

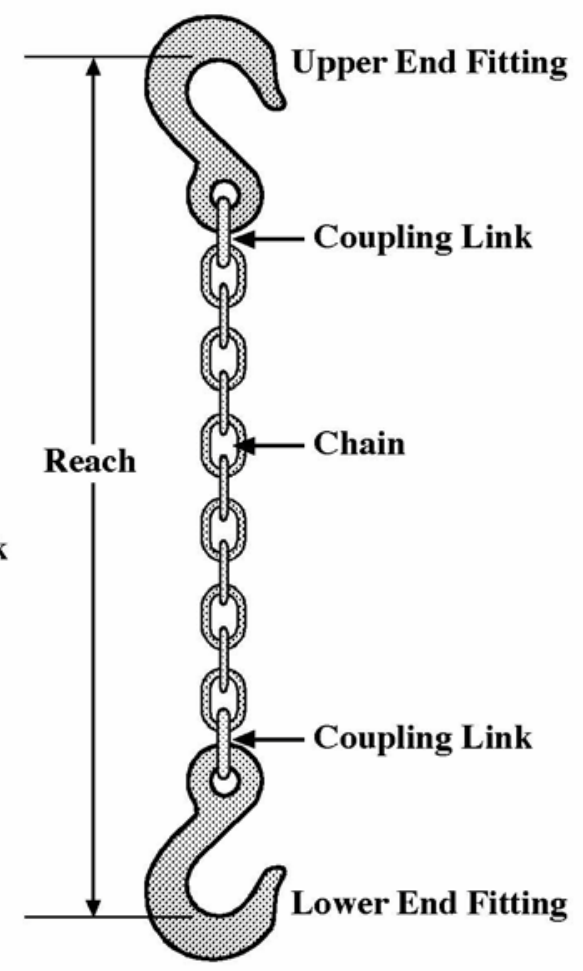

RG99020168.1

\subsubsection{Rated Loads}

The rated loads for alloy steel chain slings are presented in Table 8.1. 
Table 8.1. Rated Load for Alloy Steel Chain Slings ASTM A391

\begin{tabular}{|c|c|c|c|c|c|c|c|c|c|}
\hline \multicolumn{2}{|c|}{$\begin{array}{c}\text { Chain Size } \\
\text { Nominal }\end{array}$} & \multicolumn{2}{|c|}{$\begin{array}{l}\text { Single Leg Sling- } \\
90^{\circ} \text { to } \\
\text { Horizontal Loading }\end{array}$} & \multicolumn{6}{|c|}{$\begin{array}{c}\text { Rated Load } \\
\text { Horizontal Angle }\end{array}$} \\
\hline in & $\mathrm{mm}$ & lb & $\mathrm{kg}$ & Dot & kg & $\begin{array}{l}\text { Quac } \\
\text { lb }\end{array}$ & kg & Doul & kg \\
\hline $\begin{array}{r}9 / 32 \\
3 / 8 \\
1 / 2\end{array}$ & $\begin{array}{r}7 \\
10 \\
13\end{array}$ & $\begin{array}{r}3,500 \\
7,100 \\
12,000\end{array}$ & $\begin{array}{l}1,570 \\
3,200 \\
5,400\end{array}$ & $\begin{array}{r}6,100 \\
12,300 \\
20,800\end{array}$ & $\begin{array}{l}2,700 \\
5,500 \\
9,400\end{array}$ & $\begin{array}{r}4,900 \\
10,000 \\
17,000\end{array}$ & $\begin{array}{l}2,200 \\
4,500 \\
7,600\end{array}$ & $\begin{array}{l}3,500 \\
7,100 \\
1,200\end{array}$ & $\begin{array}{l}\mathbf{1 , 5 9 0} \\
3,200 \\
5,400\end{array}$ \\
\hline $\begin{array}{l}5 / 8 \\
3 / 4 \\
7 / 8\end{array}$ & $\begin{array}{l}16 \\
20 \\
22\end{array}$ & $\begin{array}{l}18,100 \\
28,300 \\
34,200\end{array}$ & $\begin{array}{r}8,200 \\
12,800 \\
15,500\end{array}$ & $\begin{array}{l}31,300 \\
49,000 \\
59,200\end{array}$ & $\begin{array}{l}14,200 \\
22,300 \\
27,200\end{array}$ & $\begin{array}{l}25,600 \\
40,000 \\
48,400\end{array}$ & $\begin{array}{l}11,600 \\
18,200 \\
22,200\end{array}$ & $\begin{array}{l}18,100 \\
28,300 \\
34,200\end{array}$ & $\begin{array}{r}8,200 \\
12,900 \\
15,700\end{array}$ \\
\hline $\begin{array}{r}1 \\
1-1 / 4\end{array}$ & $\begin{array}{l}26 \\
32\end{array}$ & $\begin{array}{l}47,700 \\
72,300\end{array}$ & $\begin{array}{r}21,600 \\
32,800\end{array}$ & $\begin{array}{r}82,600 \\
125,200\end{array}$ & $\begin{array}{l}37,900 \\
56,800\end{array}$ & $\begin{array}{r}67,400 \\
102,200\end{array}$ & $\begin{array}{l}31,000 \\
46,400\end{array}$ & $\begin{array}{l}47,700 \\
72,300\end{array}$ & $\begin{array}{l}21,900 \\
32,800\end{array}$ \\
\hline
\end{tabular}

1 Other grades of proof tested steel chain include Proof of Coil (Grade 28), Hi-Test (Grade 43) Chain, and Transport (Grade 70) Chain. These grades are not recommended for overhead lifting, and therefore, are not covered in this table.

2 Rating of multileg slings adjusted for angle of loading between the inclined leg and the horizontal plane of the load.

3 Triple and quadruple sling rating is the same as double sling rating because normal lifting practice may not distribute the load uniformly on all legs, leaving only two legs to carry the load. If rigging techniques, varified by a qualified rigger or rigging specialist, ensure the load is evenly distributed, then full use of three legs is allowed. Special rigging techniques verified by a qualified engineer shall be required to prove a load is evenly distributed over four or more sling legs.

79203176.1

\subsubsection{Sling Identification}

Alloy steel chain slings shall be labeled by the manufacturer with permanently affixed durable identification stating the following:

- chain size

- manufacturer’s grade (Only ASTM A391 is allowed for lifting purposes.). 
- rated load and angle upon which the rating is based

- reach

- number of legs

- manufacturer's name or trademark

- an additional tag, sticker, or other identifier shall be added by the user to indicate when the next periodic inspection is required.

\subsubsection{Effects of Environment}

Environmental limits for alloy steel chain slings are listed in Table 8-2 and are presented below:

- If the chain sling becomes heated to a temperature of $400^{\circ} \mathrm{F}\left(204^{\circ} \mathrm{C}\right)$, rated loads shall be reduced in accordance with the chain manufacturer's recommendations regarding usage both while heated and after being heated.

- If the chain slings are to be used in temperatures of $-40^{\circ} \mathrm{F}\left(-40^{\circ} \mathrm{C}\right)$ or less, the manufacturer should be consulted.

Table 8.2. Typical Reduction of Chain Sling Working Load According to Temperature(a)

\begin{tabular}{|c|c|c|}
\hline \multirow{2}{*}{ Temperature of chain (F) } & \multicolumn{2}{|c|}{ Reduction in working load (\%) } \\
\cline { 2 - 3 } & While heated & After cooling \\
\hline 400 & 10 & 10 \\
\hline 500 & 10 & 10 \\
\hline 600 & 20 & 10 \\
\hline 700 & 25 & 10 \\
\hline 800 & 45 & 10 \\
\hline 900 & 55 & 15 \\
\hline 1,000 & 60 & 20 \\
\hline \multicolumn{2}{|c|}{$\begin{array}{l}\text { This table is provided for information and may not reflect specific chain sling manufacturer's } \\
\text { recommendations. It is important that the manufacturer be contacted if a chain sling will be used at } \\
\text { temperatures of 400 EF or more. }\end{array}$} \\
\hline
\end{tabular}

\subsubsection{Attachments}

Requirements for attachments to alloy steel chain slings follow:

- Hooks, rings, oblong links, pear-shaped links, mechanical coupling links, or other attachments shall have a rated load at least equal to that of the alloy steel chain with which they are used. In cases where the particular use makes this impractical, the sling shall be marked with a rated load (working load limit) that is consistent with the least working load rating of any component. 
- Standard attachments should be of a size recommended by the sling manufacturer.

- All welded components in the sling assembly shall be proof-load tested as components or as part of the sling assembly.

- Makeshift fasteners, hooks, or links formed from bolts or rods shall not be used. Nonstandard end fittings designed by a qualified engineer may be used.

- Where used, handles shall be welded to the master link or hook before heat treating. (This prohibits welding on chain slings during field operations.)

\subsubsection{Chain Sling Inspection}

\subsection{Initial Inspection}

Before use, all new, altered, modified, or repaired slings shall be inspected by a designated person to ensure compliance with the requirements of Sections 8.2.2.1through 8.2.2.5.

\subsection{Frequent and Periodic Inspection}

Inspection of chain slings in regular service is divided into two general classifications based on the interval at which inspection should be performed. The intervals, in turn, are dependent on the degree of exposure of the sling components to wear and deterioration. The two general classifications are designated as "frequent" and "periodic," with respective intervals between inspections as defined in Table 8.3.

- Frequent Inspection. Slings shall be inspected for defects and damage at intervals as defined in Table 8.3. In addition, the following visual observations should be conducted during regular service to ensure that no damage or evidence of malfunction appears between regular inspections. Any such deficiencies shall cause the sling to be set aside for periodic inspection. 
Table 8.3. Frequent and Periodic Inspection of Chain Slings

\begin{tabular}{|l|l|l|l||}
\hline \multicolumn{1}{|c|}{ Service level } & \multicolumn{1}{|c|}{ Sling service } & Frequent inspection(a) & Periodic inspection(b) \\
\hline Normal & $\begin{array}{l}\text { Service that involves use } \\
\text { of loads within the rated } \\
\text { load }\end{array}$ & Monthly & Yearly \\
\hline Severe & $\begin{array}{l}\text { Service that involves } \\
\text { normal service coupled } \\
\text { with abnormal operating } \\
\text { conditions }\end{array}$ & Daily to weekly & Monthly to quarterly \\
\hline Special or infrequent & $\begin{array}{l}\text { Service that involves } \\
\text { operation, other than } \\
\text { normal or severe, which is } \\
\text { recommended by a } \\
\text { qualified individual }\end{array}$ & $\begin{array}{l}\text { Before and after each } \\
\text { occurrence }\end{array}$ & $\begin{array}{l}\text { Before each occurrence or } \\
\text { sequence of occurrences } \\
\text { within a 30-day period }\end{array}$ \\
\hline $\begin{array}{l}\text { (a) Visual examinations by the user with records not required. } \\
\text { (b) Visual inspection by a qualified inspector making a record of the inspection or of apparent conditions to } \\
\text { provide the basis for a continuing evaluation. }\end{array}$ &
\end{tabular}

- Chain and attachments should display no wear, nicks, cracks, breaks, gouges, stretch, bends, weld splatter, discoloration from excessive temperature, or excessive throat opening of hooks. Chain links and attachments shall hinge freely with adjacent links. Latches on hooks, if present, should hinge freely and seat properly without evidence of permanent distortion.

- The tag or other marking should be examined to verify periodic inspection is current.

- Periodic Inspection. Complete link-by-link inspections of the slings shall be performed at the intervals defined in Table 8.3. Any deficiencies shall be examined and a determination made as to whether they constitute a hazard. These inspections shall include chain sling frequent inspection, as specified above, in addition to the following.

- Each link and attachment shall be individually examined, taking care to expose inner- link surfaces of the chain and chain attachments to inspect for those items defined for frequent inspection.

- Worn links shall not exceed the values in Table 8.4 or the values that are specifically recommended by the manufacturer.

- Sharp transverse nicks and gouges shall be rounded by grinding, ${ }^{2}$ and the depth of the gouge or rounded portion shall not exceed values provided in Table 8.4.

- Hooks shall be inspected.

- If present, latches on hooks should seat properly, rotate freely, and show no permanent distortion.

\footnotetext{
${ }^{2}$ Removal of sharp transverse nicks and gouges on chain slings, within the limits of this manual, is considered maintenance, not repair.
} 
Table 8.4. Maximum Allowable Wear at any Point of Link

\begin{tabular}{|c|c|}
\hline Nominal chain or coupling size (in.)(a) & $\begin{array}{c}\text { Maximum allowable wear of cross- } \\
\text { sectional diameter (in.) }\end{array}$ \\
\hline $9 / 32$ & $3 / 64$ \\
\hline $3 / 8$ & $5 / 64$ \\
\hline $1 / 2$ & $7 / 64$ \\
\hline $5 / 8$ & $9 / 64$ \\
\hline $3 / 4$ & $10 / 64$ \\
\hline $7 / 8$ & $11 / 64$ \\
\hline 1 & $12 / 64$ \\
\hline $1-1 / 4$ & $16 / 64$ \\
\hline (a) For other sizes, consult chain or sling manufacturer. \\
\hline
\end{tabular}

- Documentation. The periodic inspection shall be documented by any one of the following methods:

- Mark a serial number on the sling and maintain inspection records by serial numbers.

- Institute a comprehensive marking program (such as color coding) to indicate when the next inspection is required.

- Mark each sling with a tag that indicates when the next periodic inspection is required. This tag becomes the record.

\subsubsection{Proof Test}

New, repaired, or reconditioned chain slings, including welded components, shall be proof tested by the sling manufacturer or repair agency to twice the rated capacity. The sling custodian shall retain a certificate of the proof test and shall make it available to authorized personnel for examination.

The proof load for multiple-leg slings shall be applied to the individual legs and shall be twice the rated capacity of a single-leg sling.

Mechanically assembled slings need not be proof tested provided all components have been proof tested.

\subsubsection{Repairs}

Repairs are typically not allowed at PNNL. Any hazardous condition disclosed during inspection or operation shall be corrected before the chain is used again. Chain repairs shall be made only by the chain manufacturer or qualified personnel vendor and reviewed by a qualified engineer. 
When repairs are made, the following criteria shall be followed:

- Alloy steel chain, attachments, and coupling links used for repair shall conform to the strength requirements and other requirements of the original sling. Cracked, broken, or bent links and attachments shall not be repaired; they shall be replaced.

- When repaired, a sling shall be permanently marked to identify the repairing agency.

- Mechanical coupling links or carbon steel repair links shall not be used to repair broken lengths of alloy chain.

\subsubsection{Operating Practices}

Operating practices and guidelines for the use of alloy steel chains are as follows:

- Slings having suitable characteristics for the type of load, hitch, and environment shall be selected.

- The weight of the load shall be within the rated load (working load limit) of the sling.

- Chain slings shall not be shortened or lengthened by knotting, twisting, or other methods not approved by the sling manufacturer.

- Slings that appear to be damaged shall not be used unless they are inspected and accepted as usable in accordance with the periodic inspection requirements stated above.

- The sling shall be hitched or rigged in a manner providing control of the load.

- Sharp corners in contact with the chain sling should be padded with material of sufficient strength to minimize damage to the sling.

- Portions of the human body should be kept from between the sling and the load and from between the sling and the crane/hoist hook.

- Personnel should stand clear of the suspended load.

- Personnel shall not ride the sling.

- Shock loading is prohibited.

- Slings should not be pulled from under a load when the load is resting on the sling.

- Slings should be stored in an area where they will not be subjected to mechanical damage, corrosive action, moisture, extreme heat, or kinking.

- Twisting and kinking the legs (branches) shall be avoided. 
- The load applied to the hook should be centered in the bowl of hooks to prevent point loading on the hook, unless the hook is designed for point loading.

- $\quad$ During lifting, with or without load, personnel shall be alert for possible snagging.

- In basket hitch, the load should be balanced to prevent slippage.

- The sling's legs (branches) should contain or support the load so that the load remains under control.

- Multiple-leg (branch) chain slings shall be selected according to Table 8-1 when used at the specific angles given in the table. Operation at other angles shall be limited to rated loads of the next lower angle given in the table or calculated trigonometrically so as to not introduce into the leg (branch) itself a working load in direct tension greater than that permitted.

- Slings should be long enough so that the rated load is adequate when the angle of the legs (branches) is taken into consideration.

- Slings should not be dragged on the floor or over an abrasive surface.

- When used in a choker hitch arrangement, slings shall be selected to prevent the load developed on any portion of the sling from exceeding the rated load of the chain sling components.

- Before using a chain sling outside the temperature range of $-40^{\circ} \mathrm{F}$ to $400^{\circ} \mathrm{F}\left(-40^{\circ} \mathrm{C}\right.$ to $\left.204^{\circ} \mathrm{C}\right)$, contact the sling manufacturer.

\subsubsection{Wire Rope Slings}

\subsubsection{Wire Rope Grades}

Wire rope slings are fabricated from various grades and types of wire rope. The manufacturer of the sling shall be consulted for specific data on the grade and type of rope used. The general configuration of the wire rope sling is shown in Figure 8.3. 


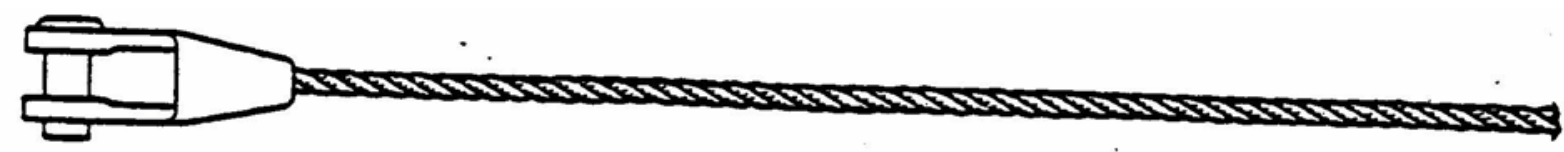

WIRE ROPE SOCKET- Dounto settren on nean

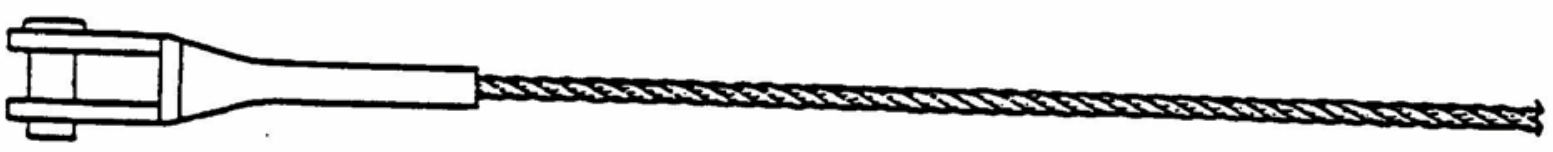

WIRE ROPE SOCKET - SWAEED
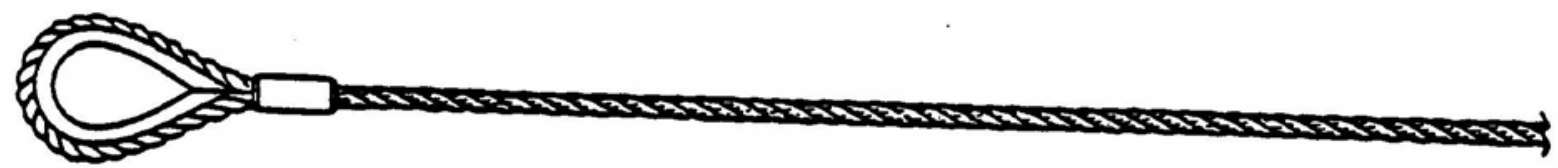

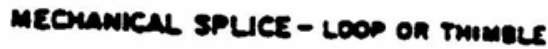

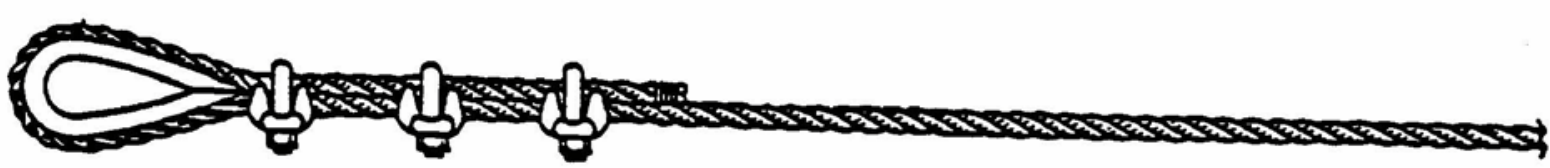

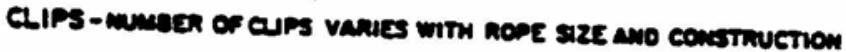

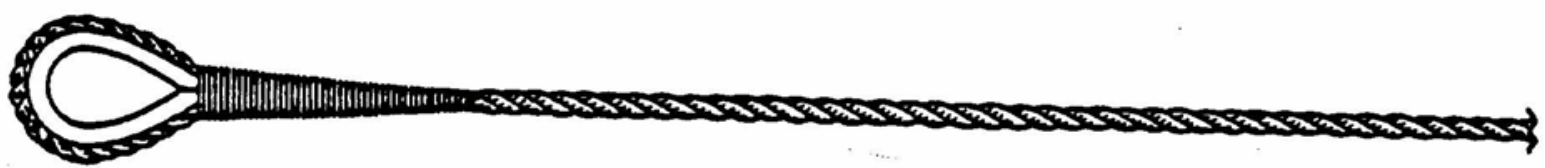

Lop on twimale spluce - mano tuckeo

Figure 8.3. Typical Wire Rope Slings

\subsubsection{Wire Rope Sling Properties}

Rated loads of wire rope slings shall be specified by the manufacturer, using a design factor of at least five. Rated loads are based on the following factors:

- $\quad$ nominal wire rope strength

- $\quad$ nominal splicing and end attachment efficiency (see Figure 8.4)

- $\quad$ angle of loading (see Figure 8.1). The rated load (load-carrying ability required) is based on sling angles. If slings are not vertical, the load carrying ability is reduced: 
Rated load $=$ vertical capacity $\mathrm{X}$ sine of minimum horizontal angle

$\begin{array}{llc}\text { Angles - } & \text { Sine } \\ 30^{\circ} & - & 0.500 \\ 45^{\circ} & - & 0.707 \\ 60^{\circ} & - & 0.866\end{array}$

- if two or more slings are used, the least horizontal angle (greatest vertical angle) shall be considered

- horizontal sling angles less than $30^{\circ}$ (vertical angle more than $60^{\circ}$ ) should not be used

- $\quad$ type of hitch (e.g., straight pull, choker hitch, or basket hitch)

- $\quad$ D/d ratio (see Figure 8.5):

$\mathrm{D}=$ diameter of curvature around which rope is bent

$\mathrm{d}=$ diameter of rope.

- When a sling is used in a choker hitch, the angle formed in the rope body as it passed through the choking eye (the choke angle) should be 120 degrees or greater. For smaller angles, the rated load shall be reduced as shown in Table 8.5:

Table 8.5. Wire Rope Slings in Choker Hitch

\begin{tabular}{|c|c|}
\hline Angle of choke (degrees) & $\begin{array}{c}\text { Percentage of choker- } \\
\text { rated load }\end{array}$ \\
\hline 120 to 180 & 100 \\
\hline 90 to 119 & 87 \\
\hline 60 to 89 & 74 \\
\hline 30 to 59 & 62 \\
\hline 0 to 29 & 49 \\
\hline
\end{tabular}

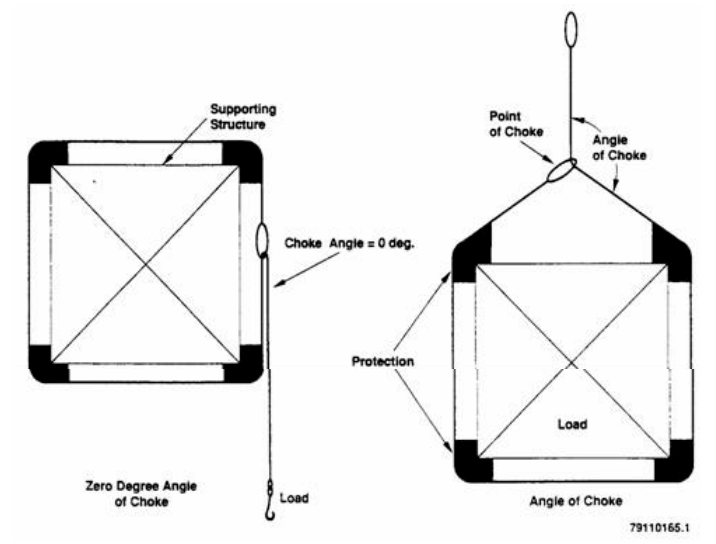




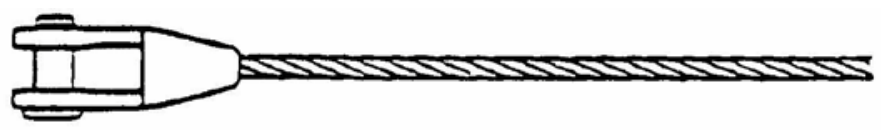

a. Wire Rope Sockets-Spelter Attachment

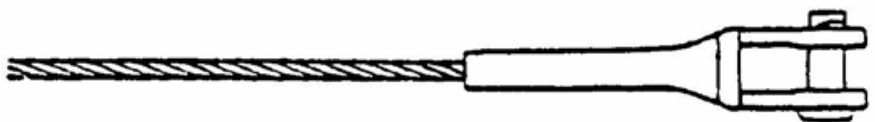

b. Wire Rope Sockets-Swaged

$100 \%$

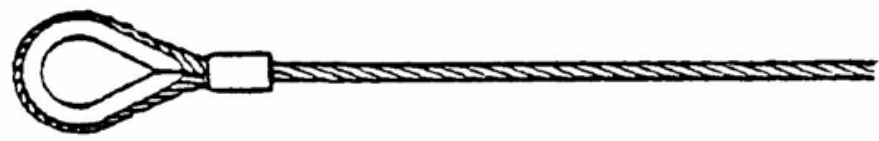

c. "Swaged-Sleeve" Loop or Thimble Attachment-

1 in. Diameter and Smaller

$11 / 2$ in. Diameter and Larger

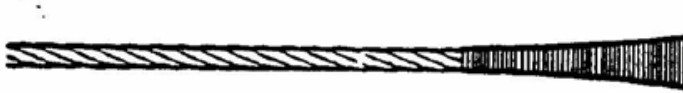

d. Loop or Thimble Splice (hand tucked)

$1 / 4$ in. ..... $90 \% \quad 3 / 8$ in. .....88\%

$5 / 16$ in. .. $89 \% \quad 7 / 16$ in.. $.87 \%$

$1 / 2$ in.. $.86 \%$

$3 / 4$ in.

$82 \%$

$5 / 8$ in.. $.84 \%$

$7 / 8$ in. and Larger ....80\%

38805-185.4

Figure 8.4. Nominal End Attachment Efficiency

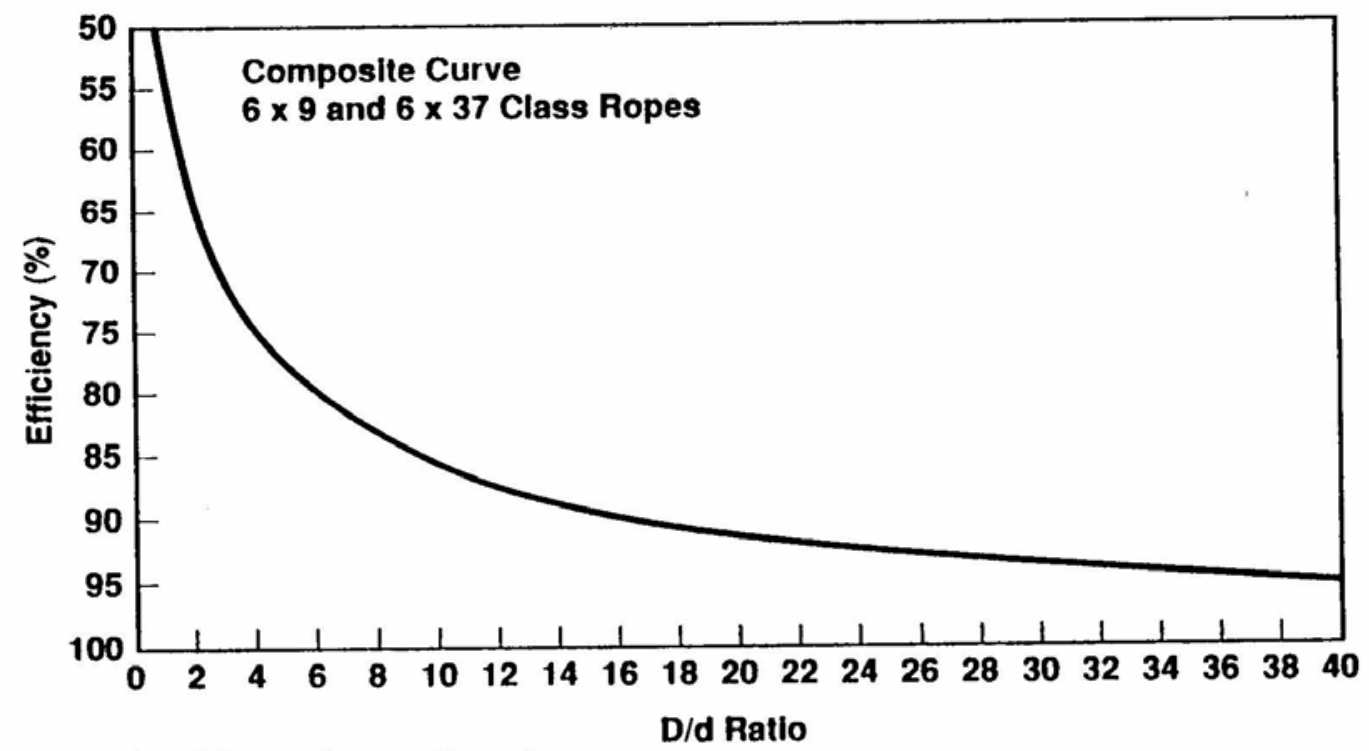

D $=$ Pin or sheave diameter

d = Wire rope diameter

79110165.2

Figure 8.5. Wire Rope Efficiencies for Various D/d Ratios 
The strength reduction (efficiency) is based on the D/d ratio. For example, a rope bent around a pin of equal diameter will have a $\mathrm{D} / \mathrm{d}$ ratio of 1 . The efficiency will be $50 \%$. The rope will have only $50 \%$ of the nominal strength attributed to it.

\subsubsection{Proof Test}

Wire rope sling assemblies shall be proof tested using the following criteria:

- Hand Tucked. The proof load for hand-tucked slings shall be a minimum of the rated load and shall not exceed 1.25 times the rated load.

- Wire Rope Clips. The proof load for wire rope clip slings shall be a minimum of the rated load and shall not exceed two times the rated load.

- Others. The proof load for other types of slings including mechanical splice, zinc-poured, resin poured, and swagged socket shall be two times the vertical rated load.

- Multiple Leg Slings. The proof load for multiple-leg bridle slings shall be applied to the individual legs. The proof load for the individual legs shall be consistent with the particular single-leg assembly stated above. Any master link to which multiple legs are connected shall be proof loaded to two times the force applied by the combined legs.

\subsubsection{Sling Identification}

Wire rope slings shall be labeled with a tag or other identification methods similar to that shown in Figure 8.6. Other identification methods that provide the same information are acceptable. The tag, or other identification method, shall state the following:

- manufacturer’s name

- $\quad$ rated load (rated capacity)

- load test date

- $\quad$ periodic inspection due date. 


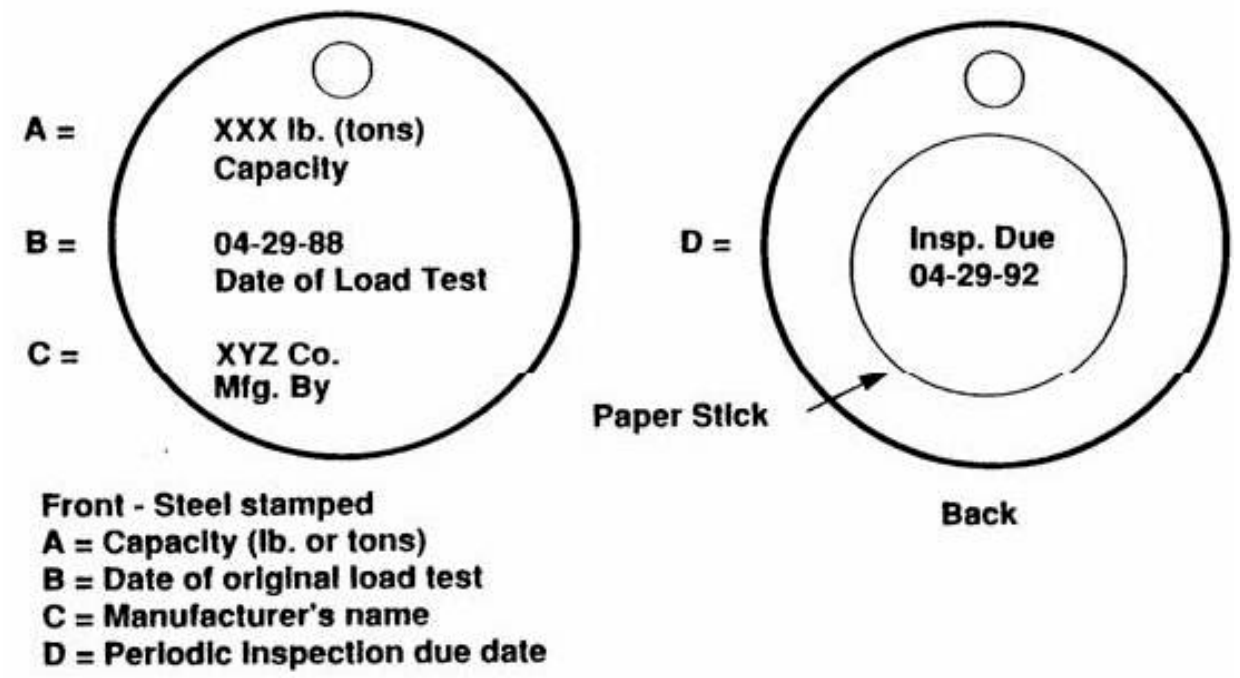

79110165.2

Figure 8.6. Rigging Tackle and Equipment Identification Tag Example

\subsubsection{Effects of Environment}

Damage from caustic or acid substances or fumes can affect wire rope sling length. A strongly oxidizing environment attacks common sling materials. The manufacturer, therefore, should be consulted before slings are used in chemically active environments. Specific environmental limits are as follows:

- Fiber core wire rope slings of all grades shall not be exposed to temperatures in excess of $180^{\circ} \mathrm{F}$ $\left(82^{\circ} \mathrm{C}\right)$ or less than $-40^{\circ} \mathrm{F}\left(-40^{\circ} \mathrm{C}\right)$.

- Wire rope slings of any grade shall be used only between $400^{\circ} \mathrm{F}\left(204^{\circ} \mathrm{C}\right)$ and $-60^{\circ} \mathrm{F}\left(-51^{\circ} \mathrm{C}\right)$ unless written approval is obtained from the wire rope manufacturer.

\subsubsection{Minimum Sling Lengths}

Slings made of rope with a 6 x 19 and 6 x 37 construction, and cable-laid slings, shall have a minimum clear length of rope 10 times the rope diameter between splices, sleeves, or end fittings.

Braided slings shall have a minimum clear length of rope 40 times the component (individual) rope diameter between the loops or end fittings.

Grommets and endless slings shall have a minimum circumferential length of 96 times the body diameter of the grommet or endless sling.

\subsubsection{End Attachments.}

Requirements for attachments to wire rope slings are presented below: 
- All welded load-bearing components (welded before or after assembly) in the sling shall have a design factor of 5:1 and shall be proof tested by the manufacturer or the manufacturer's agent to twice their rated load. The sling custodian shall retain proof test reports and shall make them available to authorized personnel for examination.

- Welding of handles or any other accessories to end attachments, except covers to thimbles, shall be performed before assembling the sling.

- Eyes in wire rope slings shall not be formed using knots.

\subsubsection{Inspection and Replacement.}

\subsection{Frequent Inspection.}

Users shall visually inspect slings each day of use for gross damage, such as listed below, which may be an immediate hazard.

- distortion of rope in the sling, such as kinking, crushing, unstranding, birdcaging, main strand displacement, or core protrusion. Loss of rope diameter in short rope lengths or unevenness of other strands should provide evidence the sling or slings should be replaced.

- general corrosion.

- broken or cut strands.

- number, destruction, and type of visible broken wires (ten randomly distributed broken wires in one rope lay or five broken wires in one strand in one rope lay).

\subsection{Periodic Inspection}

A wire rope sling periodic inspection shall be performed by a qualified inspector on a regular basis (at least annually).

- Inspection frequency shall be based on the following criteria:

- frequency of sling use

- severity of service conditions

- nature of lifts being made

- experience gained on the service life of slings used in similar circumstances.

- The periodic inspection shall be documented by any one of the following methods:

- Mark a serial number on the sling and maintaining inspection records by serial numbers.

- Institute a comprehensive marking program (such as color coding) to indicate when the next periodic inspection is required. 
- Mark each sling with a tag that indicates when the next periodic inspection is required. This tag becomes the record.

The periodic inspection shall be performed by a qualified person. Inspection shall be conducted on the entire length of each sling including splices, end attachments, and fittings. Deterioration that would result in loss of original strength shall be observed and determination made whether further use of the sling would constitute a hazard.

\subsection{Replacement}

Wire rope slings shall be immediately removed from service if any of the following conditions are present:

- For strand-laid and single-part slings, ten randomly distributed broken wires in one rope lay or five broken wires in one strand in one rope lay.

- $\quad$ Broken wires in braided and cable-laid slings (Table 8.6).

- Severe localized abrasion or scraping of one-third the original diameter of outside individual wires.

- Kinking, crushing, birdcaging, or any other damage resulting in distortion of the rope structure.

- $\quad$ Evidence of heat damage.

- End attachments that are cracked, deformed, or worn to the extent that the strength of the sling is substantially affected.

- Severe corrosion of the rope or end attachments.

- Hooks that have been opened more than $15 \%$ of the normal throat opening measured at the narrowest point or twisted more than $10^{\circ}$ from the plane of the unbent hook.

Table 8.6. Allowable Broken Wires in Braided and Cable-Laid Slings

\begin{tabular}{|l|c|c|}
\hline \multicolumn{1}{|c|}{ Sling body } & $\begin{array}{c}\text { Allowable broken wired per lay } \\
\text { or one braid }\end{array}$ & $\begin{array}{c}\text { Allowable broken strands per } \\
\text { sling length }\end{array}$ \\
\hline Less than eight-part braid & 20 & 1 \\
\hline Cable laid & 20 & 1 \\
\hline Eight-part braid and more & 40 & 1 \\
\hline
\end{tabular}

Because many variable factors are involved, no precise inspection criteria can be given for determining the exact time for replacement of a sling. In this respect, safety depends largely on the use of good judgment by a qualified person in evaluating the remaining strength in a used sling after allowing for deterioration disclosed by inspection. Safety of sling operation depends on this remaining strength. 


\subsubsection{Operating Practices}

Operating practices and guidelines for the use of wire rope slings are as follows.

- Slings having suitable characteristics for the type of load, hitch, and environment shall be selected.

- The weight of load shall be within the rated capacity of the sling.

- Wire rope slings shall not be shortened or lengthened by knotting or twisting or with wire rope clips or other methods not approved by the sling manufacturer.

- Slings that appear to be damaged shall not be used unless they are inspected and accepted as usable in accordance with the periodic inspection requirements stated above.

- $\quad$ The sling shall be hitched in a manner providing control of the load.

- Sharp corners in contact with the wire rope sling should be padded to minimize damage to the sling.

- Portions of the human body should be kept from between the sling and the load and from between the sling and the crane hook or hoist hook.

- Personnel should stand clear of the suspended load.

- Personnel shall not ride the sling.

- Shock loading is prohibited.

- Slings should not be pulled from under a load when the load is resting on the sling.

- Wire rope slings should be stored in an area where they will not be subjected to mechanical damage, corrosive action, moisture, extreme heat, or kinking.

- Twisting and kinking the legs shall be avoided.

- The load applied to the hook should be centered in the base (bowl) of the hook to prevent point loading of the hook, unless the hook is designed for point loading.

- During lifting, with or without load, personnel shall be alert for possible snagging.

- In a basket hitch, the load should be balanced to prevent slippage.

- The sling's legs should contain or support the load so that the load remains under control.

- Multiple-leg slings shall be selected so as not to introduce a working load in direct tension in any leg greater than that permitted. Triple- and quadruple-leg sling ratings should be considered the same as a double-sling rating because in normal lifting practice the load will not be uniformly 
distributed on all legs, leaving only two legs to carry the load. If rigging techniques—verified by a qualified rigger or rigging specialist — ensure the load is evenly distributed, then full use of three legs is allowed. Special rigging techniques verified by a qualified engineer shall be required to prove a load is evenly distributed over four or more sling legs.

- Slings should be long enough so that the rated load is adequate when the angle of the legs is taken into consideration.

- $\quad$ Slings should not be dragged on the floor or over an abrasive surface.

- In a choker hitch, slings shall be long enough so that the choker fitting chokes on the wire rope body and never on the fitting.

- Slings shall not be inspected by passing bare hands over the wire rope body. Broken wires, if present, may injure the hands.

- Fiber core wire rope should not be subjected to degreasing or a solvent because it will damage the core.

- Single-leg slings with hand-tucked splices can be unlaid by rotation. Care should be taken to minimize rotation.

- An object engaging the eye of a loop eye sling should not be greater in width than one-half the length of the loop eye.

\subsubsection{Cautions and Prohibitions}

The sling's intended use shall determine the type of rope and termination. The following cautions and restrictions apply to this determination:

- $\quad$ Rotation-resistant wire rope shall not be used for slings.

- Wire rope clamps (clips) shall not be used to fabricate wire rope slings except when the application of the sling prevents the use of a prefabricated sling or when the specific application is designed by a qualified person (see Figure 8-7). When used, slings fabricated using wire rope clamps shall be de-rated to $80 \%$ of the rated wire rope load capacity to account for the efficiency of the clamps. Wire rope clamps must be installed in accordance with the manufacturer's recommendations. The nuts on the clamps must be checked periodically and retorqued to the recommended value to maintain the efficiency rating. Slings made with wire rope clips should not be used as a choker hitch.

- Wire rope wedge sockets shall not be used to fabricate wire rope slings.

- Slings with eyes formed by folding back the rope (not a Flemish eye loop) and secured with one or more metal sleeves pressed (not forging) over the wire rope junction are prohibited for lifting service. 


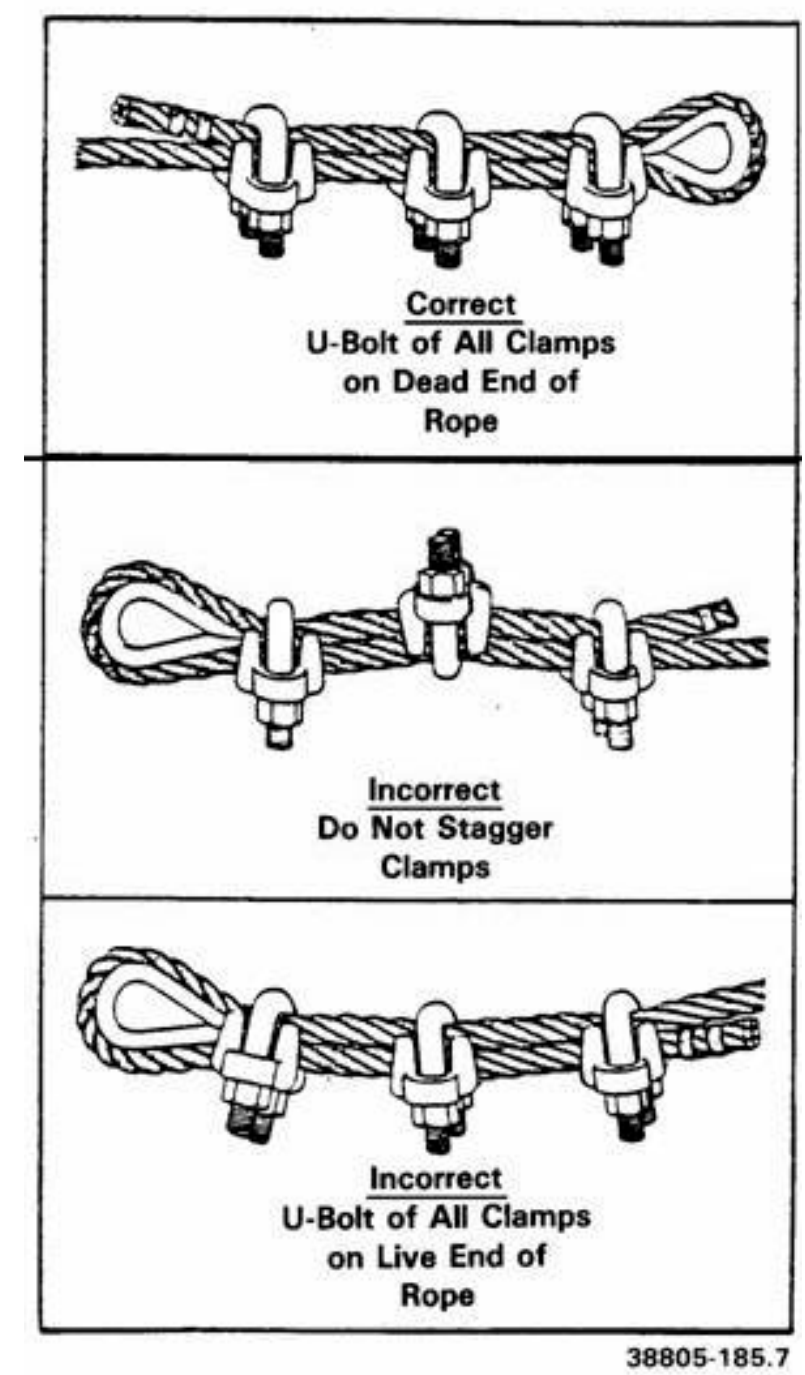

Figure 8.7. Correct and Incorrect Ways to Use Wire Rope Clips (Clamps)

Note: Number of clamps varies with rope size and construction

\subsubsection{Onsite Sling Fabrication}

Slings for lifting service may be fabricated onsite by knowledgeable craftsmen using one of the following methods:

- Wire rope clips. This method shall be used only in special cases.

- Hand tucked. The terminal efficiency is reduced (see Figure 8.4). This sling type is usually more expensive than most commercially made slings. 
- Flemish eye with swaged socket. This is the best selection for general purposes and shall be used except when use is impractical.

Slings shall be made only from new wire rope. When swaged fittings are used, they shall be used as recommended by the fitting manufacturer and the swaging machine manufacturer. Thimbles should be used unless their use makes the sling impractical.

\subsubsection{Synthetic Web Slings}

\subsubsection{Construction}

\subsection{Webbing}

Synthetic web slings fabricated by sewing woven synthetic webbing of nylon or polyester yarns form the basic sling types shown in Figures 8.8 and 8.9. Webbing shall have the following characteristics:

- sufficient certified tensile strength to meet the sling manufacturer's requirements

- uniform thickness and width

- full woven width, including selvage edges

- $\quad$ webbing ends sealed by heat, or other suitable means, to prevent raveling

- stitching shall be the only method used to attach end fittings to webbing and to form eyes. 


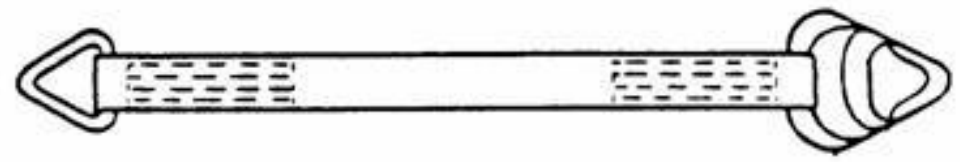

Type I Sling made with a triangle fitting on one end and a triangle choker fitting on the other end. It can be used in a vertical, basket, or choker hitch.

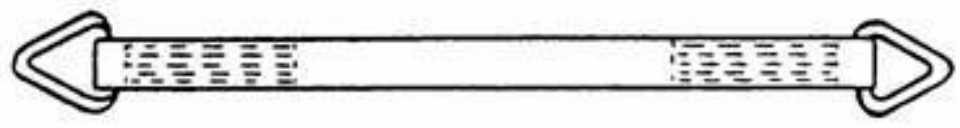

Type II Sling made with a triangle fitting on both ends. It can be used in a vertical or basket hitch only.

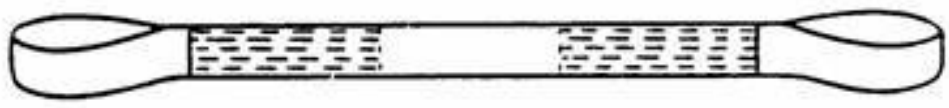

Type III Sling made with a flat loop eye on each end with loop eye opening on same plane as sling body. This type of sling is sometimes called a flat eye and eye, eye and eye, or double eye sling.

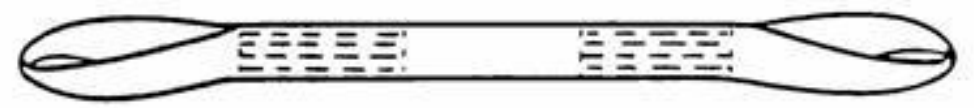

Type IV Sling made with both loop eyes formed as in Type III, except that the loop eyes are turned to form a loop eye which is at a right angle to the plane of the sling body. This type of sling is commonly referred to as a twisted eye sling.

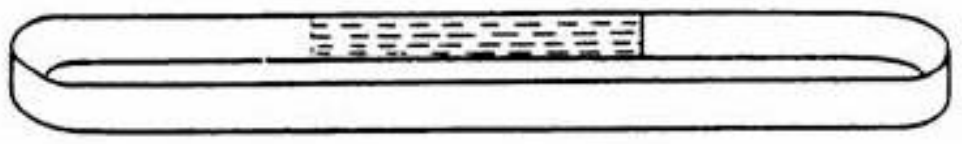

Type V Endless sling. sometimes referred to as a grommet. It is a continuous loop formed by joining the ends of the fabric together with a splice.

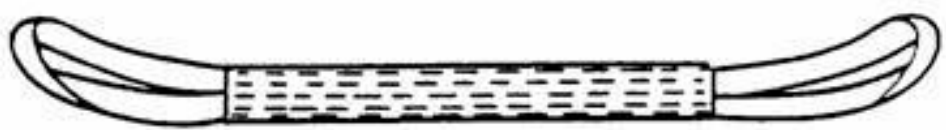

Type VI Return eye (reversed eye) sling is formed by using multiple widths of webbing held edge to edge. A wear pad is attached on one or both sides of the sling body and on one or both sides of the loop eyes to form a loop eye at each end which is at a right angle to the plane of the sling body.

38805-185.13

Figure 8.8. Synthetic Web Slings 


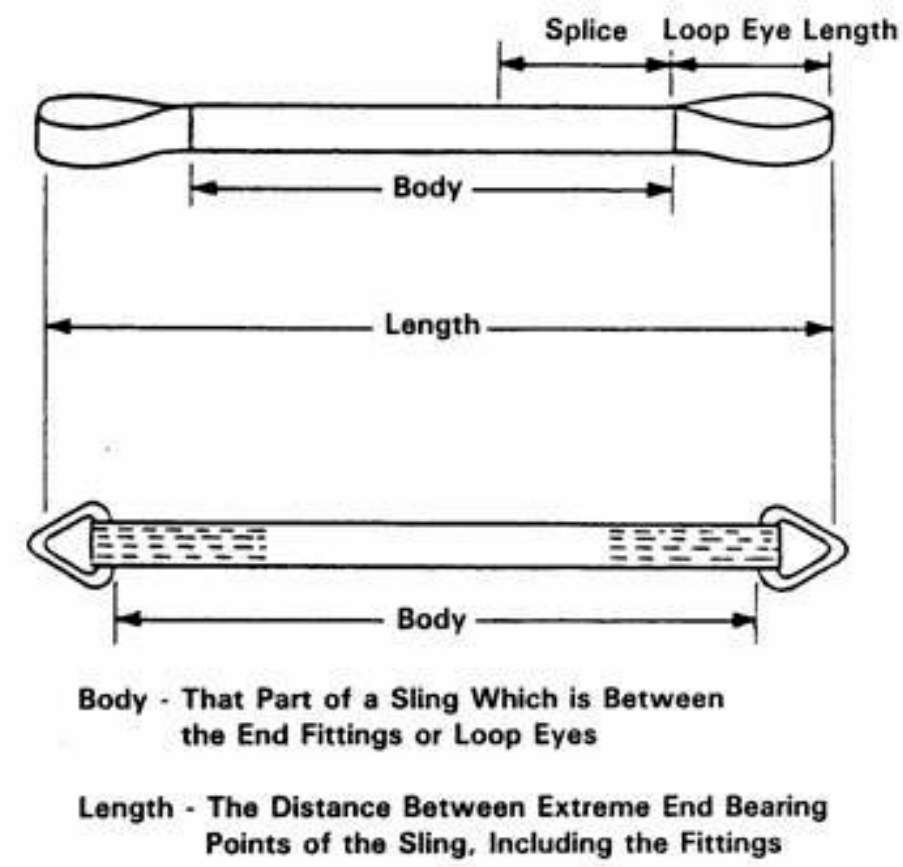

(a)
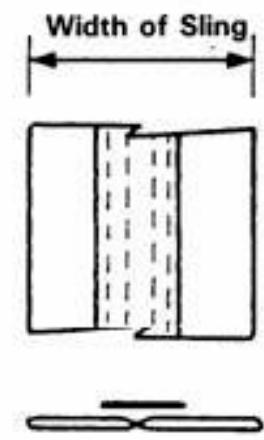

(Two or more Widths of Web Joined Side by Side with a Narrower Width of Web)
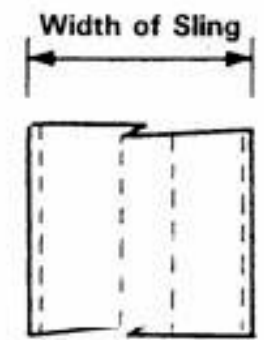

(Two or more Widths of Web Joined Side by Side with a Full Width of Web)

(b) Assembly Splice

38805-185.14

Figure 8.9. Web Sling with Loop Eyes or End Fittings

\subsection{Fittings}

If synthetic web slings incorporate metal fittings, the fittings shall have the following properties:

- Fittings shall have sufficient strength to sustain twice the rated load of the sling without permanent deformation and a minimum breaking strength equal to five times the rated capacity of the sling.

- Surfaces shall be cleanly finished and sharp edges removed to prevent damage to the webbing. 
- Slings incorporating reused or welded fittings shall be proof tested to two times the rated load of the sling.

- Slings incorporating aluminum fittings shall not be used where fumes, vapors, sprays, mists or liquids of caustics, or acids are present.

- The eye opening in the fitting shall be the proper shape and size to ensure that the fitting will seat properly in the hook or other attachment.

\subsection{Coatings}

Synthetic web slings may be coated with suitable material that will impart the following desirable characteristics:

- abrasion resistance

- $\quad$ sealing to prevent penetration of foreign particles and matter

- increased coefficient of friction

- protection from sunlight or ultraviolet degradation.

\subsubsection{Marking (Sling Identification)}

Synthetic web slings shall be labeled (a sewn-on leather tag is recommended). The label shall state the following:

- manufacturer’s name or trademark

- manufacturer's code or stock number

- $\quad$ rated loads for the types of hitches used

- type of synthetic web material

- an additional tag, sticker, or other identifier shall be added by the user to indicate when the next periodic inspection is required

- if the synthetic web sling is to be used for critical lifts, the tag or other identification means shall be used to indicate that a proof test has been performed.

\subsubsection{Design Factor}

The design factor for synthetic web slings shall be a minimum of five. 


\subsubsection{Rated Load}

A synthetic web sling shall not be used at a load greater than shown on its tag. Each manufacturer shall make available on request test data to justify the rated loads.

- Bridle slings. For rated loads of bridle slings, where both legs are not vertical and for consideration of the angle between basket hitch slings, the following equation shall be applicable.

Rated load $=$ vertical rated load $\mathrm{x}$ number of legs $\mathrm{x}$ sine of minimum horizontal angle

- Choker hitch. The rated load, in choker hitch, of single-leg slings shall be a maximum of $80 \%$ of the vertical rated load.

\subsubsection{Proof Test}

When specified by the purchaser, web slings of all types shall be proof loaded by the manufacturer. Synthetic web slings used for a critical lift shall be proof loaded.

\subsection{Single-Leg and Endless Slings}

The proof load for single-leg and endless slings shall be two times the vertical rated load.

\subsection{Multiple-Leg Bridle Slings}

The proof load for multiple leg bridle slings shall be applied to the individual legs and shall be two times the vertical rated load of a single-leg sling.

\subsubsection{Effects of Environment}

High radiation or chemically active environments can destroy the strength of synthetic web slings. Sling materials can be susceptible to caustics and acids. The manufacturer should be consulted before slings are used in chemically active environments. Radiation degrades synthetic material. Specific environmental limits are as follows:

- Nylon and polyester slings shall not be used at temperatures in excess of $180^{\circ} \mathrm{F}$.

- Synthetic slings, including $\mathrm{Kevlar}^{3}, \mathrm{~K}-\mathrm{Spec}^{4}$, nylon, and polyester may be used in radiation areas only when the responsible person ensures that the absorbed dose shall not exceed 100,000 rad during the life of the sling.

- Synthetic web slings that incorporate aluminum fittings shall not be used where fumes, vapors, sprays, mists, or liquids of caustics or acids are present.

\footnotetext{
${ }^{3}$ Kevlar is a registered trademark of DuPont de Nemours.

${ }^{4} \mathrm{~K}$-Spec is a registered trademark of SlingMax.
} 
- Nylon web slings shall not be used where fumes, vapors, sprays, mists or liquids of acids or phenolics are present.

- Polyester web slings shall not be used where fumes, vapors, sprays, mists, or liquids or caustics are present.

- Synthetic web slings are not recommended where extensive exposure to sunlight or ultraviolet light is experienced.

\subsubsection{Inspection}

\subsection{Initial inspection}

Before any new or repaired synthetic web sling is used, it shall be inspected to ensure that the correct sling is being used as well as to determine that it has proper identification.

\subsection{Frequent Inspection}

This inspection should be made by the person handling the sling each day the sling is used.

\subsection{Periodic Inspection}

A periodic inspection shall be performed by a qualified inspector on a regular basis with frequency of inspection based on the following criteria:

- frequency of sling use

- $\quad$ severity of service conditions

- nature of lifts being made

- experience gained on the service life of slings used in similar circumstances.

The periodic inspection shall be made at least annually and shall be documented by any one of the following methods:

- Marking a serial number on the sling and maintaining inspection records by serial numbers.

- Instituting a comprehensive marking program (such as color coding) to indicate when the next periodic inspection is required.

- Marking each sling with a tag that shows when the next periodic inspection is required. This tag becomes the record.

\subsubsection{Removal Criteria}

Synthetic web slings shall be removed from service if damage such as the following is visible: 
- acid, phenolic, or caustic attack

- melting or charring on any part of the sling

- $\quad$ holes, tears, cuts, or snags

- broken or worn stitching in load-bearing splices

- $\quad$ excessive abrasive wear

- knots in any part of the sling

- $\quad$ excessive pitting or corrosion, or cracked, distorted or broken fittings

- $\quad$ other visible indications that cause doubt as to the strength of the sling, such as loss of color that may indicate the potential for ultraviolet light damage

- if a synthetic sling located in a radiation area approaches its radiation exposure limit (100,000 rad during the life of the sling), it shall be removed from service.

\subsubsection{Repairs}

Synthetic web slings shall be repaired only by a sling manufacturer or a qualified repair agent. When repaired, a sling shall be permanently marked to identify the repair agent.

Temporary repairs of either webbing, fittings, or stitching shall not be permitted.

A repaired sling shall be proof tested to two times its assigned rated load before being put back into service. 


\subsection{Rigging Hardware}

\subsection{Scope}

This section provides requirements for qualification and use of rigging hardware for lifting service and includes shackles, rings, wire rope clamps (clips), eyebolts, turnbuckles, and rigging hooks.

The use of other commercially made rigging hardware designed for overhead lifting that is not included in this section (e.g., patented products) requires management approval.

\subsection{Shackles and Rings}

\subsubsection{General}

Requirements and guidelines for shackles and rings are as follows.

- Shackle specifications are defined by the following documents, depending on the shackle size:

- For shackles 3/16 to 2 3/4 inches, the specifications are derived from Federal Specification RR-C-271, "Chains and Attachments, Welded and Weldless."

- For shackles 1 1/2 to 4 inches, the specifications are derived from MIL-S-24214, "Shackles, Steel, General Purpose and High Strength.”

- For shackles 4 1/2 to 8 1/2 inches, ASTM A148M, "Standard Specification for Steel Castings, High Strength, For Structural Purposes,” should be used.

Note: For the overlaps in size, with RR-C-271 and MIL-S-24214, either specification may be used; however, RR-C-271 is most commonly used. Specification RR-C-271, Revision D, was issued in September 1990. Catalogs and manufacturers' literature will list the federal specification number as "RR-C-271(rev.)."

- Shackles are manufactured in two configurations for use in rigging: anchor shackle and chain shackle. Both are available with screw pins, round pins, or safety bolts (Figure 9.1).

- Shackles are sized by the diameter of steel in the bow section rather than the pin size.

- Design Factors: Shackles manufactured in accordance with RR-C-271 and MIL-S-24214 have a minimum design factor of 5 . Shackles manufactured to the requirements of ASTM A148M have a minimum design factor of 4 . Rings manufactured to the requirements of RR-C-271 have a minimum design factor of 6 .

- $\quad$ Rings should be forged steel and weldless. Welded rings are not recommended but may be used if designed by a qualified engineer and subjected to weld nondestructive testing. 


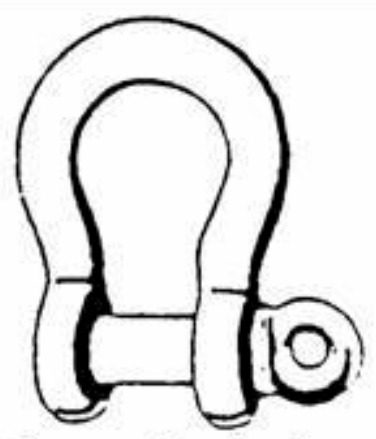

Screw Pin Anchor

Shackle

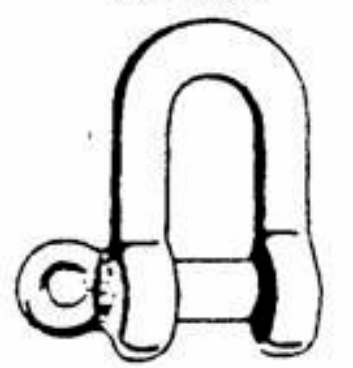

Screw Pin Chain

Shackle

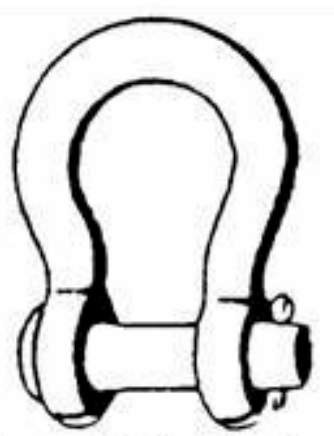

Round Pin Anchor Shackle

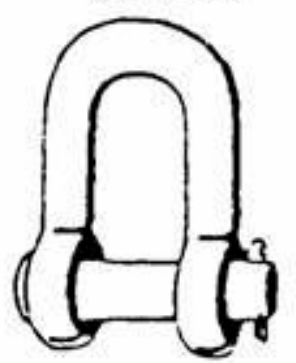

Round Pin Chain

Shackle

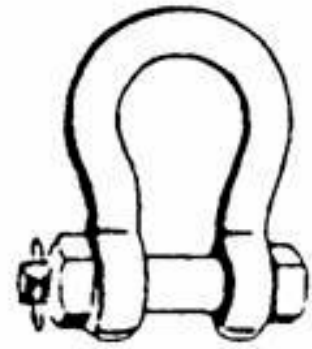

Safety Type Anchor Shackle

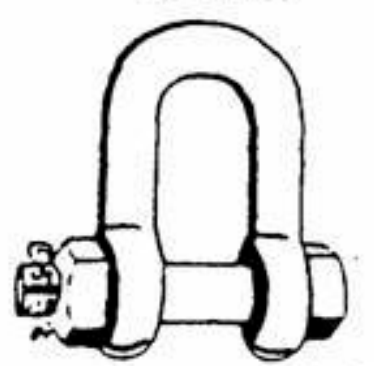

Safety Type Chain Shackle

Figure 9.1. Typical Shackles

\subsubsection{Marking and Tagging}

Marking and tagging specification for shackles and rings are listed below:

- $\quad$ Each shackle body shall be permanently and legibly marked by the manufacturer. Marking will be raised or stamped letters on the side of the shackle bow with an identifying manufacturer's name or trademark, shackle size, and safe working load (SWL).

- $\quad$ Shackle pins shall be unmarked.

- Shackles and rings that have been proof tested for critical service shall have a tag or other marking to indicate clearly to the user that proof testing has been done.

\subsubsection{Inspection}

Inspection criteria for shackles and rings are listed below.

- Before each use, shackles shall be inspected to the following criteria.

- Shackle pins shall fit freely without binding. (Seated screw pin shackles shall be disassembled by hand after the first-half turn.)

- The pin shall show no sign of deformation. 
- The shackle shall have no defect that will interfere with serviceability.

- Shackles and rings for critical-lift service shall have an initial proof load test of two times the SWL (minimum). Before making a critical lift, ensure that the shackle or ring has been proof tested.

- Before each use, rings shall be visually inspected for damage, corrosion, wear, cracks, twists, and opening.

\subsubsection{Operation}

Operating practices and guidelines for the use of shackles are as follows.

- The shackle pin shall never be replaced with a bolt; only a properly fitted pin shall be used. Bolts are not intended to take the load that is normally applied to the pin (Figure 9-2).

- Shackles shall not be used if the pin cannot be completely seated.

- Shackles shall never be pulled at an angle because the capacity will be tremendously reduced. Centralize whatever is being hoisted on the pin by suitable washers or spacers (Figure 9-3).

- Screw pin shackles shall not be used if the pin can roll under load and unscrew (Figure 9-4).

Never Replace a Shackle Pin with a Bolt

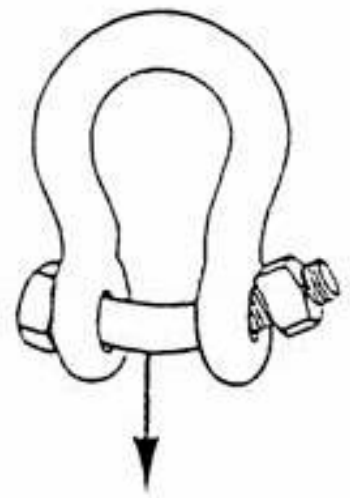

The Load will Bend the Bolt

38807139.17

Figure 9.2. Replacing Shackle Pins 


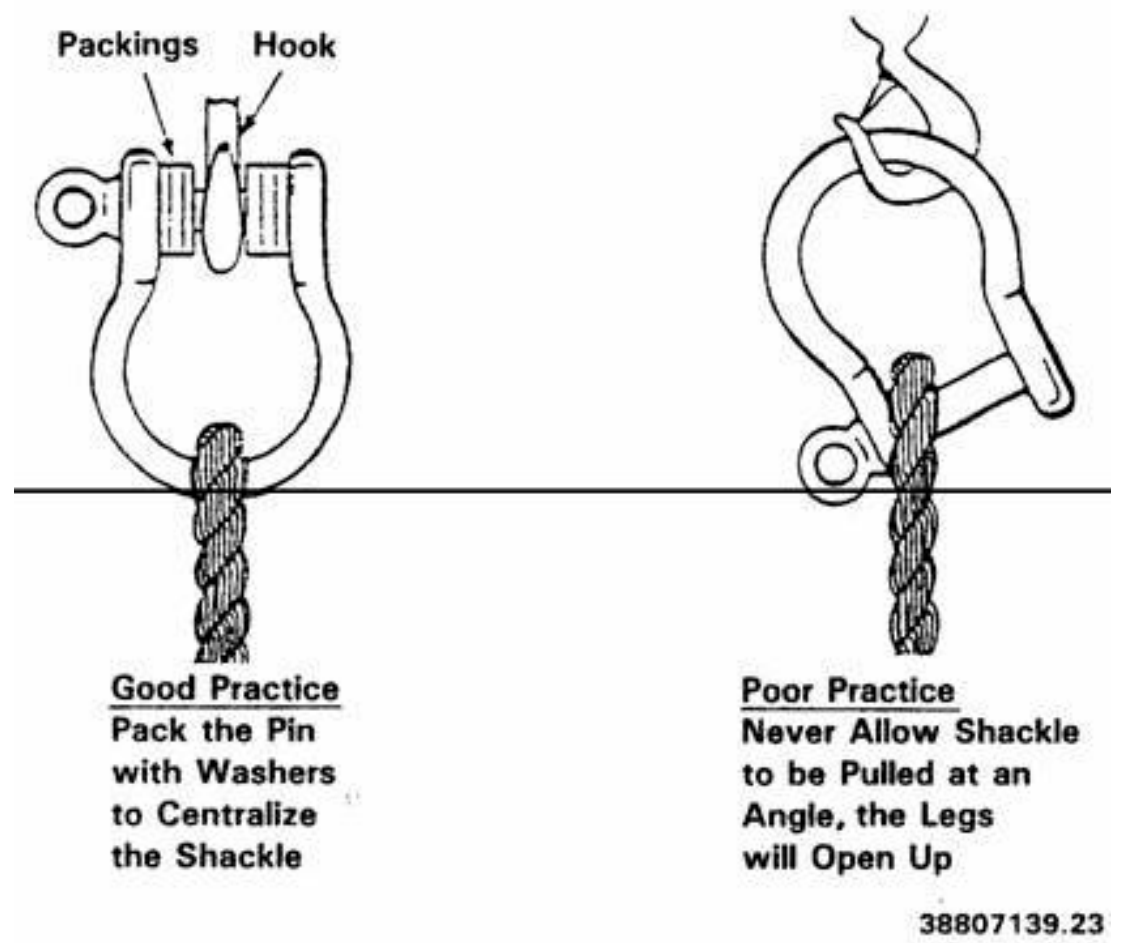

Figure 9.3. Eccentric Shackle Loads

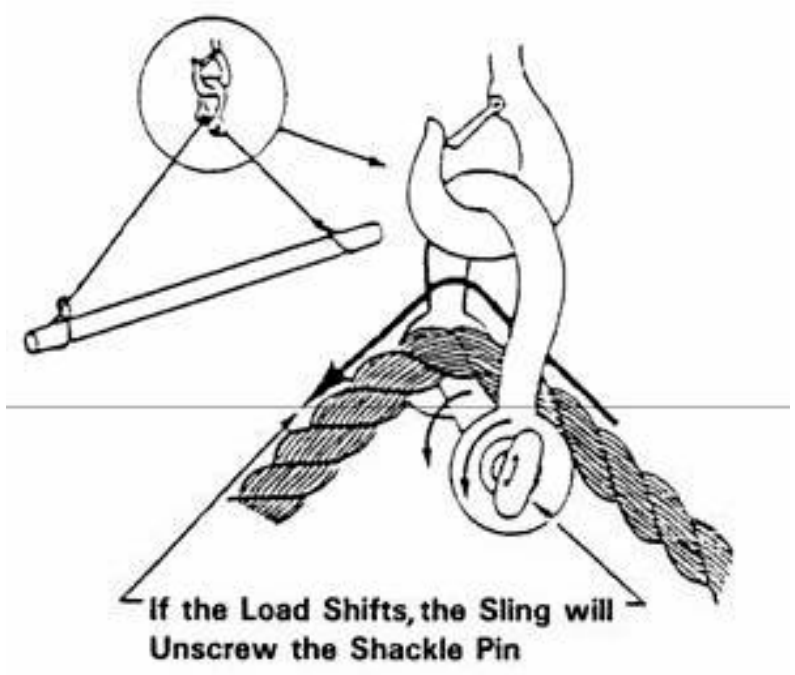

$38805-185.27$

Figure 9.4. Improper use of a Screw Pin Shackle 


\subsubsection{Proof Load Testing and Tagging}

A proof load test (minimum, two times SWL) is required for shackles and rings used in critical-lift service. A validated proof load test, conducted by the manufacturer or the Hanford Site contractor, meets this requirement.

Note: A critical-lift procedure may call for additional load testing or proof load testing of rigging and rigging hardware.

\subsection{Wire Rope Clamps}

\subsubsection{General}

Requirements and guidelines for wire rope clamps are as follows.

- Clamps (also called clips) shall meet or exceed the requirements of Federal Specification FF-C-450, "Clamps, Wire Rope.”

- Clamps shall be legibly and permanently marked with size and the manufacturer's identifying mark.

- Clamps shall be assembled using the same size, type, class, and manufacturer (see Figure 9.5). Follow the manufacturer's instructions for proper installation.

- $\quad$ For application information, see Figure 9.3. 

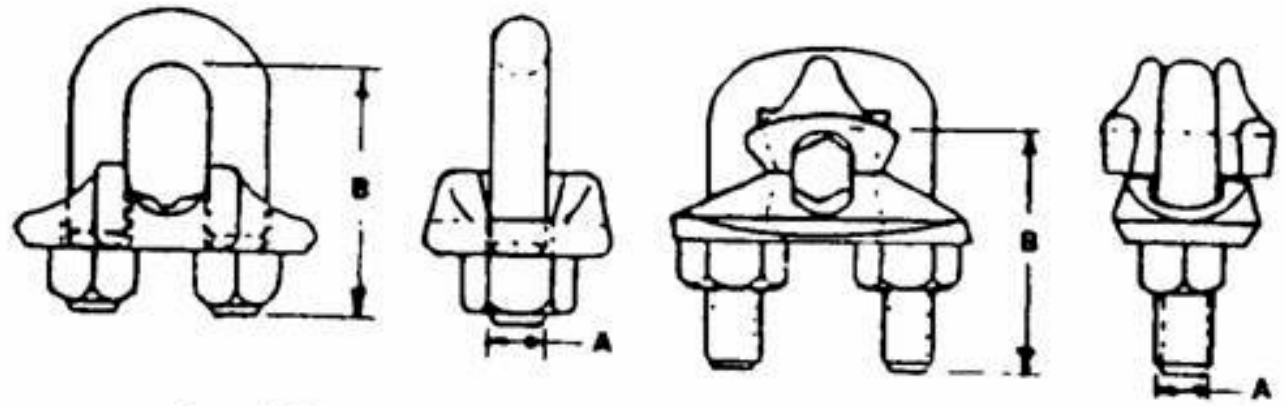

Trpe I. Single Grip. Single Seddle Wire Rope Clamp IOne Single Seddle with U-bolt!

Type H. Double Grip. Double Saddle Wire Ropo Clamp IT wo Separate Sedello with U.bolt)
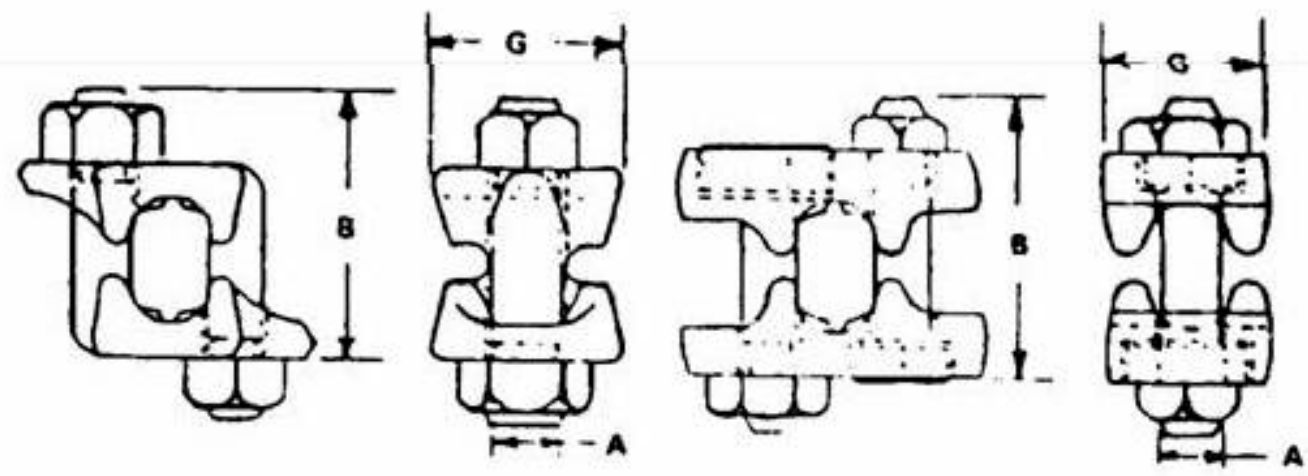

Type III, Cless 1, Double Gilp. Double Seddle Whe Rope Clamp ISaddlea Integral with Two L-shaped Clemps)

Type III. Class 2, Double Grip. Double Saddle Wire hope Clemp (Assembied with Soperale Hex Hoad Bolts and Nurel

3890518522

Figure 9.5. Type I, II, and III Wire Rope Clamps

\subsubsection{Inspection}

Inspection criteria for wire rope clamps follow:

- Before use, clamps shall be visually inspected for damage, corrosion, wear, and cracks.

- Verify that the clamp components are marked in accordance with Section 9.3.1, "General,” bullet 2 .

- Ensure that the assembled clamp contains the same size, type, and class parts. 


\subsection{Eyebolts, Manufacturer-Installed Lift Points, and Swivel Hoist Rings}

\subsubsection{Manufacturer-Installed Eyebolts vs. Eyebolts Used as Rigging Hardware}

This section specifies requirements for eyebolts that are used as rigging hardware during normal hoisting and rigging activities. Eyebolts designed for and permanently installed by the manufacturer on existing engineered equipment are considered part of the engineered equipment. They may not meet all requirements specified for rigging hardware. Eyebolts permanently installed on engineered equipment are acceptable for their intended use as long as they pass visual inspection before use.

It is important to know how the manufacturer of engineered equipment intends permanently installed eyebolts to be used. In some cases the intended use is obvious to an experienced craftsman and in other cases engineering review of vendor information may be necessary. In either case, when special eyebolt use instructions are provided by the manufacturer or vendor, such instructions shall be followed.

CAUTION: Eyebolts installed by the manufacturer to lift only parts of the engineered equipment are not suitable for lifting the completely assembled piece of equipment. When questions arise regarding the use of manufacturer

\subsubsection{Manufacturer-Installed Lift Points}

All manufacturer-installed lift points shall be inspected and evaluated by a qualified person before use for cracks, deformation, excessive wear, or damage. When questions arise regarding the use of manufacturer-installed lift points, the equipment custodian or cognizant engineer shall be consulted.

\subsubsection{Eyebolt Rigging Hardware}

The following list applies to eyebolts used as rigging hardware.

- Only shouldered eyebolts (Type 2) ${ }^{1}$ shall be used for rigging hardware, except when prohibited by the configuration of the item to which the eyebolt is attached. Where non-shouldered eyebolts (Type 1$)^{2}$ are required, they shall be used only in vertical pulls ${ }^{3}$ or in rigging systems that are designed, analyzed, and approved by a qualified person.

- Eyebolt marking:

- Carbon Steel Eyebolts. Each eyebolt shall have the manufacturer's name or identification mark forged in raised characters on the surface of the eyebolt.

\footnotetext{
1 Type 2 - Shouldered Eyebolt.

2 Type 1 - Straight Shank Eyebolt (nonshouldered).

${ }^{3}$ For vertical loading, eyebolts without shoulders have the same load-carrying ability as shouldered eyebolts; however, nonshouldered eyebolts are subject to bending, thus severely reducing their safe working load.
} 
- Alloy Steel Eyebolts. Each eyebolt shall have the symbol "A” (denoting alloy steel) and the manufacturer's name or identification mark forged in raised characters on the surface of the eyebolt.

- Eyebolts shall have a minimum design factor of 5, based on ultimate strength. Table 9.1 reflects the safe working load as listed in ANSI/ASME B18.15, "Forged Eyebolts." (Figure 9.6 depicts the angle of load described in Table 9.1) Eyebolts from selected manufacturers may have a higher SWL. For higher SWLs a design factor of no less than five shall be verified before use.

- Carbon steel eyebolts shall be made of forged carbon steel. Alloy steel eyebolts are forged, quenched, and tempered with improved toughness properties, intended primarily for lowtemperature applications.

- $\quad$ Nuts, washers, and drilled plates shall not be used or assembled to make shouldered eyebolts. Wire type and/or welded eyebolts shall not be used in lifting operations.

- Shoulders shall seat uniformly and snugly against the surface on which they bear. ${ }^{4}$

CAUTION: Size 7/8-inch eyebolts should not be used because a 7/8-9 UNC thread may be threaded into a 1-8 UNC tapped hole but will fail when loaded.

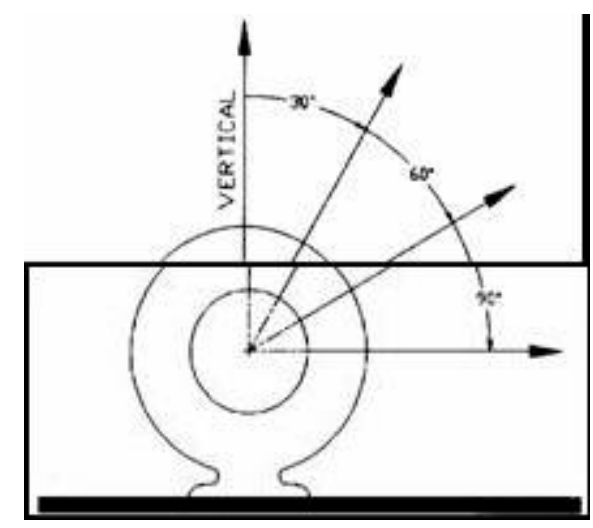

Figure 9.6. Angle of Load for use with Table 9.1

\footnotetext{
${ }^{4}$ If the shoulder does not bear firmly against the mating part, the capacity of a shouldered eyebolt is reduced to that of a nonshouldered eyebolt.
} 
Table 9.1. Safe Working Load for Carbon Steel

Shouldered Eyebolts (ANSI/ASME B18.15)

\begin{tabular}{|c|c|c|c|c|c|}
\hline \multirow{2}{*}{$\begin{array}{l}\text { Norminal size } \\
\text { (in.) }\end{array}$} & \multirow{2}{*}{$\begin{array}{c}\text { Inside } \\
\text { diameter of eye } \\
\text { (in.) }\end{array}$} & \multicolumn{4}{|c|}{ Safe Working Load per Shouldered Eyebolt (lb) } \\
\hline & & Vertical & $\begin{array}{l}30^{\circ} \text { from } \\
\text { vertical }\end{array}$ & $\begin{array}{l}60^{\circ} \text { from } \\
\text { vertical }\end{array}$ & $\begin{array}{l}90^{\circ} \text { from } \\
\text { vertical }\end{array}$ \\
\hline $1 / 4$ & 0.69 & 400 & 75 & Not recommended & Not recommended \\
\hline $3 / 8$ & 0.94 & 1,000 & 400 & 220 & 180 \\
\hline $1 / 2$ & 1.12 & 1,840 & 850 & 520 & 440 \\
\hline $5 / 8$ & 1.31 & 2,940 & 1,410 & 890 & 740 \\
\hline $3 / 4$ & 1.44 & 4,430 & 2,230 & 1,310 & 1,140 \\
\hline 1 & 1.69 & 7,880 & 3,850 & 2,630 & 2,320 \\
\hline $11 / 4$ & 2.12 & 12,600 & 6,200 & 4,125 & 3,690 \\
\hline $11 / 2$ & 2.44 & 18,260 & 9,010 & 6,040 & 5,460 \\
\hline 2 & 3.06 & 32,500 & 15,970 & 10,910 & 9,740 \\
\hline
\end{tabular}

\subsubsection{Eyebolt Inspection}

Inspection criteria for eyebolts are as follows:

- Careful visual inspection of each eyebolt immediately before use is mandatory. Eyebolts that are cracked, bent, or have damaged threads shall be discarded.

- The shank of the eyebolt shall not be undercut and shall be smoothly radiused into the plane of the shoulder.

Limiting Conditions:

- To attain the rated capacity for threaded hole applications, minimum thread shank length of engagement depends on parent material and must be as follows:

Steel: 1 thread diameter

Cast iron, brass, bronze: 1.5 times the thread diameter

Aluminum, magnesium, zinc, plastic: 2 times the thread diameter

- To attain the rated capacity for untapped through-hole applications, use shouldered eyebolts, steel washer, and a nut with required thread engagement.

- Under vertical load, Type 1, straight shank (nonshouldered) eyebolts have the same safe working load as shouldered eyebolts. Angular loading is restricted.

- Capacities shown in this table are for carbon steel ASTM A-489 eyebolts at temperatures between $30 \mathrm{EF}$ (-1 EC) and $275 \mathrm{EF}$ (135 EC). Carbon steel is subject to failure from shock loading at temperatures below $30 \mathrm{EF}$ and loses strength at temperatures above $275 \mathrm{EF}$. 
- Eyebolts from selected manufacturers may have higher SWL. Regardless of SWL, ensure that eyebolts have a design factor of 5 .

\subsubsection{Eyebolt Operation}

Operating practices and guidelines for eyebolts are as follows.

- The size of the hole shall be checked for the proper size of eyebolt before installation. The condition of the threads in the hole shall be checked to ensure that the eyebolt will secure and that the shoulder can be brought to a snug and uniformly engaged seat.

- When installed, the shoulder of the eyebolt must be flush with the surface (Figure 9.7). When eyebolts cannot be properly seated and aligned with each other, a steel washer or spacer not to exceed one thread pitch may be required to put the plane of the eye in the direction of the load when the shoulder is seated (Figure 9.7). Proper thread engagement must be maintained. Use a washer with approximately the same diameter as the eyebolt shoulder and the smallest inside diameter that will fit the eyebolt shank.

- Angular loading of eyebolts should be avoided. Angular loading occurs in any lift in which the lifting force is applied at an angle to the centerline of the eyebolt shank.

- When more than one eyebolt is used in conjunction with multiple-leg rigging, spreader bars, lifting yokes, or lifting beams should be used to eliminate angular loading. Where spreaders, yokes, or beams cannot be used, shouldered eyebolts may be used for angular lifting, providing the limiting conditions in Table 9.1 are considered.

- To keep bending forces on the eyebolt to a minimum, the load shall always be applied in the plane of the eye, never in the other direction (Figure 9.8).

- If the hook will not go completely into the eyebolt, use a shackle to avoid loading the hook tip.

- Slings shall not be reeved through an eyebolt or reeved through a pair of eyebolts. Only one leg should be attached to each eyebolt. 


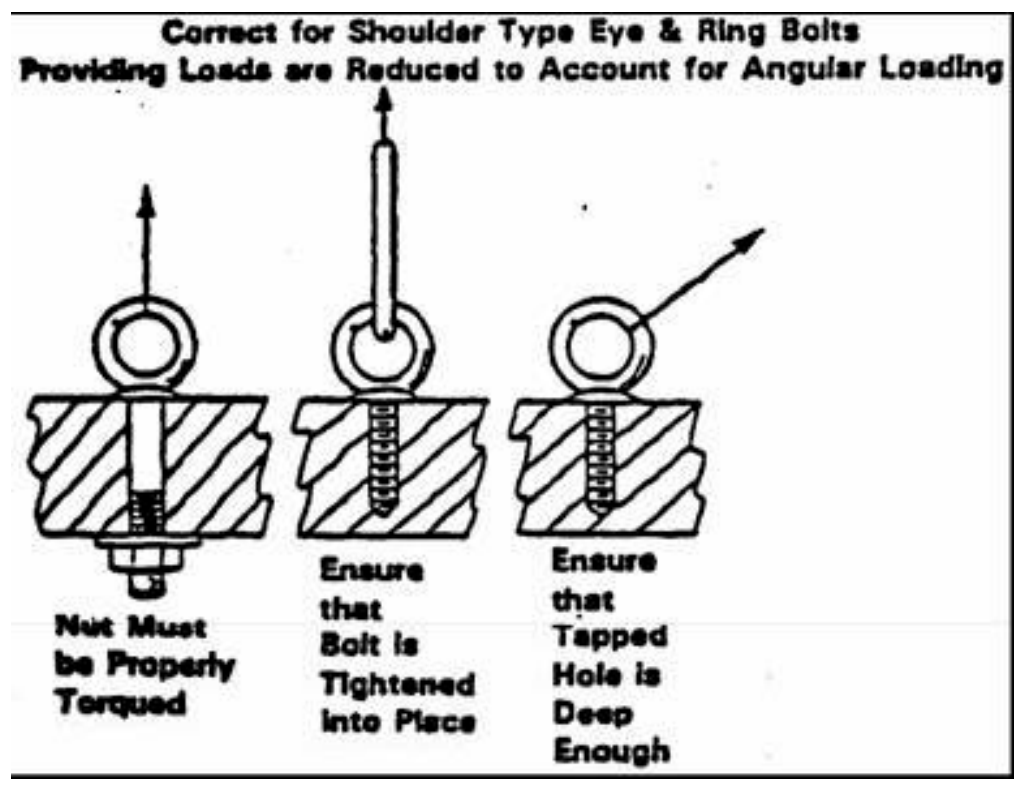

Figure 9.7. Use of Shoulder-Type Eyebolts

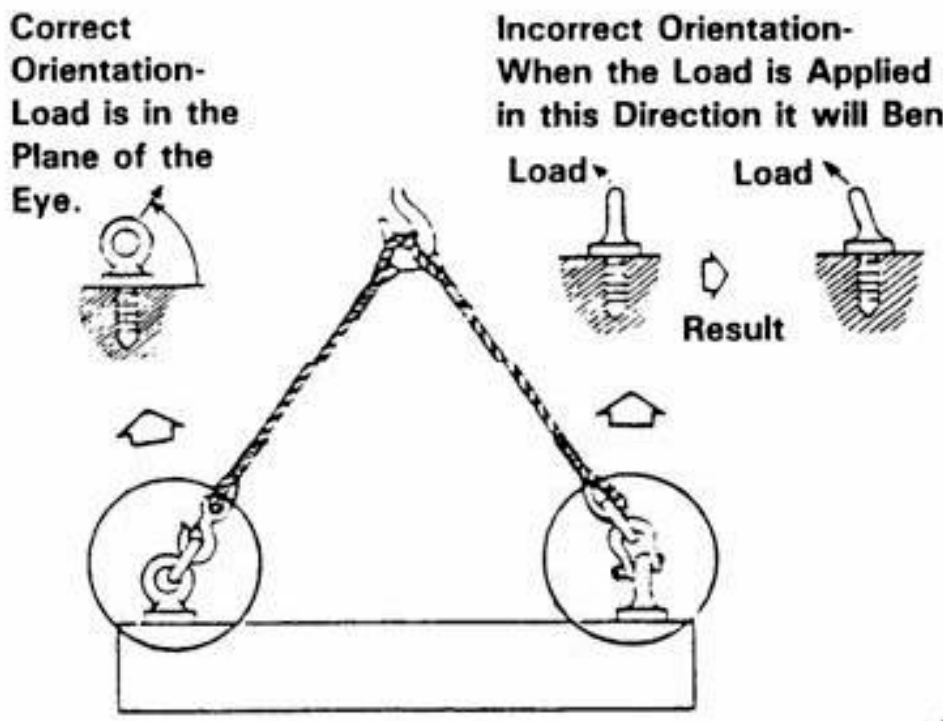

38807139.1

Figure 9.8. Orientation of Eyebolts 


\subsubsection{Swivel Hoist Ring Inspection}

Inspection criteria for swivel hoist rings are as follows (see Figure 9.9):

- The minimum design factor shall be no less than five based on ultimate strength.

- Ensure free movement of the bail. The range of movement shall be 360 degrees swivel and 180 degrees pivot.

- The work piece shall be tapped for a swivel hoist ring bolt with the axis perpendicular to the mounting surface. The work surface should be flat and smooth to provide flush seating for the bushing flange. The bolt should be tightened to the full torque loading. Unless otherwise recommended by the manufacturer, the torque tolerance is $+25 \%,-0 \%$.

Note: Loosening of a swivel hoist ring bolt may develop after prolonged service in a permanent installation. Periodically verify proper torque and retighten the mounting bolt as recommended by the manufacturer. In lieu of other direction from the manufacturer, check hoist swivel ring mounting bolts for proper torque before each lift.

- Swivel hoist rings shall be provided with instructions from the manufacturer. They shall be marked to clearly identify the manufacturer, the safe working load, and the torque value. Swivel hoist rings are available in both UNC and metric thread sizes, so they shall also be marked to identify UNC or metric threads.

- When a swivel hoist ring is installed with a retention nut, the nut must have no less than full thread engagement and shall be torqued in accordance with the manufacturer's recommendations. The nut must meet one of the following standards to develop the safe working load limit:
- ASTM A-563
(A) Grade D Hex Thick
(B) Grade DH Standard Hex

- $\quad$ SAE Grade 8 Standard Hex

- Never use free fit spacers or washers between the swivel host ring bushing flange and the mounting surface.

- $\quad$ Never use swivel hoist rings that show signs of corrosion, wear or damage.

- Read, understand, and follow the manufacturer's instructions, diagrams, and chart information before using a swivel hoist ring. 


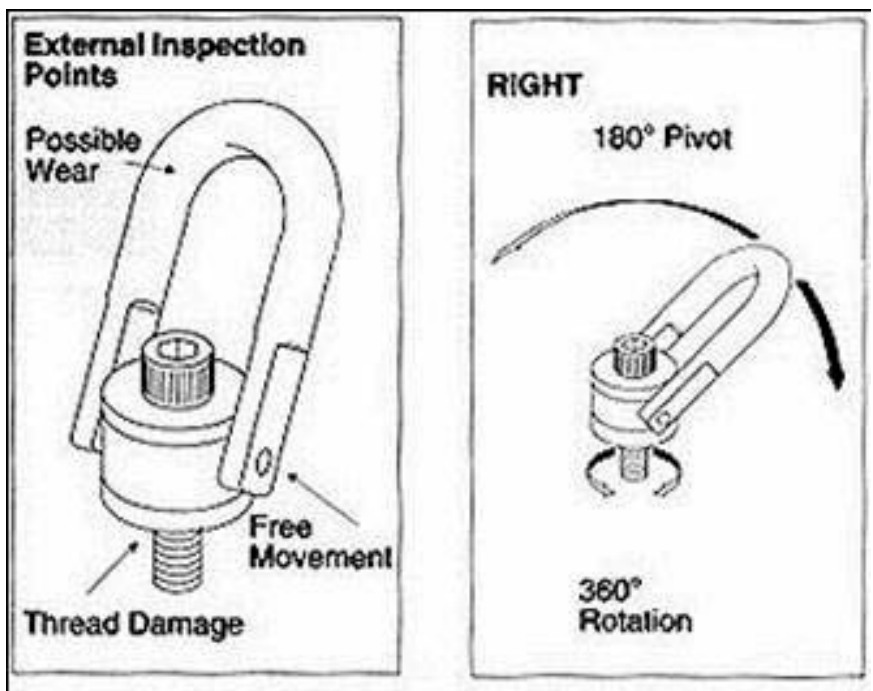

Figure 9.9. Swivel Hoist Ring Inspection Points

\subsubsection{Qualification of Eyebolts and Swivel Hoist Rings}

While additional supplementary requirements may be specified for a particular application, eyebolts and swivel hoist rings used as rigging hardware must meet the following requirements to be qualified for lifting service.

- Carbon steel eyebolts (ASTM A489) shall have the manufacturer's name or identification mark forged in raised characters on the surface of the eyebolt. Alloy steel eyebolts (ASTM F541) shall have the symbol "A” (denoting alloy steel) and the manufacturer's name or identification mark forged in raised characters on the surface of the eyebolt.

- Swivel hoist rings with standard-length bolts are designed for ferrous metal. Long bolts are designed to be used with a soft metal (e.g., aluminum) work piece. Long bolts also may be used with ferrous metal. Leaving the threaded end of a swivel hoist ring under torque in an aluminum work piece will cause stress corrosion in certain aluminum alloys. Therefore, do not leave a swivel hoist ring in aluminum loads for longer than three months. (Depending on the aluminum alloy, a qualified person may allow exceptions to the "three month rule." Exceptions shall be documented.)

- Eyebolts and swivel hoist rings shall be of uniform quality consistent with good manufacturing and inspection practices. They shall be free from imperfections which, resulting from their nature, degree, or extent, would make the eyebolt or swivel hoist ring unsuitable for the intended use.

- Never exceed the SWL of a swivel hoist ring as specified by the manufacturer. When sizing swivel hoist rings used with multiple-leg (non-vertical) rigging, make sure the load angle factor is considered to account for the total load on the swivel hoist ring. 


\subsubsection{Swivel Hoist Ring Operation}

Operating practices and guidelines for swivel hoist rings are as follows.

- Attach lifting device ensuring free fit to swivel hoist ring bail and ensuring no interference between load (work piece) and bail.
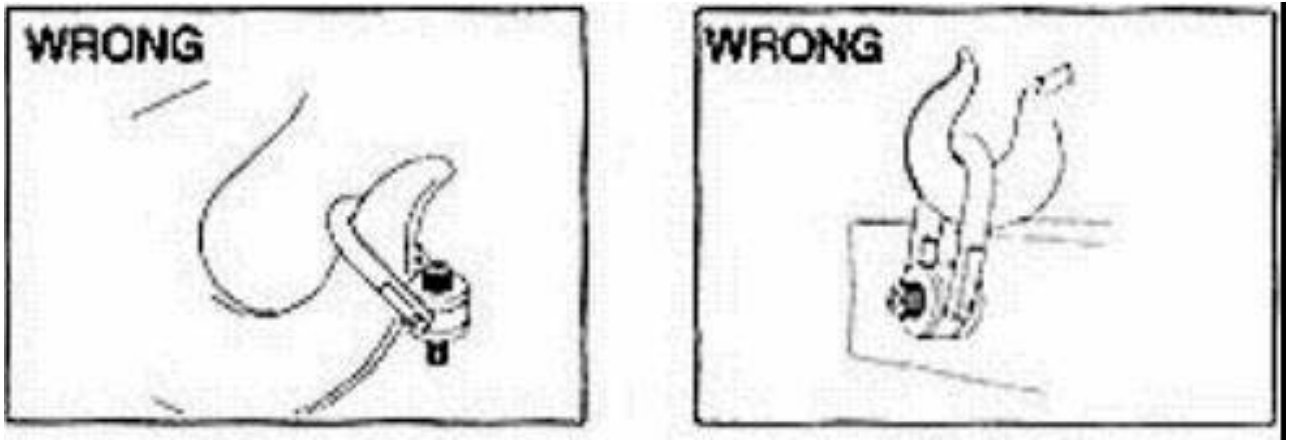

Figure 9.10. Using Swivel Hoist Rings ${ }^{5}$

- Always ensure free movement of the bail. Never use hoist rings if bail is bent or elongated
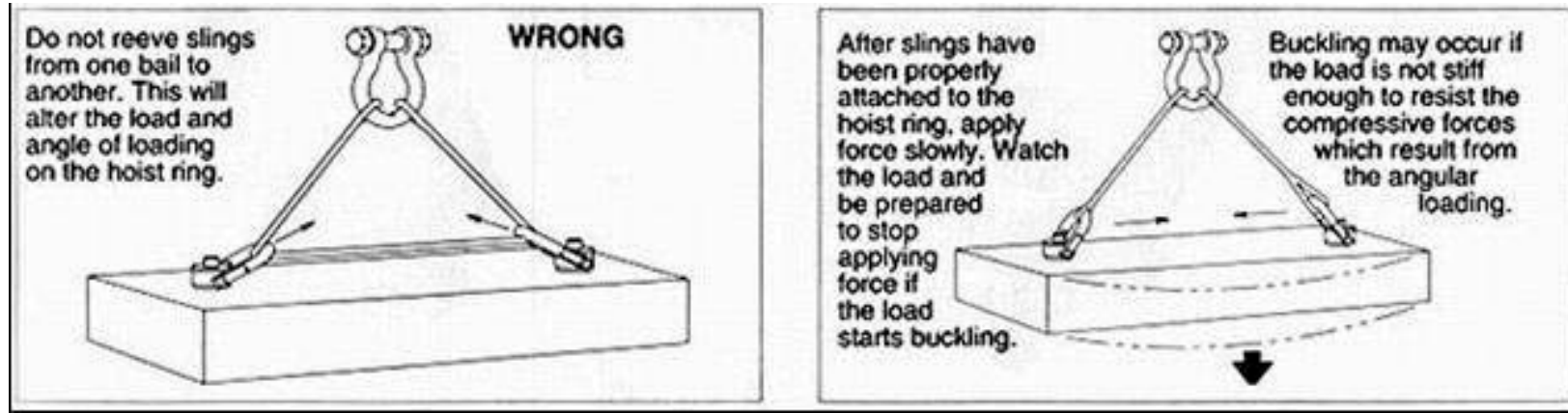

Figure 9.11. Swivel Hoist Ring Rigging Techniques

\subsubsection{Hoisting and Rigging Bulletin - Eyebolt and Swivel Hoist Ring Temperature Limitations}

Issue - Organizations and personnel using eyebolts and swivel hoist rings in rigging applications need to abide by the manufacturer's temperature limitations.

Background - Review of Standards - Eyebolts manufactured in accordance with ASTM A 489 Standard Specifications for Carbon Steel Lifting Eyes are rated for lifting service between $+30^{\circ} \mathrm{F}$ and $+275^{\circ} \mathrm{F}$.

These temperature limitations are also referenced in ASME B18.15 Forged Eyebolts.

Eyebolts manufactured in accordance with ASTM F 541 Alloy Steel Eyebolts are rated for use at a low temperature of $-40^{\circ} \mathrm{F}$. ASTM F 541 requires the symbol "A" to denote alloy steel. Some manufactures of carbon steel eyebolts employ manufacturing processes that allows usage at a lower service temperature

\footnotetext{
${ }^{5}$ Swivel hoist ring graphics courtesy of The Crosby Group.
} 
ranges. Most manufactures do not publish service temperature limitations, leaving the user to contact the manufacturer to verify temperature limitations.

Swivel hoist rings (Carbon steel or Alloy) may have similar temperature limitations as eyebolts. Components of swivel hoist rings (e.g., nuts, socket head cap screws) are typically manufactured in accordance with national standards, there is no national standard governing the manufacturer of Swivel Hoist Rings. Specifications for Swivel Hoist Rings, including temperature limitations, are specified by the manufacturer.

Action - Before using eyebolts or swivel hoist rings for lifting service, take the following steps:

- $\quad$ identify the manufacturer (identification mark forged in raised characters).

Note: If manufacture is unknown, perform an engineering evaluation and perform lift above $30^{\circ} \mathrm{F}$.

- determine if manufactured of carbon steel or alloy.

- validate with the manufacture the temperature limitations for use.

- $\quad$ ensure eyebolts and swivel hoist rings are used within the manufacture's temperature limitations.

\section{$9.5 \quad$ Turnbuckles}

\subsubsection{General}

Requirements and guidelines for turnbuckles are as follows.

- Turnbuckles shall meet or exceed the requirements of Federal Specification FF-T-791 (latest revision), "Turnbuckles."

- If turnbuckles are used in a rigging system, that system shall be approved by a qualified engineer or rigging specialist.

- The minimum design factor for turnbuckles shall be 5:1. A general description of turnbuckles and SWLs of turnbuckles is provided in Figure 9.12.

- Turnbuckles used in hoisting and rigging operations shall be fabricated from forged alloy steel.

- If a turnbuckle is used in an application where vibration is present, the end fittings should be secured to the frame with lock pins or wires to prevent them from turning and loosening (Figure 9.12). Lock nuts or jam nuts shall not be used.

- Before placing turnbuckles in critical lifting service, a stamped permanent identification tag shall be affixed. 


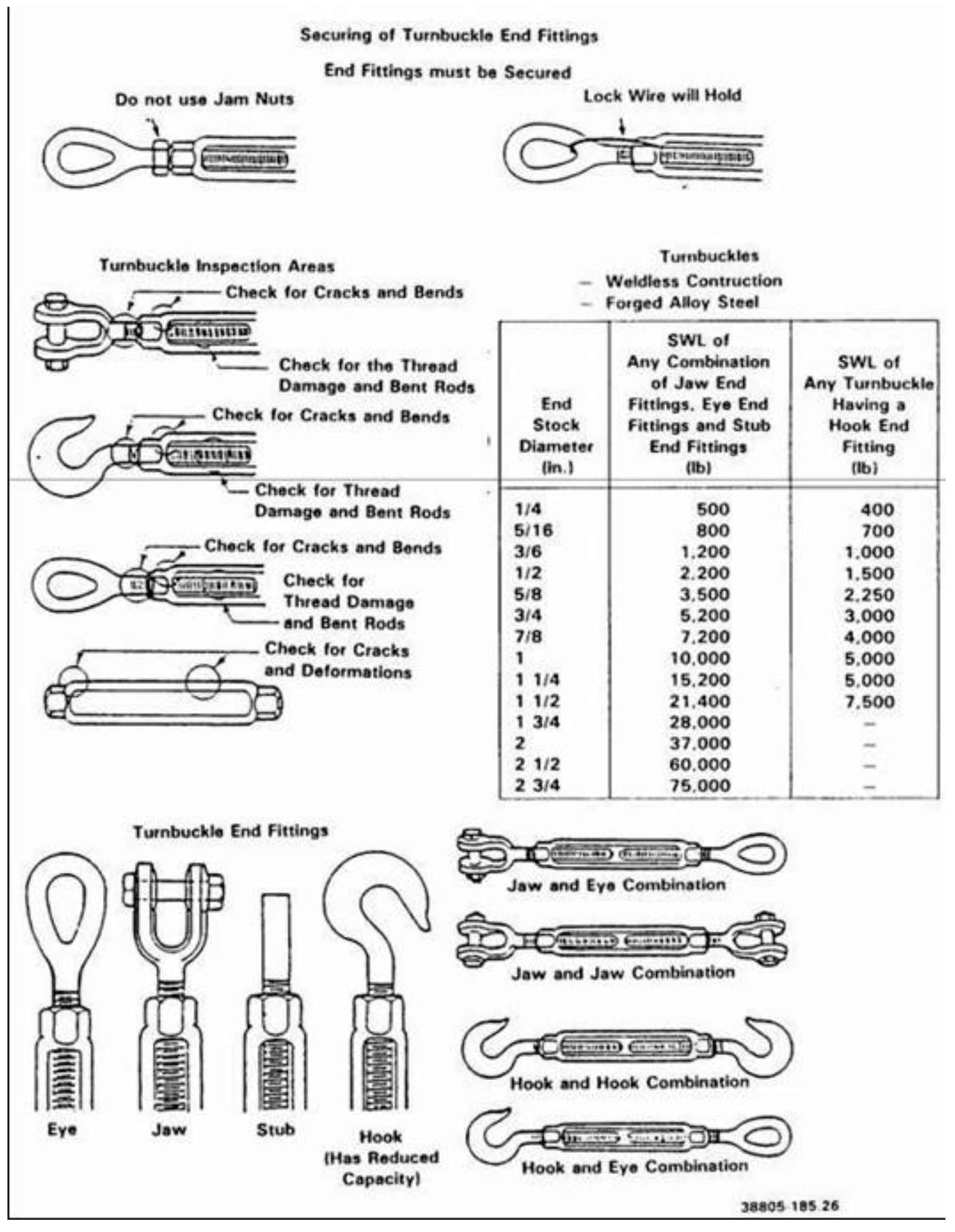

Figure 9.12. Turnbuckle Types, Inspection Areas, and Safe Working Load 


\subsubsection{Inspection}

Inspection criteria for turnbuckles are as follows:

- Inspect turnbuckles for the following: (Turnbuckle inspection areas are illustrated in Figure 9.12.)

- Cracks and bends in the frame

- Thread damage and bent rods.

- Turnbuckles shall be inspected for damage before each use. Damaged threads or bent frame members shall disqualify the unit for use.

\subsubsection{Testing of Turnbuckles}

Turnbuckles used for critical-lift service shall initially be proof tested at twice the rated capacity. Turnbuckles that have been proof tested (at the PNNL Site or by the manufacturer) shall have a tag or other marking to indicate clearly to the user that proof testing has been done.

\subsubsection{Qualification}

Turnbuckles must meet the following requirements to be qualified for lifting service at the PNNL Site.

- Turnbuckles for critical-lifting service must be initially proof load tested at two times the SWL and tagged or marked (see Section 9.5.3, “Testing of Turnbuckles”).

- Turnbuckles shall meet requirements in Sections 9.5.1, “General” and 9.5.2, "Inspection.”

\subsection{Rigging Hooks}

\subsubsection{General}

Rigging hooks are used as part of rigging tackle, such as sling assemblies, or with below-the- hook lifting devices. (See Section 4.0, “Hooks," for load hooks on hoists or cranes.) In addition to the typical rigging hooks shown in Figure 9.13, many styles of rigging hooks are available. Some rigging hooks (e.g., grab hooks and sorting hooks) are designed to carry the load near the point as well as in the bowl or saddle of the hook. Maximum safe working loads normally apply only when the load is in the bowl or saddle. Rigging hooks shall be used within the limits specified by the manufacturer. Forged alloy steel hooks generally make the best rigging hooks.

The manufacturer's identification shall be forged or die-stamped on the hook. Except as provided in the following Section, loads for rigging hooks shall be equal to or exceed the rated load of the chain, wire rope, or other suspension member to which it is attached. Where this is not feasible, special precautions shall be taken to ensure that the rated load limit of the hook is not exceeded. Welding on hooks, except 
by the hook manufacturer, is not allowed. Never repair, alter, rework, or reshape a hook by welding, heating, burning, or bending. Requirements and guidelines for rigging hooks are as follows.

- $\quad$ Rigging hooks shall meet or exceed the requirements of ANSI/ASME B30.10. (Load hooks are included in Section 4.0, "Hooks") Note: Throatlatches are recommended, but consensus standards do not require throatlatches on rigging hooks.

- Rigging hooks that do not support a load in a direct-pull configuration, such as grab hooks, sorting hooks, and sling hooks (Figure 9.13).

- The SWL for a hook used in the manner for which it is intended shall be equal to or exceed the rated load of the chain, wire rope, or other suspension member to which it is attached.

- The designated SWL applies only when the load is applied in the bowl or saddle of the hook.

- The manufacturer's identification shall be forged or die-stamped on a low-stress and nonwearing area of the hook.

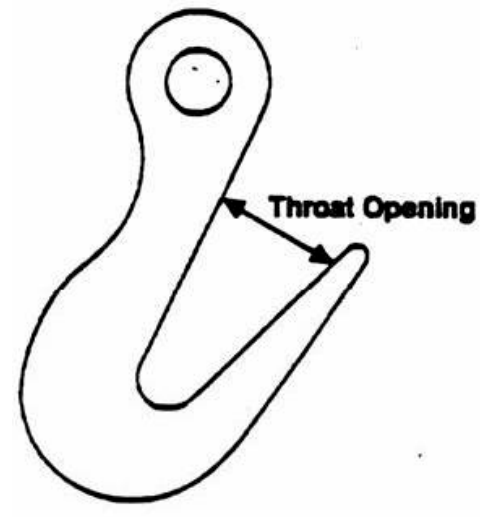

Sorting Hook

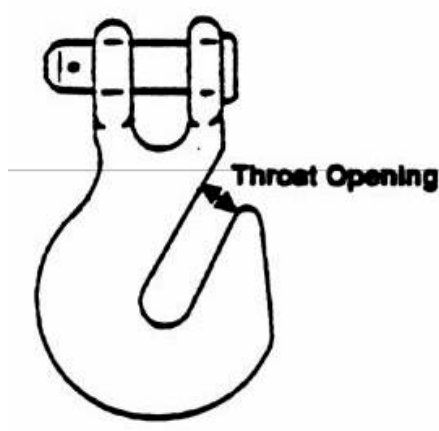

Clevis Grab Hook

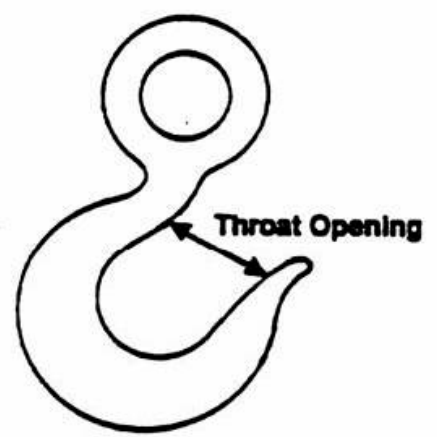

Eye Hook

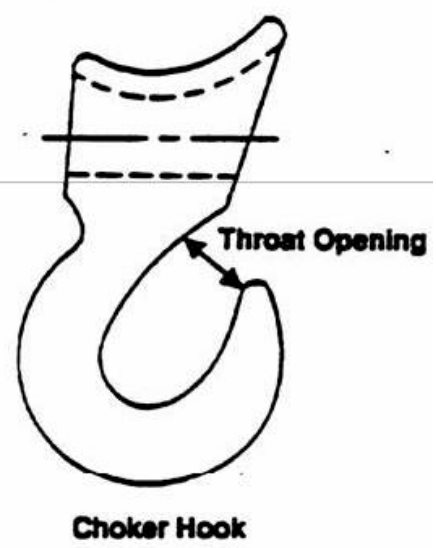

$30806-188.26$

Figure 9.13. Miscellaneous Hook 


\subsubsection{Inspection}

Inspection criteria for rigging hooks are as follows:

- Rigging hooks that are not permanently installed in a sling assembly shall be visually inspected for the following deficiencies before use:

- distortions such as bending, or twisting exceeding 10 degrees from the plane of the unbent hook

- increased throat opening exceeding $15 \%$

- wear exceeding $10 \%$ of the original dimension

- cracks, severe nicks, or gouges

- hook attachment and securing means.

- $\quad$ Rigging hooks shall be inspected as a part of the slings to which they are attached.

- The NDT of rigging hooks is not routinely required. Rigging hook NDT may be required by a critical-lift procedure. 


\subsection{Below-the-Hook Lifting Devices}

\subsection{Scope}

As defined by ASME B30.20, Below-the-Hook Lifting Devices, there are four types of below-thehook lifters. They are arranged in groups as follows:

Group I Structural and Mechanical Lifting Devices

Structural lifter. A lifter consisting of an assembly of rigid parts designed to hold and attach a load to a hoisting device.

Mechanical lifting device. A mechanism composed of two or more rigid parts that move with respect to each other for attaching a load to a hoisting device.

Group II Vacuum lifting device. A below-the-hook lifting device using a holding force by means of vacuum.

Group III Magnet, lifting, close proximity operated. A lifting magnet used in such a fashion that the operator manually positions the magnet on the load and manually guides the magnet and load during a lift.

Group IV Magnet, lifting, remotely operated. A lifting magnet that does not require the operator or other personnel to be in close proximity to the magnet or its load while the magnet is in use

Note: Unless otherwise stated, as used in this section, the term "operator" applies to the operator of a below-the-hook lifting device.

Note: Refer to 29 CFR 1926, Subpart R for special requirements relating to steel erection.

This section provides the requirements for Group I structural and mechanical below-the-hook lifting devices. The majority of below-the-hook lifting devices used at PNNL include, but are not limited to, supporting lifting devices, indentation-type pressure lifting devices, friction-type pressure lifting devices, spreader bars, lifting jigs, lifting yokes, and load test fixtures. Slings and rigging hardware that may be components in a below-the-hook lifting device are covered in previous sections of this manual.

The use of vacuum and magnetic lifting devices is very limited at PNNL and these devices have not been covered in detail. If data on vacuum or magnetic lifting devices are required, a qualified engineer must be consulted. Only the marking requirements for magnetic lifters are included in this section.

\subsection{General Features}

Structural and mechanical lifting devices are often one-of-a-kind designs. Typical devices are shown in Section 10.10, “Typical Lifting Devices.” 
In accordance with design requirements, the responsible engineer may invoke ANSI N14.6 to a below-the-hook device. ANSI N14.6 invokes criteria similar to, but not identical to ASME B30.20. ANSI N14.6 may be invoked by the responsible engineer to govern the following criteria:

- design

- fabrication

- $\quad$ acceptance testing

- maintenance

- $\quad$ assurance of continuing compliance

- inspection

- marking.

If questions arise as to how or if ANSI N14.6 applies, consult the responsible engineer.

\subsection{Design and Fabrication}

\subsubsection{Design Factor}

Load-bearing structural components of a lifter shall be designed to withstand the stresses imposed by its rated load plus the weight of the lifter, with a minimum design factor of 3 , based on the yield strength of the material, and with stress ranges that do not exceed the values given in ANSI/ American Welding Society (AWS) D14.1, Specification for Welding of Industrial and Mill Cranes and Other Material Handling Equipment, for the applicable conditions.

\subsubsection{Welding}

Welding shall be in accordance with the requirements of ANSI/AWS D14.1, Specification for Welding of Industrial and Mill Cranes and Other Material Handling Equipment.

Note: Requirements for nondestructive examination (NDE) of welds shall be determined by ANSI/AWS 14.1, Specification for Welding of Industrial and Mill Cranes and Other Material Handling Equipment, and the applicable fabrication specification.

\subsubsection{Guarding}

Guards will be provided for all moving parts or pinch points that constitute a hazard to the operator under normal operating conditions. 


\subsubsection{Electrical}

Wiring and electrical equipment shall comply with the requirements of NFPA 70, National Electrical Code (NEC), Article 610, "Cranes and Hoists."

\subsubsection{Analysis}

Site-fabricated, below-the-hook lifting devices shall be analyzed by the design engineer to verify that they conform to the required design factor.

\subsection{Marking}

Structural and mechanical below-the-hook lifting devices shall be provided with identification displaying the following data, as a minimum:

- rated load

- manufacturer's name (contractor's name if fabricated onsite)

- lifting device weight (if over 100 lbs)

- drawing number (if applicable)

- $\quad$ serial number (if applicable).

The identification data may be displayed on a name tag, nameplate, metal stamp, or other permanent marker

Note: If the lifting device comprises several lifting devices that can be detached from the assembly, these individual lifting devices shall be marked with their individual load rating also. Lifting magnets shall include, but not be limited to, the following information:

- manufacturer’s name

- manufacturer's model or unit identification

- $\quad$ weight of lifting magnet

- $\quad$ duty cycle (if applicable)

- cold current (coil is $68^{\circ} \mathrm{F}\left[20^{\circ} \mathrm{C}\right]$ and at rated voltage).

Repaired or modified magnets shall include, but not be limited to, the following information:

- name and address of the repairer or modifier

- repairer’s unit identification 
- weight of lifting magnet

- duty cycle (if applicable)

- cold current.

\section{$10.5 \quad$ Modifications}

Any modification or re-rating of below-the-hook lifting devices requires documented analysis by a qualified engineer or the manufacturer of the lifting device.

Any re-rated or modified lifting device requires a new load test. A re-rated lifting device also must be appropriately relabeled with the new rated load capacity.

\subsection{Inspections}

\subsubsection{Initial Inspection}

Before initial use, all new, modified, or repaired lifting devices shall be inspected by a designated person to ensure compliance with the provisions of ASME B30.20, Below-the-Hook Lifting Devices.

\subsubsection{Frequent Inspections}

The user shall inspect for the following deficiencies on each shift or before use. In addition, visual observations should be conducted during regular service for any damage or evidence of malfunction that appears between regular inspections. Deficiencies shall be carefully examined to determine whether they constitute a hazard:

- $\quad$ structural deformation, cracks, or excessive wear on any part of the lifter

- loose or missing guards, fasteners, covers, stops, or nameplates

- all functional operating mechanisms and automatic hold and release mechanisms for maladjustments that interfere with operations

- periodic inspections are current via inspection sticker, other documentation or verbal confirmation from equipment custodian

- all load-carrying portions of the device for deformation, cracks, and excessive wear. 


\begin{tabular}{|c|l||}
\hline \multicolumn{2}{|c|}{ Service Classifications for Below-the-Hook Lifting Devices } \\
\hline Normal & $\begin{array}{l}\text { Distributed service that involves operation with various weights within the rated load limit, } \\
\text { or uniform loads less than 65\% of rated load. }\end{array}$ \\
\hline Heavy & Service that involves operation within the rated load limit which exceeds normal service. \\
\hline Severe & Service that involves normal or heavy service with abnormal operating conditions. \\
\hline
\end{tabular}

\subsubsection{Periodic Inspections}

A complete inspection of lifting devices shall be performed by a qualified inspector at 12-month intervals for normal service, 6-month intervals for heavy service, and 3-month intervals for severe service. Fixtures not in use do not require periodic inspection, but the inspection must be performed before use. Any deficiencies shall be examined and a determination made as to whether they constitute a hazard. These inspections shall include the requirements of Section 10.6.2, "Frequent Inspections," and items such as the following, as applicable:

- loose bolts or fasteners

- $\quad$ cracked or worn gears, pulleys, sheaves, sprockets, bearings, chains, belts, and welds

- $\quad$ excessive wear of linkages and other mechanical parts

- $\quad$ excessive wear at hoist-hooking points and load-support clevises or pins

- $\quad$ marking required

- $\quad$ external evidence of damage to structure, motors, and controls.

\subsubsection{Inspection Records}

Dated inspection reports and records are to be made for each periodic inspection and any time the lifting device requires adjustment or repair. The most recent inspection records shall be retained in an equipment maintenance file by the equipment custodian.

\subsubsection{Repairs}

Any deficiencies disclosed by the inspection shall be corrected before normal operation of the lifting device is resumed.

\subsection{Maintenance}

\subsubsection{Preventive Maintenance}

A preventive maintenance program should be established, if appropriate, and be based on recommendations made by the lifting device manufacturer or designer. 


\subsubsection{Replacement Parts}

Replacement parts shall be at least equivalent to the original specifications.

\subsection{Testing}

\subsubsection{Structural and Mechanical Below-the-Hook Lifting Devices}

Keep dated reports of operational tests, rated load tests, and manufacturers' certification, as applicable, so long as the device is available for use.

- Operational Tests. Operationally test and inspect before initial use all new, altered, modified, or repaired lifting devices to confirm the lifter is suitable for its intended purpose and to ensure compliance with the following functions, as applicable:

- Moving Parts. Test lifters with moving parts to determine that the lifter operates in accordance with the manufacturer's instructions.

- Latches. Test lifters with manually operated or automatic latches to determine that the latch operates in accordance with the manufacturer's instructions.

- Markings. Determine that the lifter is properly marked.

- Welding. Determine that welding had been satisfactorily performed.

- Nondestructive Testing. NDE of welds is required by controlling documents (example ANSI/AWS D14.1, Specification for Welding of Industrial and Mill Cranes and Other Material Handling Equipment, the fabrication specification, contract, or purchase order). Determine that NDE and weld repair, if necessary, are complete.

Note: In accordance with ANSI/AWS D14.1, Specification for Welding of Industrial and Mill Cranes and Other Material Handling Equipment, all welds shall be visually examined. In addition, Joint Class I and Joint Class II weld joints, as defined in ANSI/AWS D14.1, Section 4, "Weld Joint Design," require either radiographic or ultrasonic examination and magnetic particle examination as required by ANSI/AWS D14.1, Section 8, "Weld Quality and Inspection.” Except for visual inspection, nondestructive examination of weld joints other than Joint Class I or II, when required by the specification, shall be announced in the information furnished to bidders. The information provided should designate the inspection process to be used, the welds to be examined, and the extent of examination for each weld. Such nondestructive examination shall be conducted in conformance to the requirements of ANSI/AWS D14.1, or as modified by mutual agreement between the manufacturer and purchaser.

- Guarding. When guards are required, determine that guards are secure and properly installed.

- Electrical. If applicable, determine that electrical equipment is properly installed and in good working order.

- Rated Load Test. Before initial use, load test and inspect all new, altered, modified, or repaired lifting devices unless the Manufacturer's Certification In Lieu of Rated Load Test applies (see below). Rated load tests shall be done under the direction of a qualified person. A written report 
furnished by such person confirms the load rating of the lifter. The load rating should not be more than $80 \%$ of the maximum load sustained during the test. Test loads shall not be more than $125 \%$ of the rated load unless otherwise recommended be the manufacturer.

- The rated load test includes the following operations as a minimum:

- Hoist the test load a sufficient distance to ensure that the load is supported by the lifter, or apply the required load if the test is made using a testing machine.

- After the test load is released, visually inspect the lifter for deformation, cracks, or other defects.

○ If a lifter fails a load test, it shall be repaired and retested before initial use.

- Prepare a test report that identifies the device by serial number, drawing number, or other unique identifier and includes: name and title of person directing the test, date of test, and the test load.

- The rated load test may be done by one of the following:

$\circ$ the manufacturer

$\circ$ a third-party testing company

$\circ \quad$ under the direction of the using organization.

- Manufacturer's Certification In Lieu of Rated Load Test. At the option of the using organization, a manufacturer's certification may be used in lieu of a rated load test only if all the following criteria apply:

- The lifter is manufactured by a reputable manufacturer that customarily manufactures structural and/or mechanical lift devices.

- The lifter is a standard ready-made item in the manufacturer's normal inventory. (One-of-akind items shall be load tested.)

- The manufacturer furnishes a written statement, signed and stamped by a registered professional engineer, certifying that:

- The lifter is designed to withstand the forces imposed by its rated load, with a minimum design factor of three, based on yield strength, for load-bearing structural components, and

○ The lifter fully complies with ASME B30.20, Below-The-Hook Lifting Devices.

- The lifter passes operational tests.

\subsubsection{Vacuum Devices}

Before initial use, test all new, modified, or extensively repaired vacuum below-the-hook lifting devices under the direction of a qualified person in accordance with ASME B30.20-2.3.4, "Testing." Keep reports of operational tests and the rated load test so long as the device is available for use. 


\subsubsection{Close Proximity Operated Magnets}

Before initial use, test all new, modified, or extensively repaired close proximity operated lifting magnets under the direction of a qualified person in accordance with ASME 30.20-3.3.2, “Testing.” Keep dated reports of operational tests and the rated load test so long as the device is available for use.

\subsubsection{Remotely Operated Lifting Magnets}

Before initial use, test all new, modified, or extensively repaired, remotely operated lifting magnets under the direction of a qualified person in accordance with ASME 30.20-4.3.2, “Testing." Keep reports of operational tests and the rated load test so long as the device is available for use.

\subsection{Maintenance Files}

The maintenance file is a compilation of various documents and records relating to operation, maintenance, inspection, testing, evaluating and repair of the lifter. The file may be centrally located or proportioned into satellite holding areas. The methods selected for establishing adequate information retention and retrieval shall be determined by the equipment custodian, who is the responsible person for assuring a safe and reliable maintenance program is in place.

\subsubsection{Intent of Maintenance Files}

The maintenance file shall contain, as a minimum, the required current dated periodic inspection records and other documentation to provide the user with evidence of a safe and reliable maintenance program. Keep dated reports of operational tests and the rated load test so long as the device is available for use. Inspection records should be retained in a format and location that provides for ease in accessibility. Maintenance file information should provide a source for comparing present conditions with past conditions to determine whether existing conditions show a trending pattern of wear, deterioration, or other comparable factors that may compromise safe, continued use of the lifter. Length of record retention shall be determined by the equipment custodian's established maintenance program.

\subsubsection{Maintenance File Contents}

Maintenance files shall contain the following documentation, as applicable:

- operational test reports

- $\quad$ periodic inspection records

- load test reports or manufacturer's certification in lieu of load tests

- documentation of altered, replaced, or repaired load-sustaining parts

- engineering analysis of modifications or re-rating of the lifting device 
- copies of waivers, exemptions, hostile environment plans, or similar documentation applicable to the lifter (to include manufacture's safety bulletins, safety alerts, and product recall information).

Note: Although complete maintenance information for old below-the-hook lifting devices may not be available, the custodian should acquire as much of the pertinent information as possible.

\subsection{Typical Lifting Devices}

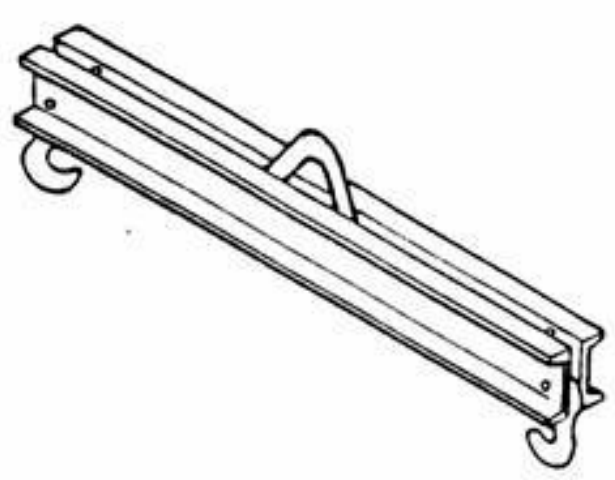

Lifting Beam (Spreader Beam)

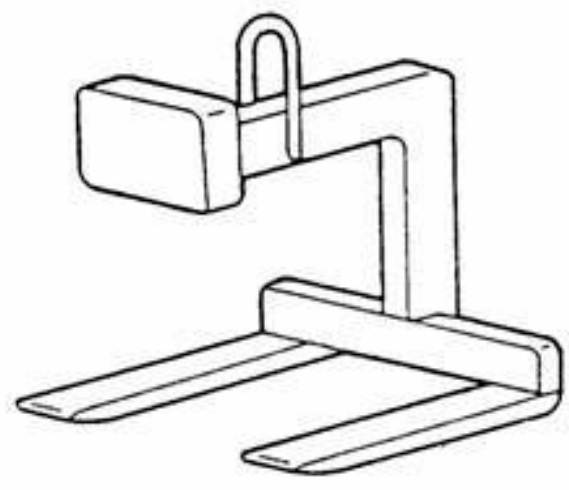

Balanced Pallet Lifter

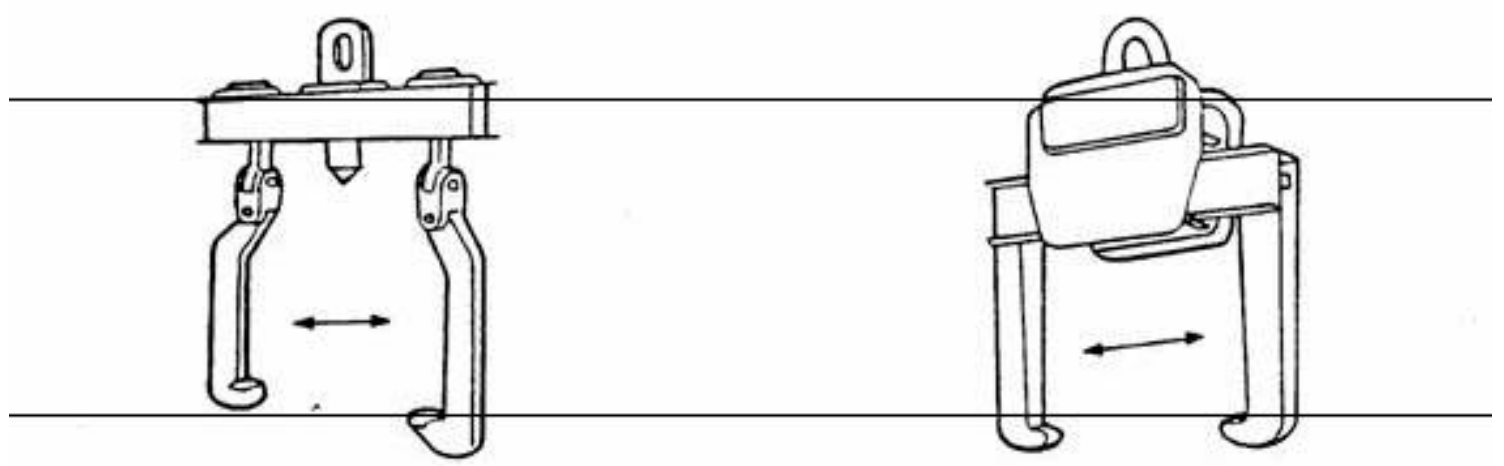

Coil Lifting Hook Beam

Telescoping Coil Grab

Figure 10.1. Load-Supporting Lifters 


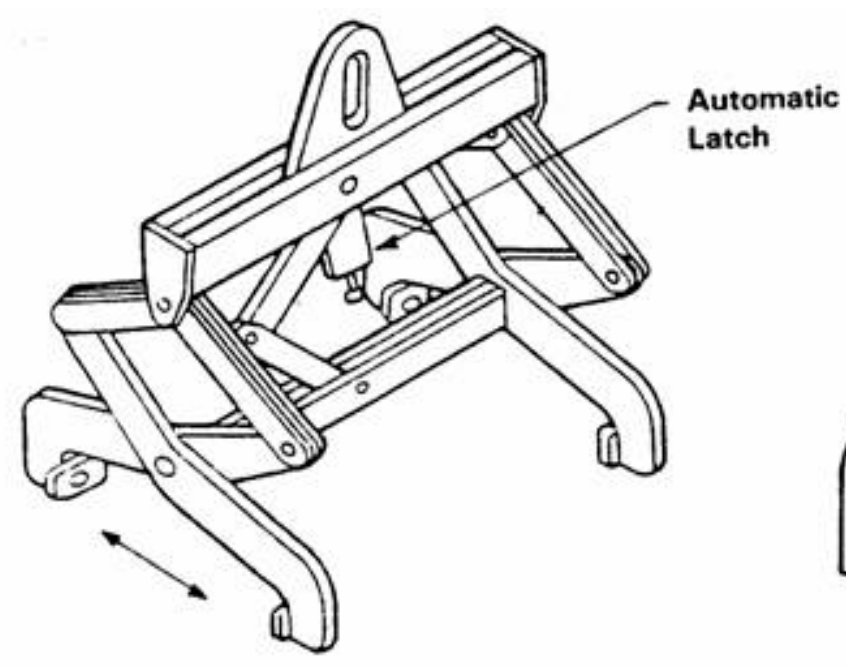

Automatic Slab Tong (Four-Point)

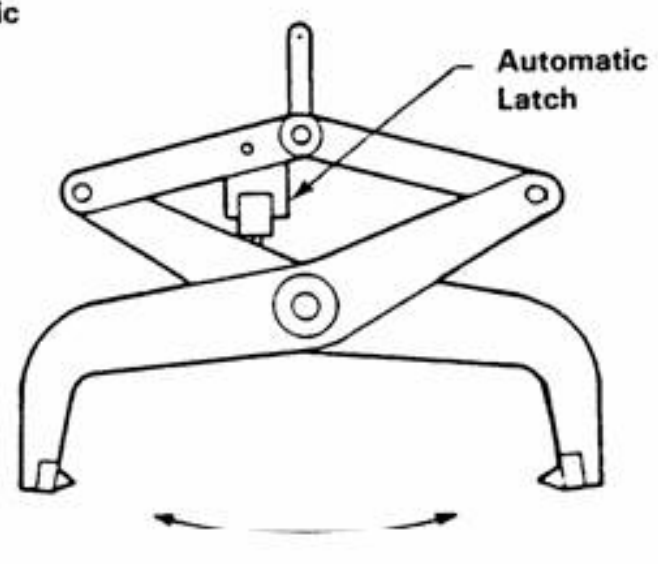

Automatic Ingot Tong

(Two-Point)

$38805-185.2$

Figure 10.2. Indentation-Type Pressure Gripping Lifters 


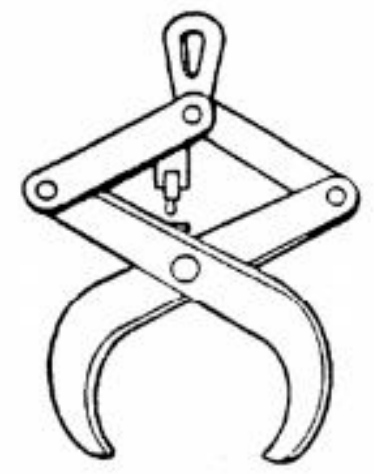

Bar Tong

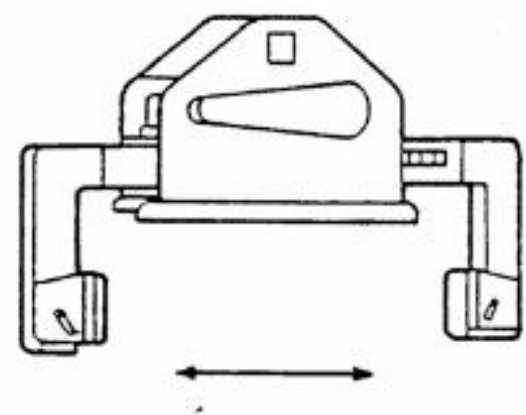

Motor Driven Roll Grab,

End Grip

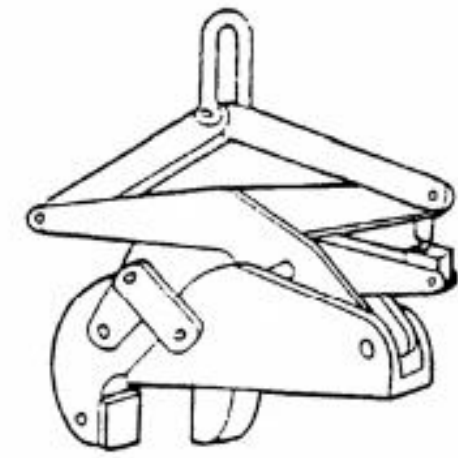

Vertical Axis Coil Grab

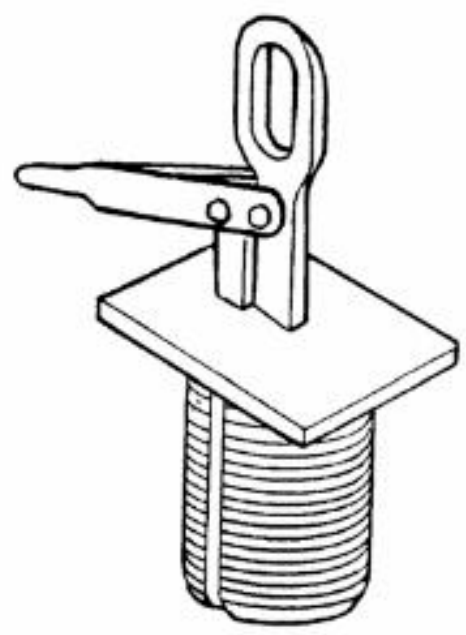

Roll Grab, Core Grip

$38805-185.3$

Figure 10.3. Friction-Type Pressure Gripping Lifters 


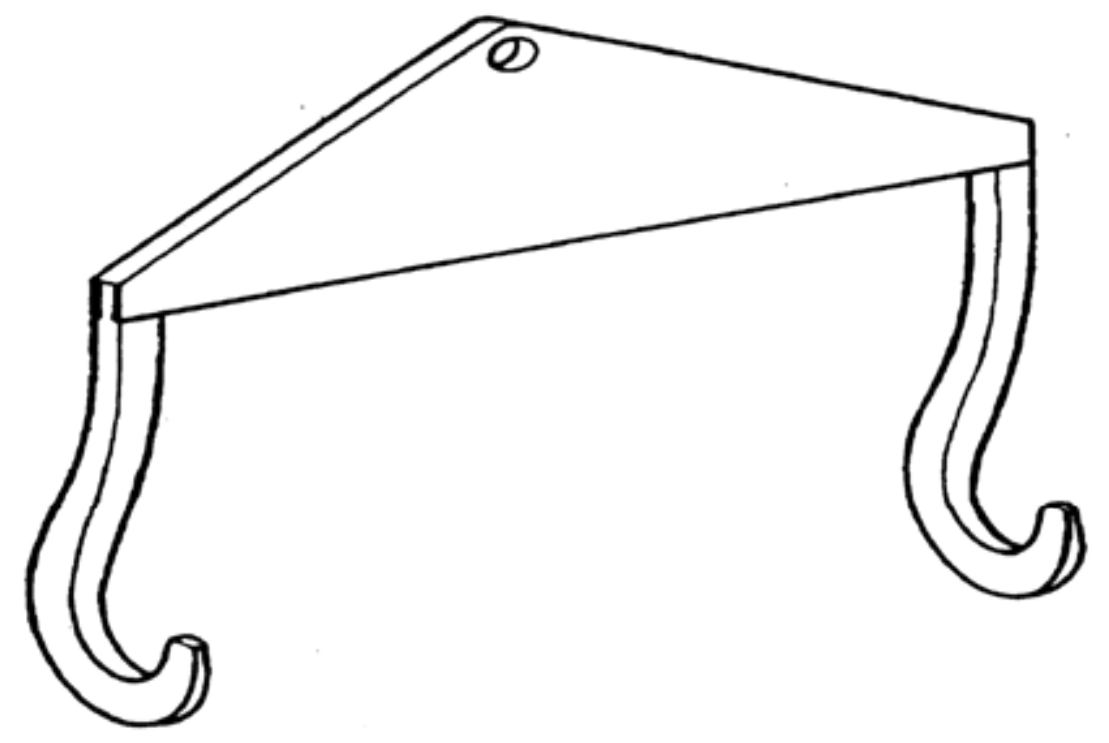

Figure 10.4. Typical Cask Lift Fixture

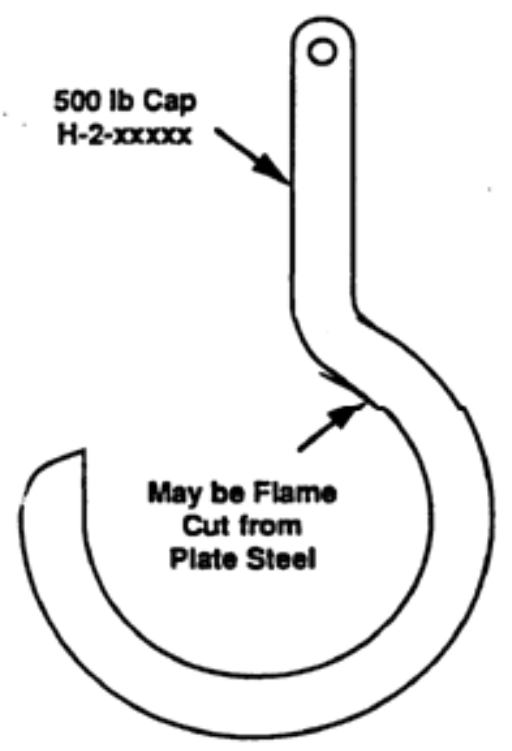

Figure 10.5. Below-the-Hook Lifting Device

Note: The "hook" shown in Figure 10.5 is categorized as a below-the-hook lifting device because of its use, not its shape. This hook may be picked up directly with a hoist hook or may have an intermediate device such as a shackle. 


\subsection{Hoists, Jib Cranes, and Monorail}

\subsection{Scope}

This section applies to the following types of material handling equipment for handling freely suspended (unguided) loads:

- monorail systems

- jib cranes and hoists, including floor- and wall-mounted models

- overhead (underhung) hoists

- manually lever-operated hoists, chain type.

Note: Section 11.16 shows examples of the different equipment types.

This section covers electric-powered, air-powered, and hand-operated equipment. Systems used for transporting personnel and specially insulated hoists used for handling electrically energized power lines require special considerations and are not included.

Note: Wire rope ratchet and pawl lever-operated hoists are not recommended for use in lifting service at PNNL (see Figure 11.1). If wire rope ratchet and pawl lever-operated hoists are used they shall comply with requirements of ASME B30.21.

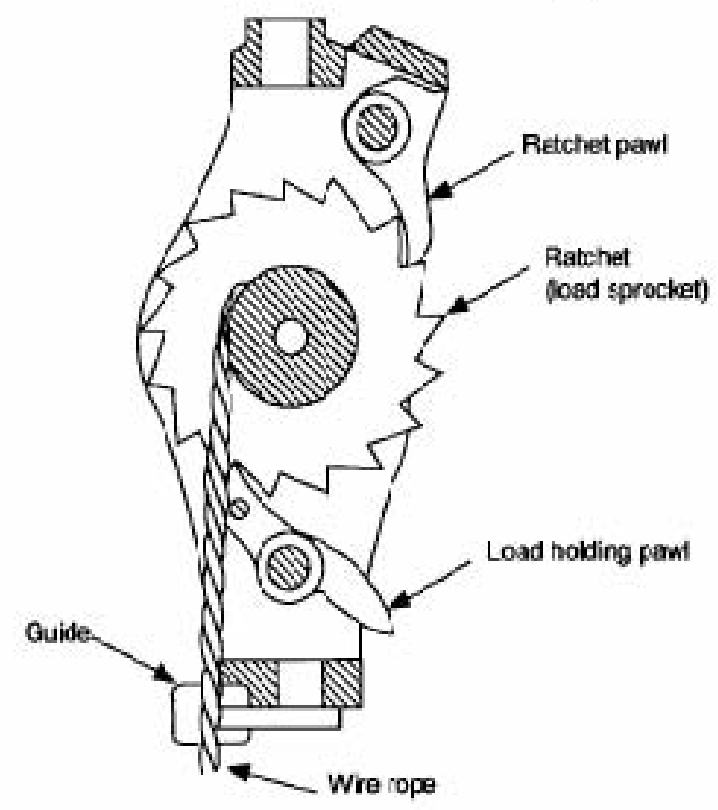

Figure 11.1. Wire Rope Ratchet and Pawl Lever-Operated Hoist 


\subsection{Installation}

Hoists should be installed as recommended by the manufacturer. The supporting structure, including trolleys, monorail, or crane, shall be designed to withstand the loads and forces imposed by the hoist for the rated load. The following rules are applicable to temporarily installed and permanently installed equipment:

- When hoists are used in hazardous locations, modifications to these rules and additional safety requirements may be necessary. If questions arise regarding the classification of an area, contact the responsible safety organization.

- When hoists are used to handle molten material, additional safety requirements may be necessary. (See ANSI Z241.2, Safety Requirements for Melting and Pouring of Metals in the Metalcasting Industry.)

- Pendant controls on electric- or air-powered hoists should be located at a convenient level above the operating floor.

- $\quad$ Proper over-travel limit protection shall be provided as required for the location and operating conditions.

- Polyphase hoist motors shall be connected to the power supply such that hook motion agrees with the control marking. Internal connections in the hoist or pendant station wiring shall not be changed to accomplish this. Phase reversal (motor reversal), if necessary, shall be accomplished by reversing the power leads to the hoist unit.

- $\quad$ Air-powered hoists shall be connected such that hook motion agrees with the control marking.

\subsection{Attaching the Load}

Follow these instructions when attaching the load:

- The hoist rope or chain shall be free from kinks or twists and shall not be wrapped around the load.

- The load shall be attached to the load block or hook by means of slings or other devices. Hook point loading shall be avoided.

- Care shall be taken to ensure that the load and slings clear all obstacles.

\subsection{Moving the Load}

Follow these instructions when moving the load:

- The appointed person directing the lift (designated leader) shall ensure that the load is well secured and properly balanced and positioned in the sling or lifting device before it is lifted more than a few inches (centimeters). 
- Before starting to lift, the following conditions should be noted:

- The load, sling, or lifting device is seated in the bowl of the hook.

- The hoist chain or rope is not kinked.

- Multiple-part lines are not twisted around each other.

- The hook is brought over the load in such a manner as to minimize swinging when the load is lifted.

- The chain or rope is properly seated on the chain sprocket or in the drum grooves and in the sheaves. (Pay special attention to this if there are or have been slack chain or rope conditions.)

- The operator shall inch powered hoists slowly into engagement with a load, but should avoid unnecessary inching and quick reversals of direction.

- During lifting, care shall be taken that:

- No sudden acceleration or deceleration of the moving load occurs.

○ The load does not contact obstructions.

- Hoists shall not be used for side pulls except when specifically authorized by a qualified person who has determined the following:

- The hoist rope or chain will not bear or rub against other members of the crane or hoist, except members specifically designed for such contact

- Such side pulls will not cause the hoist rope to be pulled out of the sheaves or across drum grooves

- Such side pulls will not result in excessive swinging of the load block or load.

$\circ$ The stability of the equipment is not thereby endangered, and that various parts of the equipment will not be overstressed.

CAUTION: Working on or under a suspended load is prohibited, except when the load can be supported by blocking or cribbing, can be securely braced, or can be supported substantially by some other means that would prevent the load from moving

- The operator shall not cause the hoist to lift, lower, or travel while anyone is on the load or hook.

- The operator shall avoid carrying loads over people.

- On rope hoists, the load shall not be lowered below the point where two wraps of rope remain on each anchorage of the hoisting drum, unless a lower limit device is provided, in which case no less than one wrap may remain on each anchorage of the hoist drum. ${ }^{1}$

\footnotetext{
${ }^{1}$ For overhead bridge and gantry cranes (Chapter 12), 29 CFR 1910.179 requires that no fewer than two wraps of rope shall remain on the drum, with or without a lower limit device.
} 
- When two or more hoists are used to lift a load, one appointed person (designated leader) shall be in charge of the operation. This person shall analyze the operation and instruct other personnel involved in the proper positioning and rigging of the load and the movements to be made.

\subsection{General Construction and Installation}

\subsubsection{Marking}

The rated load shall be marked on the hoist or load block. In addition, hoists shall be marked with identification information as follows:

- Hand-chain operated and manually lever-operated hoists:

- manufacturer's name

- manufacturer's model or serial number.

- Electric-powered hoists:

- manufacturer’s name

- manufacturer's model or serial number

- $\quad$ voltage of ac or dc power supply and phase.

- Air-powered hoists:

- manufacturer’s name

- manufacturer's model or serial number

- rated air pressure.

\subsubsection{Warning Labels}

\subsubsection{Hand-Chain Operated Hoists}

A label or labels shall be affixed to the hoist or load block of hand-chain-operated hoists. The label shall display the following information concerning operating procedures:

- The word WARNING or other legend designed to bring the label to the attention of an operator

- Cautionary language against any of the following:

- lifting more than the rated load

- $\quad$ operating the hoist with twisted, kinked, or damaged chain

- operating damaged or malfunctioning hoists

- lifting people or lifting loads over people

- operating hoists with other than manual power. 


\subsubsection{Manually Lever-Operated Chain Hoists}

Lever-operated chain hoists shall have affixed to the hoist or load block, in a readable position, information concerning operating procedures as follows:

- The word WARNING or other legend designed to bring the label to the attention of an operator

- Cautionary language against any of the following:

- lifting more than the rated load

- operating the hoist when it is restricted from forming a straight line with the direction of loading

- $\quad$ operating the hoist with twisted, kinked, or damaged chain

- operating a damaged or malfunctioning hoist

- lifting people or lifting loads over people

- operating a hoist with lever extensions

- removing or obscuring a warning label.

\subsubsection{Electric- or Air-Powered Hoists}

Powered hoists shall have affixed to the hoist, load block, or controls, a label or labels displaying information concerning operating procedures as follows:

- The word WARNING or other legend designed to bring the label to the attention of an operator

- Cautionary language against any of the following:

- lifting more than the rated load

- operating a hoist when load is not centered under hoist

- operating a hoist with twisted, kinked, or damaged chain or rope

- operating a damaged or malfunctioning hoist

- lifting people or lifting loads over people

- operating a rope hoist with a rope that is not properly seated in its groove

- removing or obscuring a warning label.

\subsubsection{Documented Evidence of Equivalent Training}

Documented evidence of equivalent training of the users of the hoist, demonstrating that the information on the warning labels has been conveyed to, and understood by the users, will waive the requirement to maintain the labels. 


\subsubsection{Hand Signal Posting}

Where hand signals are used, figures demonstrating standard hand signals for controlling hoist and crane operations shall be posted conspicuously at the job site.

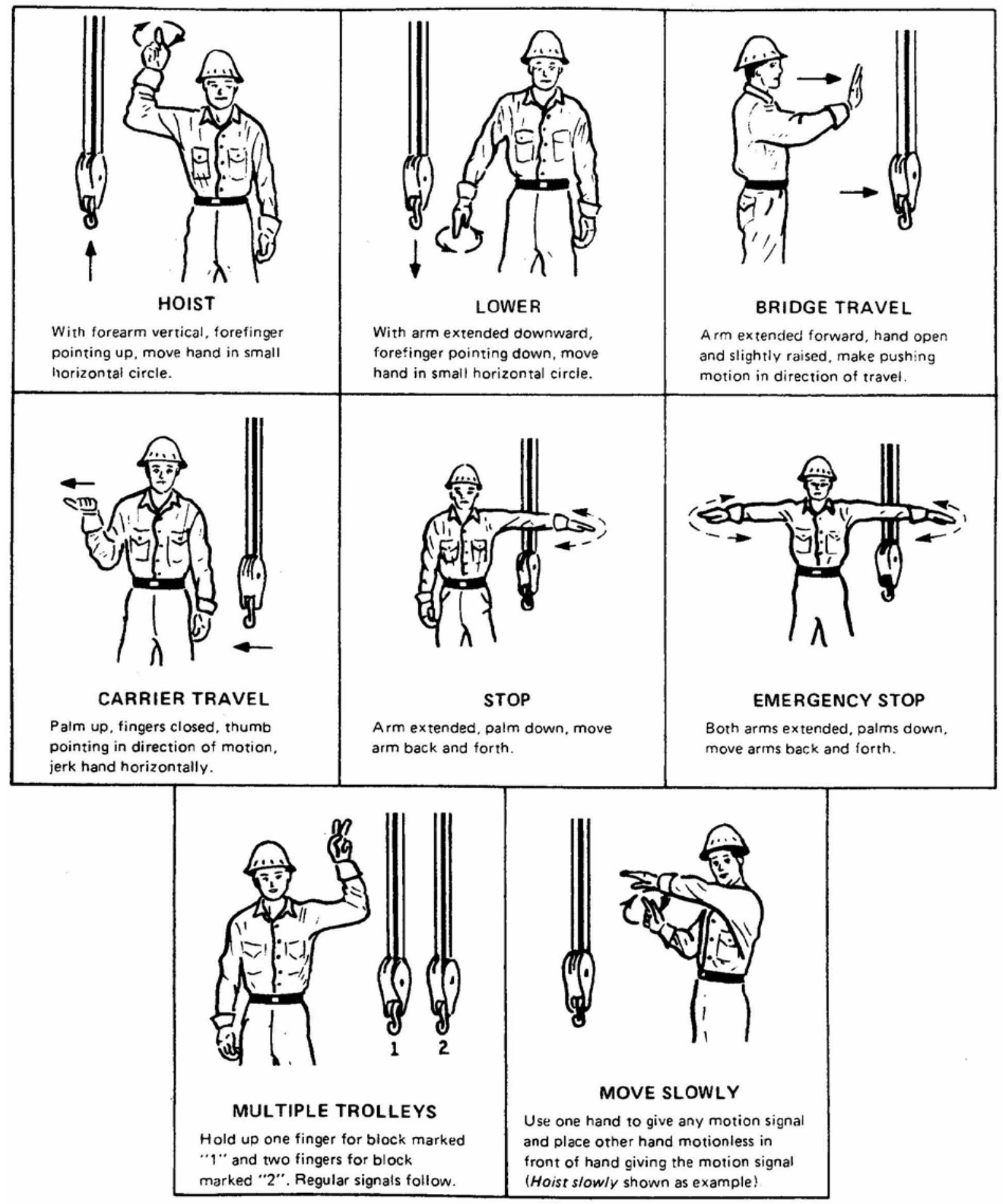

Figure 11.2. Hand Signals 


\subsubsection{Design Factors}

\subsubsection{Hand Chain-Operated Hoists and Manually Lever-Operated Chain Hoists}

Load-sustaining parts are designed so that the static stress, calculated for the rated load, will not exceed $25 \%$ of the average ultimate strength. This requirement is commonly reflected by quoting a minimum design factor of 4 to 1 .

\subsubsection{Electric- or Air-Powered Hoists}

Load-sustaining parts of powered hoists are designed so that static stress calculated for the rated load shall not exceed $20 \%$ of the average ultimate material strength. This requirement is commonly reflected by quoting a minimum design factor of 5 to 1 .

\subsubsection{Monorail Track}

The capacity of monorail track is determined in accordance with ANSI MH 27.1, American National Standard Specification for Underhung Cranes and Monorail Systems. The allowable stress in the lower load-carrying track flange and hanger rods is $20 \%$ of the minimum ultimate strength of the material used. However, because other design elements must be considered, a simple " $\mathrm{X}$ to $\mathrm{Y}$ ” design factor is not specified for monorail track systems.

\subsubsection{Stops and Lugs}

\subsubsection{Stops on Jib Cranes and Monorails}

Stops shall be provided at the ends of carrier travel. Stops or forks shall be provided at open ends of monorail track, track openers, and track switches. Stops shall be an integral part of a movable monorail track to prevent a carrier from running off either end of the movable track when the movable track is not in alignment with the stationary tracks.

\subsubsection{Lugs on Jib Cranes and Monorail Carriers}

Lugs or other means shall be provided to limit the drop of the carrier frame to 1 inch in case of wheel or axle failure, and shall be on both flanges of the track.

\subsubsection{Sheave Guards}

Sheaves carrying ropes, which can be momentarily unloaded, shall be provided with close-fitting guards, or other devices, to guide the rope back into the groove when the load is reapplied. Sheaves in the load block shall be equipped with close-fitting guards that will minimize the possibility of ropes becoming fouled when the load block is lying down with the ropes loose. 


\subsubsection{Over-Travel Protection}

\subsubsection{Lower Limit, Manually Lever-Operated, and Hand Chain-Operated Hoists}

Before the load chain can be completely run out of the hoist, it shall be restrained in its fully extended position. The restraint shall be such that the unloaded hoist can withstand a lowering hand chain or operating lever force equivalent to twice the pull required to lift the rated load, or with the rated load on the hoist, a hand chain or operating lever force equivalent to the pull required to lift the rated load.

\subsubsection{Lower Limit, Electric- or Air-Powered Hoists}

The hoist shall not be installed where, during normal operating conditions, the hook can be lowered beyond rated hook travel unless the hoist is equipped with a lower limit device. Lower limit devices should be provided for hoists where the load block enters pits or hatchways in the floor.

\subsubsection{Upper Limit, Electric- or Air-Powered Hoists}

The hoist shall be so designed and constructed that the load hook, either loaded or empty, shall not exceed the upper limit of travel. In lieu of a limit switch, a mechanism such as a slip clutch may be used.

\subsubsection{Travel Warning Devices}

On cab- and remote-operated carriers, an audible or visual warning means shall be provided, unless it is impossible for personnel to work on the floor below the hoist.

\subsubsection{Load Chain Bucket}

If slack load chain presents a potential hazard to either personnel or equipment below the hoist, a device shall be installed to contain the slack load chain as it emerges from the hoist.

\subsubsection{Throat Latches}

Latch-equipped hooks shall be used for hoisting and rigging operations unless the application makes use of the latch impractical or unsafe. The absence of a hook throat latch is not indiscriminately allowed.

\subsubsection{Monorail System, Clearance at Curves}

Clearances shall be provided and maintained at the curves of a monorail system to allow for the swing of the load when negotiating the curve. The amount of clearance shall be determined by giving due consideration to the size, weight, and speed of the carrier and the radius of the track curve. 


\subsection{Brakes - Load-Controlling Mechanism}

\subsubsection{Manually Lever Operated Hoists - Chain Type}

The hoist shall be equipped with a friction brake that shall perform the following functions under normal operating conditions with test loads of up to $125 \%$ of the rated load.

- $\quad$ Stop and hold the load when the lever force is removed.

- $\quad$ Provide for incremental movement of the load when lifting or lowering.

- $\quad$ Provide for adjustment where necessary to compensate for wear.

\subsubsection{Hand Chain-Operated Hoists}

A hand chain-operated hoist shall be so designed that, when the actuating force is removed, it will automatically stop and hold any test load up to $125 \%$ of the rated load.

\subsubsection{Electric-Powered Hoists}

Under normal operating conditions with a rated load and test conditions with test loads up to $125 \%$ of the rated load, a braking system shall perform the following functions:

- $\quad$ Stop and hold the load when controls are released.

- Limit the speed of the load during lowering, with or without power, to a maximum speed of $120 \%$ of rated lowering speed for the load being handled

- Stop and hold the load in the event of a complete power failure

- $\quad$ Provide for adjustment where necessary to compensate for wear.

\subsubsection{Air-Powered Hoists}

Under normal operating conditions with a rated load and test conditions with test loads up to $125 \%$ of the rated load, a braking system shall perform the following functions:

- $\quad$ Stop and hold the load when controls are released.

- Prevent uncontrolled lowering of the load in the event of a loss of air pressure.

- Provide for adjustment where necessary to compensate for wear. 


\subsubsection{Cab-Operated Monorail}

Cab-operated monorail cranes shall have travel brakes on the carrier. If parking brakes are provided they shall not prohibit the use of a drift point in the control circuit.

\subsubsection{Monorail Carriers (No Cab)}

On carriers, also known as trolleys, travel brakes are not required, provided that, in case of a power failure, the travel motion will stop within a travel distance equal to $10 \%$ of the rated load speed (feet/minute) when traveling at full speed with the rated load. If this requirement cannot be complied with, a brake or noncoasting mechanical drive shall be provided. If parking brakes are provided on the carrier, they shall not prohibit the use of a drift point in the control circuit.

\subsubsection{Jib Crane Carriers}

Travel brakes are not required on jib crane carriers.

\subsection{Electrical Equipment}

\subsubsection{National Electrical Code Compliance}

Wiring and equipment shall comply with NFPA 70, National Electrical Code, Article 610, "Cranes and Hoists." When electric hoists are used in locations other than general indoor applications, control enclosures should be selected in accordance with National Electrical Manufacturers Association (NEMA) ICS-6, Enclosures for Industrial Control and Systems.

\subsubsection{Pendant Controls}

The following are the requirements for pendant controls.

- Pushbutton Station. A pendant pushbutton station shall be supported so that the electrical conductors are protected from strain.

- Pendant Construction. Makeshift field-fabricated pendants shall not be used. The voltage at pendant push-buttons shall not exceed 150 volts for AC and 300 volts for DC. Pendant control boxes shall be constructed to prevent electrical shock.

- Spring Return and Marked Pushbuttons. Pushbuttons (except on/off buttons) shall springreturn to the off position when pressure is released by the operator. Buttons shall be clearly marked to identify their function.

- Resultant Motion. To the extent possible, each control shall be marked to indicate the direction of resultant motion. 


\subsubsection{Electrical Supply, Hoist, and Monorail Systems}

The electrical supply for hoists and monorail systems shall be controlled by a lockable switch or circuit breaker located on a fixed structure accessible from the floor. For temporarily installed hoists, a standard electrical connection (plug) that can be readily disconnected by the operator meets this requirement.

\subsubsection{Monorail Conductors}

Monorail conductors shall be guarded or located to minimize inadvertent contact with the conductor.

\subsection{Modifications}

\subsubsection{Monorail Systems}

A monorail system may be modified or re-rated, provided such modifications and the supporting structure are analyzed by a qualified person or the manufacturer of the equipment. A re-rated system or one whose load-supporting components have been modified shall be subjected to a load test. The new rated load shall be displayed in accordance with Section 1.5.1, "Marking."

\subsubsection{Manual- or Power-Operated Hoists}

Modifications to upgrade, re-rate, or modernize hoist equipment shall be authorized only by the original equipment manufacturer or a qualified person. The new rated load shall be displayed in accordance with Section 11.5.1, “Marking.” Also see Section 11.14.2, “Load Test,” regarding load test requirements.

\subsubsection{Documentation for Modifications}

Documentation supporting re-rating and modifications shall be retrievable and readily available to authorized personnel.

\subsection{Inspection}

Any hazardous conditions disclosed by inspection shall be corrected before use of the hoist or monorail system is resumed. Inspection requirements should be derived from information provided by the equipment manufacturer. Unless there is justification to do otherwise, the manufacturer's recommendations shall be followed. Inspection procedures should state the acceptance criteria for inspections and tests and shall be specific for the applicable make and model of equipment.

\subsubsection{Initial Inspection}

Before initial use, new, altered, modified, or extensively repaired hoists and monorail systems shall be inspected by a designated person to ensure compliance with the applicable ASME B30 standard. 
- B30.11, "Monorails and Underhung Cranes”

- B30.16, “Overhead Hoists (Underhung)”

- B30.21, “Manually Lever Operated Hoists.”

\subsubsection{Pre-Use Inspection}

During each shift, before operating the hoist or monorail system, the operator shall perform a pre- use inspection. Management shall be notified of deficiencies. Deficiencies shall be carefully examined and a determination made as to whether they constitute a hazard. Pre-use inspection shall include the following operations:

- Test all controls. If any controls do not operate properly, they should be adjusted or repaired before operations begin.

- Unless the hoist has a slip clutch in lieu of an upper limit switch, verify operation of the primary upper-limit device. The trip-setting of the primary upper-limit switch shall be checked under noload conditions by inching the block into the limit or running at slow speed. Unless recommended by the manufacturer, he pre-use inspection does not test a slip clutch limit device

- Visually inspect all ropes and load chains. These visual observations should be concerned with discovering gross damage that may be a hazard.

- Carefully scan the hoist for deficiencies that may occur between regular inspections.

- Check that motions are smooth and regular with no hesitations, vibration, binding, unusual noise, or other irregularity.

- Ensure inspections (wire rope, chain, crane or hoist) are current via inspection sticker, other documentation or verbal confirmation from equipment custodian.

\subsubsection{Inspection Classification}

Inspection of hoists and monorail systems in regular service is divided into two general classifications based on the intervals at which inspection should be performed. The intervals, in turn, depend on the nature of the equipment's exposure to wear, deterioration, or malfunction. The two general classifications are designated as frequent and periodic, with the following respective intervals.

\subsubsection{Frequent Inspection Interval}

Visual examination by the operator, with records not required, as follows:

- $\quad$ normal service - monthly

- $\quad$ heavy service - weekly 
- $\quad$ severe service - daily.

Note: For service definitions, see 15.0Appendix A, “Definitions and Acronyms,” service.

\subsubsection{Periodic Inspection Interval}

Visual inspection by a qualified inspector making records of apparent external conditions to provide the basis for a continuing evaluation, as follows:

- Normal service, equipment in place - annually

- Heavy service, equipment in place unless external conditions indicate that disassembly should be done to permit detailed inspection - semi-annually

- Severe service, equipment in place unless external conditions indicate that disassembly should be done to permit detailed inspection - quarterly.

Note: For service definitions see 15.0Appendix A, “Definitions and Acronyms,” service.

\subsubsection{Frequent Inspection}

Items shall be inspected for defects and damage at intervals. This includes observations during operation for any defects or damage that might appear between periodic inspections. A designated person shall determine whether any defects or damage constitute a hazard that will require more detailed inspection.

\subsubsection{Hoist, Hand Chain-, Electric-, and Air Operated-}

Deficiencies found during the following frequent inspections shall be examined carefully and a determination made as to whether they constitute a hazard:

- Hoist functional operating mechanisms shall be operated and checked for maladjustment and listened to for unusual sounds that may indicate problems.

- The functions of the hoist upper limit device of electric- or air-operated hoists shall be checked without a load on the hook at the beginning of each shift. Care shall be exercised. The load block shall be inched to its limit device or run in at a slow speed. Hoists may have a slip clutch in lieu of an upper limit switch. Unless recommended by the manufacturer, the frequent inspection does not test a slip clutch limit device.

- $\quad$ Lines, valves, and other parts of hoist air systems shall be checked for leakage.

- Hooks and latches shall be checked for deformation, chemical damage, cracks, and wear (see Section 4.0, “Hooks”).

- Hook latches, if used, shall be checked for proper operation. 
- Hoist rope shall be checked in accordance with Section 7.0 "Wire Rope."

- Welded-link hoist load chain shall be checked in accordance with Section 11.11.1, "Welded-Link Chain Inspection.”

- Roller chain shall be checked in accordance with Section 11.12.1, "Roller Chain Inspection.”

- Rope or load chain reeving shall be checked for compliance with recommendations of the hoist manufacturer.

\subsubsection{Jib Cranes and Monorail Systems}

Deficiencies found during the following frequent inspections shall be examined carefully and a determination made as to whether they constitute a hazard:

- Hoist inspection shall be in accordance with Section 11.9.4.1, "Frequent Inspections.”

- All functional monorail and jib crane operating mechanisms shall be checked for maladjustment.

- All tanks, valves, pumps, and other parts of air or hydraulic systems shall be checked for leakage.

\subsubsection{Lever-Operated Hoists, Chain Type}

Deficiencies found during the following frequent inspections shall be carefully examined and a determination made as to whether they constitute a hazard:

- All functional operating mechanisms shall be checked for maladjustment interfering with proper operation.

- Hooks and latches shall be checked for deformation, chemical damage, cracks, and wear (see Section 4.0, “Hooks”).

- Hook latches, if used, shall be checked for proper attachment and operation.

- The welded-link load chain shall be checked in accordance with Section 11.11.1, "Welded-Link Chain Inspection.”

- The load chain reeving shall be checked for compliance with the recommendations of the hoist manufacturer or a qualified person.

- The hoist lever shall be checked for bends, cracks, or other damage.

- The hoist support shall be checked for damage. 


\subsubsection{Periodic Inspection}

Periodic inspection shall be performed at intervals. These inspections may be performed with the hoist in its normal location ${ }^{2}$ and do not require the hoist to be dismantled. Covers and other items normally supplied to allow inspection of components should be opened or removed for these inspections.

\subsubsection{Hoists, Hand Chain-, Electric-, and Air Operated-}

Deficiencies found during the periodic inspections listed in Tables 11.1 and 11.2 shall be carefully examined and determination made as to whether they constitute a hazard or whether complete disassembly is necessary. These inspections shall include the requirements of Section 11.9.4, "Frequent Inspection,” in addition to the following:

- Bolts, nuts, and rivets shall be checked to ensure that they are not loose.

- Load blocks, suspension housings, hand chain wheels, chain attachments, clevises, yokes, suspension bolts, shafts, gears, bearings, pins, rollers, and locking and clamping devices shall be checked for evidence of wear, corrosion, cracks, or distorted parts.

- Hook-retaining nuts or collars and pins and welds or rivets used to secure the retaining members shall be checked for damage.

- Load sprockets, idler sprockets, hand chain wheel, and drums or sheaves shall be checked for evidence of damage or excessive wear.

- Hand chain-operated hoists shall be checked for evidence of worn, glazed, or oil-contaminated friction disks; worn pawls, cams, or ratchets; and corroded, stretched, or broken pawl springs in braking mechanism.

- Electric- or air-powered hoists shall be checked for evidence of excessive wear on motor and load brake.

- The electrical apparatus of electric-powered hoists shall be checked for signs of pitting or any deterioration of visible controller contacts.

- The slip clutch upper limit device, if so equipped, shall be checked in accordance with the manufacturer's recommendations.

- The secondary upper limit switch and the lower limit switch, if the hoist is so equipped, shall be checked.

- The supporting structure or trolley, if used, shall be checked for evidence of damage.

- $\quad$ The presence and legibility of warning labels shall be checked.

\footnotetext{
${ }^{2}$ Inspections cannot be properly performed from the floor or ground level if the hoist is suspended above eye level. The intent is that inspections be performed at hoist level or that the hoist be lowered for inspection.
} 
- End connections on ropes or load chains shall be checked for evidence of wear, corrosion, cracks, damage, or distortion.

- The hoist rope shall be checked in accordance with Section 7.0, "Wire Rope.”

- The welded link hoist chain shall be checked in accordance with Section 11.11.1, "Welded-Link Chain Inspection.”

- The roller chain shall be checked in accordance with Section 11.12.1, "Roller Chain Inspection.”

Table 11.1. Inspection for Hand Chain-Operated Hoists

\begin{tabular}{|c|c|c|c|c|c|c|}
\hline \multirow[b]{2}{*}{ Item } & \multicolumn{2}{|c|}{ Normal service } & \multicolumn{2}{|c|}{ Heavy service } & \multicolumn{2}{|c|}{ Severe service } \\
\hline & $\begin{array}{c}\text { Visual } \\
\text { monthly }\end{array}$ & $\begin{array}{c}\text { Record } \\
\text { yearly }^{(b)}\end{array}$ & $\begin{array}{c}\text { Visual } \\
\text { weekly }\end{array}$ & $\begin{array}{c}\text { Record } \\
\text { semi- } \\
\text { annually }^{(c)}\end{array}$ & $\begin{array}{l}\text { Visual } \\
\text { daily }^{(\text {a) }}\end{array}$ & $\begin{array}{c}\text { Record } \\
\text { quarterly }^{(\mathrm{c})}\end{array}$ \\
\hline \multicolumn{7}{|l|}{ Frequent inspection } \\
\hline $\begin{array}{l}\text { All functional operating } \\
\text { mechanisms for } \\
\text { maladjustment and unusual } \\
\text { sounds }\end{array}$ & $\mathrm{X}$ & & $\mathrm{X}$ & & $\mathrm{x}$ & \\
\hline $\begin{array}{l}\text { Hooks in accordance with } \\
\text { Section } 4\end{array}$ & $\mathrm{X}$ & & $\mathrm{x}$ & & $\mathrm{X}$ & \\
\hline Hook latch operation, if used & $\mathrm{X}$ & & $\mathrm{X}$ & & $\mathrm{X}$ & \\
\hline Load chain1 & $\mathrm{X}$ & & $\mathrm{X}$ & & $\mathrm{x}$ & \\
\hline $\begin{array}{l}\text { Load chain reeving for } \\
\text { compliance with hoist } \\
\text { manufacturer's } \\
\text { recommendations }\end{array}$ & $\mathrm{X}$ & & $\mathrm{x}$ & & $\mathrm{x}$ & \\
\hline \multicolumn{7}{|l|}{ Periodic inspection } \\
\hline $\begin{array}{l}\text { Requirements of frequent } \\
\text { inspection }\end{array}$ & & $\mathrm{x}$ & & $\mathrm{x}$ & & $\mathrm{X}$ \\
\hline $\begin{array}{l}\text { Evidence of loose bolts, nuts, } \\
\text { or rivets }\end{array}$ & & $\mathrm{x}$ & & $\mathrm{X}$ & & $\mathrm{X}$ \\
\hline $\begin{array}{l}\text { Evidence of worn, corroded, } \\
\text { cracked, or distorted parts } \\
\text { such as load blocks, } \\
\text { suspension housing, hand } \\
\text { chain wheels, chain } \\
\text { attachments, clevises, yokes, } \\
\text { suspension bolts, shafts, gears, } \\
\text { bearings, pins, rollers, and } \\
\text { locking and clamping devices }\end{array}$ & & $\mathrm{x}$ & & $\mathrm{X}$ & & $\mathrm{X}$ \\
\hline
\end{tabular}




\begin{tabular}{|l|c|c|c|c|c||}
\hline $\begin{array}{l}\text { Evidence of damage to hook } \\
\text { retaining nuts or collars and } \\
\text { pins, and welds or rivets used } \\
\text { to secure the retaining } \\
\text { members }\end{array}$ & & $\mathrm{X}$ & & $\mathrm{X}$ & $\mathrm{X}$ \\
\hline $\begin{array}{l}\text { Evidence of damage or } \\
\text { excessive wear of load } \\
\text { sprockets, idler sprockets, or } \\
\text { hand chain wheel }\end{array}$ & $\mathrm{X}$ & & $\mathrm{X}$ & $\mathrm{X}$ \\
\hline $\begin{array}{l}\text { Evidence of worn, glazed, or } \\
\text { oil-contaminated friction } \\
\text { discs; worn pawls, cams, or } \\
\text { ratchet; corroded, stretched, or } \\
\text { broken pawl springs in brake } \\
\text { mechanism }\end{array}$ & & $\mathrm{X}$ & & $\mathrm{X}$ & \\
\hline $\begin{array}{l}\text { Evidence of damage to the } \\
\text { supporting structure or trolley, } \\
\text { if used }\end{array}$ & & $\mathrm{X}$ & & $\mathrm{X}$ & $\mathrm{X}$ \\
\hline $\begin{array}{l}\text { Evidence of worn, glazed, or } \\
\text { oil-contaminated friction } \\
\text { discs; worn pawls, cams, or } \\
\text { ratchet; corroded, stretched, or } \\
\text { broken pawl springs in brake } \\
\text { mechanism }\end{array}$ & & $\mathrm{X}$ & & $\mathrm{X}$ & $\mathrm{X}$ \\
\hline $\begin{array}{l}\text { Warning label required by } \\
\text { Section 11.4.2.1, except as } \\
\text { provided in Section 11.4.2.4 }\end{array}$ & & & & $\mathrm{X}$ & $\mathrm{X}$ \\
\hline $\begin{array}{l}\text { End connections of load chain } \\
\text { (a) By operator or other designated personnel with records not required. } \\
\text { (c) As in (b), unless conditions indicate that disassembly should be done to permit detailed inspection. }\end{array}$ & & & \\
\hline \hline
\end{tabular}


Table 11.2. Inspection for Electric- or Air-Powered Hoists

\begin{tabular}{|c|c|c|c|c|c|c|}
\hline \multirow[b]{2}{*}{ Item } & \multicolumn{2}{|c|}{ Normal service } & \multicolumn{2}{|c|}{ Heavy service } & \multicolumn{2}{|c|}{ Severe service } \\
\hline & $\begin{array}{c}\text { Visual } \\
\text { monthly }\end{array}$ & $\begin{array}{l}\text { Record } \\
\text { yearly }{ }^{(b)}\end{array}$ & $\begin{array}{c}\text { Visual } \\
\text { weekly }\end{array}$ & $\begin{array}{c}\text { Record } \\
\text { semiannually }{ }^{(\mathrm{c})}\end{array}$ & $\begin{array}{l}\text { Visual } \\
\text { daily }^{\text {(a) }}\end{array}$ & $\begin{array}{c}\text { Record } \\
\text { quarterly }\end{array}$ \\
\hline \multicolumn{7}{|l|}{ Frequent inspection } \\
\hline $\begin{array}{l}\text { All functional operating } \\
\text { mechanisms for maladjustment } \\
\text { and unusual sounds }\end{array}$ & $\mathrm{X}$ & & $\mathrm{x}$ & & $\mathrm{X}$ & \\
\hline Limit devices for operation & $\mathrm{X}$ & & $\mathrm{X}$ & & $\mathrm{X}$ & \\
\hline $\begin{array}{l}\text { Air lines, valves, and other } \\
\text { parts for leakage }\end{array}$ & $\mathrm{X}$ & & $\mathrm{X}$ & & $\mathrm{x}$ & \\
\hline $\begin{array}{l}\text { Hooks in accordance with } \\
\text { Section } 4\end{array}$ & $\mathrm{X}$ & & $\mathrm{x}$ & & $\mathrm{x}$ & \\
\hline Hook latch operation, if used & $\mathrm{X}$ & & $\mathrm{x}$ & & $\mathrm{X}$ & \\
\hline Hoist rope & $\mathrm{X}$ & & $\mathrm{X}$ & & $\mathrm{X}$ & \\
\hline Load chain & $\mathrm{X}$ & & $\mathrm{x}$ & & $\mathrm{X}$ & \\
\hline $\begin{array}{l}\text { Rope or load chain reeving for } \\
\text { compliance with hoist } \\
\text { manufacturer's } \\
\text { recommendations }\end{array}$ & $\mathrm{X}$ & & $\mathrm{X}$ & & $\mathrm{X}$ & \\
\hline \multicolumn{7}{|l|}{ Periodic inspection } \\
\hline $\begin{array}{l}\text { Requirements of frequent } \\
\text { inspection }\end{array}$ & & $\mathrm{x}$ & & $\mathrm{X}$ & & $\mathrm{X}$ \\
\hline Hoist rope & & $\mathrm{X}$ & & $\mathrm{X}$ & & $\mathrm{x}$ \\
\hline $\begin{array}{l}\text { Evidence of loose bolts, nuts, } \\
\text { or rivets }\end{array}$ & & $\mathrm{X}$ & & $\mathrm{X}$ & & $\mathrm{X}$ \\
\hline $\begin{array}{l}\text { Evidence of worn, corroded, } \\
\text { cracked, or distorted parts such } \\
\text { as load blocks, suspension } \\
\text { housing, chain attachments, } \\
\text { clevises, yokes, suspension } \\
\text { bolts, shafts, gears, bearings, } \\
\text { pins, rollers, and locking and } \\
\text { clamping devices }\end{array}$ & & $\mathrm{X}$ & & $\mathrm{X}$ & & $\mathrm{X}$ \\
\hline $\begin{array}{l}\text { Evidence of damage to hook } \\
\text { retaining nuts or collars and } \\
\text { pins, and welds or rivets used } \\
\text { to secure the retaining } \\
\text { members }\end{array}$ & & $\mathrm{X}$ & & $\mathrm{X}$ & & $\mathrm{X}$ \\
\hline
\end{tabular}




\begin{tabular}{|c|c|c|c|}
\hline $\begin{array}{l}\text { Requirements of frequent } \\
\text { inspection }\end{array}$ & $\mathrm{X}$ & $\mathrm{X}$ & $\mathrm{X}$ \\
\hline Hoist rope & $\mathrm{X}$ & $\mathrm{X}$ & $\mathrm{X}$ \\
\hline $\begin{array}{l}\text { Evidence of loose bolts, nuts, } \\
\text { or rivets }\end{array}$ & $\mathrm{X}$ & $\mathrm{x}$ & $\mathrm{X}$ \\
\hline $\begin{array}{l}\text { Evidence of worn, corroded, } \\
\text { cracked, or distorted parts such } \\
\text { as load blocks, suspension } \\
\text { housing, chain attachments, } \\
\text { clevises, yokes, suspension } \\
\text { bolts, shafts, gears, bearings, } \\
\text { pins, rollers, and locking and } \\
\text { clamping devices }\end{array}$ & $\mathrm{X}$ & $\mathrm{X}$ & $\mathrm{X}$ \\
\hline $\begin{array}{l}\text { Evidence of damage to hook } \\
\text { retaining nuts or collars and } \\
\text { pins, and welds or rivets used } \\
\text { to secure the retaining } \\
\text { members }\end{array}$ & $\mathrm{X}$ & $\mathrm{X}$ & $\mathrm{X}$ \\
\hline $\begin{array}{l}\text { Evidence of damage or } \\
\text { excessive wear of load } \\
\text { sprockets, idler sprockets, and } \\
\text { drums or sheaves }\end{array}$ & $\mathrm{x}$ & $\mathrm{x}$ & $X$ \\
\hline $\begin{array}{l}\text { Evidence of excessive wear on } \\
\text { motor or load brake }\end{array}$ & $\mathrm{X}$ & $\mathrm{x}$ & $X$ \\
\hline $\begin{array}{l}\text { Electrical apparatus for signs } \\
\text { of pitting or any deterioration } \\
\text { of visible controller contacts }\end{array}$ & $\mathrm{X}$ & $\mathrm{X}$ & $X$ \\
\hline $\begin{array}{l}\text { Evidence of damage to the } \\
\text { supporting structure or trolley, } \\
\text { if used }\end{array}$ & $\mathrm{X}$ & $\mathrm{x}$ & $X$ \\
\hline $\begin{array}{l}\text { Warning label required by } \\
\text { Section 11.4.2.3, except as } \\
\text { provided in Section 11.4.2.4 }\end{array}$ & $\mathrm{X}$ & $\mathrm{x}$ & $X$ \\
\hline End connections of load chain & $\mathrm{X}$ & $\mathrm{X}$ & $X$ \\
\hline \multicolumn{4}{|c|}{$\begin{array}{l}\text { (a) By operator or other designated personnel with records not required. } \\
\text { (b) Visual inspection by a qualified inspector making records of conditions to provide the basis for a continuing } \\
\text { evaluation. } \\
\text { (c) As in (b), unless conditions indicate that disassembly should be done to permit detailed inspection. }\end{array}$} \\
\hline
\end{tabular}

\subsubsection{Jib Cranes and Monorail Systems}

Deficiencies found during the following periodic inspections of jib cranes and monorail systems shall be carefully examined and a determination made as to whether they constitute a hazard or whether 
complete disassembly is necessary. These inspections shall include the requirements of Section 11.9.4.2, "Jib Crane and Monorail Systems," in addition to the following:

- The hoist inspection shall be in accordance with Section 11.9.4.1, "Hoists, Hand Chain-, Electric, and Air Operated-.”

- Members shall be checked for deformation, cracks, and corrosion.

- Bolts, nuts, and rivets shall be checked to ensure that they are not loose.

- $\quad$ Pins, bearings, wheels, shafts, gears, rollers, locking and clamping devices, bumpers, switch baffles, interlock bolts, and stops shall be checked for wear, cracks, or distortion.

- $\quad$ Travel or parking brake system parts shall be checked for excessive wear.

- Carrier (trolley) chain drive sprockets shall be checked for excessive wear and excessive chain stretch.

- Electrical components such as, but not limited to, controllers, master switches, contacts, limit switches, and push-button stations shall be checked for deterioration.

- Drive tires shall be checked for excessive wear.

- The lower load-carrying flange of all track sections in the system, both straight and curved, shall be checked for excessive wear or deformation.

\subsubsection{Lever-Operated Hoists, Chain Type}

Deficiencies found during the periodic inspections listed in Table 11.3 shall be carefully examined and a determination made as to whether they constitute a hazard or whether complete disassembly is necessary. These inspections shall include the requirements of Section 11.9.4.3, "Lever-Operated Hoists, Chain Type," in addition to the following:

- Bolts, nuts, and rivets shall be checked to ensure that they are not loose.

- Load blocks, suspension housings, hand chain wheels, chain attachments, clevises, yokes, suspension bolts, shafts, gears, bearings, pins, rollers, and locking and clamping devices shall be checked for evidence of wear, corrosion, cracks, or distorted parts.

- Hook-retaining nuts or collars and pins and welds or rivets used to secure the retaining members shall be checked for damage.

- Load sprockets or idler sprockets shall be checked for damage or excessive wear.

- The brake mechanism shall be checked for worn, glazed, or oil-contaminated friction disks. 
- The presence and legibility of warning labels shall be checked as required by Section 11.9.4.3, “Lever-Operated Hoists, Chain Type,” except as provided by Section 11.5.2.4, “Documented Evidence of Equivalent Training.”

- End connections of load chains, including over-travel restraints, shall be checked for deterioration.

Table 11.3. Minimum Inspection for Lever-Operated Hoists - Chain Type

\begin{tabular}{|c|c|c|c|c|c|c|}
\hline \multirow[b]{2}{*}{ Item } & \multicolumn{2}{|c|}{ Normal service } & \multicolumn{2}{|c|}{ Heavy service } & \multicolumn{2}{|c|}{ Severe service } \\
\hline & $\begin{array}{c}\text { Visual } \\
\text { monthly (a) }\end{array}$ & $\begin{array}{l}\text { Record } \\
\text { yearly }\end{array}$ & $\begin{array}{c}\text { Visual } \\
\text { weekly to } \\
\text { monthly }\end{array}$ & $\begin{array}{c}\text { Record } \\
\text { semiannually } \\
(\mathrm{c})\end{array}$ & $\begin{array}{c}\text { Visual } \\
\text { daily to } \\
\text { weekly }\end{array}$ & $\begin{array}{c}\text { Record } \\
\text { quarterly }^{(\mathrm{c})}\end{array}$ \\
\hline \multicolumn{7}{|l|}{ Frequent inspection } \\
\hline $\begin{array}{l}\text { All functional mechanisms } \\
\text { for maladjustment } \\
\text { interfering with proper } \\
\text { operaton }\end{array}$ & $\mathrm{X}$ & & $\mathrm{X}$ & & $\mathrm{X}$ & \\
\hline Hoist support for damage & $\mathrm{X}$ & & $\mathrm{X}$ & & $\mathrm{X}$ & \\
\hline $\begin{array}{l}\text { Hooks and latches for } \\
\text { deformation, chemical } \\
\text { damage, cracks, and wear } \\
\text { (See Section 4) }\end{array}$ & $\mathrm{X}$ & & $\mathrm{X}$ & & $\mathrm{X}$ & \\
\hline Hook latch operation, if used & $\mathrm{X}$ & & $\mathrm{X}$ & & $\mathrm{X}$ & \\
\hline Load chain & $\mathrm{X}$ & & $\mathrm{X}$ & & $\mathrm{X}$ & \\
\hline $\begin{array}{l}\text { Load chain reeving for } \\
\text { compliance with the } \\
\text { recommendations of the } \\
\text { hoist manufacturer or a } \\
\text { qualified person }\end{array}$ & $\mathrm{X}$ & & $\mathrm{X}$ & & $\mathrm{X}$ & \\
\hline $\begin{array}{l}\text { Lever for problems such as } \\
\text { bends or cracks }\end{array}$ & $\mathrm{X}$ & & $\mathrm{X}$ & & $\mathrm{X}$ & \\
\hline \multicolumn{7}{|l|}{ Periodic inspection } \\
\hline $\begin{array}{l}\text { Requirements of frequent } \\
\text { inspection }\end{array}$ & & $\mathrm{X}$ & & $\mathrm{X}$ & & $\mathrm{X}$ \\
\hline $\begin{array}{l}\text { Evidence of loose bolts, } \\
\text { nuts, or rivets }\end{array}$ & & $\mathrm{X}$ & & $\mathrm{X}$ & & $\mathrm{X}$ \\
\hline
\end{tabular}




\begin{tabular}{|l|c|c|c|c|c||}
\hline $\begin{array}{l}\text { Evidence of worn, corroded, } \\
\text { cracked, or distorted parts } \\
\text { such as load blocks, } \\
\text { suspension housing, chain } \\
\text { attachments, clevises, yokes, } \\
\text { suspension bolts, shafts, } \\
\text { gears, bearings, pins, rollers, } \\
\text { and locking and clamping } \\
\text { devices }\end{array}$ & & $\mathrm{X}$ & & $\mathrm{X}$ & $\mathrm{X}$ \\
\hline $\begin{array}{l}\text { Evidence of damage to hook } \\
\text { retaining nuts or collars and } \\
\text { pins, and welds or rivets } \\
\text { used to secure the retaining } \\
\text { members }\end{array}$ & & $\mathrm{X}$ & & $\mathrm{X}$ & $\mathrm{X}$ \\
\hline $\begin{array}{l}\text { Evidence of damage or } \\
\text { excessive wear of load } \\
\text { sprockets or idler sprockets }\end{array}$ & & $\mathrm{X}$ & & $\mathrm{X}$ & $\mathrm{X}$ \\
\hline $\begin{array}{l}\text { Evidence of worn, glazed, or } \\
\text { oil-contaminated friction } \\
\text { disks; worn pawls, cams, or } \\
\text { ratchet; corroded, stretched, } \\
\text { or broken pawl springs in } \\
\text { brake mechanism }\end{array}$ & & $\mathrm{X}$ & & $\mathrm{X}$ & $\mathrm{X}$ \\
\hline $\begin{array}{l}\text { End connections of load } \\
\text { chain, including over-travel } \\
\text { restraints }\end{array}$ & & & & & \\
\hline $\begin{array}{l}\text { (a) By operator or other designated personnel with records not required. } \\
\text { (b) Visual inspection by a qualified inspector making records of conditions to provide the basis for a continuing } \\
\text { evaluation. } \\
\text { (c) As in (b), unless conditions indicate that disassembly should be done to permit detailed inspection. }\end{array}$ & & \\
\hline
\end{tabular}

\subsubsection{Inspection of Equipment Not in Regular Use}

- Equipment, other than standby equipment, that has been idle for a period of one month or more, but less than one year, shall be given an inspection equal to a Frequent Inspection before being placed in service.

- Equipment, other than standby equipment, that has been idle for a period of one year or more shall be given an inspection equal to a Periodic Inspection and an operating test before it is placed in service.

- Equipment that is used for standby service shall receive a Periodic Inspection and an operating test no less than annually. Standby equipment exposed to adverse environmental conditions shall be inspected and tested more frequently as determined by the responsible maintenance organization. 


\subsubsection{Hook Inspection}

Hooks shall be inspected in conjunction with the frequent and periodic hoist inspection. See Section 4.0, “Hooks," for hook inspection requirements.

\subsubsection{Third-Party Inspection}

A third-party crane/hoist inspection program is optional at the discretion of the Hanford Site contractor.

\subsubsection{Inspection Records}

Inspection records shall be kept for the life of the equipment. Following is a summary of inspection record requirements.

- Initial Inspection. A record of the initial inspection shall be made.

- Pre-use and Frequent Inspection. No records retention is required.

- Periodic Inspection. The most recent records, dated and signed by a qualified inspector, shall be retained in the maintenance file.

\subsection{Wire Rope Inspection, Replacement, and Maintenance}

See Section 7.0, “Wire Rope,” for rope inspection, replacement, and maintenance requirements.

\subsection{Welded-Link Chain Inspection, Replacement, and Maintenance}

\subsubsection{Welded-Link Chain Inspection}

Inspection information for welded-link chain is provided below:

- The hoist shall be tested under load in lifting and lowering directions and the operation of the chain and sprockets shall be observed. The chain should feed smoothly into and away from the sprockets.

- If the chain binds, jumps, or is noisy, it shall first be checked to ensure that it is clean and properly lubricated. If the trouble persists, the chain and mating parts shall be inspected for wear, distortion, or other damage.

- The chain shall be examined visually for gouges, nicks, weld spatter, corrosion, and distorted links. The chain shall then be slackened and the adjacent links moved to one side to inspect for wear at the contact points. If wear is observed or if stretching is suspected, the chain should be measured according to the hoist manufacturer's instructions. If instructions are not available, the process shall continue as follows. 
- An unworn, unstretched length of the chain shall be selected (e.g., at the slack end).

- The chain shall be suspended vertically under tension and, using a caliper-type gauge, the outside length of any convenient number of links shall be measured (approximately 12 to 24 inches overall).

- The same number of links in the used sections shall be measured and the percentage increase in length shall be calculated.

\subsubsection{Welded Link Chain Replacement}

Follow these instructions when replacing a welded link chain:

- If the used chain exceeds the hoist manufacturer's recommended length, the chain shall be replaced. Or, in the absence of such recommendations, the chain shall be replaced if one of the following conditions exist:

- For hand chain-operated or lever-operated hoists, the used chain is $2.5 \%$ longer than the unused chain.

- $\quad$ For powered hoists, the used chain is $1.5 \%$ longer than the unused chain.

CAUTION: Repairing of load chain by welding or any other means shall not be attempted by anyone other than the chain manufacturer.

- Gouges, nicks, corrosion, weld spatter, or distorted links on the chain are sufficient to question chain safety and consider chain replacement. Safety in this respect depends largely on the use of good judgment by a qualified inspector in evaluating the degree of deficiency.

- The replacement chain shall be the same size, grade, and construction as the original chain furnished by the hoist manufacturer, unless otherwise recommended by the hoist manufacturer because of actual working conditions.

- The load chain links that pass over the hoist load sprocket on edge (as opposed to those that lie flat in the pockets) shall be installed (if recommended by the hoist manufacturer) with the welds away from the center of the sprocket. This precaution is not required on idler sprockets, which change the direction but not the tension in the chain.

- The chain shall be installed without any twist between the hoist and an anchored end on either the loaded side or the slack side.

- When the chain is replaced, the mating parts (sprockets, guides, stripper) shall be disassembled and inspected for wear and replaced if necessary.

- The load chain, discarded or new, shall not be used for slings. 


\subsubsection{Welded-Link Chain Maintenance}

Follow these instructions for maintenance on a welded link chain:

- The load chain and hand chain should be kept clean and free from any coating or deposit that will build up and change their dimensions or reduce flexibility. The cleaning process shall not damage these chains, and any solution used in the cleaning process shall be acid-free.

- The load chain articulates slowly under high bearing pressure and should be lubricated as specified by the hoist manufacturer or responsible maintenance organization. The hand chain is lightly loaded and normally requires no lubrication.

\subsection{Roller Chain Inspection, Replacement, and Maintenance}

\subsubsection{Roller Chain Inspection}

Follow these instructions when inspecting a roller chain:

- The hoist shall be tested under load in lifting and lowering directions and the operation of the chain and sprockets shall be observed. The chain should feed smoothly into and away from the sprockets.

- If the chain binds, jumps, or is noisy, it shall first be checked to ensure that it is clean and properly lubricated. If the trouble persists, the chain shall be inspected as specified in the following items and the mating parts shall be inspected for wear, distortion, or other damage.

- The roller chain should first be inspected while it is in the hoist. With the hoist suspended in normal position, a light load of approximately $50 \mathrm{lbs}$ shall be applied.

- Elongation shall be checked following the hoist manufacturer's instruction. In absence of specific instructions, the chain can be checked by determining the normal pitch and measuring a 12-inch section of chain that normally travels over the load sprocket. Using a caliper-type gauge, check the dimension from the edge of one chain pin to the corresponding edge of another pin for the number of pitches per foot. If elongation exceeds 0.25 inch in 12 inches, the chain shall be replaced. For example, a 0.75-inch- pitch chain should measure 12 inches over 16 pitches. Chain shall be rejected if measurement over 16 pitches exceeds 12.25 inches.

- The chain shall be checked for twist. The chain shall be replaced if the twist in any 5-foot section exceeds 15 degrees.

- Straightness (side bow) in plane perpendicular to the plane of the rollers shall be checked. A chain that has a bow exceeding 0.25 inch in any 5 -foot section shall be replaced.

- Additional inspection of the chain should be made by removing the chain from the hoist and cleaning it thoroughly in an acid-free solvent. A check then should be made for any of the following deficiencies:

- $\quad$ pins turned from their original position 
- $\quad$ rollers that do not run freely with light finger pressure

- joints that cannot be flexed by easy hand pressure

- side plates that are spread open (a visual check of the pin head extension at the damaged area, as compared to the pin extension at a free end of the chain, can determine the amount of spread and the condition of the chain.)

- corrosion, pitting, or discoloration of chain (generally indicative of serious impairment)

- gouges, nicks, or weld splatter.

\subsubsection{Roller Chain Replacement}

Follow these instructions when replacing a roller chain:

- The roller chain shall be replaced if any of the conditions exist as stated in Section 11.12.1, "Roller Chain Inspection," bullet 3. Repairing of roller chain by welding or heating shall not be attempted.

- The existence of any of the deficiencies as stated in Section 11.12.1, "Roller Chain Inspection," bullet 4 , is reason for questioning chain safety and considering its replacement. Safety in this respect depends largely on the use of good judgment by a designated person in evaluating the degree of deficiency.

- The replacement chain shall be the same size, grade, and construction as the original chain furnished by the hoist manufacturer unless otherwise recommended by the manufacturer because of actual working conditions.

- When the chain is replaced, the mating parts (sprockets, guides, stripper) should be disassembled and inspected for wear and replaced if necessary.

- When the chain is replaced, it should be reeved in the manner recommended by the hoist manufacturer and should operate freely over all load and idler sprockets. All connecting links and chain end fasteners should be inspected and properly secured. The hoist manufacturer's recommendations should be followed on the selection and installation of connecting links.

- $\quad$ Roller chains, discarded or new, shall not be used for slings.

\subsubsection{Roller Chain Maintenance}

Perform the following for roller chain maintenance:

- Roller chains should be kept clean and free from rust. Excessively dirty chains should be soaked in a clean, acid-free solvent. Chains should be agitated to ensure that joints are free from grit and foreign matter.

- Roller chains should be lubricated in accordance with hoist manufacturer's recommendations. In the absence of specific lubrication instructions, the chain should be lubricated with automotive 
oil, Society of Automotive Engineers (SAE) grade 20 or 30. Grease should never be applied to the chain.

\subsection{Maintenance}

\subsubsection{Preventive Maintenance}

Perform the following for preventive maintenance:

- Refer to maintenance manuals provided by the manufacturer.

- A preventive maintenance program based on the manufacturers, or a qualified person's, recommendations shall be established.

- Replacement parts shall be at least equal to the original manufacturer's specifications.

\subsubsection{Maintenance Procedure}

CAUTION: Adhere to established fall-protection requirements (guardrail system, safety net system, or personal fall-arrest system) when positioned on a walking or working surface with an unprotected side or edge that is $6 \mathrm{ft}(2 \mathrm{~m})$ or more above a lower level. Consult with your supervisor or occupational safety representative for specific details.

The following precautions shall be taken as applicable.

- The hoist, monorail crane, or carrier (trolley) to be repaired shall be moved to a location where it will cause minimum interference with other equipment. Equipment that cannot be readily moved from its operating location can be maintained at the operating location, providing precautions are taken to ensure the safety of maintenance personnel and other personnel.

- All controllers shall be placed in the off condition.

- If the equipment is electrically powered, the main or emergency switch on the line feeding the hoist or monorail system shall be locked in the de-energized position, except as required to perform the maintenance. Lock and tag procedures shall be strictly followed.

- If air-powered, the supply shall be disconnected or the valve on the air line feeding the hoist or monorail system shall be closed, except as required to perform the maintenance. Lock and tag procedures shall be strictly followed.

- Effective markings and barriers shall be used where work creates a hazardous area on the floor beneath the equipment. Warning or "out of order" signs should be placed on the hoist. If personnel can access the equipment and signs are not visible from the floor beneath, place warning signs visible from the floor. 
- Only properly trained personnel shall work on energized equipment. Extra caution is required when working on energized equipment.

- For monorail systems:

- Where other carriers are operating on the same monorail track, temporary stops should be provided to prevent interference with the idle equipment.

- Where temporary stops are not possible or practical, a signal person shall be placed at a vantage point for observing the approach of an active unit and warning its operator when it reaches a safe distance from the idle unit.

- After adjustments and repairs have been made, the equipment shall not be restored to service until all guards have been reinstalled, safety devices reactivated, and maintenance equipment removed.

\subsubsection{Adjustments and Repairs.}

- Any hazardous conditions disclosed by inspection or during operation shall be corrected before normal operation of the hoist is resumed. Adjustments and repairs shall be done only by designated personnel.

- Adjustments shall be maintained to ensure correct functioning of components. The following are examples:

- all functional operating mechanisms

- limit devices

- control systems

- brakes.

- Repairs or replacements shall be made as needed. The following are examples:

- Hooks showing indications described in Section 4.0, "Hooks."

- All critical parts that are cracked, broken, bent, or excessively worn.

- Pitted or burned electrical contacts should be corrected only by replacement and in sets. Controller parts should be lubricated as recommended by the manufacturer.

- Function labels on pendant control stations shall be kept legible.

- If repairs of load-sustaining members are made by welding, materials shall be identified and appropriate welding procedures shall be assigned by a qualified welding engineer, and welds shall be made by a qualified welding operator.

\subsubsection{Hoist Rope Anchor}

Replacement rope ends shall be anchored by a clamp securely attached to the drum, or by a socket arrangement approved by the hoist or rope manufacturer. For wire rope replacement requirements see Section 7.0, "Wire Rope.” 


\subsubsection{Preoperational Check after Maintenance or Repair}

A preoperational check shall be performed to verify the proper function of activities such as motion controls and interlocks. Special attention shall be given to those areas likely to have been affected by maintenance or repair.

\subsubsection{Lubrication}

Moving parts of the hoist for which lubrication is specified shall be regularly lubricated. Both manual and remote lubricating systems should be checked for delivery of lubricant. Care should be taken to follow manufacturer's recommendations as to points and frequency of lubrication, maintenance of lubricant levels, and types of lubricant to be used. Unless equipped for automatic or remote lubrication, hoist machinery and carriers shall be stationary while lubricants are being applied, except when lubricating chain or rope.

\subsection{Testing}

\subsubsection{Operational Tests}

Before initial use, new, reinstalled, altered, repaired, or modified hoists that have not been used within the preceding 12 months shall be tested before being placed in service by or under the direction of a designated person to ensure that the hoist is in good operating condition, including the following functions:

- Hand Chain-Operated and Lever-Operated Hoists

- Functions of the hoists, including lifting and lowering, shall be checked with the hoist suspended in the unloaded state. (Some hoists may require a nominal load or pull on the load line to test the lowering motion.)

- After testing Lever-Operated Hoists in the unloaded state, a load of at least 100 pounds (46 kg) times the number of load supporting parts of chain shall be applied to the hoist to check proper load control.

- After testing Hand Chain-Operated Hoists in the unloaded state, a load of at least 50 pounds (23 kg) times the number of load supporting parts of chain shall be applied to the hoist to check proper load control.

- Electric- or Air-Powered Hoists

- Lifting and lowering (testing through complete rated lift length is not required)

- Operation of brake(s)

- The trip-setting of primary limit devices shall be determined by tests under no-load conditions. Tests shall be conducted first by hand, if practical, and then under the slowest speed obtainable. Test with increasing speeds up to the maximum speed. Actuating mechanisms shall be located so that they will trip the switches or limiting devices in sufficient time to stop motion without damaging any part of the hoisting arrangement. On hoists with adjustable trip-setting limit devices, care shall be taken to achieve adjustment 
setting without the load block striking the hoist frame or without all the slack being taken out of the unloaded chain or with less than one wrap of rope on the drum.

- Jib Crane and Monorail Systems

- Check hoists as required in Section 11.14.1, “Operational Tests,” item 1 or 2, as applicable.

- Check carrier travel

- $\quad$ Check travel-limiting devices

- On monorail systems, check locking and safety devices for interlocking mechanisms, track switches, drop sections, and lift sections.

\subsubsection{Load Test}

\section{- Hand Chain-Operated and Lever-Operated Hoists}

- New hoists shall be tested by the manufacturer with a test load of at least $125 \%$ of the rated load, except if testing of the hoist cannot be performed by the manufacturer, the test shall be accomplished by or under the direction of a person designated by the user (buyer).

- Hoists in which load-suspension parts3 have been altered, replaced, or repaired shall be tested statically or dynamically by or under the direction of a designated person. The applied test load shall be at least equal to the rated load or greater as approved by the manufacturer. A record of the test shall be retained in the maintenance file. The replacement of load chain is specifically excluded from this hoist load test; however, an operational test shall be made in accordance with Section 11.14.1, “Operational Tests,” before returning the hoist to service.

- Before a load test, test anchorages or suspensions will be checked to ensure that they will safely sustain the load.

\section{- Electric- or Air-Powered Hoists}

- Complete new hoists shall be dynamically tested by the manufacturer as specified in Section 11.6.3, "Electric-Powered Hoists," with a load of at least $125 \%$ of the rated load, except, if testing of the hoist cannot be performed by the manufacturer. If the manufacture cannot perform the hoist test, the test shall be accomplished by or under the direction of a person designated by the user (buyer). A record of the test shall be retained in the maintenance file.

- Hoists in which load-suspension parts have been altered, replaced, or repaired shall be tested dynamically by, or under the direction of, a designated person. The applied test load shall be at least equal to the rated load or greater as approved by the manufacturer. A record of the test shall be retained in the maintenance file. The replacement of load chain and rope is specifically excluded from this hoist load test; however, an operational test of the hoist under a normal operating load shall be made before returning the hoist to service. For testing after rope replacement see Section 7.0, "Wire Rope.”

- Before a load test, test anchorages or suspensions will be checked to ensure that they will safely sustain the load.

\footnotetext{
${ }^{3}$ Load-suspension parts of the hoist include the means of suspension (hook or lug), the structure or housing that supports the drum or load sprocket, the drum or load sprocket, the rope or load chain, the sheaves or sprockets, and the load block or hook.
} 
- Jib Crane and Monorail Systems

- a. Hoists shall be tested as specified in Section 11.14.2, "Load Test," item 1 or 2, whichever applies.

- b. New, reinstalled, altered, repaired, and modified equipment should be load tested before initial use as determined by a qualified person. Load testing of altered, repaired, and modified equipment may be limited to the functions affected by the alteration, repair, or modification, as determined by a qualified person.

- c. If a load test is conducted, the load shall be not less than $100 \%$ of the rated load of the equipment or more than $125 \%$ of the rated load of the equipment, unless otherwise recommended by the manufacturer. For equipment engineered on site, the responsible engineer or design authority has the authority otherwise taken by the manufacturer.

- d. If a load test is conducted, operations shall be performed as outlined in Section 11.14.5, "Load Test Procedure," or as modified by a qualified person.

\subsubsection{Periodic Load Test}

Scheduled periodic load tests are not routinely required. Hoists may be load-tested up to $100 \%$ of rated capacity when or if specified by a Critical Lift Procedure. For hoists that frequently make critical lifts, especially if lifts are at or near rated capacity, a scheduled load-test program may be implemented. Such periodic load-tests shall not exceed the rated capacity. If a scheduled load-test program is implemented, a five-year frequency is recommended.

\subsubsection{Load-Test Weight}

The load-test weight should be within a tolerance of $(+0 \%,-5 \%)$ and shall be traceable to a recognized standard or verified by calculations.

\subsubsection{Load-Test Procedures}

Load tests shall be conducted in accordance with a written step-by-step procedure. A hold point shall be included in the load-test procedure to verify that inspection and maintenance is up to date. Load tests should be made where no critical items are installed, stored, or being worked on. The following guidelines are for information. Actual conditions may require changes to meet different situations and equipment configurations.

- Verify that hoist inspection and maintenance is up to date.

- State the type of load test. Example: "Special Test Before Critical Lift," "Test Before Returning to Service," or a "Rated Load Test."

- $\quad$ State test loads used.

- Lift the test load a few inches and hold for 5 minutes; from this position, lift an additional distance, not less than 3 feet above the floor (ground), and hold for 5 minutes. Then slowly lower the load; stop about 1 foot above the floor (ground), and hold for 5 minutes. At intermediate 
levels during hoisting and lowering, verify that the hoist operates properly and holds the load without slippage of more than 0.5 inch.

- For electric- or air-powered hoists, at least once in a raising and once in a lowering condition, at a height of no more than 1 foot, disconnect the electric or air power source. The load shall stop immediately with less than 0.5 -inch movement. There should be no slippage of the load or overheating of the brakes after 5 minutes of power off. The holding brakes should control the load throughout the test, and the load should not drop more than 0.5 inch when the lifting motion is again initiated.

- For monorail and jib cranes, transport the test load with the carrier (trolley) over the trolley's entire range. For jib cranes, rotate the jib boom over the full range of motion while the carrier is at the outside end of the boom. Load transporting should be done with the test load approximately 1 foot or less above the floor (ground) or obstructions.

- The test load should not rotate on the load block. Use taglines as appropriate. If the hook has power rotation, rotate the load through the full range of motion.

- The hoist and carrier (trolley) shall function smoothly, without sticking or binding.

- Following the load test, verify that no visible load-bearing part (e.g., gearing, shafting, bearing, rope or chain end-connection, brake components) has been adversely affected by the test.

- $\quad$ Place the load test report in the maintenance file.

\subsubsection{Hook Nondestructive Testing}

Hook nondestructive examination is not routinely required. If the hooks are to have NDE, the examination shall be done after the load test. If NDE is performed, attach the hook NDE report to the load test report.

\subsection{Maintenance Files}

The maintenance file is a compilation of various documents and records relating to operation, maintenance, inspection, testing, evaluating and repair of the equipment. The file may be centrally located or proportioned into satellite holding areas. The methods selected for establishing adequate information retention and retrieval shall be determined by the equipment custodian, who is the responsible person for ensuring that a safe and reliable maintenance program is in place.

\subsubsection{Intent of Maintenance Files}

The maintenance file shall contain, as a minimum, the required current dated periodic inspection records and other documentation to provide the user with evidence of a safe and reliable maintenance program. Inspection records should be retained in a format and location that allows easy accessibility. Maintenance file information should provide a source for comparing existing and past conditions to determine whether existing conditions show a trending pattern of wear, deterioration, or other similar 
factors that may compromise safe, continued use of the equipment. Length of record retention shall be determined by the equipment custodian's established maintenance program.

\subsubsection{Maintenance File Contents}

Maintenance files shall contain the following documentation, as applicable:

- $\quad$ periodic inspection records

- $\quad$ load test reports

- documentation of altered, replaced, or repaired load-sustaining parts

- records of special inspections on safety-related items such as brakes, hooks, ropes, hydraulic and pneumatic cylinders, and hydraulic and pneumatic pressure relief valves

- copies of waivers, exemptions, hostile environment plans, or similar documentation applicable to the equipment (to include manufacturer's safety bulletins, safety alerts, and product recall information)

- documentation for replacement ropes (see Section 7.0, "Wire Rope”)

- $\quad$ wire rope manufacture’s certification for replacement ropes.

Note: Although complete maintenance information for old equipment may not be available, the custodian should acquire as much of the pertinent information as possible.

\subsection{Equipment Types}

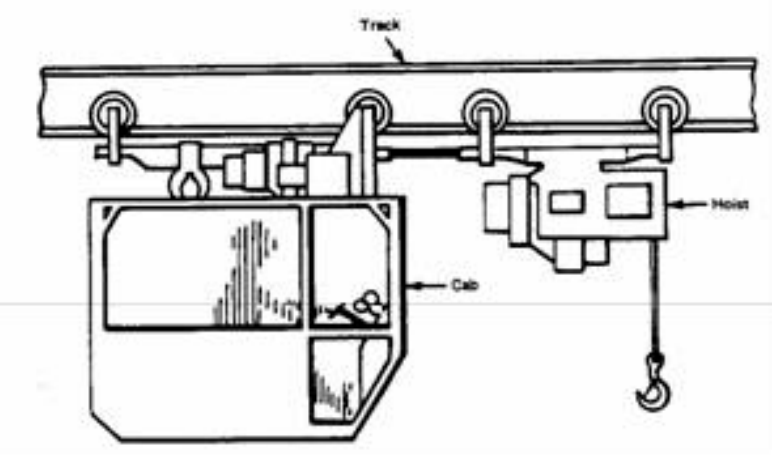

Figure 11.3. Monorail Cab-Operated Carrier 


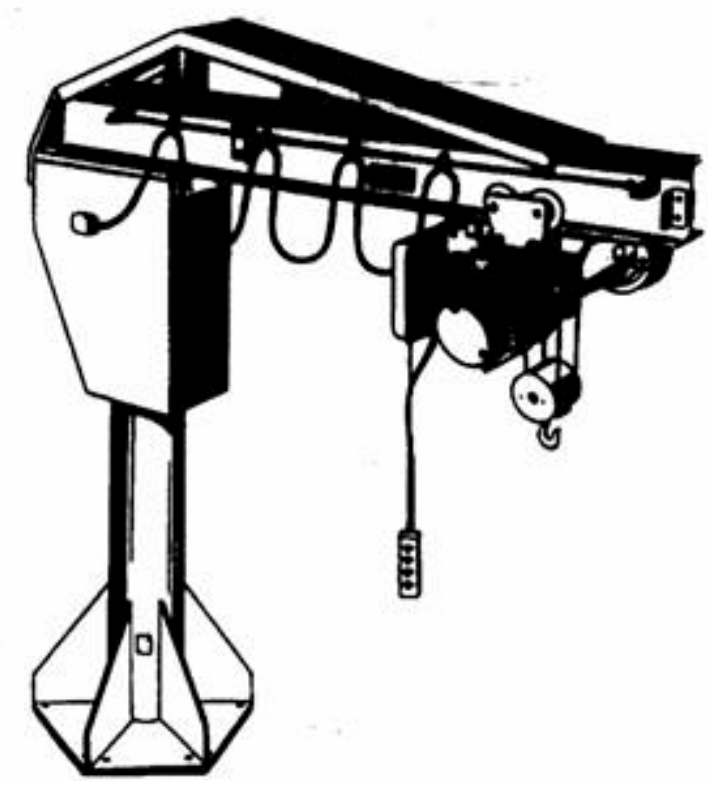

Figure 11.4. Pedestal Jib Crane

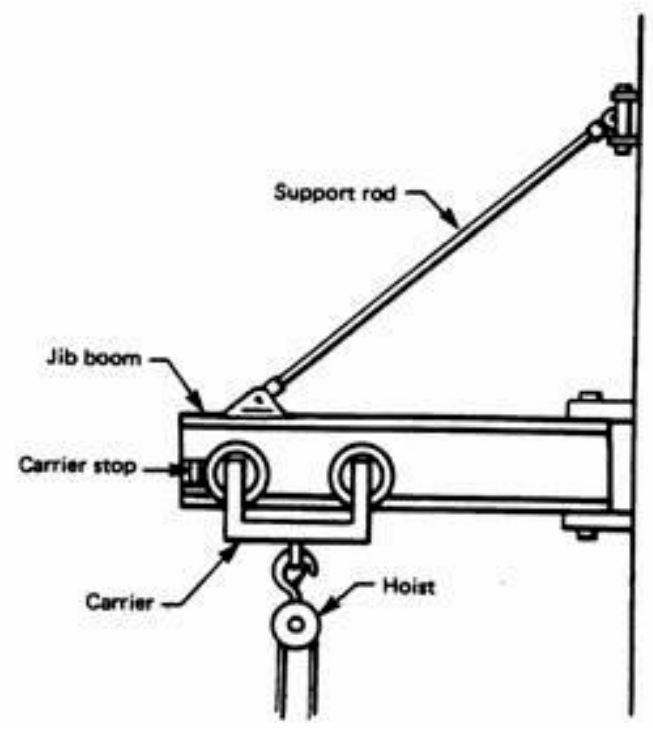

Figure 11.5. Wall-Supported Jib Crane 


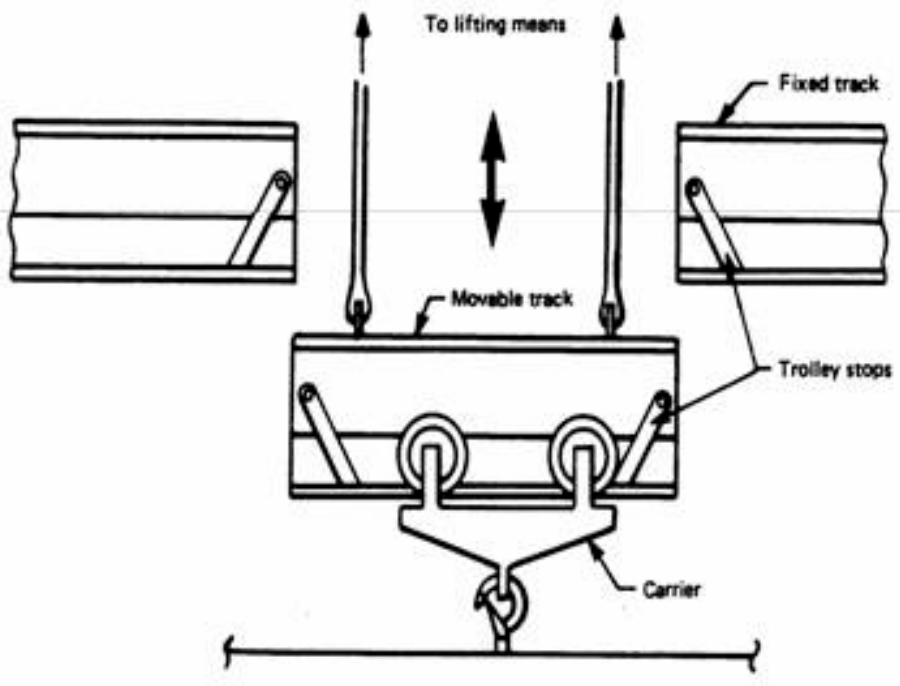

Figure 11.6. Monorail Drop Section (Lift Section)
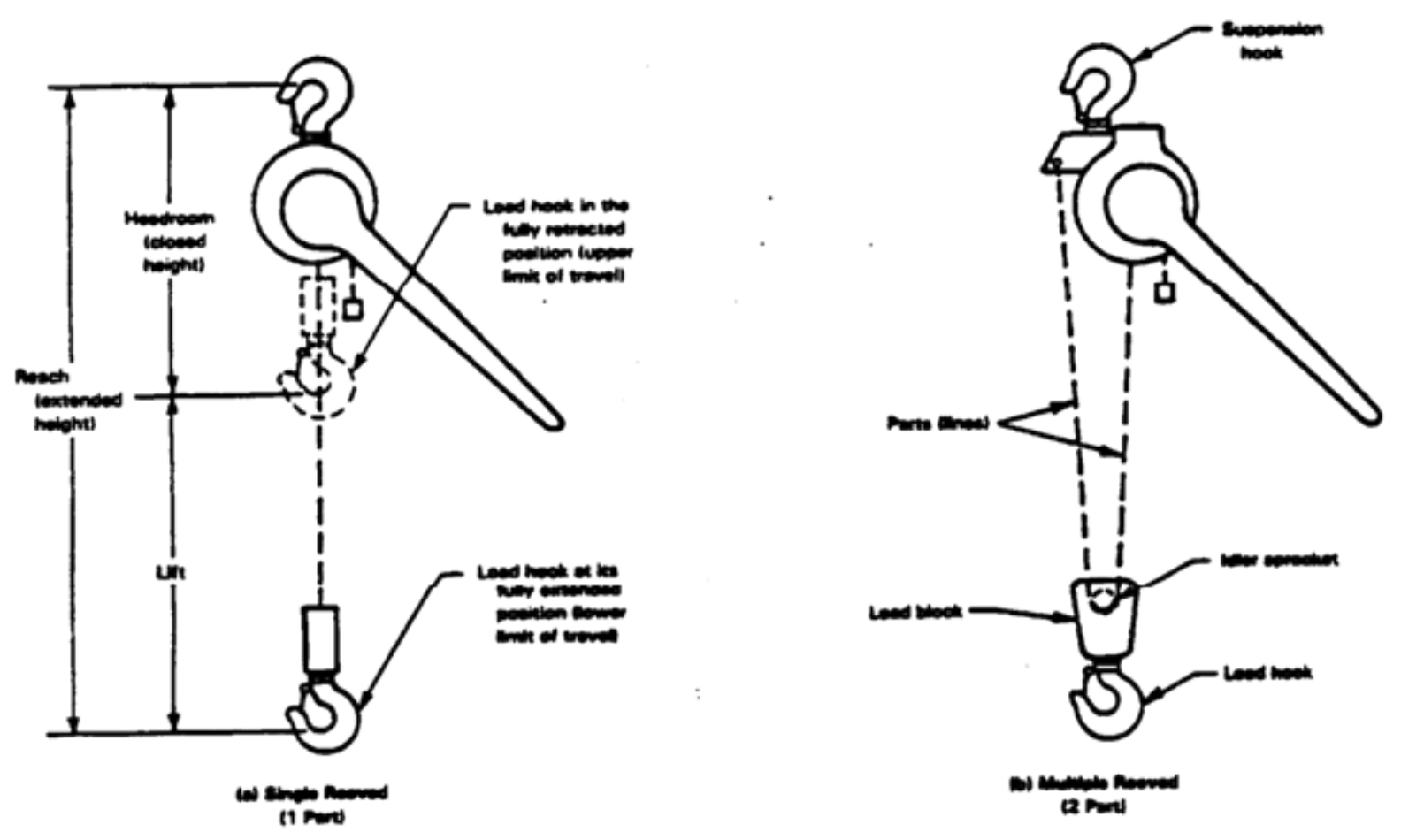

Figure 11.7. Lever-Operated Hoist - Chain Type 

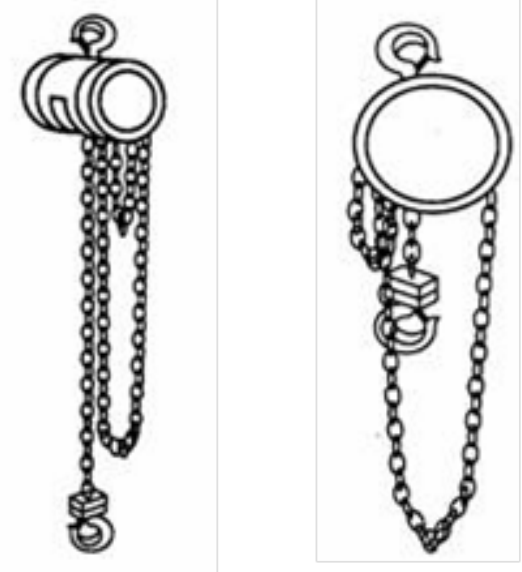

Figure 11.8. Hand-Chain-Operated Chain Hoists
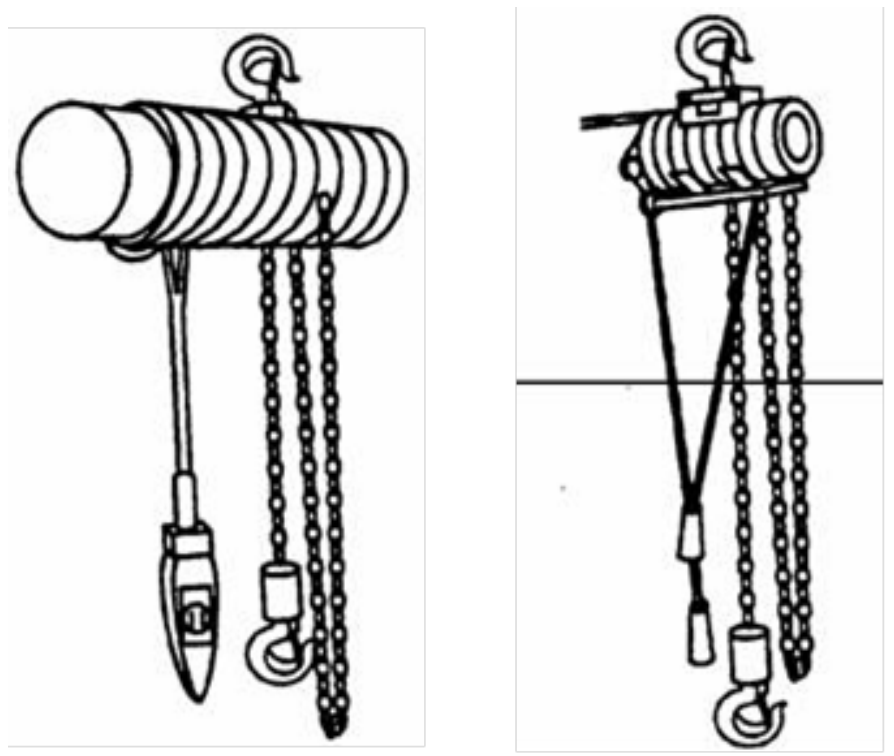

Figure 11.9. Electric-Powered Chain Hoists 


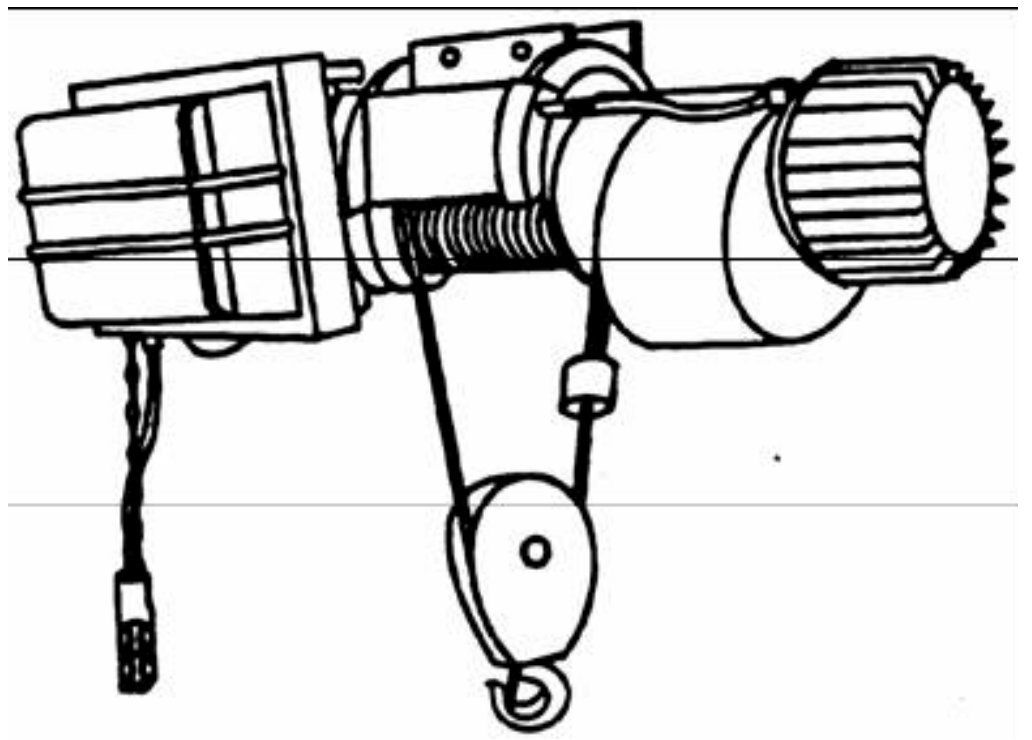

Figure 11.10. Air-Powered Wire Rope Hoist

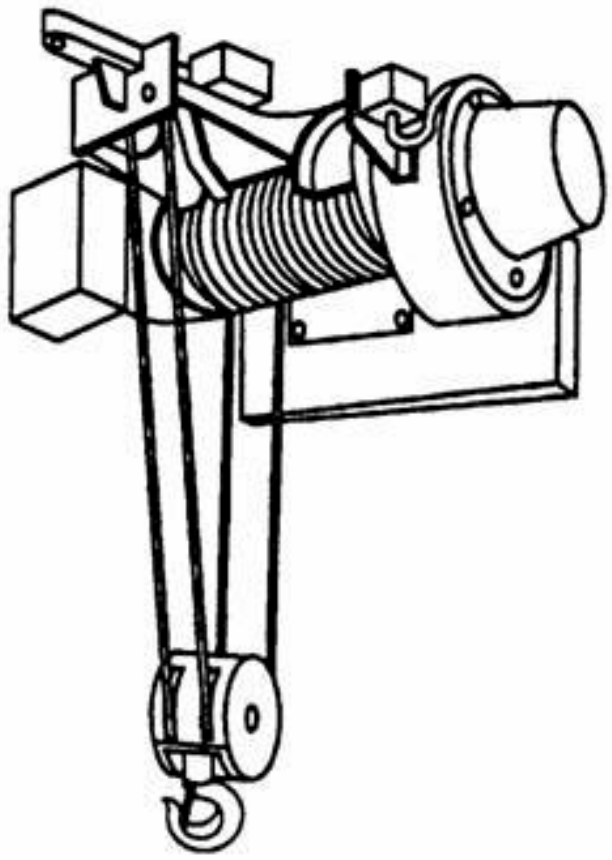

Figure 11.11. Electric-Powered Wire Rope Hoist 


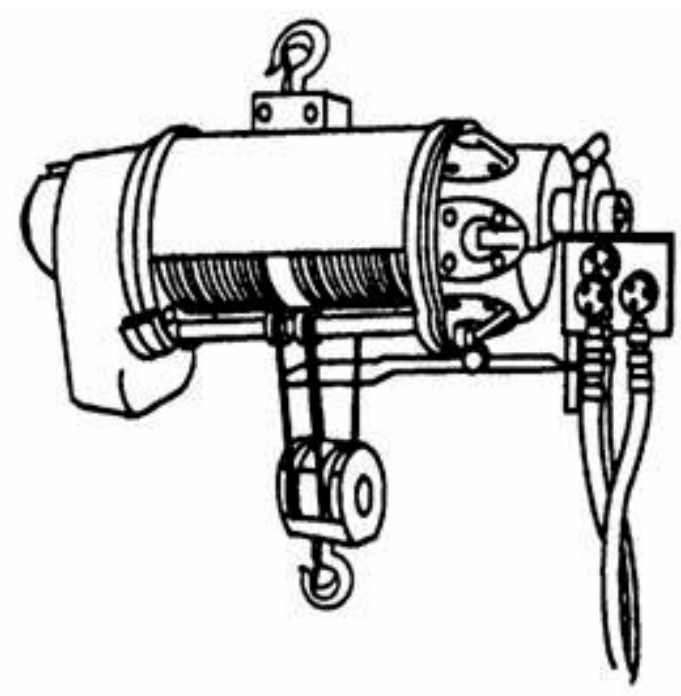

Figure 11.12. Air-Powered Wire Rope Hoist 



\subsection{Overhead and Gantry Cranes}

\subsection{Scope}

This section applies to overhead and gantry cranes, including semigantry, cantilever gantry, wall cranes, storage bridge cranes, and others having the same fundamental characteristics. These cranes may be top-running, under-running, single- or double-girder (see Section 12.4, “Crane Types”). Hoist units and trolleys are most commonly electric powered, but can be air powered or hand chain operated. These cranes may be cab operated, pulpit operated, floor operated, or remotely operated. Such cranes are grouped together because all have trolleys and similar travel characteristics and are governed by Occupational Safety and Health Administration regulation, 29 CFR 1910.179.

\subsection{Inspection, Maintenance, and Testing}

\subsubsection{Inspection}

Inspection requirements shall be derived from information provided by the crane manufacturer. Unless there is justification to do otherwise, the manufacturer's recommendations shall be followed. Inspection procedures should state the acceptance criteria for inspections and tests and shall be specific for the applicable make and model of crane.

\subsubsection{Initial Inspection}

Before initial use, new, reinstalled, altered, modified, or extensively repaired cranes shall be inspected in accordance with a written procedure. This inspection shall include the following functions: (1) hoisting and lowering, (2) trolley travel, (3) bridge travel, and (4) limit switches and locking and safety devices.

\subsubsection{Pre-use and Daily Inspection}

The crane custodian shall be notified and deficiencies shall be carefully examined and a determination made as to whether they constitute a hazard.

\subsection{Pre-use Inspection}

On each shift, before operating the crane, the operator shall perform the following operations:

- Test All Controls. If any controls do not operate properly, they should be adjusted or repaired before operations are begun.

- Verify Operation of the Primary Upper-Limit Device. The trip-setting of primary upper- limit switches shall be checked under no-load conditions by inching the block into the limit (running at slow speed). 
- Visually Inspect Ropes and Load Chains. These visual observations should be concerned with discovering gross damage that may be a hazard.

- Ensure inspections (wire rope, chains, and crane) are current via inspection sticker, other documentation, or verbal confirmation from equipment custodian.

\subsubsection{Daily Inspection}

Each day of use the operator shall carefully scan the crane for deficiencies that may occur between regular inspections:

- Check that motions are smooth and regular with no hesitations, vibration, binding, weaving, unusual noise, or other irregularity.

- Check for deterioration or leakage in lines, tanks, valves, drain pumps, and other parts of air or hydraulic systems.

\subsubsection{Frequent Inspection}

- Cranes In Regular Service, Inspection Interval - Cranes that are in use shall have visual

- Inspection by the operator or other designated personnel with records not required ${ }^{1}$ as follows:

- $\quad$ normal service - monthly

- heavy service - weekly to monthly

- $\quad$ severe service - daily to weekly.

Note: For service definitions see 15.0Appendix A, "Definitions and Acronyms," crane service.

- Cranes Not In Regular Service. A crane that is used in infrequent service that has been idle for 1 month or more, but less than 6 months, shall receive a frequent inspection before being placed in service.

- Instructions. The equipment custodian shall ensure that frequent inspection instructions are readily available. ${ }^{2}$ The frequent inspection instructions or an attachment thereto, shall state how deficiencies shall be reported.

- Frequent Inspection Steps. The operator or other designated personnel shall perform the following. ${ }^{3}$

\footnotetext{
${ }^{1}$ Frequent inspection records are not required, but a checklist, located on or near the crane, is recommended to demonstrate that the inspection has been performed.

${ }^{2}$ Inspection instructions provided by the manufacturer may be sufficient. For complex equipment or equipment in a hostile environment, a frequent inspection procedure prepared onsite may be needed.

${ }^{3}$ For reference, sample inspection checklists are included in Attachment 13.3, "Sample Inspection Checklist."
} 
- Check that motions are smooth and regular for all speed steps, with no hesitations, vibration, binding, weaving, unusual noise, or other irregularity.

- Ensure that hooks and hook throat latches, if installed, show no noticeable damage, wear, or deformation.

- Ensure that brakes operate smoothly.

- Visually ensure that hoisting ropes ${ }^{4}$ and/or chains are in good condition. The hoist chain shall feed smoothly into and away from sprockets. Inspect the chain for excessive wear, twist, distorted links interfering with proper function, or stretch. Inspect hoist ropes for proper spooling onto the drums and sheaves.

- Ensure that there is no visible leakage of lubricant.

- Check the trip-setting of primary upper-limit switches under no-load conditions by inching the block into the limit (running at slow speed).

- If the crane is equipped with a lower-limit switch, check the lower-limit switch by slowly moving the block into the switch (no load on hook). The drum should be observed during this operation to ensure that at least two full wraps of wire rope remain on the drum at the lower limit.

- For a cab-operated crane, check for a charged 10-B:C (or larger) fire extinguisher and ensure that the extinguisher inspection tag is current.

- Complete any other inspections that are specific for the crane.

\subsubsection{Periodic Inspection}

- Cranes in Regular Service, Inspection Interval: Cranes that are in use shall be visually inspected by a qualified inspector who will document apparent external conditions. These documents will provide the basis for a continuing evaluation, as follows:

- normal service - yearly

- heavy service - yearly

- $\quad$ severe service - quarterly.

- Cranes Not In Regular Service. A crane that is used infrequently and has been idle for a period of 6 months or more shall receive a periodic inspection before being placed in service.

- Qualified Inspector. A qualified inspector shall perform periodic inspections.

- Requirements of Periodic Inspection Procedure. A periodic inspection procedure shall provide specific inspection requirements and methods. Inspection acceptance criteria shall be provided with the inspection procedure or by reference to another document that is available to the inspector. The procedure shall be based on the requirements and recommendations of the manufacturer (or qualified engineer in the absence of manufacturer recommendations), and the activity, operating environment, severity of service, and equipment history. A periodic inspection checklist follows:

\footnotetext{
${ }^{4}$ See Chapter 7 for rope-inspection details.
} 
- Include pre-inspection safety requirements (e.g., lock and tag requirements) and ensure that the crane is in the proper location for inspection.

- Include inspections recommended by the manufacturer or a qualified engineer.

- Require a check of all limit devices, including hoist limit switches and bridge and trolley travel limit switches.

- Require a check of functional operating mechanisms.

- Require a check of control systems, if applicable, to include electrical apparatus for signs of pitting or any deterioration of visible controller contacts.

- Require a check for leakage in lines, tanks, valves, pumps, and other parts of air or hydraulic systems.

- Require a visual inspection of hooks for cracks, increased throat opening, twists, damage to hook retaining nuts, collars, or pins, and welds or rivets used to secure the retaining members. (See Section 4.0, “Hooks.”)

- Require inspection for deformed, cracked, or corroded members.

- Require an inspection for loose bolts or rivets.

- Require an inspection for cracked or worn sheaves, drums, and load or idler sprockets.

- Require an inspection of running ropes and/or load chain, including end connections.

- Require an inspection for worn, cracked, or distorted parts such as pins, bearings, shafts, gears, rollers, locking and clamping devices.

- Require a check of brake systems parts, lining, pawls, and ratchets.

- Require a check of rail alignment and rail condition.

- Require a check of load, wind, and other indicators over their full range, for any significant inaccuracies.

- Require a check of gasoline, diesel, electric, or other power plants for improper performance or noncompliance with applicable safety requirements.

- Provide a document on which to record measurements, tests, or examinations.

- State the acceptance criteria for measurements, tests, and examinations.

- Provide specific "how-to"-type instructions for any inspection activity that is not "common sense” to qualified inspection personnel.

Note: See Section 12.2.1.6, "Wire Rope Inspection,” regarding wire rope periodic inspection requirements. See Sections 12.2.1.7, "Monthly Chain Inspection,” and 12.2.1.8, "Load Chain Inspection,” regarding load chain periodic inspection.

\subsubsection{Predictive Maintenance}

The responsible engineering or maintenance organization should use predictive maintenance examinations or tests as necessary to diagnose problems and predict maintenance requirements (e.g., chemical/microscopic tests of used lubricants and vibration analysis of rotating equipment). 


\subsubsection{Wire Rope Inspection.}

- Monthly Wire Rope Certification. For in-service cranes (overhead traveling cranes and gantry cranes), a monthly documented rope inspection is required. Cranes not in regular use that have been idle for 1 month or more, but less than 6 months shall have an inspection before returning to service. Cranes that have been out of service for more than 6 months shall have a periodic wire rope inspection before returning to service. Monthly inspection shall be performed in accordance with Section 7.0, “Wire Rope.”

- Periodic Wire Rope Inspection. Periodic wire rope inspection is required. Periodic inspection, more thorough than the monthly rope inspection, should be performed in conjunction with and on the same schedule with the crane periodic inspection as required by Section 12.2.1.4, "Periodic Inspection.” See Section 7.0, “Wire Rope,” for rope inspection details.

\subsubsection{Monthly Chain Inspection (Welded Link and Roller Type).}

Monthly Chain Inspection. For overhead and gantry cranes that are in service, load chains shall be inspected monthly. Cranes not in regular use that have been idle for 1 month or more, but less than 6 months, shall have a chain inspection, equal to a monthly chain inspection, before returning to service. This inspection shall include end connections and the hoist chain to check for excessive worn, twisted, or distorted links interfering with proper function, or stretching beyond manufacturer's recommendations. This inspection shall be documented with a certification record that includes the date of inspection, the signature of the person who performed the inspection, and an identifier of the chain that was inspected.

A checklist near the operator's station is recommended. Cranes (with load chain) that have been out of service for more than 6 months shall have a periodic load chain inspection before returning to service.

\subsubsection{Load Chain Inspection (Welded Link and Roller Type).}

\subsection{Periodic Load Chain Inspection, Welded Link.}

Periodic load chain inspection should be performed in conjunction with the overall crane periodic inspection. Periodic load chain inspection, more thorough than the monthly inspection, shall include a careful link-by-link inspection of load chain as follows.

- Check for link wear to less than $90 \%$ of the original bar diameter.

- Check for nicking, cracking, or corrosion of a link that, when ground out to a smooth surface, leaves less than $90 \%$ of the original bar diameter.

- $\quad$ Check for stiffening or poor hinging of linkage.

- Check for distortion by bending or kinking of $15 \%$ of any overall link dimension.

- $\quad$ Check for evidence of heat damage.

- Check for elongation in excess of the manufacturer's recommended allowable. 
- Check for worn, nicked, or corroded fittings.

Note: See Section 12.2.2.6, "Hoist Rope and Load Chain Replacement,” item 2, regarding welded link-type load chain replacement.

\subsection{Periodic Load Chain Inspection, Roller Type.}

Test the hoist under load in lifting and lowering directions and observe the operation of the chain and sprockets. The chain should feed smoothly into and away from the sprockets.

If the chain binds, jumps, or is noisy, first see that it is clean and properly lubricated. If the trouble persists, inspect the chain in accordance with the following:

- Roller chain should first be inspected while it is in the hoist space. With the hoist suspended in normal position, apply a light load of approximately $100 \mathrm{lbs}$.

- Check for elongation following the hoist manufacturer's instructions. In absence of specific instructions, the chain can be checked by determining the normal pitch and measuring a 12inch (30.5 centimeter) section of chain that normally travels over the load sprocket. Using a caliper-type gage, check the dimension from the edge of one chain pin to the corresponding edge of another pin for the number of pitches per foot. If elongation exceeds 0.25 inch (6.3 millimeters) in 12 inches (30.5 centimeters) the chain shall be replaced. For example, a 0.75inch pitch chain should measure 12 inches over 16 pitches. Chain shall be rejected if measurement over 16 pitches exceeds 12.25 inches.

- Check chain for twist. The chain shall be replaced if the twist in any 5 feet (1.52 meters) section exceeds 15 degrees.

- Check for straightness in plane perpendicular to plane of rollers. A chain that has a bow exceeding 0.25 inch (6.3 millimeters) in any 5 -foot (1.52 meter) section shall be replaced.

- Additional inspection of the chain should be made by removing chain from hoist and cleaning it thoroughly in an acid-free solvent. A check should then be made for any of the following deficiencies:

- Pins turned from their original position

- Rollers that do not run freely with light finger pressure

- Points that cannot be flexed by easy hand pressure

- Side plates that are spread open (a visual check of the pin head extension at the damaged area, as compared to the pin extension at a free end of the chain, can determine the amount of spread and the condition of the chain)

- Corrosion, pitting, or discoloration of chain (generally indicative of serious impairment)

- Gouges, nicks, or weld splatter.

Note: See Section 12.2.2.6, "Hoist Rope and Load Chain Replacement,” bullet 3, regarding roller-type load chain replacement. 


\subsubsection{Inspection of Cranes Not In Regular Use}

Cranes that are out of service shall be inspected before being returned to service. The following identifies inspection requirements for returning cranes to service.

- Idle Greater Than One Month. A crane that has been idle more than 1 month, but less than 6 months, shall be given a frequent inspection and a documented monthly hook, rope, or load chain inspection.

- Idle Greater Than Six Months. A crane that has been idle more than 6 months shall have a periodic inspection, including a documented hook, rope, or load-chain inspection.

- Standby. Standby cranes shall have a frequent inspection and a documented (equivalent to monthly) hook, rope, or chain inspection every 6 months.

Note: Cranes that are out of service AND are exempt from inspections shall be tagged out of service in accordance with the facility-specific lock and tag procedure. Standby cranes are not out of service.

\subsubsection{Hooks}

Hooks shall be inspected in conjunction with the frequent and periodic crane inspection. Monthly documented hook inspection is required. See Section 4.0, "Hooks," for hook inspection details.

\subsubsection{Inspection Records}

Inspection records shall be kept throughout the life of the crane.

- Pre-Use and Frequent Inspection. No records retention is required. A frequent inspection verification checklist is recommended.

- Monthly Hook, Wire Rope, and Load Chain Inspection. The most recent records, dated and signed by a qualified inspector, shall be retained in the crane maintenance file.

- Periodic Inspection. The most recent records, dated and signed by a qualified inspector, shall be retained in the crane maintenance file.

\subsubsection{Maintenance}

\subsubsection{Preventive Maintenance}

A preventive maintenance program based on the crane manufacturer's recommendations shall be established. If the manufacturer's recommendations are not available or complete, a preventive maintenance program shall be developed by the responsible maintenance or engineering organization. 


\subsubsection{Preventive Maintenance Procedure}

Preventive maintenance shall be performed in accordance with written procedures. Procedures shall state specific precautions, such as lock and tag requirements, to be taken before beginning maintenance. A copy of the preventive maintenance procedures shall be retained in the crane history file.

\subsubsection{Maintenance Records}

The most recent copy of dated records that document maintenance of critical items such as hoisting machinery, sheaves, hooks, chains, ropes, and other lifting devices shall be retained in a maintenance file. Maintenance records shall be retained in the crane history file, or an electronic recordkeeping system may be used. If a computer system is used, and maintenance records are not retained in the crane history file, the crane history file shall state where the electronic maintenance records are available.

\subsubsection{Maintenance Procedure}

- Precautions before Maintenance. Before adjustments or repairs are started, the following precautions shall be taken, as applicable.

- The crane to be repaired shall be moved to a location where it will cause the least interference with other equipment and operations in the area.

- Controllers shall be set in the off condition.

- The main switch (crane disconnect) shall be de-energized and locked, tagged, or flagged in the de-energized position.

Note: Facility-specific lock and tag procedures shall be strictly followed. While maintenance is under way, "warning" or "out of order" signs shall be placed on the crane. If personnel have access to the floor beneath the crane, place warning signs that are visible from the floor. Lock and tag procedures shall be followed.

- Effective markings and barriers shall be used when maintenance work creates a hazardous area on the floor beneath the crane or crane runway.

- Where other cranes are in operation on the same runway, rail stops or other means shall be provided to prevent interference with the idle crane or work area.

- Where temporary protective rail stops or other means are not available or practical, a signal person shall be placed at a visual vantage point for observing the approach of an active crane and warning its operator when reaching the limit of safe distance from the idle crane or work area.

- Only trained personnel shall work on energized equipment when adjustments and tests are required.

- After maintenance work is completed and before restoring the crane to normal operation, the following activities shall be completed:

- Guards shall be reinstalled.

- $\quad$ Safety devices shall be reactivated. 
- Replaced parts and loose material shall be removed.

- Maintenance equipment shall be removed.

\subsubsection{Adjustments and Repairs}

- Any hazardous conditions disclosed by inspection or during operation shall be corrected before normal operation of the crane is resumed. Adjustments and repairs shall be done only by designated personnel.

- Adjustments shall be maintained to ensure correct functioning of components. The following are examples:

- all functional operating mechanisms

- limit devices

- control systems

- brakes.

- Repairs or replacements shall be made as needed. The following are examples:

- Crane hooks showing indications described in Section 4.0, "Hooks," shall be repaired or replaced.

- All critical parts that are cracked, broken, bent, or excessively worn shall be replaced.

- Pitted or burned electrical contacts should be corrected only by replacement and in sets. Control parts should be lubricated as recommended by the manufacturer.

- Function labels on pendant control stations shall be kept legible.

- If repairs of load-sustaining members are made by welding, identification of materials shall be made and appropriate welding procedures shall be assigned by a qualified welding engineer. The welds shall be made by a qualified welding operator.

\subsubsection{Hoist Rope and Load Chain Replacement.}

- Replacement Rope. The end of the rope shall be anchored by a clamp securely attached to the drum, or by a socket arrangement approved by the crane or rope manufacturer. For wire rope requirements, see Section 7.0, "Wire Rope.”

- Replacement Load Chain (Welded Link Type). The replacement welded link chain shall be the same size, grade, and construction as the original furnished by the crane or hoist manufacturer, unless use of a different type is justified. Repairing welded link chain by welding or heating shall not be attempted.

If for any reason a chain that is different from the original is used, or the original chain is unknown and the manufacturer is not available to specify the proper replacement, a qualified engineer shall approve the specification of the replacement chain. 
- Roller Chain Replacement. The roller chain shall be replaced if any of the conditions exist as stated in Section 12.2.1.8, "Load Chain Inspection (Welded Link and Roller Type).” Repairing of roller chain by welding or heating shall not be attempted.

- The replacement chain shall be the same size, grade, and construction as the original chain furnished by the hoist manufacturer unless otherwise recommended by the manufacturer because of actual working conditions.

- When the chain is replaced, disassemble and inspect the mating parts (sprockets, guides, and stripper) for wear: replace, if necessary.

- When the chain is replaced, it should be reeved in the recommended manner and should operate freely over all load and idler sprockets. All connecting links and chain end fasteners should be inspected and properly secured. The hoist manufacturer's recommendations should be followed on the selection and installation of connecting links.

- The roller chains, discarded or new, shall not be used for slings.

- After Load Chain Replacement. After chain (roller type or welded link type) replacement and before the initial load, do the following:

- Ensure that the proper chain is used.

- Ensure that chain limit overtravel restraint requirements are met to prevent the chain from running off the hoist.

- For hand-operated hoists, before the load chain can be completely run out of the hoist, it shall be restrained in the fully extended position.

- An electric- or air-powered hoist shall not be installed where the load hook can be lowered beyond rated hook travel under normal operating conditions unless the hoist is equipped with a lower limit device.

- Whenever a load chain (welded link type or roller type) is replaced, the following most recent documentation shall be retained in the crane maintenance file:

- date replacement was completed

- $\quad$ purchase order (PO) number and PO item number, if known

- chain manufacturer

- $\quad$ size, grade, construction, and manufacturer’s certification of the breaking strength.

\subsubsection{Preoperational Check after Maintenance or Repair}

A preoperational check shall be performed to verify the proper function of activities such as crane motion controls and interlocks. Special attention shall be given to those areas likely to have been affected by maintenance or repair.

\subsubsection{Lubrication}

A closely controlled lubrication plan is required to prevent over- or under- lubrication. The lubrication frequency shall be specified by the responsible engineering or maintenance organization and should be based on the manufacturer's recommendations. If inspection finds over- or under-lubrication, 
the lubrication method or frequency shall be adjusted. Lubricant types used on motors, bearings, gear boxes, and other lubrication points shall be specified by the responsible engineering or maintenance organization and should be as recommended by the crane manufacturer. Lubricants used on wire rope and chain should be as recommended by the manufacturer and shall be as specified by the responsible engineering or maintenance organization or qualified inspector.

\section{- Sheave-Bearing Lubrication.}

- Normal Operation. Sheave bearings, including equalizer sheaves, shall be individually lubricated on a regular schedule.

- Load Blocks in Water. Load blocks that are immersed in water shall have special provisions to prevent lubricant loss to the water. In this case, lubrication frequency and lubricant type should be carefully evaluated.

- Hoist Rope Lubrication. Hoist ropes, except for stainless steel rope (consult manufacturer), shall be lubricated. When ropes are immersed in water, the type of lubricant shall be selected to reduce the loss of lubricant to water.

- Motor Lubrication. For those motors that require lubrication, a closely controlled lubrication plan is required.

\subsubsection{Testing}

\subsubsection{Periodic Load-Test}

Scheduled load-tests are not routinely required. Overhead and gantry cranes may be load-tested up to $100 \%$ of rated capacity when (if) specified in a critical lift procedure. For cranes that frequently make critical lifts, especially if the lifts are at or near rated capacity, responsible management may implement a periodic load-test program. Such periodic load-tests shall not exceed the rated capacity. Responsible management shall set the load-test frequency. (A five-year frequency is recommended.)

\subsubsection{Cranes Removed from Service}

At the discretion of facility management, a crane that has been out of service may be load-tested before returning to service. Consider the following when determining whether a load-test shall be required: (1) Will the crane make critical lifts? (2) What is the general condition and age of the crane? (3) What is the previous load-test and maintenance history of the crane? This load test shall be done only after a return-to-service inspection is completed and should not exceed the rated capacity.

\subsubsection{Operational Tests}

Before initial use, new, reinstalled, altered, repaired, or modified cranes shall be tested by a designated person to ensure that the crane is in good operating condition, including the following functions:

- $\quad$ lifting and lowering 
- trolley travel

- $\quad$ bridge travel

- limit devices.

- Check the hoist limit device(s), primary and secondary if so equipped, by slowly moving the block into the switch (no load on hook). Then check the hoist limit device(s) at increasing speeds up to the maximum speed.

- The actuating mechanism of the upper-limit device shall be located or adjusted so that it will trip the device in sufficient time to prevent contact of the load block or load with any part of the trolley or bridge;

- Travel-limiting devices; and

- Locking and indicating devices, if provided.

Note: Operational testing of altered, repaired and modified cranes may be limited to the functions affected by the alteration, repair, or modification, as determined by a qualified person.

\subsubsection{Rated Load-Test.}

- New, reinstalled, altered, repaired, and modified cranes should be load-tested prior to initial use, as determined by a qualified person.

- Load-testing of altered, repaired and modified cranes may be limited to the functions affected by the alteration, repair, or modification, as determined by a qualified person. To resolve questions, the crane manufacturer should be consulted.

- The replacement of load chain and rope is specifically excluded from load-test requirements; however, an operational test of the hoist shall be made in accordance with Section 12.2.3.3, "Operational Tests," before returning the crane to service.

- When rope clips or wedge socket end connections are used on a load line, the hoist should be cycled several times with a load no less than the maximum operational load (normally $100 \%$ of the rated capacity). Next, if rope clips are used, check and retighten nuts to the recommended torque. If a wedge socket is used, verify that the rope is properly seated.

- If a load-test is conducted, the load shall be not less than $100 \%$ of the rated load of the crane or hoists, whichever governs; or more than $125 \%$ of the rated load of the crane or hoists, whichever governs; unless otherwise recommended by the manufacturer or a qualified person.

- If a load-test is conducted, it shall be conducted in accordance with Section 12.2.3.7, "Load-Test Procedure,” and documented in accordance with Section 12.2.3.8, "Load-Test Report.” 


\subsubsection{Load-Test Weight}

The load-test weight should be within a tolerance of $(+0 \%,-5 \%)$ and shall be traceable to a recognized standard or verified by engineering calculations. Any one of the following options will meet this requirement:

- Use a calibrated (+0\%, $-5 \%)$ load-measuring device during the load test.

- Determine the test load with a calibrated load-measuring device before the test.

- Calculate the test load based on known unit weights and dimensions of the test fixture. Dimensions and calculations must be checked (signed and dated) by a qualified engineer and determined to be accurate within tolerance $(+0 \%,-5 \%)$.

\subsubsection{Prerequisite to Load Test}

Load tests shall be performed only after inspection and maintenance of the crane are confirmed as current and any outstanding discrepancies have been addressed.

\subsubsection{Load-Test Procedure}

If a load-test is conducted, it shall be performed as follows or as modified by a qualified person.

- Hoist the test load a distance to ensure the load is supported by the crane and held by the hoist brakes.

- $\quad$ Transport the test load by means of the trolley for the full length of the bridge.

- With the trolley as close as practical to one end of the crane, transport the test load by means or the bridge for the full length of the runway in one direction and in the other direction with the trolley as close as practical to the other end of the crane.

- $\quad$ Lower the load, and stop and hold the load with the brakes.

\subsubsection{Load-Test Report}

After the test is completed, the load-test report shall be signed and dated by the person in charge of conducting the load test. The person in charge shall ensure that the test is placed in the crane maintenance file.

\subsubsection{Hook Nondestructive Testing}

Hook nondestructive examination is not routinely required before a load test. If the crane hooks are to have NDE, the NDE should be done after the load test. 


\subsection{Crane Maintenance Files}

The crane maintenance file is a compilation of various documents and records relating to operation, maintenance, inspection, testing, evaluating and repair of the equipment. The file may be centrally located or proportioned into satellite holding areas. The methods selected for establishing adequate information retention and retrieval shall be determined by the equipment custodian, who is the responsible person for ensuring that a safe and reliable maintenance program is in place.

The crane maintenance file shall contain, as a minimum, the required current dated periodic inspection records and other documentation to provide the user with evidence of a safe and reliable maintenance program. Inspection records should be retained in a format and location that provides for ease in accessibility. Maintenance file information should provide a source for comparing present conditions with past conditions to determine whether existing conditions show a trending pattern of wear, deterioration, or other comparable factors that may compromise safe, continued use of the equipment. Length of record retention shall be determined by the equipment custodian's established maintenance program. 


\subsection{Crane Types}
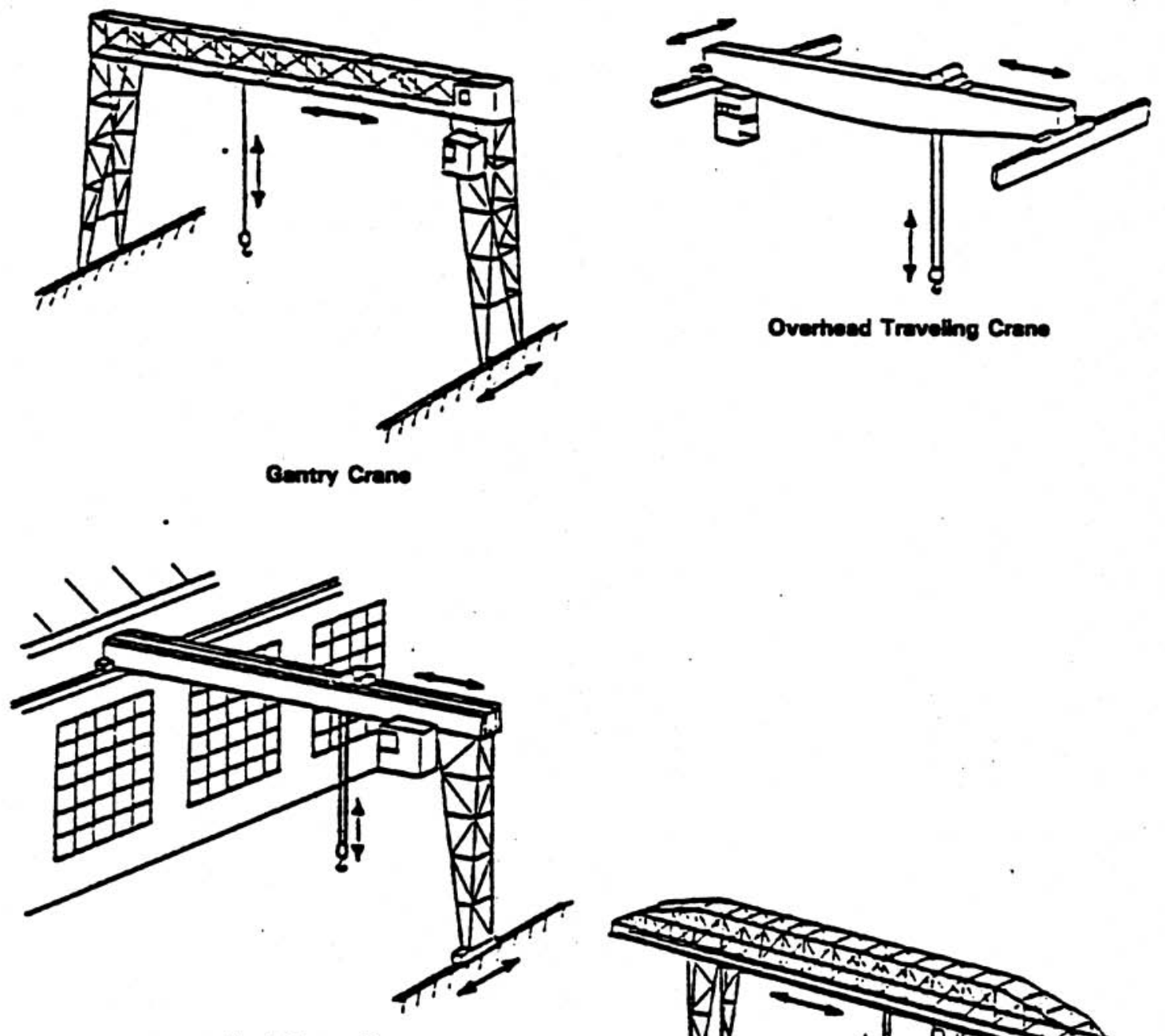

Sem-Gantry Crano

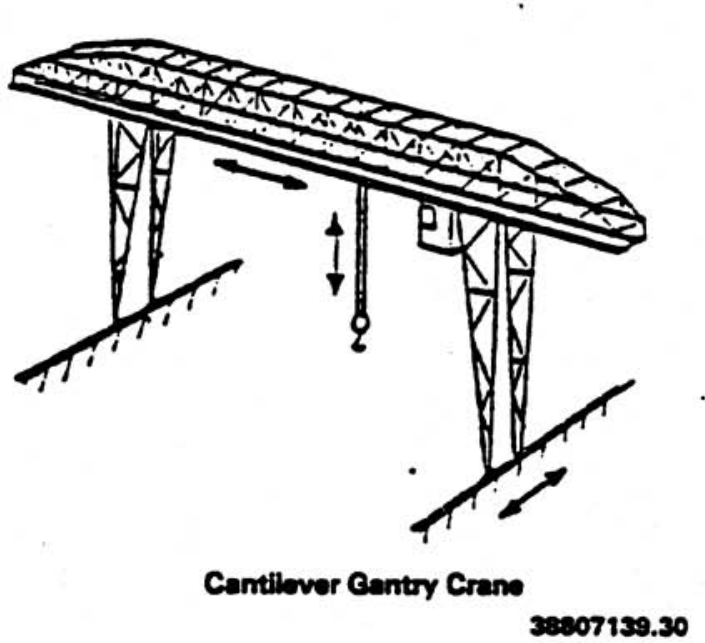

Figure 12.1. Top-Running Single-Girder Bridge with Underhung Trolley Hoist 


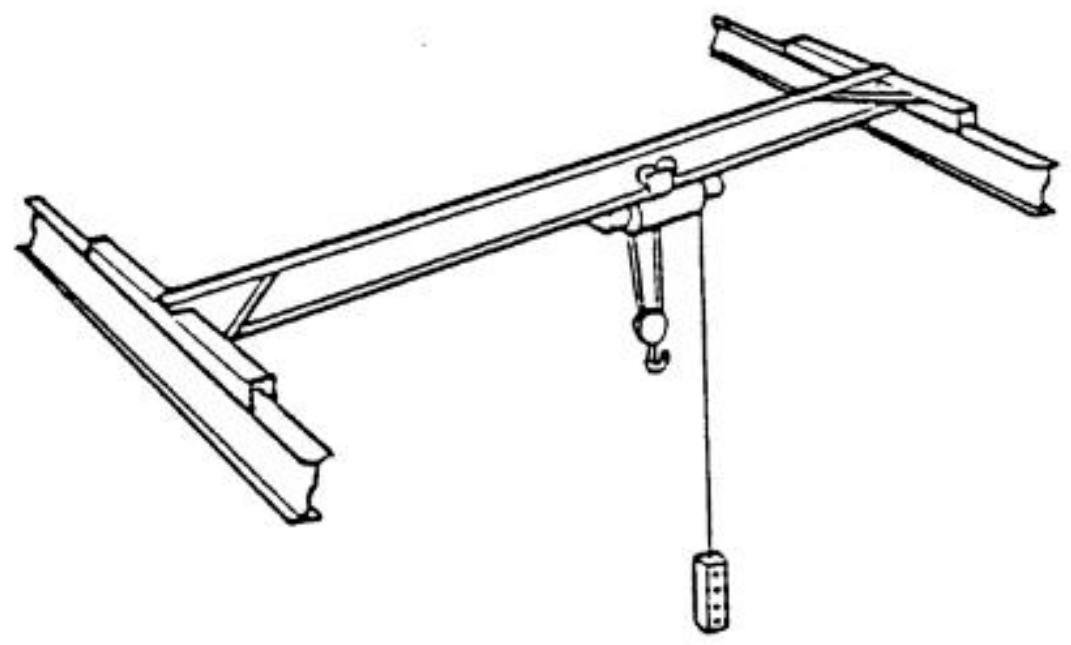

Overhead Floor-Operated Crane

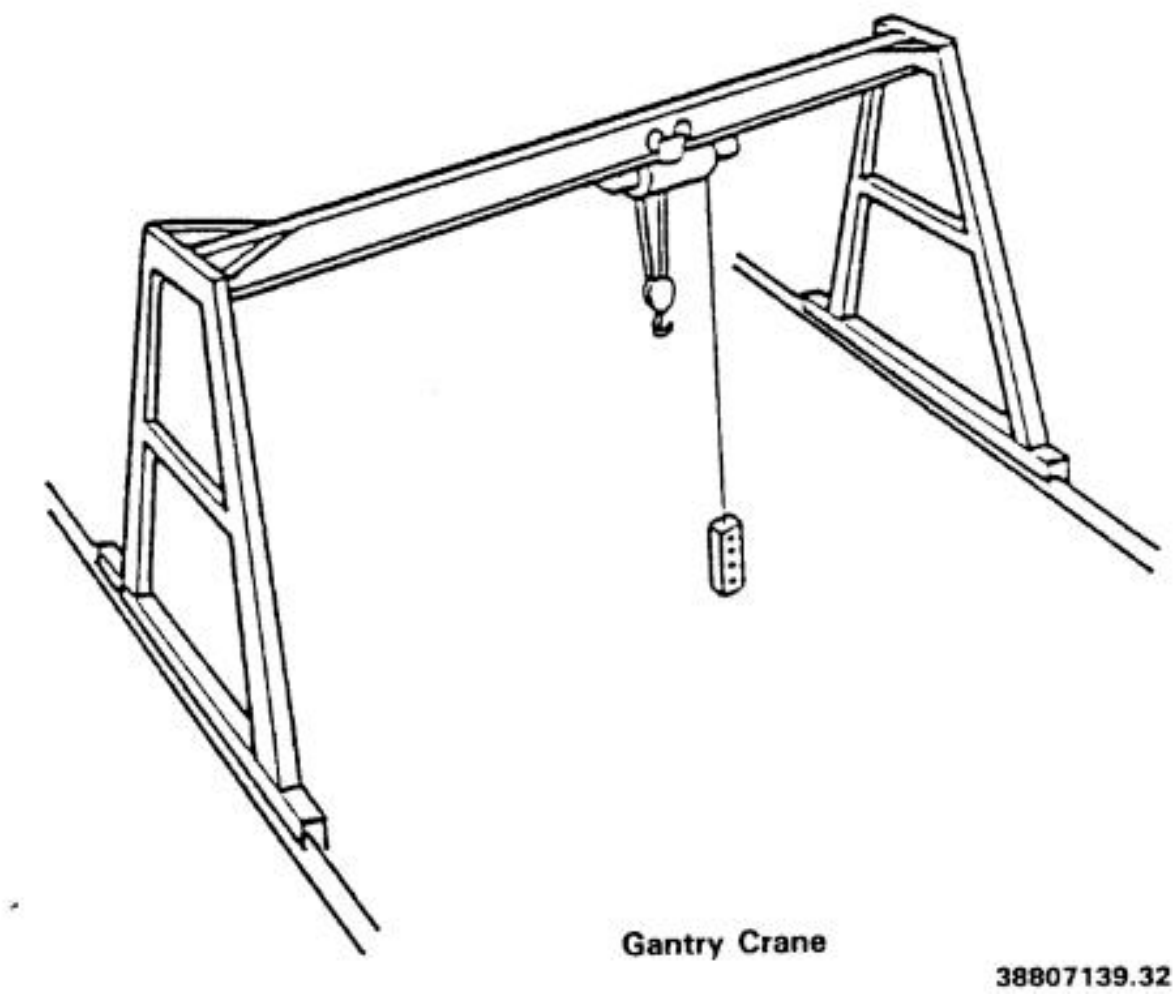

Figure 12.2. Overhead Floor Operated Crane and Gantry Crane 


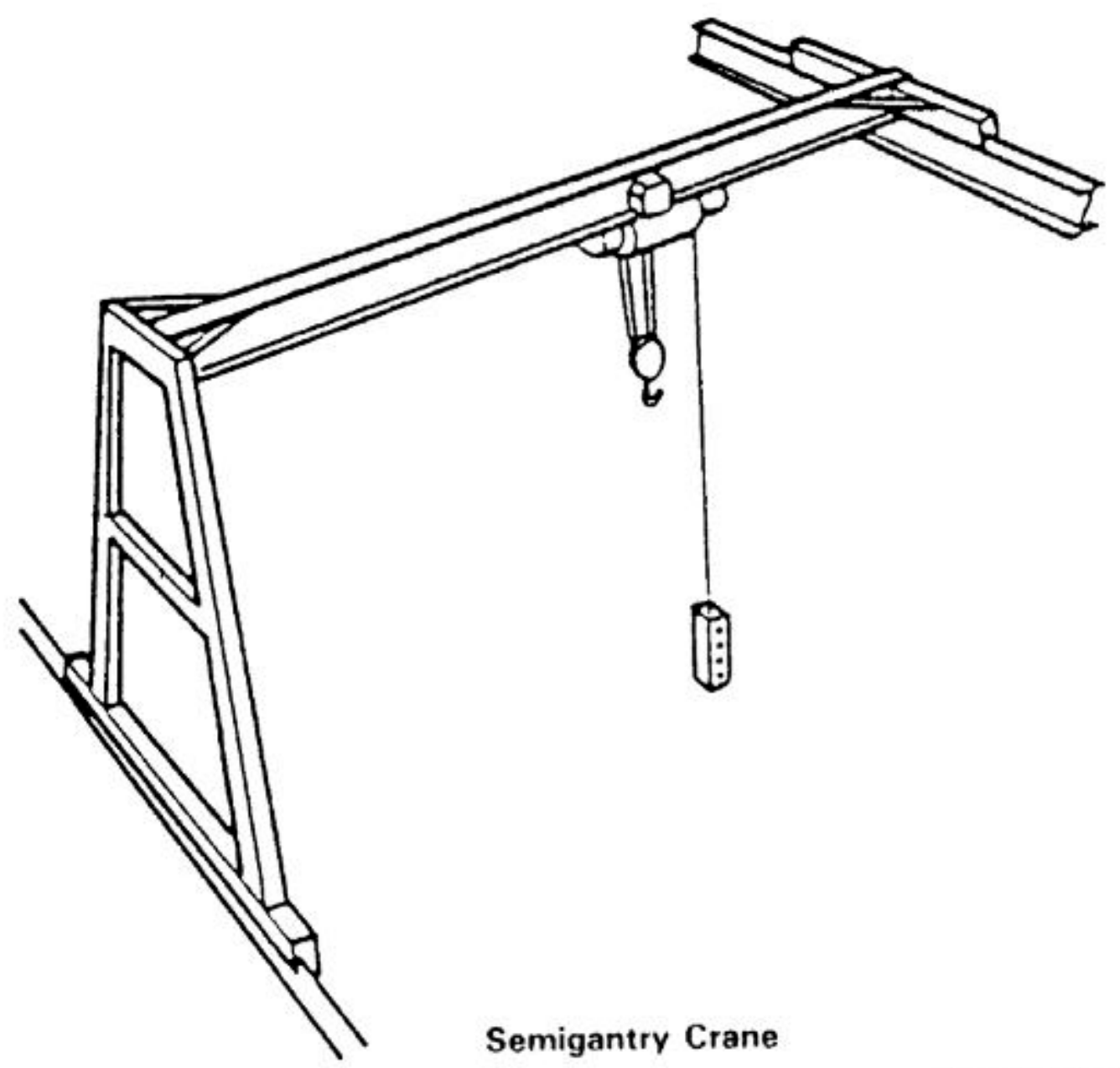

38807139.33

Figure 12.3. Semigantry Crane 


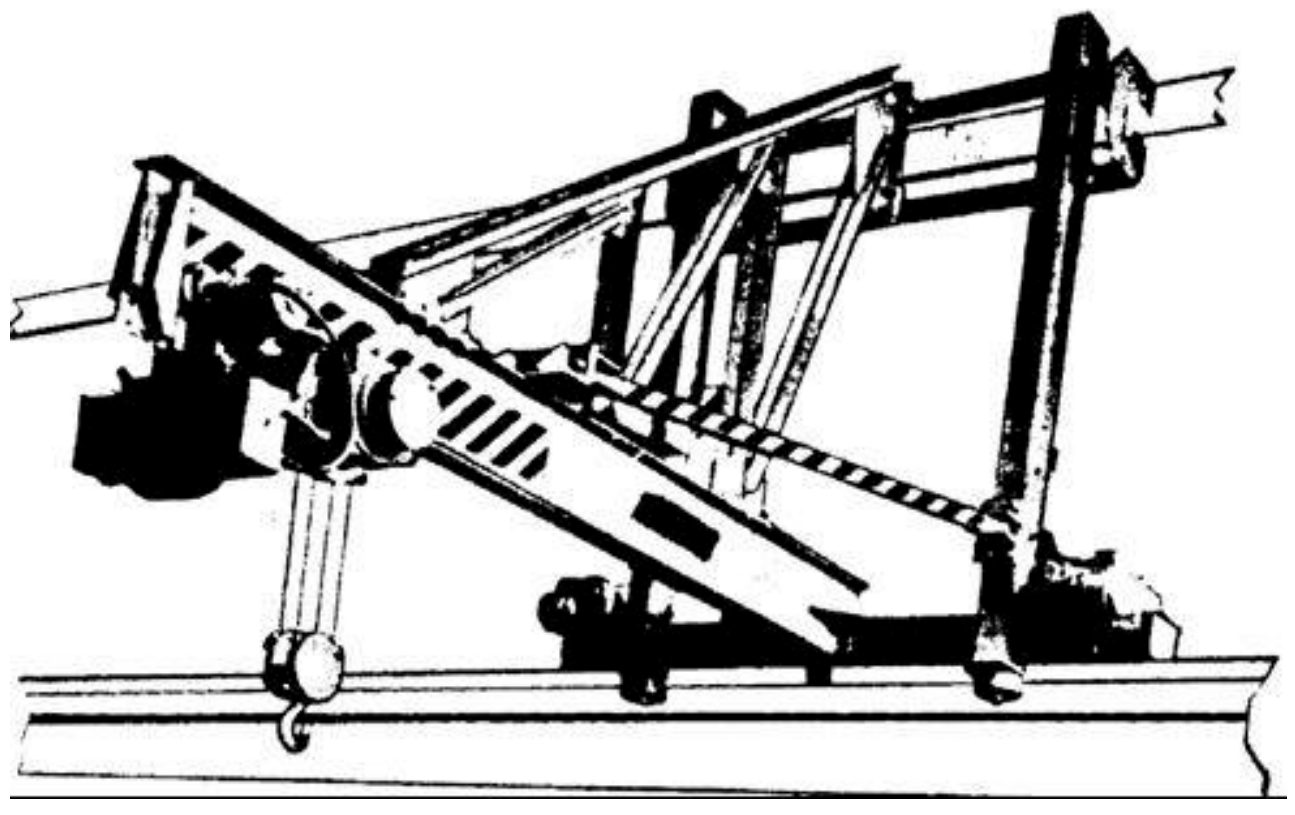

Figure 12.4. Wall Crane

170 


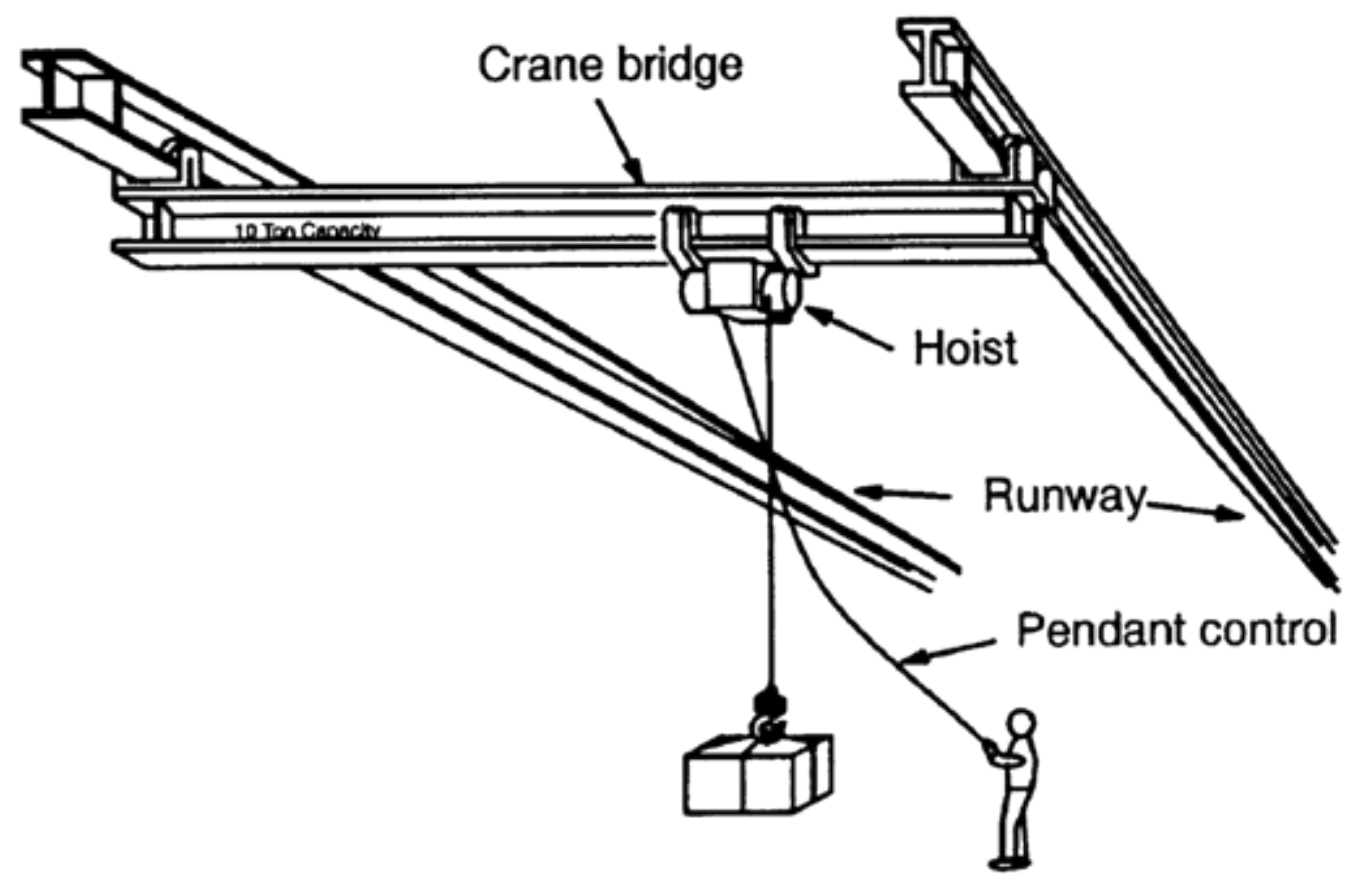

Underhung Floor-Operated Crane

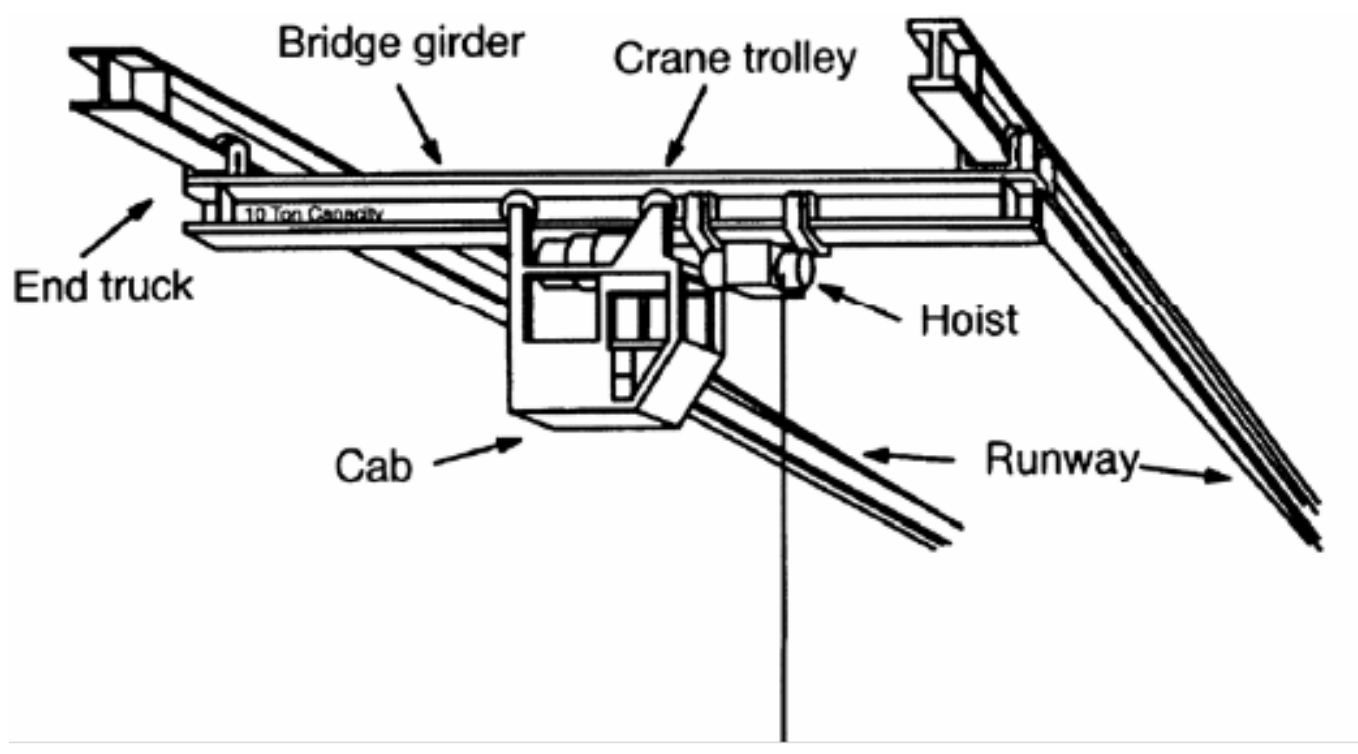

Underhung Cab-Operated Crane

Figure 12.5. Underhung Cranes 


\subsection{Hoisting and Rigging in Hostile Environments}

\subsection{Scope}

\subsubsection{Normal Operations}

Hoisting and rigging activities can usually be accomplished where the environment will allow normal operations with access for hands-on equipment contact. In such situations, operations, maintenance, inspections, and tests shall be done in accordance with regular provisions of this manual.

\subsubsection{Special Provisions}

This section contains the special provisions for hoisting and rigging operations and equipment in hostile environments where standard operating, maintenance, inspection, or test procedures cannot be followed as a result of radiation or contamination, toxic/hazardous chemicals or gasses, or temperature extremes.

\subsection{Equipment and Operations Review}

\subsubsection{Prerequisite Review}

The hoisting and rigging equipment or operations shall be reviewed by a designated person to determine compliance with the requirements of this manual. If it is determined to be impossible or unreasonable for the requirements of this manual to be met as a result of hostile environmental conditions, then a hostile environment plan shall be prepared to document alternative compliance methods and procedures.

\subsubsection{As Low As Reasonably Achievable}

All hoisting and rigging operations shall be consistent with the U.S. Department of Energy's radiation exposure policy of "as low as reasonably achievable” (ALARA).

\subsubsection{First Priority}

Safety of personnel shall remain the first priority.

\subsection{Hostile Environment Plan}

\subsubsection{Preparation}

A hostile environment plan shall be prepared by a designated person and shall cover operations, equipment, inspection, testing, and maintenance. See Appendix 15.0B.11, “Typical Hostile Environment Plan.” 


\subsubsection{Review/Approval Requirements}

As a minimum, the plan shall be reviewed and approved (signed and dated) by responsible management at the facility where the crane/hoist or other equipment is located and responsible management of an overview organization (such as Safety or Quality Assurance). Depending upon the site-specific organizational structure, the following review/approvals are recommended:

- *Facility manager

- *Responsible management, oversight organization (safety or quality assurance/control)

- Responsible operations manager

- Equipment custodian

- Cognizant engineer.

*Review/approval is mandatory.

\subsubsection{Hostile Environment Plan Contents}

The plan shall address only those actions or features that require deviation from the requirements of this manual because of a hostile environment, but shall contain the following information as a minimum:

- The specific requirement(s) that are not in compliance.

- The difference between the requirement and actual conditions.

- Justification for not meeting this manual's requirements.

- A statement of actions or features to be used to compensate for the differences.

- Specific maintenance, inspections, and tests to be performed whenever access is possible.

- Replacement or retirement criteria for equipment that is designed to operate with minimum or no maintenance.

\subsubsection{Additional Procedures}

Detailed operation, inspection, testing, and maintenance procedures that state specific requirements and acceptance criteria shall be prepared based upon the hostile environment plan.

\subsubsection{Hostile Environment Plan Distribution}

The facility manager shall ensure that the approved hostile environment plan is distributed as follows:

- Equipment operators, maintenance organizations, and other organizations/personnel affected by the plan. 
- Equipment history file.

Note: Hostile environment plans in the equipment history file shall be readily available to appointed personnel.

\subsection{Marking and Posting}

Equipment that requires a hostile environment plan should be posted "Hostile Environment PlanSpecial Maintenance and Operating Instructions.”

\subsection{Inspection and Material Limitations}

\subsubsection{Hardware}

Handling fixtures, rigging, and rigging accessories shall be marked, tagged, load tested, and otherwise qualified, as appropriate, in accordance with this manual before being exposed to the hostile environment.

\subsubsection{Polyester}

Polyester (rope or webbing) slings shall not be used in a radiation area.

\subsubsection{Nylon}

Nylon (rope or webbing) slings should not be used in a radiation area unless absolutely necessary. When it is necessary to use a nylon sling in a radiation area, the responsible manager shall ensure radiation exposure does not exceed 100,000 rads during the life of the sling. 


\subsection{References and Bibliography}

\subsection{References}

Note: References listed in this section are cited in the document text.

10 CFR 710, "Criteria and Procedures for Determining Eligibility for Access to Classified Matter or Special Nuclear Material,” Code of Federal Regulations, U.S. Department of Energy. Washington, D.C.

29 CFR, “Labor,” Code of Federal Regulations, U.S. Department of Labor. Washington, D.C.

1910, Occupational Safety and Health Administration

1910.27, "Fixed Ladders"

1910.178, "Powered Industrial Trucks"

1910.179, "Overhead and Gantry Cranes”

1910.184, "Slings”

1926, Safety and Health Regulations for Construction

1926.251, "Rigging Equipment for Material Handling”

American National Standards Institute. Washington, D.C.

MH27.1, "Specifications for Underhung Cranes and Monorail Systems"

N14.6, “American National Standard for Radioactive Materials - Special Lifting Devices for

Shipping Containers Weighing 10,000 Pounds (4500 kg) or More"

Z241.2, "Safety Requirements for Melting and Pouring of Metals in the Metalcasting Industry"

American National Standards Institute/American Society of Mechanical Engineers. Washington, D.C./New York, New York.

A12.1, "Safety Code for Floor and Wall Openings, Railings, and Toeboards"

B18.15, "Forged Eyebolt"

American Society of Mechanical Engineers. New York, New York.

B30.2, “Overhead and Gantry Cranes Top Running Bridge, Single or Multiple Girder, Top

Running Trolley Hoist”

B30.9, "Slings"

B30.10, "Hooks"

B30.11, "Monorails and Underhung Cranes"

B30.16, "Overhead Hoists (Underhung)"

B30.17, "Overhead and Gantry Cranes (Top Running Bridge, Single Girder, Underhung Hoist)”

B30.20, "Below-the-Hook Lifting Devices"

B30.21, "Manually Lever Operated Hoists"

B56.1, "Safety Standard for Low Lift and High Lift Trucks"

7.5, "Nameplates and Markings"

7.25, "Forks"

7.35, "Platforms"

B56.1, "Safety Standard for Low Lift and High Lift Trucks"

B56.6, "Safety Standard for Rough Terrain Forklift Trucks" 
PALD-1997, Portable Automotive Lifting Devices, part 12, “Shop Cranes”

American National Standards Institute /American Welding Society. New York, New York/Miami, Florida.

D1.1, "Structural Welding Code - Steel”

D1.2, "Structural Welding Code - Aluminum"

D14.1, "Specification for Welding of Industrial and Mill Cranes and Other Material Handling Equipment”

American Society of Testing and Materials. Washington, D.C.

A148/A148M, “Standard Specification for Steel Castings, High Strength, For Structural Purposes"

A391/A391M, "Standard Specification for Grade 80 for Alloy Steel Chain”

A489, "Standard Specification for Carbon Steel Eyebolts"

E165, "Standard Practice for Liquid Penetrant Inspection Method"

E790, "Standard Practice for Magnetic Particle Examination"

F541, "Standard Specifications for Alloy Steel Eyebolts"

CMAA, Crane Manufacturer's Association of America, Charlotte, North Carolina:

70, “Specifications for Top Running Bridge \& Gantry Type Multiple Girder Electric Overhead Traveling Cranes"

74, “Specifications for Top Running \& Under Running Single Girder Electric Overhead Traveling Cranes Utilizing Under Running Trolley Hoist”

DOE-HDBK-1205-97, “Guide to Good Practices for Design Development and Implementation.” U.S. Department of Energy.Washington, D.C.

DOE-HDBK-1206-98, “Guide to Good Practices for on-the-Job Training.” U.S. Department of Energy. Washington, D.C.

DOE Order 5480.4, “Environmental Protection, Safety, and Health Protection Standards.” U.S.

Department of Energy. Washington, D.C.

DOE Order 5480.20A, "Personnel Selection, Qualification, and Training Requirements for DOE Nuclear Facilities.” U.S. Department of Energy. Washington, D.C.

Federal Specification. General Services Administration. Washington, D.C.

FF-T-791, "Turnbuckle”

RR-C-271, “Chains and Attachments, Welded and Weldless”

Functions, Responsibilities and Authorities Manual. U.S. Department of Energy. Richland Operations Office. Richland, Washington.

NEMA. "Enclosures for Industrial Control and Systems, ICS-6.” National Electrical Manufacturers Association. Rosslyn, Virginia.

National Fire Protection Agency. Quincy, Massachusetts. 
505, "Powered Industrial Trucks Including Type Designations, Areas of Use, Conversions, Maintenance, and Operation"

70, National Electrical Code

Article 610, "Cranes and Hoists"

J765, “Crane Load Stability Test Code.” SAE International. Warrendale, Pennsylvania.

\subsection{Bibliography}

Note: References that are listed in this section are not cited in the document text, but include sections that relate to topics in this document.

29 CFR, “Labor,” Code of Federal Regulations, Washington, D.C.:

1910, Occupational Safety and Health Standards

1926, Safety and Health Regulations for Construction 1926.106, "Working"

American National Standards Institute, New York, New York:

A1264.1, "Safety Requirements for Workplace Floor and Wall Openings, Stairs and Railing Systems"

N14.6, "For Radioactive Materials Special Lifting Devices for Shipping Containers Weighing 10,000 Pounds $(4,500 \mathrm{~kg})$ or More”

ASME, American Society of Mechanical Engineers, New York, New York:

B56.10, "Manually Propelled High Lift Industrial Trucks”

NOG-1, "Rules for Construction of Overhead and Gantry Cranes (Top Running Bridge, Multiple Girder)"

NUM-1, "Rules for Construction of Cranes, Monorails, and Hoist (with bridge or trolley or hoist of the underhung type)"

The Crosby General Catalog. The Crosby Group, Inc. Tulsa, Oklahoma.

Construction Safety Association of Ontario. Toronto, Ontario, Canada.

Mobile Crane Manual

Rigging Manual

RR-W-410D, “Wire Rope and Strand.” General Services Administration. Washington, D.C.

UL, Underwriters Laboratories, New York, New York:

558, "Standard for Safety Industrial Trucks, Internal Combustion Engine-Powered"

583, "Standard for Safety Electric-Battery-Powered Industrial Trucks"

WAC 296-24, “General Safety and Health Standards.” Washington State Department of Labor \& Industries. Olympia, Washington. 
Wire Rope Technical Board. Granbury, Texas.

Wire Rope Sling Users Manual, 1990.

Wire Rope Users Manual, 3rd Edition, 1993. 


\subsection{Revision History}

September 2005, Revision $0 \quad$ The PNNL Hoisting and Rigging Manual was developed using the DOE Hanford Hosting and Rigging manual as a basis. The DOE Hanford Hoisting and Rigging Manual is no longer required by contract.

December 2005, Revision 1 Clarification statements were provided for issues involving forklift attachment manufacturer approvals.

December 2008, Revision 1.1 Reformatted and edited for official, external release. Minor update to Hook Inspection section. 

Appendix A

\section{Definitions and Acronyms}





\section{Appendix A: Definitions and Acronyms}

The following specialized terms and acronyms are used regarding hoisting and rigging operations and equipment. Not all of these terms are used in this manual but have been included for general information.

AC

acceleration stress

ACI

administrative or

regulatory authority

aggregate strength

AGMA

AISC

AISE

AISI

Albert's lay

alternate lay

alternator/generator

(eddy current brake)

angle of loading

ANS

API

appointed person

armored rope

ASLE
Alternating current.

Additional stress imposed by an increase in the load velocity.

American Concrete Institute.

Governmental agency, or the employer in the absence of governmental jurisdiction.

The wire rope strength derived by totaling the individual breaking strengths of the elements of the strand or rope. This strength does not recognize the reduction in strength resulting from the angularity of the elements in the rope or from other factors that may affect efficiency.

American Gear Manufacturers Association.

American Institute of Steel Construction.

Association of Iron and Steel Engineers.

American Iron and Steel Institute.

Synonymous with lang lay.

Lay of wire rope in which the strands are alternately regular lay and lang lay.

When used in conjunction with an eddy current brake, it provides staider excitation in the event of simultaneous loss of power and mechanical brake failure. Provides for a safe lowering of a suspended load after power failure.

Inclination of a leg or branch of a sling as measured from the horizontal or vertical plane.

American Nuclear Society.

American Petroleum Institute.

Person assigned specific responsibilities for an activity.

See steel clad rope.

American Society of Lubrication Engineers. 
ASM

ASME

ASNT

attachment, forklift

truck

authorized

authorized service

center

auxiliary hoist

AWG

bail

barrel

base

basket of socket

bearing life (rated life)

becket line

becket loop

bird cage
American Society of Metals.

American Society of Mechanical Engineers.

American Society for Nondestructive Testing.

A device other than conventional forks or load backrest extension, mounted permanently or removably on the elevating mechanism of a forklift truck for handling the load. Popular types are fork extensions, clamps, rotating devices, side shifters, load stabilizers, rams, and booms.

Approved by a duly constituted administrator or regulatory authority.

An independent service facility designated by the manufacturer to repair and test equipment of their manufacture.

Supplemental hoisting unit usually smaller and faster than the main hoist.

American Wire Gage.

(a) The U-shaped member of a bucket or load usually used as a lifting point; or (b) A U-shaped portion of a socket, or other fitting used on wire rope.

The lagging or body part of a rope drum in a drum hoist.

The mounting flanges or feet used to attach a hoist to its supporting structure or foundation.

The conical portion of a socket into which a splayed rope end is inserted and secured with zinc.

The number of revolutions or the number of hours at a constant speed that $90 \%$ of an apparently identical group of bearings will complete or exceed before the first evidence of fatigue develops; i.e., 10 out of 100 bearings will fail before rated life. Minimum life and $\mathbf{L 1 0}$ life are also used to mean rated life.

That part of the rope in a multi-ply reeving system that is dead-ended on one of the blocks.

A loop of small rope or strand fastened to the end of a large wire rope to facilitate installation.

A colloquial term describing the appearance of wire rope forced into compression. The outer strands form a "cage" and, at times, displace the core. 
bleeding line

block

brake

brake, eddy current

brake, holding or parking

brake, mechanical load

braking, counter torque

breaking strength

bridge crane

bridge travel

bridge trucks

bridle sling

bright rope

brooming

bull ring

bumper (buffer)
A condition caused when wire rope is overloaded, forcing the lubricant in the cable to be squeezed out and run excessively.

A term applied to a wire rope sheave (pulley) enclosed inside plates and fitted with some attachment such as a hook or shackle.

A device used for retarding or stopping motion by friction or power means.

A device for controlling load speed in the hoisting or lowering direction by placing a supplementary load on the motor. This loading results from the interaction of magnetic fields produced by an adjustable or variable direct current in the stator coils and induced currents in the rotor.

A brake that automatically sets and prevents motion when power is off.

A friction device, usually using multiple discs or shoes, for controlling load speed in the lowering direction only. The brake prevents the load from overhauling the motor.

See counter torque.

The measured tensile load required to cause failure of cable, chain, wire rope, or any other load-bearing element.

\section{See cranes, types of.}

Horizontal travel of the crane parallel with bridge runway rails.

An assembly consisting of wheels, bearings, axles, and structural framework that supports the end reactions of the bridge girders.

Sling composed of multiple wire rope legs with a fitting that attaches to the lifting hook.

Wire rope made of wires that are not coated with zinc or tin.

Unlaying and straightening of strands and wires in the end of wire ropes during the process of installing a wire rope socket.

The main, large ring of a sling to which sling legs are attached; also called master link.

An energy-absorbing device that reduces impact when two moving cranes or trolleys come into contact or when a moving crane or trolley reaches the end of its permitted travel. 
cab

cab, normal

cab, skeleton

cable

cable crowd rope

cable-laid wire rope

cableway

cab-operated crane

camber

CFR

cheek plate(s)

cheek weights

choker

choker hitch

class (of load)

clearance

clevis

clip

closed cell

closed socket
Operator's compartment on a crane.

Operator's compartment from which a crane is controlled.

Operator's compartment used for occasional cab operation of a normally floor- or remote-operated crane.

A term loosely applied to wire ropes, wire strand, and electrical conductors. Wire rope is the preferred term for hoisting and rigging application.

Wire rope used to force the bucket of a power shovel into the material being handled.

A wire rope consisting of several independent wire ropes wrapped around a fiber or wire rope core.

Aerial conveying system for transporting single loads along a suspended track cable.

\section{See cranes, types of.}

The slight curvature given to beams and girders to compensate for deflections caused by loading.

Code of Federal Regulations.

The stationary plate that support(s) the pin (axle) of a sheave or load.

Overhauling weights attached to the side plates of a lower load block.

Sling, wire rope with eyes spliced on each end, which is used to lift load.

Sling with one end passing under the load and through a loop end attachment on other end of sling.

See critical service and critical lift.

The horizontal or vertical distance from any part of the crane to a point of the nearest obstruction.

A U-shaped fitting with holes in each end through which a pin or bolt is run.

Fitting for clamping two parts of wire rope.

For the purposes of this manual, access to closed cells is limited during some operating cycles. See hot cell.

Wire rope end fitting consisting of integral basket and bail. 
closing line

CMAA

CMV

coil

collector

come-along

conductors (bridge or

runway)

conical drum

continuous bend

control braking means

controller

controller, spring return

control panel

core

corrosion
Wire rope that closes a clamshell or orange-peel bucket, and then operates as a hoisting rope.

Crane Manufacturers Association of America.

Commercial Motor Vehicle.

Circular bundle of wire or fiber rope not packed on a reel.

Contacting device mounted on bridge or trolley for collecting current from conductor system.

Lever-operated chain or wire rope devices designed for pulling, not lifting; also called pullers. Unlike hoists, the tension is held by a releasable ratchet. Much smaller and lighter than hoists of equal capacity, they are not intended nor allowed for lifting, but are suited for activities such as skidding machinery.

Electrical conductors located along the bridge girder(s) or runway to provide power and/or control circuits to the crane and trolley.

Grooved hoisting drum of tapering diameter.

Reeving of wire rope over sheaves and drums so that it bends in one direction, as opposed to reverse bend.

A method of controlling hoisting or lowering speed of the load by removing energy from the moving load or by imparting energy in the opposite direction.

A device or group of devices that serve to govern, in some predetermined manner, the power delivered to the motor to which it is connected.

A controller which, when released, will return automatically to a neutral position.

An assembly of magnetic or static electrical components that govern the flow of power to or from a motor in response to signals from a master switch, push-button station, or remote control.

Core member of wire rope about which the strands are laid. It may be fiber, a wire strand, or an independent wire rope.

Chemical decomposition by exposure to moisture, acids, alkalis, or other destructive agents. 
corrugated

cover plate

crane

crane classification

crane service
A term used to describe the grooves of a sheave or drum when worn so as to show the impression of a wire rope.

The top or bottom plate of a box girder or junction box.

A machine for lifting and lowering a load vertically and moving it horizontally with the hoisting mechanism as an integral part of the machine. The term is applicable to fixed and mobile machines and to powered or manually driven machines.

The CMAA has established six service classes to enable the purchaser to specify the most economical class of crane for a particular installation. It is not economical either to under specify or to over specify when choosing a service class. Specifying a crane with too light a service class will reduce cost but may result in excessive maintenance. A crane with too high a service class may decrease maintenance costs but at an excessive initial investment. See crane service.

\section{Class A (Standby or Infrequent Service)}

Class A1 (Standby Service) - This service class covers cranes used in installations such as power houses, public utilities, turbine rooms, nuclear reactor buildings, motor rooms, nuclear fuel handling and transformer stations, where precise handling of valuable machinery at slow speeds with long idle periods between lifts is required.

Class A2 (Infrequent Use)-These cranes are used in installations such as small maintenance shops, pump rooms, testing laboratories, and similar operations where the loads are relatively light, speeds are slow, and a low degree of control accuracy is required. The loads may vary anywhere from no load to full rated load with a frequency of a few lifts per day or month.

Class B (Light Service) - This service covers cranes that may be used in repair shops, light assembly operations, service buildings, or light warehousing, where service requirements are light, and the speed is slow. Loads may vary from no load to occasional full rated loads with two to five lifts per hour, averaging 3 meters (10 feet) per lift. 
Class C (Moderate Service)-This service covers cranes that may be used in machine shops or paper-mill machine rooms, where service requirements are moderate. In this type of service, the crane will handle loads that average $50 \%$ of the rated capacity with 5 to 10 lifts per hour, averaging 4.6 meters (15 feet), not over $50 \%$ of the lifts at rated capacity.

In this type of service, loads approaching $50 \%$ of the rated capacity will be handled constantly during the working period. High speeds are desirable for this type of service with 10 to 20 lifts per hour averaging 4.6 meters (15 feet), not over $65 \%$ of the lifts at rated capacity.

Class E (Severe Service) - This type of service requires a crane capable of handling loads approaching a rated capacity throughout its life. Applications may include magnet, bucket, magnet/bucket combination cranes for scrap yards, cement mills, lumber mills, fertilizer plant, or container handling, with 20 or more lifts per hour at or near the rated capacity.

Class F (Continuous Severe Service)-This type of service requires a crane capable of handling loads approaching rated capacity continuously under severe service conditions throughout its life. Applications may include custom-design specialty cranes essential to performing the critical work tasks affecting the total production facility. These cranes must provide the highest reliability with special attention to ease of maintenance features.

automatic crane-A crane that, when activated, operates through a preset cycle or cycles.

bridge crane - A crane with a single- or multiple-girder movable bridge, carrying a movable trolley or fixed hoisting mechanism, and traveling on an overhead fixed runway structure.

crawler crane - A crane consisting of a rotating superstructure with power plant, operating machinery, and boom, mounted on a base, equipped with crawler treads for travel. Its function is to hoist, lower, and swing loads at various radii.

double-girder crane - A crane having two bridge girders mounted between, and supported from, the end trucks.

floor-operated crane-A power-operated crane that is controlled by an operator from the floor or an independent platform or walkway located in the crane-way, using power control switches or push-buttons on a pendant. 
gantry crane-A crane similar to an overhead bridge crane, except that the bridge for carrying the trolley or trolleys is rigidly supported on two or more legs running on fixed rails or other runway, usually 3 meters (10 feet) or more below the bottom of the bridge.

jib crane - A fixed crane with a vertical rotating member supported at the bottom (also at the top in some types), from which an arm extends to carry the hoist trolley. Jib cranes are most commonly mounted on a vertical column, supplied as part of the jib crane or mounted on existing structural members (e.g., a wall-mounted jib crane).

manually operated crane-A crane whose hoist mechanism is driven by pulling an endless chain, or whose travel mechanism is driven in the same manner or by manually moving the load.

monorail crane - A crane or hoist attached to a trolley that runs on the flanges of a structural beam.

overhead crane - A crane with a single or multiple girder movable bridge, carrying a movable trolley or fixed hoisting mechanism, and traveling on an overhead fixed runway structure.

power-operated crane-A crane whose mechanism is driven by electricity, air, hydraulic, or internal combustion engine, as opposed to hand-operated movements.

remotely operated crane - A crane controlled by any method other than with a pendant, rope, or attached cab.

semigantry crane - A gantry crane with one end of the bridge rigidly supported by leg(s) that run on a fixed rail or runway and the other end supported by end trucks that run on an elevated rail or runway.

single-girder crane - A crane having one bridge girder mounted between, and supported from the end trucks.

wall-mounted jib-See cranes, types of, jib crane.

wall crane - A crane having a jib, with or without a trolley, supported from a side wall or line of columns of a building. It is a traveling-type crane and operates on a runway attached to the side wall or line of columns.

craneway

creep speed
The area in length and width served by a crane.

A very slow, constant, continuous, fixed rate of motion of the hoist, trolley, or bridge, usually established at $1 \%$ to $10 \%$ of the normal full-load speed. 


\author{
critical diameter \\ Diameter of the smallest bend for a given wire rope that permits the wires \\ and strands to adjust themselves by relative movement while remaining in \\ normal position. \\ critical load \\ In accordance with ANSI N14.6: Any lifted load whose uncontrolled \\ movement or release could adversely affect any safety-related system when \\ such system is required for unit safety or could result in potential off-site \\ exposures comparable to the guideline exposures outlined in Code of Federal \\ Regulations, Title 10, Part 100. \\ critical load \\ critical service \\ crossover points \\ In accordance with ASME NOG-1: Any lifted load whose uncontrolled \\ movement or release could adversely affect any safety-related system when \\ such system is required for unit safety or could result in potential off-site \\ exposures in excess of the limit determined by the equipment purchaser. \\ The use of equipment or tackle for hoisting, rigging, or handling of critical \\ items, or other items in, around, or above spaces containing critical items. \\ In multiple-layer spooling of rope on a drum, those points of rope contact \\ where the rope crosses the preceding rope layer. \\ custodian \\ cylindrical drum \\ DC \\ D/d RATIO \\ An individual designated as having custodial responsibility for equipment. \\ The custodian takes "ownership" of assigned equipment and ensures that \\ required maintenance, inspections, and tests remain current. The custodian \\ will have quick access to the equipment history file. \\ Hoisting drum of uniform diameter. \\ Direct current. \\ A term regarding wire rope. $\mathrm{D}=$ Diameter of curvature around which the \\ rope is bent. $d=$ diameter of rope. Example: With 0.5-inch-diameter rope \\ passing over a 20 -inch-diameter sheave, the $\mathrm{D} / \mathrm{d}$ ratio is 40 . The $\mathrm{D} / \mathrm{d}$ ratio is \\ a key factor in load-carrying ability and life span of a wire rope. \\ dead end \\ deadman \\ deceleration stress \\ The point of fastening of one rope end in a running rope system, the other \\ end being fastened at the rope drum. \\ An object or structure, either existing or built for the purpose, used as \\ anchorage for a guy rope. \\ Additional stress imposed on rigging resulting from a decrease in load \\ velocity.
}


deflection

derrick

design factor

designated

diameter (wire rope)

direct geared

dog leg

DOL

DOT

dragline

drifting

drift point

drive (a) The sag across a span of a load member caused by the imposed live and/or dead loads, which is usually measured at mid-span as the distance along a straight horizontal line drawn between the supports; (b) any deviation from a straight horizontal line.

An apparatus for lifting or lowering loads, consisting of a mast or equivalent member held at the head by guys or braces, with or without a boom, for use with hoists and ropes.

The conservatism used in design calculations. As a function of design, this factor can be based upon the point of equipment failure, such as crane tipping, and brake stopping capacity, or based upon strength of materials, ultimate, nominal, or yield. Consensus standards and this manual express design factors as a ratio (for example: 5:1, 3:1, 3.5:1) or as a single number (for example: 5 , 3, or 3.5, understood to mean the " $X$ " to 1 ). Although "design factor" is sometimes referred to as a "safety factor," "design factor" is the preferred term. An inexperienced person may incorrectly assume this factor of design conservatism will make up for such conditions as shock loading, poor rigging, improper equipment selection, and overload conditions.

Selected or assigned by the employer or employer's representative as being qualified to perform specific duties. See appointed person.

The diameter of wire rope is the diameter of the circle that will contain the rope.

A hoist with drum(s) geared directly to its power source.

Permanent short bend or kink in wire rope caused by improper use.

U.S. Department of Labor.

U.S. Department of Transportation.

Wire rope used to pull an excavating or drag bucket. Also used as an expression of a particular type of mobile crane using a drag bucket during excavation.

Pulling a suspended load laterally to change its horizontal position.

A point on a travel motion controller that releases the brake while the motor is not energized. This allows for coasting before the brake is set.

An assembly consisting of motors, couplings, gear, and gear case(s) that is used to propel a bridge, trolley, or hoist. 
drive girder

drum

drum capacity, rope

drum hoist

dynamic loading

efficiency (wire rope)

elastic limi

end control

end penetration

end termination

end tie

end truck

endless rope

equalizer
Girder on which the bridge drive, cross shaft, walk, railing, and operator's cab are mounted.

(a) A cylindrical-flanged barrel of uniform (cylindrical drum) or tapering (conical drum) diameter on which cable is wound for operation or storage, which may be smooth or grooved; (b) the cylindrical member around which rope is wound for lifting or lowering the load or boom, or swinging the boom supporting structure.

The length of a specific diameter of rope that can be wound on a drum.

A hoisting mechanism incorporating one or more rope drums; also called hoist, winch, or hoisting engine.

Loads introduced into the machine or its components by forces in motion.

Ratio of a wire rope's measured breaking strength and the aggregate strength of all individual wires tested separately, which is usually expressed as a percentage. The breaking strength of wire ropes seldom exceeds $90 \%$ of the aggregate strength of all the wires, the average being about $82.5 \%$.

Limit of stress above which a permanent deformation takes place within the material. This limit is approximately $55 \%$ to $65 \%$ of breaking strength of steel wire ropes.

The operator-control position is located at the end opposite the load end of the truck.

The treatment of the end of a length of wire rope designed primarily as an aid for pulling the rope through a reeving system or tight drum opening. These are not designed for use as a method for making a permanent connection.

The treatment at the end or ends of a length of wire rope, which is usually made by forming an eye or attaching a fitting, designed to be the permanent end termination on the wire rope that connects it to the load.

A structural member, other than the end truck, that connects the ends of the girders to maintain the squareness of the bridge.

An assembly consisting of structural members such as wheels, bearings, and axles that supports the bridge girder(s) or the trolley cross member(s).

Rope whose two ends are spliced together.

Device used to compensate for unequal length or stretch of a hoist rope and connects two or more systems to a single running block. 


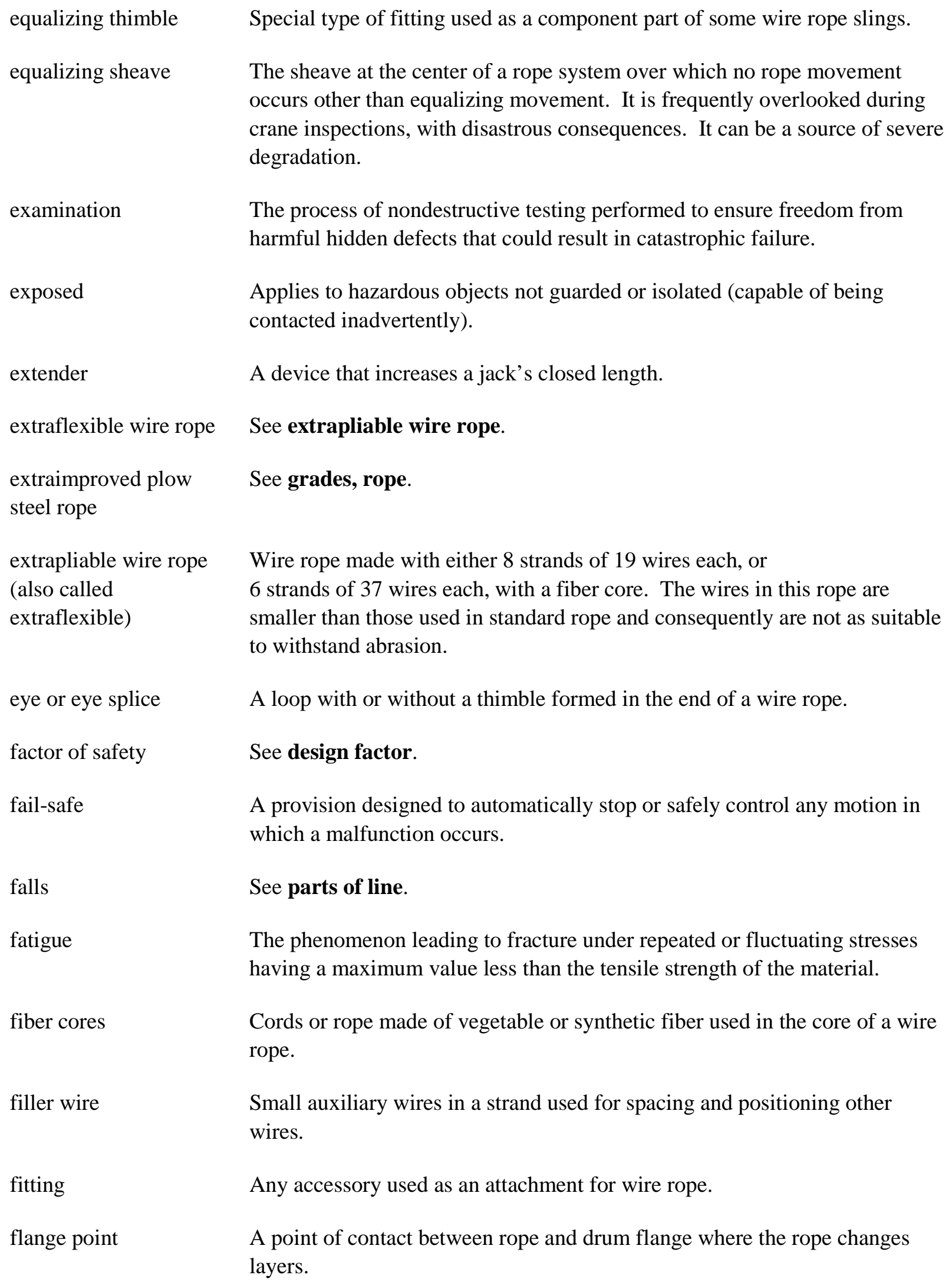

filler wire $\quad$ Small auxiliary wires in a strand used for spacing and positioning other wires.

fitting $\quad$ Any accessory used as an attachment for wire rope.

flange point A point of contact between rope and drum flange where the rope changes layers. 
flat rope

fleet angle

fleeting sheave

flemish eye

floor-operated crane

footblock

foot-walk

forklift truck

front-end attachment

gage points

galvanized rope

galvanized strand

gantry crane

girder, bridge

girder, drive (Girder

"A")

girder, idler (Girder "B”)

girder, runway
Wire rope made of parallel alternating right-lay and left-lay ropes sewn together by relatively soft wire.

The maximum angle between a rope and the line perpendicular to the drum on which it winds.

Sheave mounted on a shaft parallel to the rope-drum shaft and arranged so that it can slide laterally as the rope spools, permitting close sheave placement without excessive fleet angle.

A type or method of making a wire rope eye splice. Same as a "Molly Hogan.”

See cranes, types of.

A steel weldment or assembly serving as the base mounting for a guy derrick, gin pole, or boom derrick.

A walkway with handrail and toeboards, attached to the bridge or trolley for access purposes.

A high-lift, self-loading truck, equipped with load carriage and forks for transporting and tiering loads.

\section{see attachment, fork-lift truck}

Permanent marks on a hook that are used to determine any change in the throat-opening dimension.

Wire rope made of galvanized wire.

Strand made of galvanized wire.

\section{See cranes, types of.}

The principal horizontal beam(s) of the crane, which supports the trolley, is supported by the end trucks, and is perpendicular to the runway.

The bridge girder to which the bridge motor and gear-case(s) are attached. For cranes having a drive on each girder, it is the girder to which the control panels and/or the cab are attached.

The bridge that does not have the bridge drive attached, but usually carries the bridge conductors.

A horizontal beam attached to the building columns or wall and supporting a runway rail on which the crane travels. 
girder, auxiliary

(outrigger)

grades, rope

grooved drum

Grooves

handling fixture

hazardous (classified)

location

high consequence

HMI

hoist
An additional girder, either solid or latticed, arranged parallel to the bridge girder(s) for supporting the footwalk, control panels, or operator's cab to reduce the torsional forces such loads might otherwise impose.

Classification of wire rope by its breaking strength. Listed in order of increasing breaking strengths: iron, traction, mild plow steel, plow steel, improved plow steel, and extraimproved plow steel.

Drum with a grooved surface that accommodates and guides the rope.

Depressions in the periphery of a sheave or drum used for positioning and supporting a rope.

A cradle, handling structure, shipping fixture, or container designed specifically to support or facilitate component lifting or handling during fabrication, loading, shipping, storage, installation, or use.

Locations where fire or explosion hazards may exist. Locations are classified depending on the properties of the flammable vapors, liquids, or gases, or combustible dusts or fibers which may be present and the likelihood that a flammable or combustible concentration or quantity is present.

Class I-Locations in which flammable gases or vapors are, or may be, present in the air in quantities sufficient to produce explosive or ignitable mixtures.

Class II-Locations that are hazardous because of the presence of combustible dust.

Class III-Locations where easily ignitable fibers or flyings are present but not likely to be suspended in quantities sufficient to produce ignitable mixtures.

\section{See critical item, critical lift, and critical service.}

Hoist Manufacturers Institute.

Noun: (a) A lifting device for raising or lowering loads. Its service area is vertical over its mounting. Hoists may be attached to fixed or moveable structures by an upper hook or bracket and can be either power or manually operated; (b) A power-operated component of a crane or monorail system that provides torque to raise a load or lower it at a controlled speed and hold a load stationary; (c) A power-driven drum or drums capable of lifting and lowering loads.

Verb: The action of raising a load. 


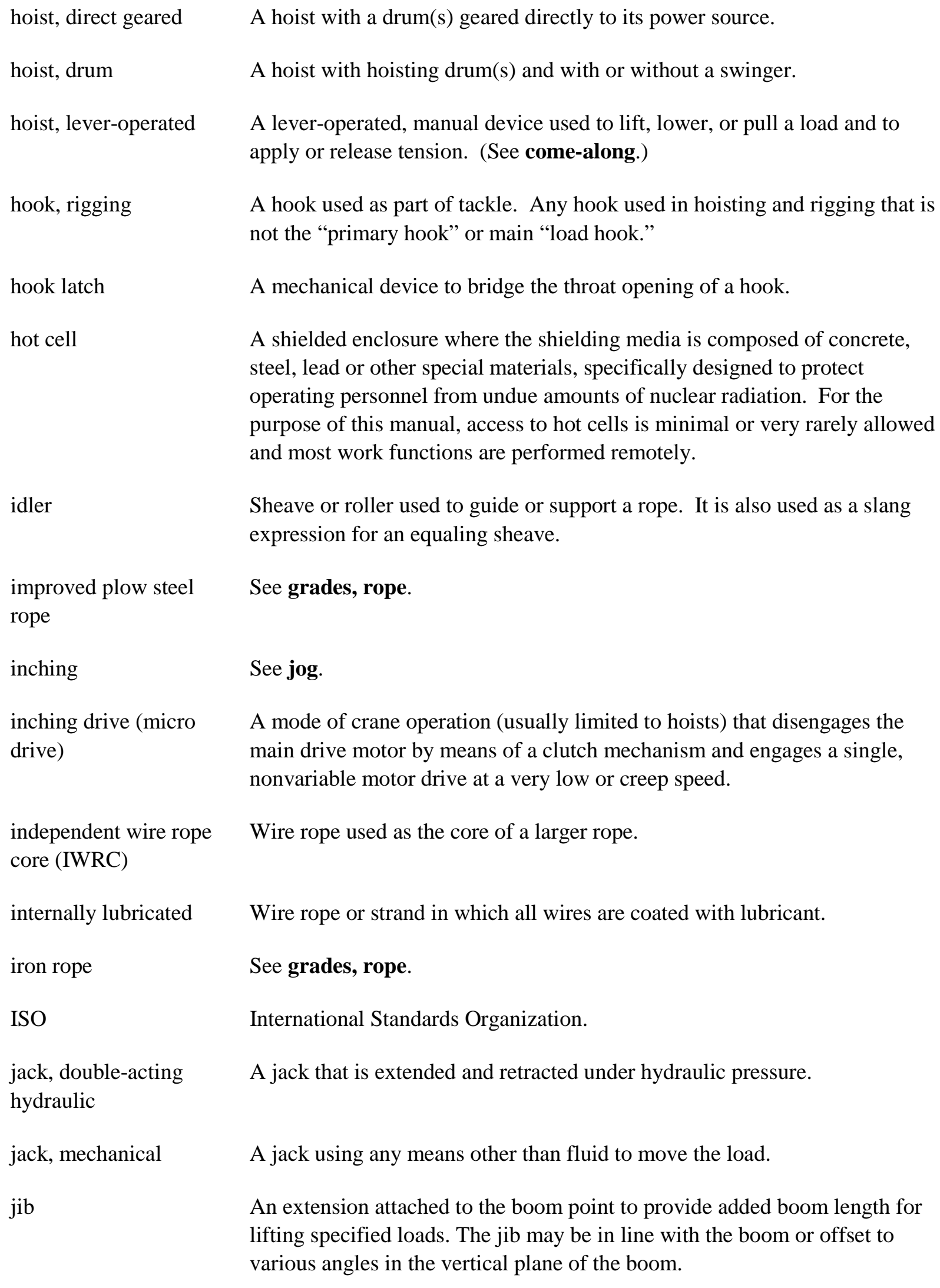

A lever-operated, manual device used to lift, lower, or pull a load and to apply or release tension. (See come-along.)

A hook used as part of tackle. Any hook used in hoisting and rigging that is not the "primary hook" or main "load hook."

A mechanical device to bridge the throat opening of a hook.

A shielded enclosure where the shielding media is composed of concrete, steel, lead or other special materials, specifically designed to protect operating personnel from undue amounts of nuclear radiation. For the purpose of this manual, access to hot cells is minimal or very rarely allowed and most work functions are performed remotely.

Sheave or roller used to guide or support a rope. It is also used as a slang expression for an equaling sheave.

\section{See grades, rope.}

See jog.

A mode of crane operation (usually limited to hoists) that disengages the main drive motor by means of a clutch mechanism and engages a single, nonvariable motor drive at a very low or creep speed.

Wire rope used as the core of a larger rope.

\footnotetext{
Wire rope or strand in which all wires are coated with lubricant.

International Standards Organization.
A jack that is extended and retracted under hydraulic pressure.

International Standards Organization.
A jack that is extended and retracted under hydraulic pressure.

A jack using any means other than fluid to move the load.

various angles in the vertical plane of the boom.
} 
jib crane

jog (inch)

kink

laced blocks

lagging

lang lay rope

latch, hook

lay (wire rope)

lead line

lefthand end

left lay

lift

lift beam

lifting devices

lifting eye

\section{See cranes, types of.}

To move the hook, trolley, or bridge in a series of short, discontinuous increments by momentary operation of a controller.

Permanent distortion of wires and strands resulting from sharp bends.

Passing wire rope through a set of blocks by starting from an outside sheave and following in rotation. Will usually tilt travel block when running empty.

External wood covering on a reel to protect the wire rope, strand, or grooved drum.

Wire rope in which the wires in the strands and the strands in the rope are laid in same direction. Synonymous with albert's lay.

A device used to bridge the throat opening of a hook.

(a) The manner in which the wires in a strand or the strands in a rope are helically laid, or (b) the distance measured parallel to the axis of the rope (or strand) in which a strand (or wire) makes one complete helical convolution about the core (or center). In this connection, lay is also referred to as "lay length" or "pitch."

That part of a rope tackle leading from the first or fast sheave to the drum.

A reference to parts or dimensions on the viewer's left of the centerline of span, established when facing the drive girder side of the crane.

(a) strand--strand in which cover wires are laid in a helical pitch, similar to left-hand screw; (b) rope--rope in which strands are laid in a helix having a left-hand pitch, similar to left-hand screw.

(a) Any sequence of operations in which a hoisting device raises an object above the ground, floor, or support, and then places it on the ground, floor, or support; (b) maximum safe vertical distance through which the hook can travel; (c) the hoisting of a load.

\section{See spreader beam.}

Devices that are not reeved onto the hoist ropes, such as hook-on buckets, magnets, grabs, load-spreader bars, and other supplemental units used for ease of handling certain types of loads. The weight of these devices is to be considered part of the working load.

A point of attachment on the item to be lifted, having a looped head designed to accommodate a hook or shackle. Also called a slinging eye. 
limiting devices

limit switch

line

line pull

line speed

load

load-bearing parts

load block, lower

load block, upper

load center (forklifts)

load, critical

load, dead

load float
A device that is operated by some part of a power-driven machine or equipment to control motions of the machine or equipment.

An electrical device that is operated by the bridge, trolley, or hoist motion to disconnect the circuit, to establish a new circuit, or to provide a warning.

Rope used for supporting and controlling a suspended load.

The pulling force attainable in a rope leading off a rope drum or lagging at a particular pitch diameter (number of layers).

The speed attainable in a rope leading off a rope drum or lagging at a particular pitch diameter (number of layers).

The total superimposed weight or force to be overcome by the hoisting and rigging equipment.

Any part of a material-handling device in which the induced stress is influenced by the hook load. A primary load-bearing part is one, where the failure of which could result in dropping, upset, or uncontrolled motion of the load. Load-bearing parts which, if failed, would result in no more than stoppage of the equipment without causing dropping, upset, or loss of control of the load, are not considered to be primary load-bearing parts.

The assembly of hook or shackle, swivel, sheaves, pins, and frame suspended by hoisting ropes.

The assembly of sheaves, pins, and frame suspended from the hoisting platform or from the boom in mobile cranes.

The horizontal longitudinal distance from the intersection of the horizontal load-carrying surfaces and vertical load engaging faces of the forks (or equivalent load positioning structure) to the center of gravity of the load.

\section{See critical load.}

The load(s) on a portion of the crane, which remain(s) in a fixed position relative to the member being considered.

A control system that enables stepless operation of a hoist in either the lifting or lowering direction for a range of about $0 \%$ to $5 \%$ of full-rated speed, as well as permitting the load to be suspended stationary for a very short time with the holding brake(s) released. 
load, live

load point

load point, auxiliary

load, rated

load rating

load, safe working

(SWL)

load, working

locked coil strand

lowest service

temperature (LST)

magnet

magnetic controls

magnetic particle

examination

main hoist

main switch
A load that moves or varies relative to the member being considered. For the trolley, the live load consists of the rated load plus the weight of the block. For the bridge, the live load consists of the rated load plus the weight of the trolley.

The point of load application.

Any point of load application other than the load point.

The maximum static vertical load for which a crane or an individual hoist is designed. See rated capacity.

Rating in pounds established by the manufacturer.

The maximum load a piece of equipment (or tackle) can handle without exceeding the rated capacity (the rated capacity of the lowest capacity item used in the lift). See load, rated.

The external load, in pounds applied to the crane. For mobile cranes and derricks, the weight of load-attaching equipment is included as part of the working load (e.g., load blocks, hooks, shackles, and slings). In permanently installed cranes such as overhead, gantry, and monorail cranes and hoists, the weight of the load block and hook is not part of the working load.

Smooth-surfaced strand composed of shaped wires laid in concentric layers around a center of round wires.

A predetermined temperature below which all lifting equipment, assemblies, or fixtures should not be used.

An electromagnetic device carried on a crane hook that picks up loads magnetically.

Controls in which acceleration and deceleration are controlled as a master switch or pushbutton is moved from neutral to the forward or reverse positions. A combination of electromagnetically operated contractors and relays that actuate sequentially to vary the motor torque by changing the resistance.

A nondestructive test that reveals defects in ferromagnetic materials via detection of leakage fields at discontinuities in magnetic flow paths.

The hoist mechanism provided for lifting the machine's maximum-rated load.

A switch controlling the entire power supply to the hoist. 

marlin spike
Tapered steel pin used in splicing wire rope.
master link
Forged or welded steel link used to support all members (legs) of an alloy- steel chain or wire rope sling (includes bull ring, pear link, oblong link, and weldless sling link). Also called bull- ring.
master switch
A manual or automatic device that governs the operation of contractors and/or auxiliary devices of an electric control and provides for shutdown of all electric power to a crane or hoist.
MHI
micro drive
mild plow
milking
minimum life
Molly Hagan
monorail
monthly
mousing
narrow-aisle truck
NCR
NDA
NDT
Material Handling Institute.
See inching drive.
See grades, rope.
The progressive movement of strands along the axis of the rope, resulting from the ropes movement through a restricted passage such as a tight sheave.

\section{See bearing life.}
A type or method of making a wire rope eye splice. Same as a "flemish eye.”
Usually a series of continuous beams with curves, switches, and stops that carry loads over a predetermined route or routes.
Once each calendar month. A maintenance/inspection program should accomplish monthly tasks at approximately the same time each calendar month. To manage such programs, tasks should be scheduled as "due" on a particular date. If a task cannot reasonably be performed on the scheduled "due" date, it should promptly be rescheduled for a date during the same calendar month.
A method of bridging the throat opening of a hook to prevent the release of load lines and slings, under service or slack conditions, by wrapping with soft wire, rope, heavy tape, or similar materials.
A self-loading truck primarily intended for right-angle stacking in aisles narrower than those normally required by counterbalance trucks of the same capacity.
Nonconformance report.
Nondestructive assessment.
Nondestructive test. 
nil-ductility transition

temperature

NLGI

NLGI Grade number

nominal strength, wire

rope

nondestructive

examination (NDE)

nonrotating wire rope

nonspinning wire rope

normal operating

conditions

NRC

open socket

overhead guard

overload

overtravel

parts of line

paying out
The maximum temperature at which a standard drop-weight specimen breaks when tested in accordance with ASTM E-208.

National Lubricating Grease Institute.

A grade number defining the consistency of grease in accordance with methods prescribed by the National Lubricating Grease Institute.

Nominal wire rope strengths as calculated by a standardized industryaccepted procedure. Minimum acceptance strength is 22\% lower than nominal strength. (Re: Wire Rope Users Manual.)

A name applied to a variety of tests which make use of indirect means to locate material discontinuities (e.g., radiography, dye penetrant, magnetic particle, ultrasonic).

\section{See rotation-resistant rope.}

\section{See rotation-resistant rope.}

Those conditions during which a crane or carrier is being operated and is performing functions within the scope of the original design. For a caboperated crane, the operator is at the operating control devices in the cab and no other person is on the crane. For a floor-operated crane or carrier, the operator is at the operating control devices, which are suspended from the crane but operated with the operator off the crane, and no person is on the crane. For a remote-operated crane or carrier, the operator is at the operator control devices, which are not attached to any part of the crane, and no person is on the crane.

U.S. Nuclear Regulatory Commission.

Wire rope fitting consisting of a basket and two ears with a pin.

A framework fitted to a truck over the head of a riding operator.

Any load in excess of the safe working load or rated capacity of the equipment or tackle.

Movement beyond maximum travel for which the jack was designed.

A number of running ropes supporting a load or force, also called parts or falls.

Adding slack to a line or relieving load on a line by letting (spooling) out rope. 
pendant control station

peening

pitch diameter

plug

plugging

plugging relay

power-controlled

lowering

powered industrial

truck

power-operated crane

pre-engineered lift

preece test

preformed strand

preformed wire rope

pressure gripping

lifters,

friction type
Controls suspended from an overhead crane, gantry crane, or overhead hoist for operating the unit. (Commonly called the pendant.)

Permanent distortion of outside wire in a rope caused by pounding.

The distance, measured through the center of a drum or sheave, from center to center of a rope passed about the periphery of the drum or sheave.

To operate a controller in such a manner that the motor line voltage polarity or phase sequence is reversed before the motor rotation has stopped, thereby developing a counter torque that acts as a retarding force.

Stopping the forward motion of the bridge or trolley travel by reversing the controller to the opposite direction.

A current relay that senses current in the motor secondary circuit of an alternating current motor and limits reverse torque of the motor until the motor rotation has stopped. In a direct current control panel, the relay performs the same function by establishing a sensing circuit at the motor armature (also known as the antiplugging relay.)

A system or device in the power train, other than the load holding brake, that can control the lowering speed of the load hoist mechanism.

A mobile, power-driven vehicle used to carry, push, pull, lift, stack, or tier material.

See cranes, types of.

A noncritical lift that management has designated as requiring additional controls by having a qualified individual or engineer independently preidentify load weight, load center of gravity, lift attachment points, and minimum lifting hardware (slings, below-the-hook lifting devices, shackles, etc.) capacities that will be used for the lift or series of lifts. Pre-identified information shall be provided to the personnel involved in the lift.

A recognized standard of testing the galvanized coating on wire.

Strand in which the wires are permanently shaped, before fabrication in the strands, to the helical form they assume in the strand.

Wire rope in which the strands are permanently shaped, before fabrication into the rope, to the helical form they assume in the wire rope.

Lifters that grip the load without significant or harmful

permanent deformation of the load surfaces. 


\author{
pressure gripping \\ lifters, \\ indentation type \\ prestressing \\ proof load \\ pullers \\ qualified engineer
}

qualified rigger

qualified welder

rail, bridge

rail, runway

rail sweep

ratchet

rated life

rated load (capacity)

rated rope (line) pull
Lifters that carry the load by applying sufficient force to

permanently indent the sides of the load.

Stressing a wire rope or strand before use under such a tension and for such a time that the construction stretch is largely removed.

The load applied in performance of a proof test.

Also called come-along.

A person who, by possession of a recognized degree or certificate of professional standing, or who, by extensive knowledge, training, and experience, has successfully demonstrated the ability to solve or resolve problems relating to the subject matter and work. The cognizant manager shall have the right of review (including right to approve or reject) all qualifications.

One whose competence in this skill has been demonstrated by experience satisfactory to the appointed person.

A person holding a certificate as proof that qualified test welds have been performed and passed in accordance with the governing welding code.

The track supported by the bridge girder(s) on which the trolley travels.

The track supported by the runway beams on which the crane travels.

A mechanical device attached to the end truck of a bridge or trolley, located in front of the leading wheels, to remove foreign objects from the rail.

A toothed member, attached to or a part of the drum, for engagement with the pawl.

See bearing life.

(a) The maximum load designated by the manufacturer for which a crane, hoist, rigging, or other lifting device is designed and built; (b) For a truck equipped with load carriage and forks or attachments it is the weight established by the manufacturer or a registered professional engineer at a required load center that a given truck can transport and stack to an established height.

The manufacturer's recommended load in pounds (kilograms) applied to the rope attached to the hoist drum. 
reel

reeve

reeved blocks

reeving

reeving diagram

regenerative

regular-lay rope

remote-operated crane

repetitive pickup point

rerate

reverse bend

reverse lay

right-hand end

right-lay

rigging

rigging hook

rocker beam
The flanged spool on which wire rope or strand is wound for storage or shipment.

The pattern that a rope forms between sheaves in a hoisting system.

Passing rope through a set of blocks, as opposed to laced blocks, and in such a manner that there are no lines crossed or rubbing each other.

A rope system in which the rope travels around drums and sheaves in a prescribed manner.

A diagram showing the path of the rope through a system of sheaves (blocks).

A method of control in which the electrical energy generated by the motor is fed back into the power system.

Wire rope in which the wires in the strands and the strands in the rope are laid in opposite directions.

\section{See cranes, Types of.}

When operating on a short cycle operation, the rope being used on single layer and being spooled repetitively over a short portion of the drum.

To change the rated load (capacity). The rated capacity may be increased or decreased.

Reeving of a wire rope over sheaves and drums so that it bends in opposite directions.

See alternate lay.

A reference to parts or dimensions on the viewer's right of the centerline of span, established when facing the drive-girder side of the crane.

(a) Strand in which the cover wires are laid in a helix having a right-hand pitch, similar to a right-hand screw; (b) Rope in which the strands are laid in a helix having a right-hand pitch, similar to a right-hand screw.

The act of attaching hoisting equipment to the load.

See hook, rigging.

Beam used for hoisting flimsy trusses or long flimsy loads. Also used to equalize the weight and to keep a load, such as tank plate, from buckling. 
rollers

rope

rope drum

rotation-resistant rope

running line

running sheave

runway

safe working load

(SWL)

safety factor

sag

seale

seize

seizing strand

seizing wire

serve

service, normal

service, heavy
Relatively small-diameter cylinders or wide-faced sheaves for supporting or guiding ropes.

Refers to wire rope unless otherwise specified.

That part of a drum hoist that consists of a rotating cylinder with side flanges on which hoisting rope is spooled in or out (wrapped).

A wire rope consisting of an inner layer of strands laid in one direction, covered by a layer of strands laid in the opposite direction. This has the effect of counteracting torque by reducing the tendency of the finished rope to rotate.

A rope that moves over sheaves or drums.

A pulley-type device that changes location in relation to the hoisting device.

An assembly of rails, girders, and brackets that form a structural support on which a crane operates.

See rated (load) capacity.

See design factor.

See deflection.

A strand construction having one size of cover wires with the same number of one size of wires in the inner layer and each layer having the same length and direction of lay. Most common construction is one center wire, nine inner wires, and nine cover wires.

To bind securely the end of a wire rope or strand with seizing wire or strand.

Small strand, usually of seven wires, made of soft-annealed-iron wire.

A soft-annealed-iron wire.

To cover the surface of a wire rope or strand with a wrapping of wire.

That service which involves operation with randomly distributed loads within the rated load limit, or uniform loads of less than $65 \%$ of the rated load for not more than $15 \%$ of the time for manually operated hoists and $25 \%$ of the time for electric- or air-powered hoists, of a single work shift.

that service which involves operation within the rated load limit which exceeds normal service. 
service, severe

shackle

shaft, cross (squaring

shaft)

(drive shaft)

shall

sheave

shock loading

should

side pull

side loading

siemens-martin strand

single galvanized

strand

slewing

slinging eye

slings

slings, braided

slings, endless and that service which involves normal or heavy service with abnormal operating conditions.

A type of clevis normally used for lifting.

The shaft(s) extending the length of the bridge, used to transmit

torque from the motor to a wheel(s) at each end of the bridge.

Word indicating that the rule is mandatory and must be followed.

A wheel or pulley with a circumferential groove designed for a particular size of wire rope; used to change direction of a running rope.

Term used to call attention to the application of any sudden, unplanned loading of equipment that would jeopardize the safety of the lift. Typical examples that could result in shock loading are: (a) rapid travel of the burden block without alteration of speed before all slack is removed from the sling(s), (b) unplanned shifting of the load while suspended, (c) fracture of a lifting system component resulting in the application of unknown loading on remaining components.

Word indicating that the rule is a recommendation, the advisability of which depends on the facts in each situation.

That portion of the hoist pull acting horizontally when the hoist lines are not operated vertically.

A loading applied at any angle to the vertical plane of the boom.

A grade of galvanized strand.

Strand made in the "common grade” or wiped galvanized wires.

A crane or derrick function wherein the boom or load-supporting member rotates about a vertical axis (axis of rotation); also called swing.

See lifting eye.

Wire ropes, chains, or synthetic fabric made into forms, with or without fittings, for handling loads.

A very flexible sling composed of several individual wire ropes braided into a single sling.

A wire rope made endless from one continuous length of cable- 
grommet wire rope
slings, four-leg bridle
slings, three-leg bridle
slings, two-leg bridle

slip (motor)

smooth coil strand

snatch block

socket

softeners

span

splicing

spooling (rope)

spreader bar

spreader beam

stainless steel rope

standby

standing line laid rope with the ends joined by one or more metallic fittings.

Sling made with four single-rope legs, secured to a single lifting ring.

-Slings made with three single-rope legs, secured to a single lifting ring.

Slings with single-rope legs, equalizing double-rope legs, or multiple-part rope legs.

The difference between theoretical, or synchronous, speed and actual speed in an induction motor. Under standard conditions, an induction motor never reaches synchronous speed, at which zero torque is developed.

Strand composed entirely of round wires.

A single- or double-sheave block arranged so one or both cheek plates can be opened, permitting the block to be reeved without having to use a free rope end; also called gate block. (The brand name SKOCUM is also used generically; (thus, snatch blocks are also called skocum blocks.)

Type of wire rope fitting. See bridge sockets, closed sockets, open sockets, and wedge sockets.

Anything used to protect the load or the rigging from damage while making a lift. Also, prevents load from slipping.

The horizontal distance center-to-center of runway rails.

Interweaving of two ends of ropes to make a continuous or endless length without appreciably increasing the diameter. Also, making a loop or eye in the end or a rope by tucking the ends of the strands.

Winding of rope on a cylindrical drum in evenly spaced, uniform layers.

A frame, forming part of the boom suspension, supporting sheaves for the live suspension ropes and attached to the fixed suspension ropes (pendants); also called bridle, spreader, live spreader, or flating harness.

A fixture made of rigid parts, such as pipe, wide-flange, I-beam, channel, plate, etc., to assist in rigging a load; also called lifting beam.

Wire rope made of low-carbon corrosion-resistant steel.

A crane or derrick that is not in regular service, but one that is used occasionally or intermittently as required.

A fixed-length line that supports loads without being spooled on or off a drum; a line of which both ends are dead; also called stay rope or pendant. 
standing rope (pendant) A supporting rope that maintains a constant distance between the points of attachment to the two components connected by the rope.

static controls

stirrup

stop

strand, wire rope

strength margin

structural competence

SUS

swaged fittings

switch

switch, emergency stop

switch, limit

switch, main
Controls that provide a function similar to that of magnetic controls. The accelerating resistors and contactors are replaced with thyristors, siliconcontrolled rectifiers (SCRS), and similar static electronic devices. Operating characteristics are similar to those that might be obtained from magnetic control having an infinite number of accelerating contacts between the first and final control points.

The U-bolt or eyebolt attachment on a bridge socket.

A member to physically limit the travel of a trolley or bridge. This member is rigidly attached to a fixed structure and normally does not have energyabsorbing ability.

A plurality of round or shaped wires helically laid about an axis.

The ratio of structural failure load (or stress) to actual or permitted load (or stress).

The ability of the equipment and its components to support the stresses imposed by operating loads without the stresses exceeding specified limits.

Saybolt universal seconds.

Fittings in which wire rope is inserted and attached by a cold-forming method.

A device for making, breaking, or changing the connections in a control circuit. It is also a device for changing directions of a trolley from one monorail system (track) to another.

A manually or automatically operated electric switch to cut off electric power independently of the regular operating controls.

A switch that is operated by some part or motion of a power-driven machine or equipment to open or close the electrical circuit associated with the machine or equipment.

A switch controlling the entire power supply to the crane, often called the disconnect switch. 
synchronous speed

tackle

tag line

taking up

technical approver

test load

thimble

third-party inspection

tiller rope

tinned wire

torque, locked-rotor

torque, motor

breakdown

torque, motor full-load
The synchronous speed of an alternating current (ac) motor is directly proportional to the supply frequency and inversely proportional to the number of poles. For example, the synchronous speed of a four pole motor operating at $60 \mathrm{~Hz}$ is determined by the following equation:

\section{Synchronous Speed $=120 \mathrm{X}$ Frequency $/$ \# of Poles}

Those pieces of rigging such as slings, spreader bars, chokers shackles, thimbles, eyebolts, rings, or other handling fixtures used for attachment of the load to the crane or hoist.

A length of rope used to guide a load that is being lifted into a desired position.

The process of removing slack from a line or drawing (spooling) in on a line; loading a line by drawing in on it.

An individual assigned to review critical lift plans who has technical knowledge and experience applicable to the requirements of this manual, mandatory standards, and equipment identified in the critical lift plan.

A load that is periodically applied to hoisting equipment to ensure that it has the ability to safely handle the rated capacity of the equipment. The test load is usually some percentage of the rated load capacity-100\% to $150 \%$ of rated load.

Grooved-metal fitting designed to prevent crushing or overstressing wire rope at the terminal end which is used to protect the eye of a wire rope or sling.

An inspection made by an independent party who is a crane and hoist specialist. See qualified inspector.

A very flexible operating rope, commonly made by cable laying six 6 x 7 ropes around a fiber core.

Wire coated with tin.

The minimum torque which an induction motor will develop at rest, for all angular positions of the rotor, with rated voltage applied at rated frequency. Not applicable to wound-rotor (slipping motors).

The maximum torque that an induction motor will develop with rated voltage applied at rated frequency without an abrupt drop in speed.

The torque developed by an electric motor (ac or direct current [dc]) to produce its rated horsepower at rated full-load speed. 


\begin{tabular}{|c|c|}
\hline torque, motor pull-up & $\begin{array}{l}\text { The minimum torque developed by an induction motor during the period of } \\
\text { acceleration from rest to the speed at which breakdown torque occurs. For } \\
\text { induction motors with } 8 \% \text { or greater slip, the pull-up torque, the breakdown } \\
\text { torque, and the starting torque are all equal and occur at zero speed. }\end{array}$ \\
\hline traction steel & A grade of wire rope used in elevator service. See grades, rope. \\
\hline tram & The practice of placing punch marks on a hook for gauging use. \\
\hline travel & $\begin{array}{l}\text { (a) Movement of a mobile or wheel-mounted crane about a job site under its } \\
\text { own power; }\end{array}$ \\
\hline & (b) Linear extending or retracting movement of a jack. \\
\hline travel base & The base mounting for a wheel-mounted (traveling) tower crane. \\
\hline tread diameter & $\begin{array}{l}\text { The diameter of a sheave or grooved rope drum measured at the base of the } \\
\text { groove. The diameter of a smooth barrel on a rope drum. }\end{array}$ \\
\hline trolley & $\begin{array}{l}\text { A unit that travels on the bridge rails consisting of frame, end trucks, drive } \\
\text { supporting the hoisting mechanism, rope, and load block that supports the } \\
\text { load, or a unit that travels on the lower flange of a beam or monorail system } \\
\text { supporting a hoist. }\end{array}$ \\
\hline trolley girts & $\begin{array}{l}\text { Structural members that are supported on the trolley trucks and contain the } \\
\text { upper sheave assemblies. }\end{array}$ \\
\hline trolley travel & The trolley movement. \\
\hline trolley truck & $\begin{array}{l}\text { An assembly consisting of wheels, bearings, axles, and structural framework } \\
\text { that supports the hoist mechanism. }\end{array}$ \\
\hline turnbuckle & $\begin{array}{l}\text { Device attached to wire rope chain or rods for making limited adjustments in } \\
\text { length, which consists of a barrel and right-hand and left-hand threaded } \\
\text { bolts. }\end{array}$ \\
\hline UBC & Uniform Building Code. \\
\hline UL & Underwriters Laboratory. \\
\hline ultimate strength & $\begin{array}{l}\text { The maximum conventional stress, tensile, compressive, or shear that a } \\
\text { material can stand without failure. }\end{array}$ \\
\hline
\end{tabular}




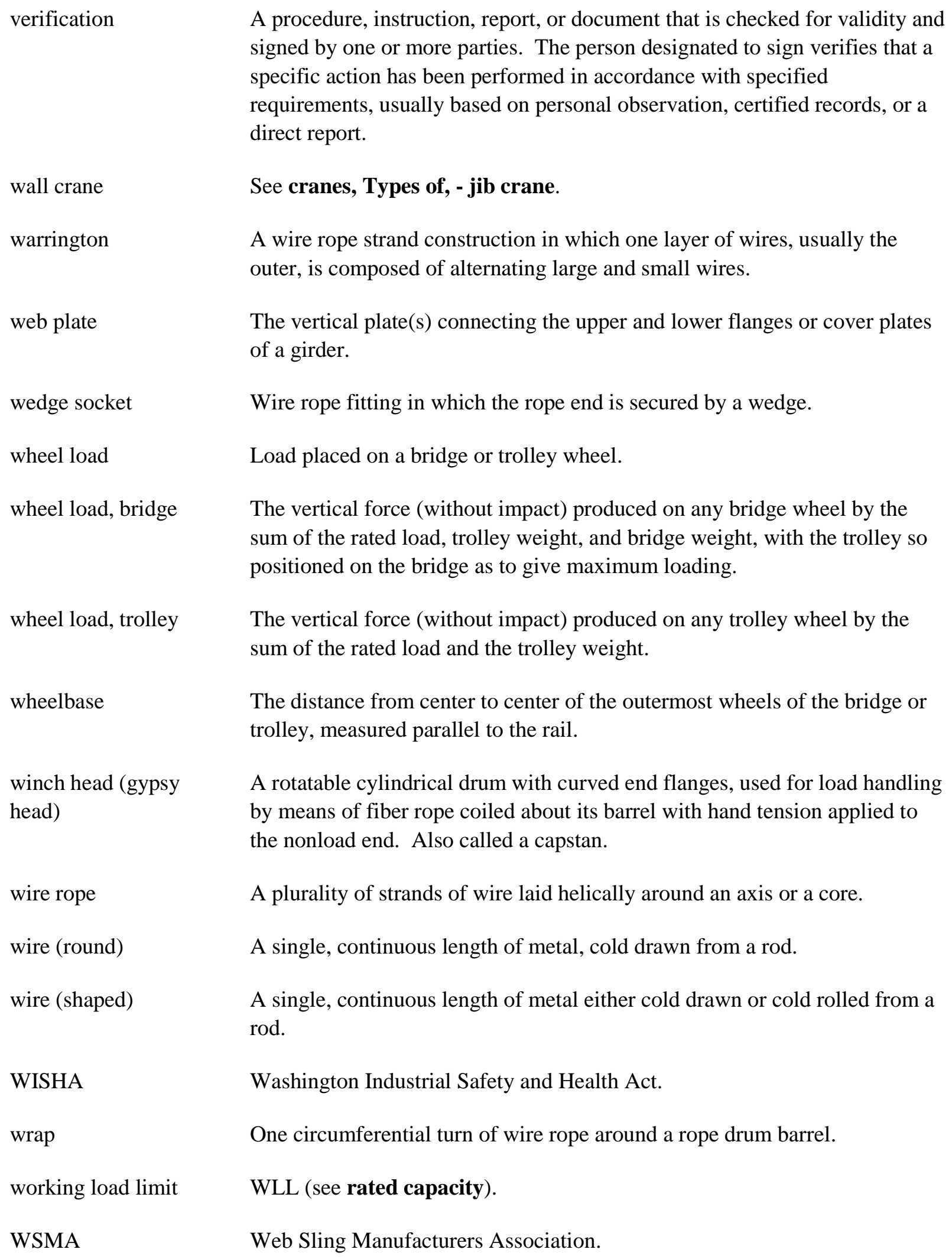
signed by one or more parties. The person designated to sign verifies that a specific action has been performed in accordance with specified requirements, usually based on personal observation, certified records, or a direct report.

wall crane
warrington
web plate
wedge socket
wheel load
wheel load, bridge

wheel load, trolley

wheelbase

winch head (gypsy head)

wire rope

wire (round)

wire (shaped)

WISHA

wrap

working load limit

WSMA

\section{See cranes, Types of, - jib crane.}

A wire rope strand construction in which one layer of wires, usually the outer, is composed of alternating large and small wires.

The vertical plate(s) connecting the upper and lower flanges or cover plates of a girder.

Wire rope fitting in which the rope end is secured by a wedge.

Load placed on a bridge or trolley wheel.

The vertical force (without impact) produced on any bridge wheel by the sum of the rated load, trolley weight, and bridge weight, with the trolley so positioned on the bridge as to give maximum loading.

The vertical force (without impact) produced on any trolley wheel by the sum of the rated load and the trolley weight.

The distance from center to center of the outermost wheels of the bridge or trolley, measured parallel to the rail.

A rotatable cylindrical drum with curved end flanges, used for load handling by means of fiber rope coiled about its barrel with hand tension applied to the nonload end. Also called a capstan.

A plurality of strands of wire laid helically around an axis or a core.

A single, continuous length of metal, cold drawn from a rod.

A single, continuous length of metal either cold drawn or cold rolled from a rod.

Washington Industrial Safety and Health Act.

One circumferential turn of wire rope around a rope drum barrel.

WLL (see rated capacity).

Web Sling Manufacturers Association. 
Appendix B

Worksheets and Checklists 



\section{Appendix B: Worksheets and Checklists}

\section{B.1 Lift Determination Worksheet}

\section{Lift Description:}

\section{Load Category}

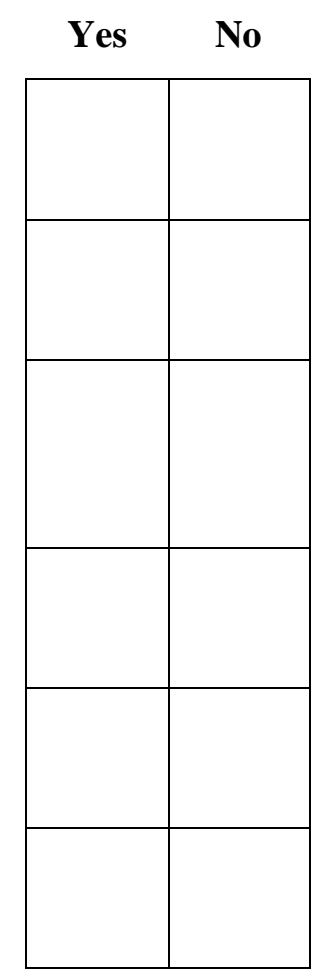

* Damage would result in a release of radioactive or hazardous material exceeding established Permissible Environmental Limits

* The item, if damaged would be irreplaceable or not repairable and is vital to a system, facility, or project operation

* The cost to replace or repair the item, or delay in operations of having the item damaged would have a negative impact on facility, organizational, or DOE budget to the extent that it would affect program commitments

* The item, although non critical, is to be lifted above or in close proximity to a critical item.

** Load is $95 \%$ or more of mobile crane's capacity chart rating for the maximum that will be experienced.

* Two cranes will be used and the load share equals more than $70 \%$ of one or both crane's chart rating for the maximum radius that will be experienced

* Generally required, depending on the situation and equipment used

** Required.

The manager who has responsibility for this lift should consider the lift for critical-lift status when a yes response is recorded.
Critical Lift
Yes
No $\square$

Reviewer

Date

Print

Sign 


\section{B.2 Special Lift Determination Worksheet}

\section{Lift Description:}

\section{Load Category}

\begin{tabular}{|l|l|}
\hline \multicolumn{1}{l|}{ Yes } & No \\
\hline & \\
& \\
& \\
& \\
& \\
&
\end{tabular}

Lifting personnel with forklifts. Follow the requirements found in "Forklifts."

Two or more cranes will be used to make a lift. For hoists, jib cranes, and monorail systems, follow the requirements found in "Hoists, Jib Cranes, and Monorail Systems.” For overhead and gantry cranes, follow the requirements found in "Overhead and Gantry Cranes."

Handling large or unusually configured loads outside a forklift truck’s load center. Follow the requirements found in "Forklifts."

Working in close proximity to an existing building or operating equipment. Consider drawings, validating clearances with site analysis, identifying limitations and hazards with review in pre-job meeting.

Use of non routine rigging configurations. Consider drawings identifying attachment points, validating load weight, validating capacities, calculation of slings/lifting devices and rigging hardware loading, analysis identifying limitations and hazards with review in pre-job meeting.

The manager who has responsibility for this lift should consider the lift for special-lift status based on safety of personnel or equipment when a yes response is recorded.

\begin{tabular}{|c|c|}
\hline Special Lift & Yes \\
\hline
\end{tabular}

Reviewer

Date

Print Sign




\section{B.3 Load Worksheet}

\section{Lift Description:}

\begin{tabular}{|l|l|}
\hline Applicable \\
\hline Yes & No \\
\hline & \\
\hline & \\
\hline & \\
\hline & \\
\hline & \\
\hline & \\
\hline
\end{tabular}

Check only those items that are applicable to this lift.

Load weight was calculated and calculations used to determine weight were validated or the source documents were verified.

Weight of all items to be lifted with load and rigging have been included in total lift weight.

Load center of gravity has been determined.

Attachment points have been identified.

Attachment points have been inspected for defects.

Attachment point share of load has been calculated.

Items checked with yes are applicable to this lift and should be identified in the lift plan.

Reviewer

Date

Print

Sign 


\section{B.4 Rigging Hardware Worksheet}

Lift Description:

Applicable

\begin{tabular}{|l|l|}
\hline Yes & No \\
\hline & \\
\hline & \\
\hline & \\
\hline & \\
\hline & \\
\hline & \\
\hline & \\
\hline & \\
\hline
\end{tabular}

Check only those items that are applicable to this lift.

Wire rope Slings are in good condition, have traceable documentation or tagging with current inspection and load test date and sling is marked by manufacturer with name and rated capacity.

Synthetic slings are in good condition, have traceable documentation or tagging with current inspection and load test date and marked by manufacturer with name or trademark, manufacturer code or stock number, type of synthetic material and rated capacity for types of hitches.

Alloy Steel Chain Slings are in good condition, have traceable documentation or tagging with current inspection and load test date and sling is marked by manufacturer with name or trademark, manufacturer's grade, chain size, reach, rated capacity and angle upon which rating is based and number of legs.

Alloy Steel Chain Slings are in good condition, have traceable documentation or tagging with current inspection and load test date and sling is marked by manufacturer with name or trademark, manufacturer's grade, chain size, reach, rated capacity and angle upon which rating is based and number of legs.

Shackles are in good condition have tagging with load test date and shackle is marked with manufacturer name or trademark, size and safe working load or working load limit marked on the shackle bow.

Eye bolts are in good condition, is properly installed, has traceable documentation or tagging with load test date and is marked by manufacturer with name or trademark, (marked with an” A" is alloy).

Swivel Hoist rings are in good condition is installed per manufacturer instructions has traceable documentation or tagging with load test date and marked by manufacturer with name or trademark, Safe working load or working load limit, and torque value.

Weld less rings are in good condition, have tagging with load test date.

Welded rings are in good condition; have tagging with load test date, traceable documentation that ring was designed by qualified engineer, and have been subjected to weld nondestructive testing.

Turnbuckles are in good condition; were approved by a qualified engineer or rigging specialist; have tagging with inspection due date, load test date, manufacturer's name, and rated capacity or capacity. 


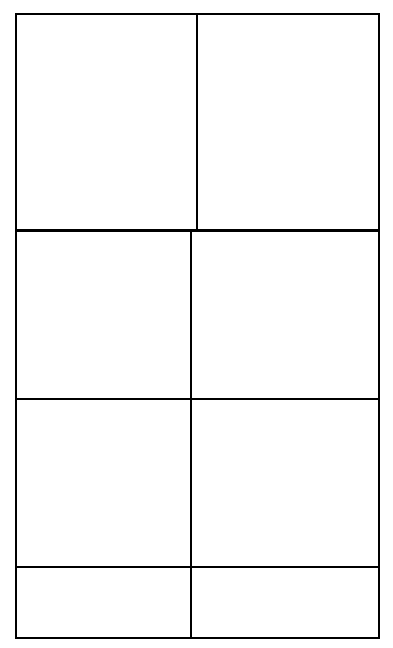

Below the hook lifting devices are in good condition; have traceable documentation or tagging with current inspection and load test date; and are marked by manufacturer with name or trademark, rated capacity weight if over $100 \mathrm{lb}$, drawing number, and serial number when applicable.

Dynamometers and precision load position devices have traceable documentation or tagging with load test date and are marked by manufacturer with name or trademark and rated capacity.

Permanently installed rigging hardware on engineered equipment installed by manufacturer without load test documentation is approved for use by rigging specialist and inspected by qualified inspector before use.

Taglines will be needed for load positioning.

Items checked with yes are applicable to this lift and should be identified in the lift plan.

Reviewer

Date

Print Sign 


\section{B.5 Crane Worksheet}

\section{Lift Description:}

\begin{tabular}{l} 
Applicable \\
\begin{tabular}{|l|l|}
\hline Yes & No \\
\hline & \\
\hline & \\
\hline & \\
\hline & \\
\hline & \\
\hline & \\
\hline & \\
\hline & \\
\hline
\end{tabular} \\
\hline
\end{tabular}

Check only those items that are applicable to this lift.

Crane monthly, annual, and pre-use inspections are current and crane is in good working condition.

Crane net capacity, as configured, is greater than or equal to total intended gross load at maximum radius that will be experienced for mobile cranes.

Crane or hoist has a load-limiting device (optional).

Crane has a load-indicating device or load moment indicator (optional).

Crane or hoist intended travel path and or swing radius is clear of obstructions.

Crane or hoist hook is capable of holding the intended rigging.

Sufficient headroom between the lower block and upper drum, point sheaves, or antitwo block device exists at all lift points considering rigging, load, and load block.

More than one crane or hoist will support the load and intended share of load for each has been calculated.

Mobile crane position has been identified and ground stability and loading has been evaluated and restrictions identified.

Environmental restrictions and limitations that can affect the lift (radiological, biological, weather, etc.) have been considered and identified.

Items checked with yes are applicable to this lift and should be identified in the lift plan.

Reviewer

Date 


\section{B.6 Forklift Worksheet}

\section{Lift Description:}

\begin{tabular}{l} 
Applicable \\
\begin{tabular}{|l|l|}
\hline Yes & No \\
\hline & \\
\hline & \\
\hline & \\
\hline & \\
\hline & \\
\hline
\end{tabular} \\
\hline
\end{tabular}

Check only those items that are applicable to this lift.

Forklift inspections are current, lift is in good working condition, and pre-use inspection is performed.

Forklift capacity, with attachments as configured, is greater than or equal to total intended load.

Forklift's load center and load center of gravity of load have been evaluated and calculations were performed to confirm forklifts capacity will not be exceeded.

Forklift and attachments have compatible operation plates, tags, or decals identifying approved use and capacity.

Forklifts intended travel path is clear of obstructions, and ramps or grades have been taken into consideration.

Sufficient headroom between mast or load and overhead obstructions exists. Ground stability and or floor loading have been evaluated.

Items checked with yes are applicable to this lift and should be identified in the lift plan.

Reviewer

Date

Print Sign 


\section{B.7 Personnel Worksheet}

\section{Lift Description:}

Applicable
\begin{tabular}{|l|l|}
\hline Yes & No \\
\hline & \\
& \\
\hline & \\
\hline & \\
\hline & \\
& \\
\hline & \\
\hline & \\
\hline
\end{tabular}

Check only those items that are applicable to this lift.

Qualified designated leader has been assigned and identified (the facility may assign this responsibility to a qualified facility-assigned)

Qualified crane operator has been assigned.

Qualified riggers have been assigned.

Additional support personnel have been identified and assigned.

Spotter has been assigned for mobile crane working within extendable boom length of power lines.

Qualified signaler has been assigned.

Qualified forklift operator has been assigned.

Items checked with yes are applicable to this lift and should be identified in the lift plan.

Reviewer

Date

Print Sign




\section{B.8 Plan Worksheet}

\section{Lift Description:}

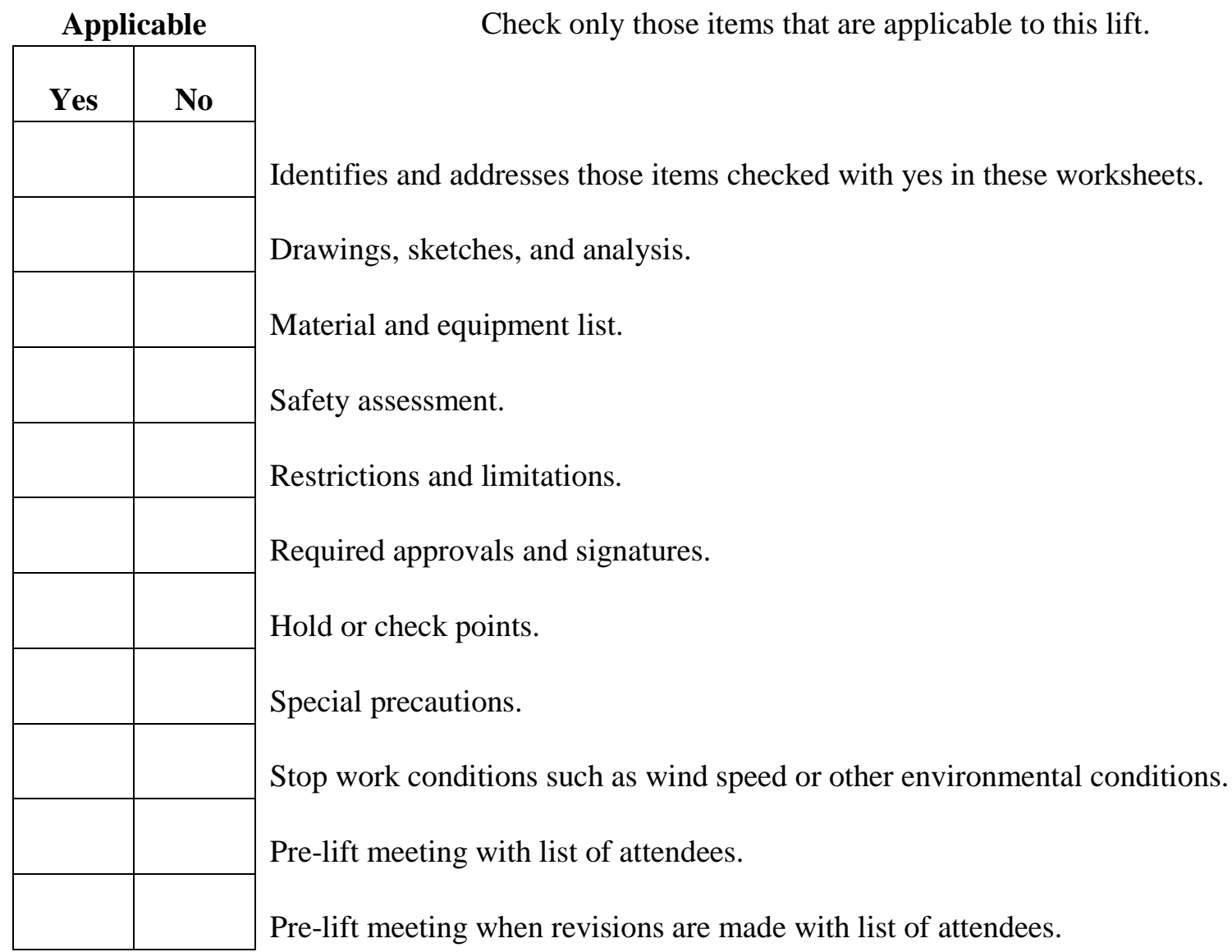

Items checked with yes are applicable to this lift and should be identified in the lift plan.

Reviewer

Date

Print Sign




\section{B.9 Forklift Workplace Hazard Evaluation Checklist}

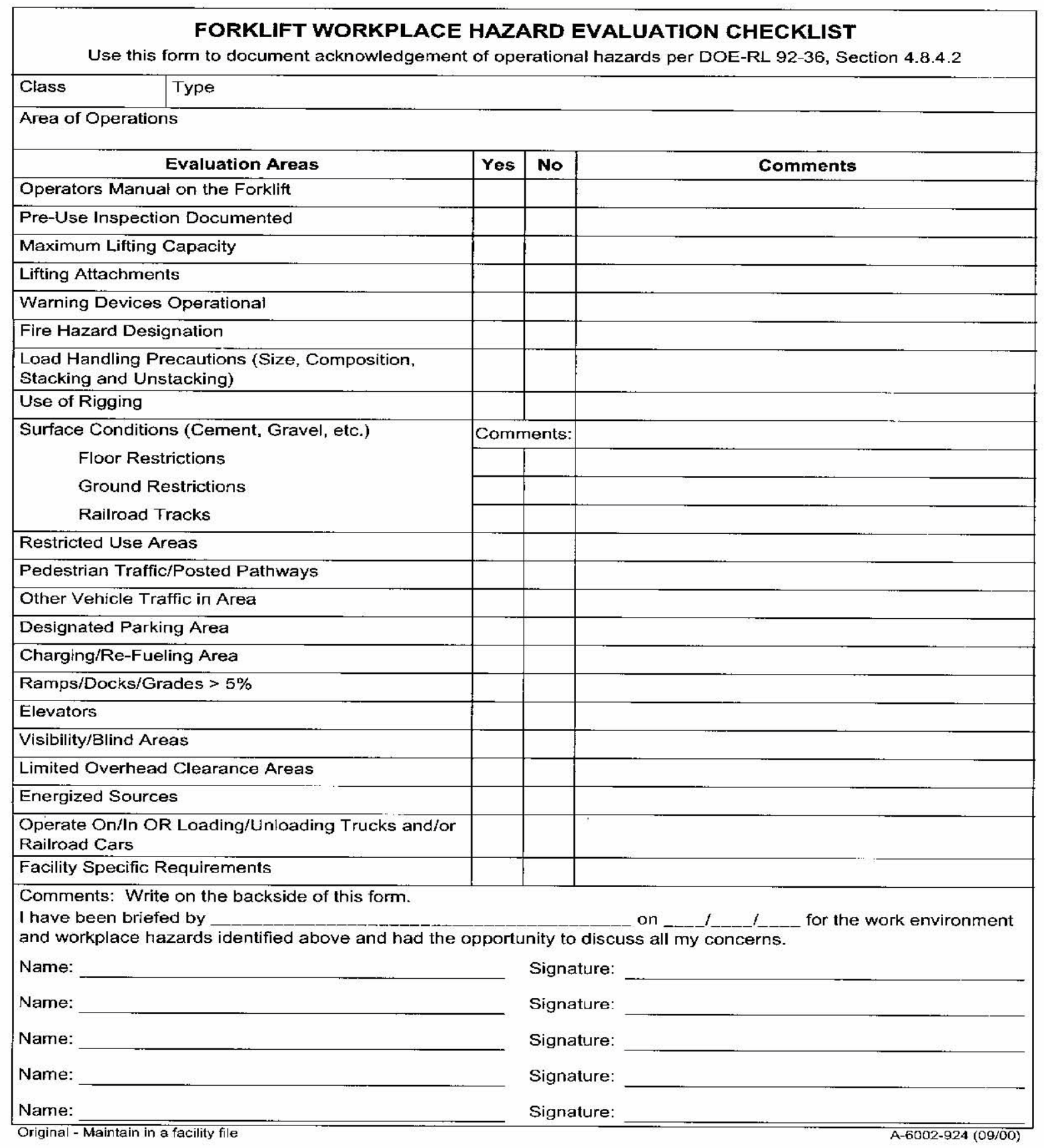




\section{B.10 Wire Rope Replacement Checklist}

Equipment Identification and Location:

Date of replacement rope installation:

Rope Manufacturer:

\begin{tabular}{|l|l|l|l|}
\hline & Diameter: & Wires/strand: & Lay: \\
\hline
\end{tabular}

Wire rope purchase order number:

\begin{tabular}{|c|c|c|c|c|}
\hline Grade of wire: & Type of core: & \multicolumn{3}{|c|}{ Nominal strength: } \\
\hline \multicolumn{3}{|c|}{ PRIOR TO INITIAL LOAD CYCLE } & $\mathrm{OK}$ & N/A \\
\hline \multicolumn{3}{|c|}{ Rope attachment points properly installed } & & \\
\hline \multicolumn{3}{|c|}{ Fasteners properly torqued } & & \\
\hline \multicolumn{3}{|c|}{ Record torque value applied at drum attachment: } & & \\
\hline \multicolumn{3}{|c|}{ Record torque value applied at dead end: } & & \\
\hline \multicolumn{3}{|c|}{ Overhead crane or hoist } & & \\
\hline \multicolumn{3}{|c|}{ No less than two full wraps on drum with hook at lower limit } & & \\
\hline \multicolumn{3}{|l|}{ Mobile crane } & & \\
\hline \multicolumn{3}{|c|}{$\begin{array}{l}\text { Neither load nor boom lowering will result in less than two full } \\
\text { wraps on the respective drum. }\end{array}$} & & \\
\hline Reeving in acc & acturer's recor & & & \\
\hline
\end{tabular}




\begin{tabular}{|l|l|l|}
\hline \multicolumn{1}{|c|}{ INITIAL LOAD CYCLE } & & \\
\hline $\begin{array}{l}\text { Initial load cycle performed (maximum down to maximum up position } 8 \text { to } \\
10 \text { times with } 10 \% \text { to } 20 \% \text { of rate load }\end{array}$ & & \\
\hline $\begin{array}{l}\text { After Initial Load Cycle, re-torque impact rope attachment points (drum } \\
\text { and dead end) }\end{array}$ & & \\
\hline Rope manufacturer's certification placed in equipment maintenance file & & \\
\hline Comments: & & \\
Qualified Inspector: & & \\
\hline
\end{tabular}




\section{B.11 Typical Hostile Environment Plan}

Building:

Location:

Type crane/hoist:

(e.g., overhead top-

running bridge and trolley; top-running bridge with underhung hoist; jib crane; monorail hoist; overhead hoist)

Capacity (main and auxiliary):

Power method: (e.g., hand operated, electrical powered)

Manufacturer:

1.a. Paragraph of the H\&R manual requirement that will not be met:

(Copy the applicable paragraph)

1.b. Difference between manual requirement and what is to be allowed by this plan:

1.c. Justification for not meeting the manual requirement:

1.d. Actions or features to compensate for differences:

Include information regarding replacement or retirement criteria for this equipment. Also include information regarding any special design, maintenance, or test considerations that apply to this equipment.

[ADD ADDITIONAL SECTIONS TO THIS PLAN AS REQUIRED.(e.g., 2.a THROUGH 2.d).]

\section{Approvals}

Facility Manager Manager, Oversight Organization: (signature/date)

(signature/date)

- Other:

(signature/date)

* Modify approval cycle, see "Hostile Environment Plan, Review/Approval Requirements" Place approved Hostile Environment Plan in Equipment History File Make readily available to operating and maintenance personnel 


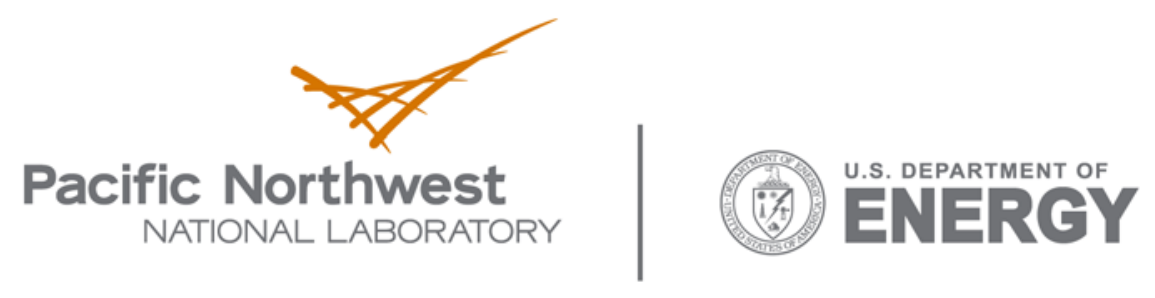

902 Battelle Boulevard

P.O. Box 999

Richland, WA 99352

1-888-375-PNNL (7665)

www.pnl.gov 